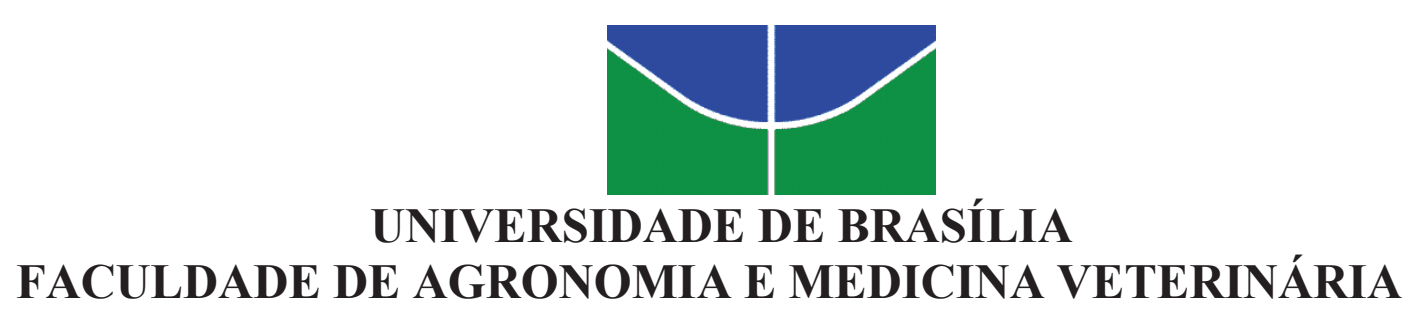
ALTERNATIVAS PARA AUMENTAR A RESISTÊNCIA DO OVÓCITO BOVINO A CRIOPRESERVAÇÃO

JOSÉ FELIPE WARMLING SPRÍCIGO

TESE DE DOUTORADO EM CIÊNCIAS ANIMAIS

BRASÍLIA/DF

FEVEREIRO DE 2016 


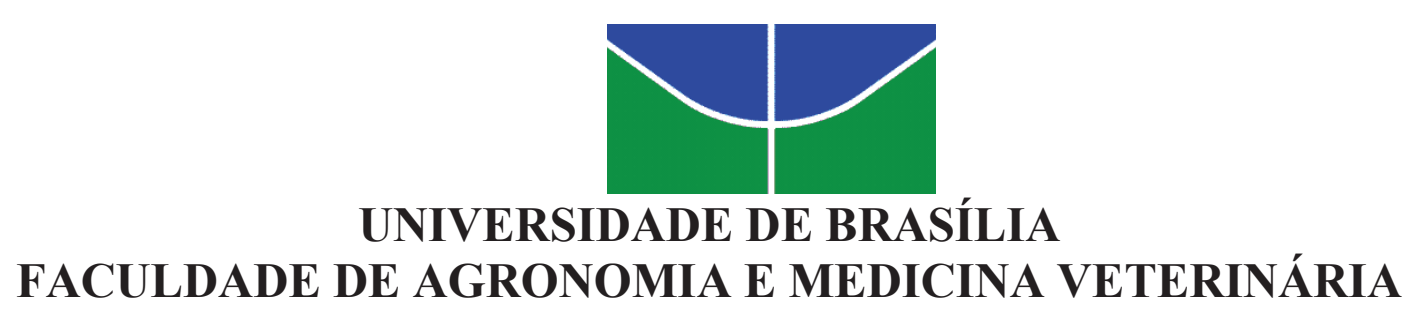

\title{
ALTERNATIVAS PARA AUMENTAR A RESISTÊNCIA DO OVÓCITO BOVINO A CRIOPRESERVAÇÃO
}

\author{
José Felipe Warmling Sprícigo \\ Orientadora: Margot Alves Nunes Dode \\ Tese de Doutorado em Ciências Animais
}

PUBLICAÇÃO 148D/2016

BRASÍLIA/DF

FEVEREIRO DE 2016 
Ficha catalográfica elaborada automaticamente, com os dados fornecidos pelo(a) autor(a)

Sprícigo, José Felipe Warmling

Alternativas para aumentar a resistência do ovócito bovino a criopreservação. / José Felipe Warmling Sprícigo; orientador Margot Alves Nunes Dode. -- Brasília, 2016. $150 \mathrm{p}$.

Tese (Doutorado - Doutorado em Ciência Animal) -Universidade de Brasília, 2016.

1. Vitrificaçãoq. 2. Complexo- cumulus-ovócito. 3. Imaturo. 4. Maturado. I. Alves Nunes Dode, Margot, orient. II. Título. 


\title{
UNIVERSIDADE DE BRASÍLIA \\ FACULDADE DE AGRONOMIA E MEDICINA VETERINÁRIA
}

\begin{abstract}
ALTERNATIVAS PARA AUMENTAR A RESISTÊNCIA DO OVÓCITO BOVINO A CRIOPRESERVAÇÃO
\end{abstract}

JOSÉ FELIPE WARMLING SPRÍCIGO

TESE DE DOUTORADO SUBMETIDA AO PROGRAMA DE PÓS-GRADUAÇÃO EM CIÊNCIAS ANIMAIS, COMO PARTE DOS REQUISITOS NECESSÁRIOS À OBTENÇÃO DO GRAU DE DOUTOR EM CIÊNCIAS ANIMAIS.

APROVADA POR:

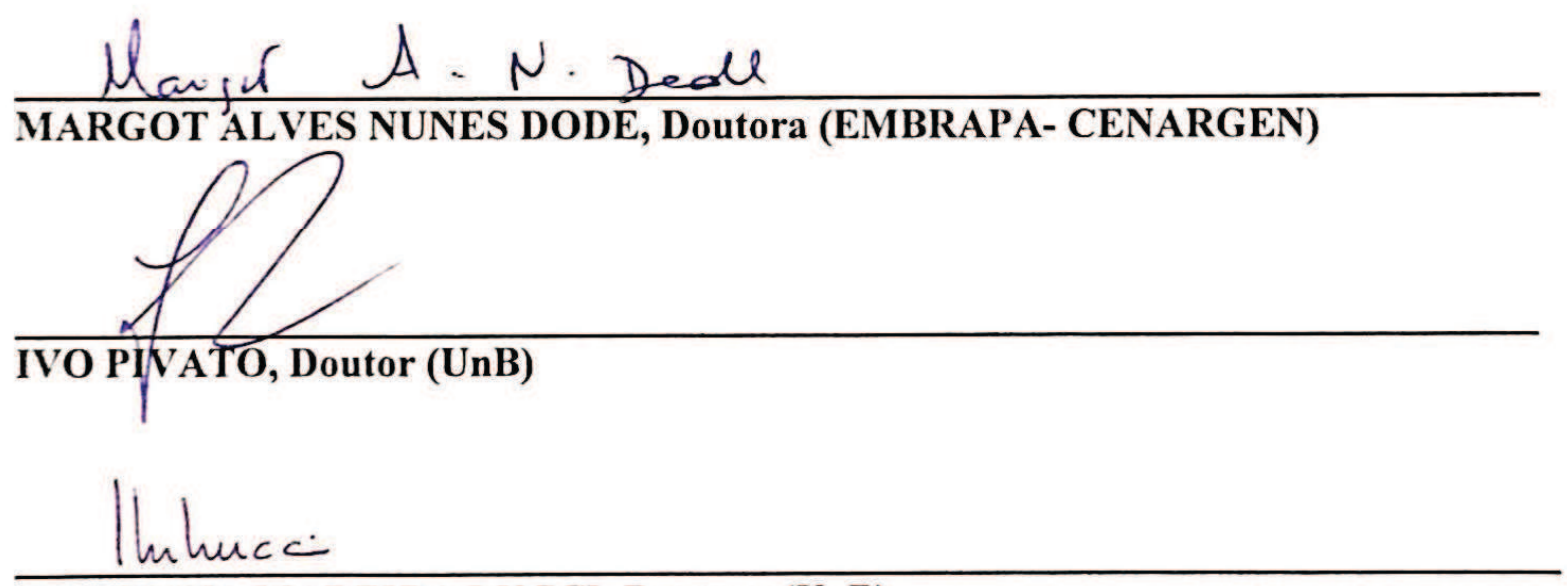

CAROLINA MADEIRA LUCCI, Doutora (UnB)

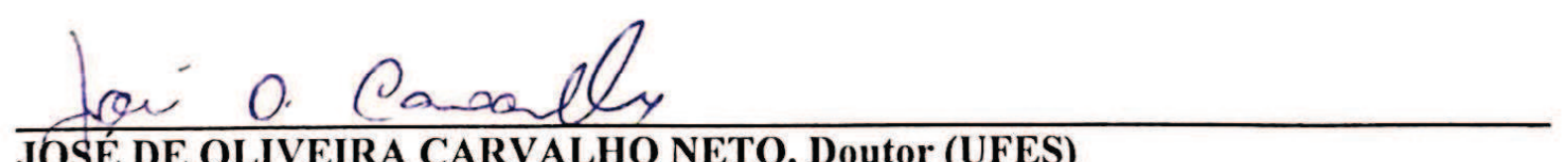

JOSÉ DE OLIVEIRA CARVALHO NETO, Doutor (UFES)

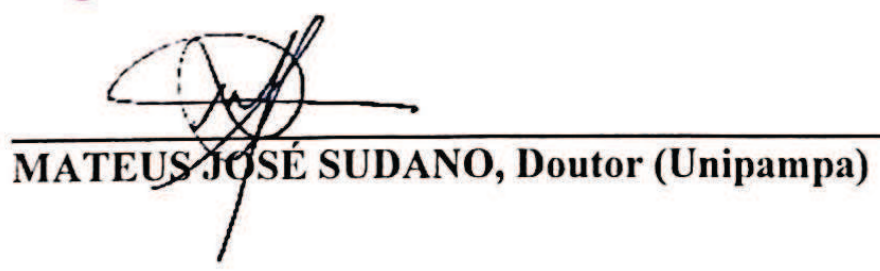

BRASÍLIA/DF, 04 de fevereiro de 2016. 
Aos meus pais, Duílio e Sílvia, ao meu melhor irmão Olímpio, à minha esposa Carolle e à toda minha família. Dedico a vocês esse trabalho. 


\section{AGRADECIMENTOS}

À minha mãe Sílvia, meu pai Duílio, meu irmão Olímpio, e a toda minha família, pelo carinho, amor, apoio e por sempre me orientarem a fazer boas escolhas.

À minha esposa, Carolle, pela ajuda nos experimentos, mas principalmente pela paciência e carinho, praticados em tempo integral.

À Dra. Margot, por ter sido uma ótima orientadora, pela paciência, dedicação e preocupação empregada para a realização do projeto e pelos bons conselhos em momentos de dúvidas profissionais.

Ao Dr. Ivo Pivato, por todo o seu conhecimento, transmitido de forma ímpar, também por ter aceitado participar da banca e por ser um grande amigo.

À Dra. Teresa A. Mogás, pela orientação durante o período de doutorado sanduíche.

Aos colegas de laboratório, que se tornam ao longo do caminho, amigos para a vida.

Aos pesquisadores, funcionários e amigos do Laboratório de Reprodução Animal e do Campo Experimental Sucupira, EMBRAPA- Recursos Genéticos e Biotecnologia.

Ao programa Ciências Sem Fronteiras, pela concessão da bolsa de Doutorado Sanduiche.

À Universidade Autônoma de Barcelona (UAB), pela recepção e suporte durante o Doutorado Sanduíche.

À EMBRAPA Recursos Genéticos e Biotecnologia.

À CAPES pelo suporte e pela bolsa concedida. 
Ao programa de Pós-Graduação em Ciências Animais (PPGCA).

À Universidade de Brasília (UnB) pelo curso oferecido. 


\section{ÍNDICE}

\begin{tabular}{|c|c|}
\hline RESUMO & ix \\
\hline ABSTRACT & $\mathrm{xi}$ \\
\hline LISTA DE FIGURAS & xiii \\
\hline LISTA DE TABELAS & xvii \\
\hline LISTA DE SÍMBOLOS E ABREVIAÇÕES & xxii \\
\hline \multicolumn{2}{|l|}{ CAPÍTULO 1} \\
\hline 1 INTRODUÇÃO & 2 \\
\hline 1.1 Objetivo Geral & 3 \\
\hline 1.2 Objetivos Específicos & 3 \\
\hline 1.3 Hipótese & 4 \\
\hline 1.4 Justificativa & 4 \\
\hline 2 REVISÃO DE LITERATURA & 6 \\
\hline 2.1 Maturação Ovocitária & 6 \\
\hline 2.2 Criopreservação Ovocitária & 8 \\
\hline 2.3 Alternativas para aumentar a resistência do ovócito a vitrificação & 10 \\
\hline 2.3.1 Sistema de maturação, fecundação e cultivo & 11 \\
\hline 2.3.2 Antioxidantes & 13 \\
\hline 2.3.3 Delipidação e alteração de membrana & 14 \\
\hline 3 REFERÊNCIAS BIBLIOGRAFICAS & 17 \\
\hline \multicolumn{2}{|l|}{ CAPÍTULO 2} \\
\hline 1 RESUMO & 28 \\
\hline 2 ABSTRACT & 29 \\
\hline 3 INTRODUÇÃO & 30 \\
\hline 4 MATERIAL E MÉTODOS & 33 \\
\hline 4.1 Obtenção dos ovócitos e preparação da solução de M $\beta C D$ & 33 \\
\hline 4.2 Vitrificação e aquecimento & 34 \\
\hline 4.3 Maturação in vitro & 35 \\
\hline 4.4 Avaliação da maturação nuclear & 35 \\
\hline
\end{tabular}




\begin{tabular}{|c|c|}
\hline 4.5 Seleção espermática e fecundação in vitro & 35 \\
\hline 4.6 Avaliação das taxas de fecundação & 36 \\
\hline 4.7 Delineamento experimental & 37 \\
\hline $\begin{array}{l}\text { 4.7.1 Efeito de diferentes concentrações } M \beta C D \text { sobre a maturação } \\
\text { in vitro e desenvolvimento de ovócitos de bovinos submetidos ao } \\
\text { estresse pelo frio durante } 10 \text { minutos }\end{array}$ & 37 \\
\hline $\begin{array}{l}\text { 4.7.2 Efeito de M } \beta C D \text { sobre a resposta de ovócitos bovinos imaturos } \\
\text { à exposição ao frio por períodos mais longos de tempo }\end{array}$ & 37 \\
\hline $\begin{array}{l}\text { 4.7.3 Capacidade de fecundação e de desenvolvimento embrionário } \\
\text { de ovócitos bovinos imaturos expostos ao } \mathrm{M} \beta \mathrm{CD} \text { antes da } \\
\text { vitrificação e desvitrificação }\end{array}$ & 38 \\
\hline 4.8 Análise estatística & 38 \\
\hline 5 RESULTADOS E DISCUSSÃO & 40 \\
\hline 5.1 Resultados & 40 \\
\hline $\begin{array}{l}\text { 5.1.1 Experimento } 1 \text { - Efeito de diferentes concentrações } \mathrm{M} \beta \mathrm{CD} \\
\text { sobre a maturação in vitro e desenvolvimento de ovócitos de bovinos } \\
\text { submetidos ao estresse pelo frio durante } 10 \text { minutos }\end{array}$ & 40 \\
\hline $\begin{array}{l}\text { 5.1.2 Experimento } 2 \text { - Efeito de } \mathrm{M} \beta \mathrm{CD} \text { sobre a resposta de ovócitos } \\
\text { bovinos imaturos à exposição ao frio por períodos mais longos de } \\
\text { tempo }\end{array}$ & 41 \\
\hline $\begin{array}{l}\text { 5.1.3. Experimento 3- Capacidade de fecundação e de } \\
\text { desenvolvimento embrionário de ovócitos bovinos imaturos } \\
\text { expostos ao } \mathrm{M} \beta \mathrm{CD} \text { antes da vitrificação e desvitrificação }\end{array}$ & 42 \\
\hline 5.2 Discussão & 44 \\
\hline 6 CONCLUSÕES & 48 \\
\hline 7 REFERÊNCIAS BIBLIOGRÁFICAS & 49 \\
\hline \multicolumn{2}{|l|}{ CAPÍTULO 3} \\
\hline 1 RESUMO & 54 \\
\hline 2 ABSTRACT & 56 \\
\hline 3 INTRODUÇÃO & 57 \\
\hline 4 MATERIAL E MÉTODOS & 60 \\
\hline 4.1 Obtenção dos ovócitos e maturação in vitro & 60 \\
\hline 4.2 Vitrificação e aquecimento & 60 \\
\hline
\end{tabular}




\begin{tabular}{|c|c|}
\hline 4.3 Maturação in vitro & 61 \\
\hline 4.4 Fecundação e cultivo in vitro. & 62 \\
\hline 4.5 Avaliação dos cromossomos e fusos meióticos & 62 \\
\hline 4.6 Avaliação da fragmentação de DNA (TUNEL) & 64 \\
\hline 4.7 Avaliação da atividade das Caspases & 65 \\
\hline 4.8 Análise da expressão gênica & 65 \\
\hline 4.9 Delineamento experimental & 67 \\
\hline 4.10 Análise estatística & 68 \\
\hline 5 RESULTADOS E DISCUSSÃO & 69 \\
\hline 5.1 Resultados & 69 \\
\hline $\begin{array}{l}\text { 5.1.1 Efeito da suplementação com L-Carnitina, Resveratrol ou L- } \\
\text { Carnitina + Resveratrol durante a MIV na configuração dos fusos } \\
\text { meióticos de ovócitos maturados bovinos frescos ou vitrificados }\end{array}$ & 69 \\
\hline $\begin{array}{l}\text { 5.1.2 Efeito da suplementação com L-Carnitina, Resveratrol ou L- } \\
\text { Carnitina + Resveratrol durante a MIV na fragmentação de DNA, } \\
\text { em ovócitos bovinos frescos ou vitrificados }\end{array}$ & 70 \\
\hline $\begin{array}{l}\text { 5.1.3 Efeito da suplementação com L-Carnitina, Resveratrol ou L- } \\
\text { Carnitina + Resveratrol durante a MIV na ativação das Caspases, } \\
\text { em ovócitos bovinos frescos ou vitrificados }\end{array}$ & 71 \\
\hline $\begin{array}{l}\text { 5.1.4 Efeito da suplementação com L-Carnitina, Resveratrol ou L- } \\
\text { Carnitina + Resveratrol durante a MIV na expressão gênica, em } \\
\text { ovócitos bovinos frescos ou vitrificados }\end{array}$ & 72 \\
\hline $\begin{array}{l}\text { 5.1.5 Efeito da suplementação com L-Carnitina, Resveratrol ou L- } \\
\text { Carnitina + Resveratrol durante a MIV na expressão gênica, em } \\
\text { ovócitos bovinos frescos ou vitrificados }\end{array}$ & 73 \\
\hline 5.2 Discussão & 75 \\
\hline 6 CONCLUSÕES & 79 \\
\hline 7 REFERÊNCIAS BIBLIOGRÁFICAS & 80 \\
\hline \multicolumn{2}{|l|}{ CAPÍTULO 4} \\
\hline 1 RESUMO & 87 \\
\hline 2 ABSTRACT & 89 \\
\hline 3 INTRODUÇÃO & 91 \\
\hline 4 MATERIAL E MÉTODOS & 94 \\
\hline
\end{tabular}




\begin{tabular}{|c|c|}
\hline 4.1 Delineamento experimental & 94 \\
\hline 4.2 Obtenção de ovócitos de abatedouro & 96 \\
\hline 4.3 Recuperação de ovócitos por OPU & 97 \\
\hline 4.4 Maturação in vitro & 97 \\
\hline 4.5 Sincronização de estro, estimulação ovariana e maturação in vivo & 97 \\
\hline 4.6 Avaliação da vascularização folicular com o Color Doppler & 98 \\
\hline 4.7 Fecundação (FIV) e cultivo in vitro de embriões (CIV) & 99 \\
\hline 4.8 Vitrificação e aquecimento & 99 \\
\hline 4.9 Avaliação de aquisição de maturação & 100 \\
\hline 4.10 Mensuração dos embriões e contagem do número de células & 100 \\
\hline 4.11 Espectrometria de massa lipídio MALDI-TOF & 101 \\
\hline 4.11.1 Preparação de amostra & 101 \\
\hline 4.11.2 MALDI-TOF & 102 \\
\hline $\begin{array}{l}\text { 4.11.3 Determinação do perfil de fosfolípideos da membrana } \\
\text { plasmática }\end{array}$ & 102 \\
\hline 4.12 Análise estatística & 102 \\
\hline 5 RESULTADOS E DISCUSSÃO & 104 \\
\hline 5.1 Resultados & 104 \\
\hline $\begin{array}{l}\text { 5.1.1 Pré-experimento: Determinação do momento ideal para a } \\
\text { obtenção de ovócitos maturados in vivo }\end{array}$ & 104 \\
\hline $\begin{array}{l}\text { 5.1.2 Contagem do número total e vascularização folicular no } \\
\text { momento da OPU e recuperação ovocitária para os diferentes } \\
\text { tratamentos }\end{array}$ & 104 \\
\hline $\begin{array}{l}\text { 5.1.3 Desenvolvimento embrionário e qualidade dos blastocistos, } \\
\text { depois da vitrificação e aquecimento dos ovócitos }\end{array}$ & 106 \\
\hline $\begin{array}{l}\text { 5.1.4 Determinação do perfil de fosfolipídeos de membrana } \\
\text { plasmáticas, em ovócitos oriundos dos diferentes sistemas de } \\
\text { maturação }\end{array}$ & 109 \\
\hline 5.2 Discussão & 113 \\
\hline 6 CONCLUSÕES & 117 \\
\hline 7 REFERÊNCIAS BIBLIOGRÁFICAS & 118 \\
\hline CAPÍTULO 5 & \\
\hline
\end{tabular}




\begin{tabular}{|c|c|}
\hline 1 RESUMO & 124 \\
\hline 2 ABSTRACT & 125 \\
\hline 3 INTRODUÇÃO & 126 \\
\hline 4 MATERIAL E MÉTODOS & 129 \\
\hline 4.1 Delineamento experimental & 129 \\
\hline 4.2 Obtenção de ovócitos de abatedouro & 130 \\
\hline 4.3 Maturação in vitro & 131 \\
\hline 4.4 Fecundação (FIV) e cultivo in vitro de embriões (CIV) & 131 \\
\hline $\begin{array}{l}\text { 4.5 Sincronização do ciclo estral e transferência intrafolicular de ovócitos } \\
\text { imaturos (TIFOI) }\end{array}$ & 131 \\
\hline 4.6 Avaliação do diâmetro e vascularização folicular com o Color Doppler & 132 \\
\hline 4.7 Lavagem uterina e recuperação embrionária & 133 \\
\hline 4.8 Vitrificação e aquecimento & 133 \\
\hline $\begin{array}{l}\text { 4.9 Contagem do número total de células (Hoechst 33342), número total e } \\
\text { razão de células apoptóticas (Terminal deoxinucleotidil transferase dUTP } \\
\text { nick end labeling [TUNEL]) }\end{array}$ & 134 \\
\hline 4.10 Análise estatística & 135 \\
\hline 5 RESULTADOS E DISCUSSÃO & 136 \\
\hline 5.1 Resultados & 136 \\
\hline 5.1.1 Viabilidade da TIFOI & 136 \\
\hline $\begin{array}{l}\text { 5.1.2 Taxas de recuperação de ovócitos imaturos frescos ou } \\
\text { vitrificados antes da TIFOI }\end{array}$ & 136 \\
\hline $\begin{array}{l}\text { 5.1.3 Desenvolvimento embrionário a partir de ovócitos bovinos } \\
\text { frescos ou vitrificados, produzidos in vitro ou in vivo pela TIFOI }\end{array}$ & 138 \\
\hline $\begin{array}{l}\text { 5.1.4 Contagem do número total de células, número de células } \\
\text { apoptóticas e a razão total/apoptóticas }\end{array}$ & 139 \\
\hline 5.2 Discussão & 140 \\
\hline 6 CONCLUSÕES & 143 \\
\hline 7 REFERÊNCIAS BIBLIOGRÁFICAS & 144 \\
\hline CONSIDERAÇÕES FINAIS & 148 \\
\hline
\end{tabular}




\title{
RESUMO
}

\section{ALTERNATIVAS PARA AUMENTAR A RESISTÊNCIA DO OVÓCITO BOVINO A CRIOPRESERVAÇÃO}

\author{
José Felipe Warmling Sprícigo ${ }^{1}$, Margot Alves Nunes Dode ${ }^{1,2}$. \\ ${ }^{1}$ Faculdade de Agronomia e Veterinária - UnB, DF, ${ }^{2}$ Embrapa Recursos Genéticos e \\ Biotecnologia, DF.
}

Acriopreservação do ovócito bovino ainda é um desafio. O tamanho celular, a quantidade de água no citoplasma, a reserva de ácidos graxos, a composição da membrana plasmática, são alguns dos fatores responsáveis pela baixa eficiência da técnica. Entre as metodologias utilizadas para a criopreservação de ovócitos, a vitrificação ainda é considerado o método mais eficaz. O objetivo principal deste trabalho foi avaliar diferentes alternativas para minimizar os efeitos deletérios da vitrificação em ovócitos bovinos imaturos ou maturados. Entre as abordagens utilizadas estão (1) o uso de beta- metil- ciclodextrina (M $\beta C D)$, como substância para alterar a membrana plasmática e aumentar a fluidez da mesma; (2) a associação de L-Carnitina e Resveratrol durante a maturação in vitro (MIV), para diminuir a reserva de gotículas lipídicas, aumentar a produção de ATP e proteger o ovócito contra o acúmulo de espécies reativas de oxigênio (EROs); (3) o uso da maturação in vivo para melhorar a qualidade do ovócito e, (4) o uso da transferência intrafolicular de ovócito imaturo, para proporcionar aos ovócitos vitrificados uma ambiente in vivo durante todos os passos da produção de embriões. Em cada experimento, diferentes avaliações foram utilizadas para identificar o sucesso ou 
insucesso das alternativas propostas. Apesar de alguns procedimentos como o uso de $\mathrm{M} \beta \mathrm{CD}$, terem melhorado a maturação nuclear, nenhum dos procedimentos utilizados aumentou a produção de blastocistos a partir de ovócito vitrificados. Os resultados obtidos mostraram que as lesões sofridas pelo ovócito bovino durante a vitrificação e aquecimento, o comprometem de forma muito severa e irreversível.

Palavras chaves: vitrificação, complexo - cumulus - ovócito, imaturo, maturado. 


\title{
ALTERNATIVES TO INCREASE THE BOVINE OOCYTE RESISTANCE TO CRYOPRESERVATION
}

\author{
José Felipe Warmling Sprícigo ${ }^{1}$, Margot Alves Nunes Dode ${ }^{1,2}$. \\ ${ }^{1}$ School of Agronomy and Veterinary Medicine - UnB, DF, ${ }^{2}$ Embrapa Genetic Resources and \\ Biotechnology, DF.
}

Cryopreservation of bovine oocyte is still a challenge. The cell size, the amount of water in the cytoplasm, the reservation of fatty acids, plasma membrane composition , are some of factors responsible for low efficiency of technique for bovine oocytes. Among the methodologies used for cryopreservation of oocytes, vitrification is the one that can minimize the effects of water flow. The main objective of present thesis was to prove different methodologies for vitrification of immature or matured bovine oocytes. For different alternatives were proved: (1) M $\beta C D$, a substance to alter the plasma membrane and increase membrane fluidity. (2) the combination of L-carnitine and resveratrol during IVM, to reduce reserves of lipid droplets, increase ATP production and protect against ROS aa. (3) in vivo maturation system where, after hormonal stimulation on bovine heifers, in vivo and theatrically better oocyte were produced. (4) intrafollicular transfer of immature oocyte, we adapted a methodology for immature oocytes could be injected into pre-ovulatory follicles, resulting in a in vivo system. For each experiment, different assessments were used to identify the successes or failures of our hypothesis. A common evaluation used for all experiments was the use of immature or for some experiments matured oocytes, destined for blastocyst development, after IVF. In none of proposed experiments, we have succeeded in increasing the production of blastocysts from vitrified oocytes. Likewise, the results, indicated that the injuries suffered by bovine oocyte during vitrification and thawing, compromise the oocyte at very severe intensity. 
Keywords: vitrification, cumulus-oocyte-complex, immature, mature. 


\section{LISTA DE FIGURAS}

Figura

Página

\section{Capítulo 2}

Figura 2.1. Ovócito em VG (A); Ovócito MII (B); Ovócitos com cromatina 36 anormal (C); Ovócitos com cromatina degenerada (D). As setas indicam a cromatina em cada imagem.

Figura 2.2. Ovócitos fecundados: fecundação normal, presença de dois pró-núcleos (A); fecundação polispérmica, presença de três pró-núcleos e de uma cabeça de espermatozoide solta (B). Setas e asterisco indicam os pró-núcleos e a cabeça do espermatozoide, respectivamente.

\section{Capítulo 3}

Figura 3.1. Configurações de microtúbulos e de cromossomos analisados por imunocitoquímica de ovócitos frescos ou vitrificados, maturados in vitro em meio controle, suplementado com LCarnitina, Reveratrol ou ambos. (A) Morfologia dos fusos em MII normal, em forma de barril; (B-D) Ovócitos vitrificadosaquecidos exibindo estruturas de fuso anormais. (B) Morfologia do fuso anormal mostrando cromossomos, em parte, desorganizados; (C) Microtúbulos e cromossomos desorganizados. Vermelho, indica a tubulina (Alexa Fluor 594); azul, os cromossomas (DAPI).

Figura 3.2. Porcentagem de ovócitos com a fragmentação do DNA. CTR: grupo controle ( $\mathrm{n}=59$ ); LC: MIV suplementação com 3,72 mM de ( $\mathrm{n}=43)$; R: MIV suplementado com $1 \mu \mathrm{M}$ de $\mathrm{R}(\mathrm{n}=58)$; LC + R: MIV suplementado com 3,72 mM de LC e $1 \mu \mathrm{M}$ de R (n 
= 61). CTR Vit $(n=67)$, LC Vit $(n=49)$, R Vit $(n=52), L C+$ R Vit ( maturação in vitro nas mesmas condições de seus respectivos controles.

Figura 3.3. A expressão relativa de ACACA, PLIN2, SLC2A, HSPA1A, GXP1 e SOD1, em ovócitos bovinos maturados in vitro na presença de 3,72 $\mathrm{mM}$ de $\mathrm{LC}$ e / ou $1 \mu \mathrm{M}$ de R. Em ovócitos frescos ou vitrificados.

\section{Capítulo 4}

Figura 4.1. Esquema representativo do desenho experimental.

Figura 4.2. Imagem do ultrassom Color Dopller, indicando folículos com irrigação ausente (A), irrigação intermediária (B) e com irrigação intensa $(\mathrm{C})$.

Figura 4.3. Embrião em D8, maior que $160 \mu \mathrm{m}$, corado com Hoechst 3334, para contagem do número total de células.

Figura 4.4. $\quad$ APC 2D para os dados de MALDI-TOF de único ovócito: a) CONT indica o perfil lipídico de ovócitos maturados in vitro, depois da punção de ovários de abatedouro $(\mathrm{n}=12)$; IMAovócitos obtidos por OPU de fêmeas não superestimuladas (n =13) e FSH, puncionados de fêmeas superestimuladas $(\mathrm{n}=13)$. Também o perfil de ovócitos maturados in vivo, obtidos por OPU de fêmeas superestimuladas e que receberam um indutor da ovulação (MII, $\mathrm{n}=10$ ). b) indica os íons responsáveis pela diferença encontrada: 782,6; 760,4. Os componentes principais 2D foram capazes de explicar $>65 \%$ da variabilidade dos dados. 
Figura 4.5. $\quad$ APC 3D para os dados de MALDI-TOF de único ovócito. a) vermelho $(n=12)$, azul $(n=13)$, rosa $(n=13)$ e amarelo escuro $(\mathrm{n}=10)$ indica o resultados do APC 3D do perfil lipídico para ovócitos maturados in vitro imaturos e em recuperados de ovários de abatedouro (CONT), obtido por OPU de fêmeas não superestimuladas (IMA) e a partir de fêmeas superestimuladas (FSH) e de ovócitos maturados in vivo após OPU de fêmeas superovuladas que receberam um indutor da ovulação (MII), respectivamente; b) indica os principais íons apontados pelo APC: 782,6, 760,4 e 640,6 e que foram responsáveis pela maior variabilidade entre os tratamentos. O APC 3D foi capaz de explicar $>73 \%$ da variabilidade entre os dados.

Figura 4.6. Espectros representativos de MALDI-TOF adquiridos no modo de íons positivo para ovócito bovinos maturados em sistemas diferentes. A intensidade apresentada é relativa a máxima obtida: (A) ovócitos de ovários de abatedouro maturados in vitro (CONT; $\mathrm{n}=12$ ); (B) ovócitos recuperados por OPU de fêmeas não superestimuladas e maturados in vitro (IMA; $\mathrm{n}=$ 13); (C) ovócitos recuperados por OPU de fêmeas superestimuladas e maturados in vitro $(\mathrm{FSH} ; \mathrm{n}=13)$ e $(\mathrm{D})$ ovócitos maturados in vivo (MII; $\mathrm{n}=10)$.

\section{Capítulo 5}

Figura 5.1. Representação da sequência do experimento: a) aquisição de ovócitos e seleção; b) ovócitos frescos ou vitrificados seguindo na produção in vitro, resultando em blastocistos no D7; c) ovócitos frescos ou vitrificados seguindo para a produção in vivo (TIFOI), resultando em blastocistos em D7 e d) microscopia fluorescente para avaliação dos blastocistos expandidos, quanto ao número total de células (Hoechst) e número de céluals em apoptose (TUNEL) 
Figura 5.2. Imagens ilustrativas da contagem do número total de células, avaliado pela coloração com Hoechst (A) e contagem de células apoptóticas, após coloração pelo Tunel (B) 


\section{LISTA DE TABELAS}

\section{Tabela}

Página

\section{Capítulo 2}

Tabela 2.1. Efeito da exposição à beta-metil-ciclodextrina (M $\beta C D)$, na maturação nuclear de ovócitos bovinos imaturos expostos ao estresse pelo frio $(\mathrm{EF})$ por 10 minutos a $4^{\circ} \mathrm{C}$, antes da maturação in vitro.

Tabela 2.2. Taxas de clivagem e de desenvolvimento de blastocistos a partir de ovócitos imaturos expostos à diferentes concentrações de beta-metil-ciclodextrina (M $\beta \mathrm{CD})$ e submetidos ao estresse pelo frio $(\mathrm{EF})$ por 10 minutos a $4^{\circ} \mathrm{C}$, antes da maturação in vitro.

Tabela 2.3. Efeito da beta-metil-ciclodextrina (MBCD) na maturação nuclear de ovócitos bovinos imaturos, expostos ao estresse pelo frio (EF) por 30 minutos a $4^{\circ} \mathrm{C}$, antes da maturação in vitro.

Tabela 2.4. Taxas de clivagem e de desenvolvimento de blastocistos de ovócitos imaturos expostos à diferentes concentrações de betametil- beta-ciclodextrina (M $\beta C D)$ e submetidos ao estresse pelo frio $(\mathrm{EF})$ por 30 minutos à $4^{\circ} \mathrm{C}$, antes da maturação in vitro.

Tabela 2.5. Efeito da $\mathrm{M} \beta \mathrm{CD}$ na maturação nuclear de ovócitos bovinos imaturos expostos a de beta-metil-ciclodextrina (MBCD) e vitrificados (Vit).

Tabela 2.6. Taxas de clivagem e de desenvolvimento embrionário a partir de ovócitos bovinos imaturos expostos a de beta-metil-ciclodextrina $(\mathrm{M} \beta \mathrm{CD})$ e vitrificados (Vit) antes da maturação in vitro. 
Tabela 2.7. Taxas de fecundação de ovócitos bovinos imaturos expostos à beta-metil-ciclodextrina (M $\beta C D)$ e vitrificados (Vit), antes da maturação in vitro.

\section{Capítulo 3}

Tabela 3.1. Informações sobre os primers e condições utilizados para a amplificação dos fragmentos dos genes de interesse, utilizadas para análises em PCR quantitativo.

Tabela 3.2. Efeito da suplementação com L-Carnitina e/ou Resveratrol durante a maturação in vitro. Número total $(\mathrm{N})$, porcentagem \pm desvio padrão $(\% \pm \mathrm{DP})$ de ovócitos com fusos normais, anormais e cromossomos dispersos ou degenerados, em ovócitos frescos ou vitrificados.

Tabela 3.3. Efeito da suplementação com L-Carnitina, Resveratrol ou LCarnitina + Resveratrol durante a MIV. Número total $(\mathrm{N})$, porcentagem \pm desvio padrão $(\% \pm \mathrm{DP})$ de ovócitos normais (FLICA-/PI-), com ativação de Caspases (FLICA+/PI-) ou mortos (PI+), frescos ou vitrificados, após a coloração com FLICCA/Hoechst 33342/PI.

Tabela 3.4. Efeito da suplementação com L-Carnitina, Resveratrol ou LCarnitina + Resveratrol durante a maturação in vitro (MIV). Número total $(\mathrm{N})$, porcentagem \pm desvio padrão $(\% \pm \mathrm{DP})$ de clivagem em D2, no estágio de blastocisto em D7 e D8, para os ovócitos dos grupos frescos ou vitrificados. 


\section{Capítulo 4}

Tabela 4.1. Número total $(\mathrm{N})$, média do número total e desvio padrão $( \pm$ D.P.) de folículos por fêmea, média de folículos por diâmetro, em um total de nove repetições, em animais não superstimulados (IMA), superestimuladas (FSH) e de fêmeas superestimuladas que receberam um indutor da ovulação (MII).

Tabela 4.2. Número total $(\mathrm{N})$, média e desvio padrão $( \pm \mathrm{DP})$ de folículos por 106 fêmea, avaliados e classificados pelo Color Doppler, após nove repetições, vascularização intensa, moderada ou ausente nos ovários de fêmeas não superestimuladas (IMA), de fêmeas superestimuladas (FSH) e de fêmeas superestimuladas que receberam um indutor da ovulação (MII).

Tabela 4.3. Número total (N) e porcentagem (\%) de ovócitos viáveis e não 106 viáveis recuperados por OPU, depois de nove repetições, a partir de ovários de fêmeas não superestimuladas (IMA), de fêmeas superestimuladas (FSH) e de fêmeas superestimuladas, que receberam o indutor de ovulação (MII).

Tabela 4.4. Desenvolvimento de blastocistos a partir de ovócitos MII, após a vitrificação e aquecimento. Os ovócitos foram obtidos a partir de ovários de abatedouro (CONT) ou pela OPU, pela punção de ovários de fêmeas não superestimuladas (IMA), fêmeas superestimuladas (FSH) e fêmeas superestimuladas que receberam um indutor da ovulação (MII). 
Tabela 4.5. Média e desvio padrão (DP) do tamanho $(\mu \mathrm{m})$ dos embriões em D8 e número total de células dos blastocistos $(160 \mu \mathrm{m})$, derivados de ovócitos de diferentes condições de maturação: ovócitos obtidos por punção de ovários de abatedouro (CONT) ou por OPU, a partir de ovários de não fêmeas superestimuladas (IMA), fêmeas superestimuladas (FSH) e fêmeas superestimuladas que tinham recebido um indutor de ovulação (MII).

\section{Capítulo 5}

Tabela 5.1. Número (N) ode ovócitos injetados (D0), número e porcentagem de estruturas recuperadas (D7), estágio de desenvolvimento dos embriões recuperados, recuperação total e porcentagem de recuperação depois da exclusão do ovócito incluso no folículo da receptora, em cada injeção.

Tabela 5.2. Estágio de desenvolvimento e classificação embrionária. Diagnóstico de gestação com 60 dias após a transferência dos embriões produzidos.

Tabela 5.3. Média \pm desvio padrão (média \pm DP) do diâmetro e da irrigação 138 folicular no dia da transferência folicular de ovócitos imaturos (TIFOI) em D0 e do corpo lúteo em D7 e, recuperação total de estruturas e de embriões em D7, após a TIFOI com ovócitos frescos ou vitrificados.

Tabela 5.4. Avaliação do desenvolvimento embrionário, a partir de ovócitos frescos ou vitrificados e submetidos ao sistema in vivo ou in vitro, expressos em número $(\mathrm{N})$, porcentagem \pm desvio padrão (\% $\%$ DP), da clivagem em D2, blastocistos total e blastocistos expandidos (D7).

Tabela 5.5. Avaliação da qualidade dos blastocistos expandidos (D7), produzidos a partir de ovócitos frescos ou vitrificados e submetidos ao sistema in vivo ou in vitro. Expressa quanto ao 
número \pm desvio padrão $(\mathrm{N} \pm \mathrm{DP})$ de células totais e apoptóticas.

Além, da porcentagem de células apoptóticas (\%). 


\section{LISTA DE SÍMBOLOS E ABREVIAÇÕES}

$\boldsymbol{\mu g}$ - Micrograma

$\mu \mathrm{g}$ - microgramas

$\boldsymbol{\mu} \mathbf{L}$ - microlitro

$\boldsymbol{\mu M}$ - micro molar

$\boldsymbol{\mu m}$ - Micrômetro

2D- bidimensional

3D- tridimensional

ACACA- acetyl-CoA- carboxylase alpha

ANOVA- análise de variância

APC- análise de componentes principais (APC)

ARTS- assisted reproductive technologies

Be- blastocisto eclodido

Bn- blastocisto em eclosão

Bx- blastocisto expandido

Caspase 3 - cysteine Aspartic Specific Acid Protease

CCO- complexo cumulus ovócito

CES- Campo Experimental Sucupira (CES),

cGMP- Monofosfato cíclico de guanosina

CEUA- comitê de Experimentação e Uso Animal

CIV- cultivo in vitro (CIV).

CL- corpo lúteo

Cont- controle

D.P.- desvio padrão

DHB- 2,5- ácido dihidrobenzóico

DMSO- dimetilsulfóxido

DNA - ácido Desoxirribonucleico

DV1- solução de desvitrificação 1

DV2- solução de desvitrificação 2

EF- estresse pelo frio

EG- Etileno Glicol

EP- erro padrão (EP)

EUA- Estados Unidos

FCF - fator de crescimento de fibroblasto (FCF)

FCS- fetal calf serum

FIV - fecundação in vitro

FL- fosfolipídeos (FL)

FSH - Hormônio folículo estimulante

g- giros

GAPDH- gliceraldeido-3-fosfate deidrogenase (GAPDH)

GLY - Glicerol

GnRH- hormônio liberador de gonadotrofinas

GPX1- glutathione peroxidase 1

GSH- glutationa na forma reduzida

GVBD- rompimento da vesícula germinativa

HSL- Hormônio sensível a ligase

HSPA1A- heat shock protein family A (Hsp70) member 1A 
i.m.- intramuscular

IA- inseminação artificial (IA),

IFIOT- intra-follicular immature oocyte transfer

IMA- grupo imaturo

IVM- in vitro maturation

LC + R- grupo suplementado com L-Carnitina e Resveratrol

LC- grupo suplementado com L-Carnitina

LH - hormônio luteinizante

LRA- laboratórios de reprodução animal (LRA)

M- Molar

$\mathbf{m} / \mathbf{z}$ - razão massa/ carga

MALDI/TOF- matrix associated laser desorption-ionization

MI - Metáfase I

MII - Metáfase II

Min- minutos

MIV- Maturação in vitro

ml- mililitro

Mm- milímetro

MP- membrana plasmática

MPF - fator promotor da meiose

MBCD- $\beta$-metil- ciclodextrina

N- número total

$\mathbf{N}_{2} \mathbf{L}$ - Nitrogênio líquido

NaCl- solução salina

O2- oxigênio

OPS- Open Pulled Straw

OPU-ovum pick-up

P4- progesterona

PBS - solução salina em tampão fosfato

PBS-PVP- solução salina em tampão fosfato com polivinilpirrolidona

PC- fosfatidilcolina (PC)

PDE- fosfodiesterases

PGF2a- (d-cloprostenol

PI- pós inseminação

PIV - produção in vitro

PLIN2- perilipin 2

PKA-

PPIA- peptidilprolil isomerase A

RNA- Ácido ribonucleico

RNAm - RNA mensageiro

ROS- reactive oxigen species

SFB - Soro fetal bovino

SFB- soro fetal bovino

SLC2A1- solute carrier family 2 (facilitated glucose transporter), member 1

SM- esfingomielina (SM)

SM- solução de manutenção

SOD1- superoxide dismutase 1

SOF- fluido sintético de oviduto

SOFaaci- fluído sintético de oviduto suplementado com aminoácidos

Spp.- espécie 
SS- solução de estoque

SV1- solução de equilíbrio

SV1- Solução de vitrificação 1

SV2- solução de vitrificação 2

TCM - Tissue culture medium

TE- Transferência de Embriões

TIFOI- transferência intrafolicular de ovócitos imaturos

TRAs- técnicas de reprodução assistida

TUNEL- terminal deoxinucleotidil transferase dUTP nick end labeling

UI- unidade internacional

UNB- Universidade de Brasília

v/v- razão volume/volume

VG - vesícula Germinativa

VGBD - quebra da vesícula germinativa

Vit- vitrificados

ZP - Zona Pelúcida 


$$
-
$$




\section{INTRODUÇÃO}

A criopreservação de ovócitos é uma técnica essencial para o armazenamento de gametas femininos (Kuwayama et al. 2005; Zhou et al 2010) tanto para a formação de bancos de germoplasma quanto para a comercialização de material genético. Sendo indispensável para a conservação de raças e espécies ameaçadas de extinção, já que para que essas possam ser regeneradas, é fundamental que sejam recuperáveis não somente os espermatozoides, mas também os ovócitos. Além disso, a criopreservação de ovócitos é importante para a saúde humana, principalmente para meninas e mulheres com perda prematura da função ovariana, como por exemplo, devido a processos malignos em que tratamentos de quimioterapia ou radioterapia são necessários (Boiso et al., 2002; Kim et al., 2007).

Apesar de inúmeros estudos terem sido feitos nessa área, a taxa de sobrevivência de ovócitos criopreservados de animais domésticos ainda é extremamente baixa, indicando a necessidade de otimização dessa técnica (Vieira et al., 2002; Men et al., 2006; Spricigo et al., 2012). Esses resultados são, provavelmente, devido às características da célula, pois o ovócito de mamíferos é uma célula muito grande, que apresenta uma dinâmica de organelas e processos bioquímicos muito peculiares. Portanto, quando criopreservada sofre muitos danos morfológicos e funcionais, que ainda podem ser agravados, especialmente em animais doméstico, devido ao alto conteúdo lipídico no citoplasma (Mcevoy et al., 2000).

Apesar de não haver ainda um método considerado eficaz para criopreservação de ovócitos bovinos, a vitrificação parece ser o mais indicado para humanos e animais domésticos (Boldt, 2011; Saragusty et al., 2011). Essa técnica é baseada na alta concentração de crioprotetores, que tornam a solução viscosa, associada 
à uma acentuada curva de resfriamento. Desta forma, o que ocorre durante o resfriamento é a solidificação da solução viscosa e não a formação de cristais de gelo, diminuindo as lesões de organelas e membranas (Vajta et al., 1998).

Porém, além da formação de cristais de gelo intracelulares outros fatores estão envolvidos no comprometimento do ovócito após a criopreservação, tais como a desorganização do citoesqueleto (Morato et al., 2008c), estresse oxidativo (Chankitisakul et al., 2013), comprometimento dos estoques de RNA (Chamayou et al., 2011), vacuolização do citoplasma e da cromatina (Tharasanit et al., 2006a; Spricigo et al., 2014) e lesões das membranas celulares (Horvath et al., 2006).

Ao longo das últimas décadas algumas alternativas vêm sendo estudadas e desenvolvidas para aumentar à resistência dos ovócitos a criopreservação. Além da utilização de diferentes metodologias (Vieira et al., 2002; Kuwayama et al., 2005b) podese destacar o uso de agentes estabilizadores do citoesqueleto (Morato et al., 2008d), antioxidantes (Dalvit et al., 2005), substâncias lipolíticas (Men et al., 2006; Chankitisakul et al., 2013; Moawad et al., 2013) e modificadores de membrana (Horvath et al., 2006; Spricigo et al., 2012). Porém, apesar dos esforços empregados, os avanços obtidos com a criopreservação de ovócitos de animais domésticos, ainda são insuficientes e a demanda por mais pesquisas nesta área ainda é uma realidade.

\subsection{Objetivo Geral}

Avaliar diferentes alternativas para aumentar a resistência do ovócito bovino à criopreservação.

\subsubsection{Objetivos Específicos}

a) Utilizar a beta- metil- ciclodextrina para alterar a membrana plasmática de ovócitos imaturos e aumentar a tolerância a criopreservação;

b) avaliar o efeito da suplementação de agentes lipolíticos e antioxidantes aos meios de maturação in vitro, na resposta à vitrificação; 
c) verificar os efeitos de diferentes sistemas de maturação na resistência do ovócito após a vitrificação e sobre o perfil fosfolipídico da membrana plasmática (MP) ovocitária; d) adaptar e otimizar um sistema de produção in vivo de embriões, para que ovócitos imaturos possam ser maturados, fecundados e cultivados in vivo após a vitrificação.

\subsection{Hipótese}

O aumento da permeabilidade da MP, a diminuição dos lipídeos intracitoplasmáticos, além da utilização de sistemas in vivo de produção embrionária, poderiam aumentar a resistência do ovócito bovino a criopreservação.

\subsection{Justificativa}

A criopreservação do gameta feminino é uma ferramenta fundamental para diversas técnicas de reprodução assistida. Entretanto, devido à complexidade e ao grande volume do ovócito, sua criopreservação é extremamente difícil na maioria dos mamíferos. Portanto, o desenvolvimento de procedimentos que diminuam ou amenizem os danos causados pela criopreservação, são necessários para a obtenção de melhores resultados. Estudos em nosso laboratório demonstraram que dentre as estruturas celulares, o citoplasma é mais drasticamente afetado, independente do estágio de maturação em que o ovócito bovino é vitrificado (Sprícigo et al., 2012). Esse resultado sugere que isso ocorre, provavelmente, devido ao tamanho da célula. Entretanto, Chang et al. (2013) relatam que a produção embrionária de ovócitos humanos vitrificados $(55,1 \%)$ é semelhante à obtida com ovócitos frescos (53,2\%). Estas observações indicam que os problemas decorrentes do tamanho celular podem ser superados. Comparando os ovócitos que são vitrificados nessas duas espécies, as diferenças mais evidentes encontradas são o sistema de maturação utilizado, que em humanos é o in vivo, e o conteúdo de lipídeos 
que é substancialmente inferior em humanos. Além da maturação, a fecundação e cultivo in vivo dos zigotos, poderiam aumentar a viabilidade dos ovócitos imaturos após a vitrificação.

Com base nessas informações, estudos devem ser realizados na tentativa de verificar se alternativas como o uso de ovócitos maturados in vivo, a redução do conteúdo de lipídeos, alteração na composição de fosfolipídeos da membrana ou mesmo a utilização de um sistema in vivo, que suporte o desenvolvimento posterior do ovócito imaturo, poderiam melhorar a resposta de ovócitos bovinos à criopreservação. 


\section{REVISÃO DE LITERATURA}

\subsection{Maturação Ovocitária}

A ovogênese é o processo de formação do gameta feminino e tem seu início ainda durante a vida fetal. As células germinativas primordiais são originadas do epiblasto no endoderma e, migram para as cristas genitais para colonizar as futuras gônadas. Após a chegada às gônadas em formação essas células param de se dividir mitóticamente, e iniciam a divisão meiótica.

Em bovinos o processo de divisão meiótica começa aos 75-80 dias de vida fetal, porém, o ciclo celular é interrompido na fase de prófase I no estágio de diplóteno, comumente chamado de vesícula germinativa (VG). Os ovócitos ficam quiescentes até a fase púbere, quando um pouco antes da ovulação sob o estímulo do hormônio luteinizante (LH) o ovócito no folículo pré-ovulatório retoma a meiose e o ciclo celular progride de prófase I para metáfase II. In vitro essa retomada da meiose é estimulada pela simples remoção do ovócito do ambiente folicular (Sirard et al., 2006).

O processo de retomada da meiose, in vivo é acompanhado por alterações nucleares e citoplasmáticas chamadas de maturação ovocitária, que compreende os eventos necessários para que o ovócito seja capaz de ser fecundado e de suportar a formação de um novo individuo (Sirard et al., 2006; Farin et al., 2007).

A maturação nuclear dura aproximadamente 24 horas na vaca e envolve o rompimento do envoltório nuclear e progressão da meiose (Luciano et al., 2009) para metáfase I, anáfase I e telófase I com expulsão do primeiro corpúsculo polar, e finalmente atingindo metáfase II (Cha et al., 1998). 
Já a maturação citoplasmática envolve uma série de eventos bioquímicos que permitem ao ovócito expressar seu potencial de desenvolvimento. Durante este período são observadas alterações, como a reorganização de organelas, migração de mitocôndrias para uma região mais central, modificações no complexo de Golgi e migração de grânulos corticais para região mais periférica (Humblot et al., 2005; Sirard et al., 2006).

Durante a maturação citoplasmática ocorre síntese de várias proteínas e uma série de mudanças e reestruturações das proteínas responsáveis pelo trânsito de organelas e cromossomos. Essas proteínas são a base do citoesqueleto celular, constituído por microtúbulos e microfilamentos, originados a partir de tubulina e actina, respectivamente (Boiso et al., 2002; Luciano et al., 2009). Falhas nos mecanismos responsáveis pela organização destas proteínas podem induzir a má formação da placa metafásica ou mesmo levar a falhas na fecundação (Asgari et al., 2011). Além das proteínas do citoesqueleto, outras como a p34cdc2, ciclina B1, MPF e MAPK são importantes para o processo de retomada da meiose e de aquisição de competência (Bilodeau-Goeseels, 2011). Ainda com relação à maturação citoplasmática, durante a fase de crescimento ovocitário é de extrema importância que ocorra a transcrição, armazenamento e até a tradução de vários grupos de mRNAs e proteínas. Esses estoques servirão de suporte durante a maturação e primeiras divisões mitóticas do embrião até a ativação de genoma embrionário (Chohan et al., 2003; Racedo et al., 2008), que no bovino ocorre entre oito e dezesseis células.

Outro evento que ocorre durante o processo de maturação, é a produção de ácido hialurônico pelas células do cumulus, resultando na produção de uma matriz gelatinosa que se deposita entre elas causando a expansão destas células (Tharasanit et al., 2006b; Zhou et al., 2010). A expansão das células do cumulus está também associada à perda da ligação metabólica existente entre elas e o ovócito. Esse processo in vivo é mediado por fatores de crescimento, ampiregulina e epiregulina ativados em resposta a ligação do hormônio luteinizante (LH) nas células da teca e nas células da granulosa. Já in vitro esse processo ocorre pela ligação do hormônio folículo-estimulante (FSH) a receptores nas células do cumulus (Bilodeau-Goeseels, 2011).

A retomada da meiose in vivo e a ovulação em mamíferos também são controladas pelo LH (Van Den Hurk et al., 2005). In vitro, a simples remoção dos complexos-cumulus-ovócitos (CCOs) do ambiente folicular, é capaz de desencadear a retomada da meiose, sugerindo que existe no ambiente folicular algum fator que mantém o 
ovócito no estágio de vesícula germinativa. De fato, já foi demonstrado que a retenção é mantida pela concentração intra ovocitária de AMPc (Van Den Hurk et al., 2005). Essa concentração de AMPc é regulada pelo equilíbrio entre a atividade de dois tipos de enzimas a adenil ciclase (AC), que produzem o AMPc, e as fosfodiesterase (PDE) que o degradam. Durante a retomada da meiose in vivo, ou retirado do ovócito do ambiente folicular ocorre a perda da transferência do cGMP das células foliculares, o que ativa a fosfodiesterase tipo 3 que causa a degradação e diminuição dos níveis de AMPc. Essa queda no AMPc desfosforiliza PKA que é desativada, e com isso ocorre ativação da fosfatase CDC25b, desfosforilação do CDK1 e o MPF é ativado induzindo a retomada da meiose (BilodeauGoeseels, 2011).

A retomada da meiose está relacionada com a perda da membrana nuclear, desintegração da vesícula germinativa, condensação da cromatina em cromossomos bivalentes, separação dos cromossomos homólogos e extrusão do primeiro corpúsculo polar (Van Den Hurk et al., 2005). A saída da fase de metáfase II ocorrerá devido ao aumento dos níveis de cálcio induzido pelo espermatozoide, o que causará a degradação da ciclina e, consequentemente inativação do MPF. Com o progresso da metáfase II ocorre uma nova divisão desigual do citoplasma resultando na liberação do segundo corpúsculo polar (Tripathi et al., 2010).

\subsection{Criopreservações de ovócitos}

A criopreservação é o processo pelo qual células, gametas, embriões e tecidos são armazenados em baixas temperaturas em $\mathrm{N}_{2} \mathrm{~L}$ (Nitrogênio Líquido) por um período de tempo indeterminado. A criopreservação, porém, é dependente do uso de solutos orgânicos conhecidos como crioprotetores, que são compostos responsáveis por substituir a água intracelular, e estabilizar as membranas, promovendo proteção às células (Leibo, 2008).

Junto à queda de temperatura, durante o processo de criopreservação, ocorre a organização das moléculas de água em cristais, este fenômeno é inicialmente observado no meio extracelular, devido a um maior volume de água. A formação destes cristais concentra os solutos na água não congelada, aumentando a osmolaridade do meio extracelular promovendo a desidratação da célula (Leibo, 2008). Porém, quanto maior a velocidade de resfriamento "menor" é o tempo que a água tem para migrar do meio intra 
para o meio extracelular, fato este que culmina em uma maior formação de cristais de gelo intracelulares. Por outro lado, se a velocidade de congelamento for demasiadamente lenta, a desidratação pode ser exacerbada levando ao "efeito solução". Nessa situação os componentes celulares irão precipitar em resposta a uma desidratação muito acentuada, comprometendo funções biológicas através da inviabilização de enzimas e proteínas. $\mathrm{O}$ ideal para processos de congelamento seria um método capaz de evitar a formação de cristais de gelo sem causar o efeito solução (Mazur, 1984) que permitisse a entrada dos crioprotetores na mesma velocidade da saída de $\mathrm{H}_{2} \mathrm{O}$.

Estas injúrias decorrentes da criopreservação ocorrem em todos os tecidos e células, entretanto, tais lesões parecem estar potencializadas no gameta feminino. Isso porque o ovócito é uma célula muito volumosa, possuindo grande quantidade de água o que facilita a formação de cristais de gelo. Além disso, o ovócito apresenta uma dinâmica de organelas e processos bioquímicos muito peculiares, estando sujeito a danos morfológicos e funcionais (Hyttel et al., 2000). O comprometimento dos ovócitos após a criopreservação pode também ser atribuído às lesões na maquinaria meiótica, como desorganização de fusos e perda de microtúbulos, além de outras alterações ultraestruturais(Vieira et al., 2002; Men et al., 2005; Horvath et al., 2006; Morato et al., 2008b; c; Anchamparuthy et al., 2009; Shirazi et al., 2012).

Outro fator que afeta o resultado da criopreservação de ovócitos é o estágio da meiose em que esses se encontram (Hochi et al., 1998; Luna et al., 2001; Boiso et al., 2002; Men et al., 2005). A maioria dos estudos tem focado na criopreservação de ovócitos maturados em estágio de metáfase II (MII) (Dinnyes et al., 2000; Hyttel et al., 2000; Horvath et al., 2006; Asgari et al., 2011) em que os cromossomos estão ligados à microtúbulos do fuso meiótico, na placa metafásica.

O congelamento clássico é um dos métodos disponíveis para a criopreservação celular, porém resultados mostram não ser um método eficaz para ovócitos (Gualtieri et al., 2011; Saragusty et al., 2011). Isso porque associado ao resfriamento das soluções durante a queda de temperatura, ocorre a formação intensa de cristais de gelo de tamanhos e formas irregulares, que afetam as organelas e membranas, inviabilizando a função celular pós- descongelamento (Rall et al., 1985).

Atualmente a técnica mais indicada para criopreservação de ovócitos é a vitrificação. Esse método é baseado no processo pelo qual uma solução viscosa se solidifica durante o resfriamento, sem a formação de cristais de gelo, mantendo desta forma, as células em um estágio quiescente (Vajta et al., 2006). Danos irreversíveis 
relacionados à integridade da membrana são causados pelo resfriamento, principalmente durante a fase de transição lipídica. Estes danos estão diretamente relacionados à quantidade e ao perfil dos fosfolipídeos presentes nas membranas celulares em células de mamíferos. As esfingomielinas (SM) e fosfatidilcolinas (PC) são os principais fosfolipídeos presentes nas membranas celulares de mamíferos (Ferreira et al., 2010; Sudano et al., 2012). Quanto menor as cadeias carbônicas dos fosfolipídeos e maiores o nível de instaurações, mais fluidas são as membranas, e, por conseguinte, mais resistente a danos durante o resfriamento (Arav et al., 1996).

Uma das vantagens da vitrificação é a rápida passagem pela fase de transição lipídica $\left(15\right.$ à - $\left.5^{\circ} \mathrm{C}\right)$ (Arav et al., 1996). Outra vantagem, é que a técnica dispensa a utilização de equipamento mais especializado. Porém, para que bons resultados possam ser observados, é necessário o emprego de meio com alta viscosidade e alta concentração para que o volume final possa ser reduzido ao máximo, possibilitando assim o armazenamento de ovócitos em $\mathrm{N}_{2} \mathrm{~L}$ (Saragusty et al., 2009).

A vitrificação apesar de já ter sido utilizada em embriologia de mamíferos, desde 1985 (Rall et al., 1985), um avanço significativo só foi obtido quando se aumentou consideravelmente a taxa de resfriamento e aquecimento pela redução no volume da solução de vitrificação (Vajta et al., 1998). Para reduzir o volume, vários dispositivos foram desenvolvidos, dentre esses, o cryotop (Kuwayama et al., 2005) foi um avanço importante para a metodologia de vitrificação.

O cryotop é atualmente a técnica mais utilizada para a criopreservação de ovócitos humanos (Cobo et al., 2010; Rienzi et al., 2010; Parmegiani et al., 2011; Sole et al., 2013). No entanto, também tem sido utilizada para vitrificação de ovócitos de várias espécies de animais domésticos, a exemplo de equinos, ovinos, suínos e bovinos (Kuwayama et al., 2005a; Kuwayama et al., 2005b; Anchamparuthy et al., 2009; Sripunya et al., 2010; Garcia-Velasco et al., 2013). Porém apesar dos avanços obtidos nas últimas décadas, os resultados com ovócitos de bovinos ainda são insatisfatórios.

\subsection{Alternativas para aumentar a resistência do ovócito à vitrificação}

A caracterização das alterações que ocorrem no ovócito após a vitrificação, tais como o estágio da meiose em que o ovócito é mais afetado e/ou quais as estruturas ou atividades metabólicas são mais danificadas durante o processo, é essencial para que 
se possam propor alternativas que melhorem os resultados. A manipulação do sistema de maturação para obter ovócitos de melhor qualidade, mudanças nas condições de cultivo para reduzir o acúmulo de lipídeos, a utilização de antioxidantes (Giaretta et al., 2015)e agentes estabilizadores de microtúbulos (Morato et al., 2008a) e a exposição à pressão hidrostática sub letal (Siqueira Filho et al., 2011), com o intuito de ativar vias de proteção celular tem sido algumas das metodologias empregadas para tentar aumentar a resistência do ovócito à criopreservação.

\subsubsection{Sistema de maturação, fecundação e cultivo}

A maturação in vitro (MIV) busca cultivar os ovócitos em um sistema que proporcione a maturação citoplasmática e nuclear, mimetizando o que ocorreria in vivo, para torná-los aptos a serem fecundados e a sustentarem o desenvolvimento embrionário. No entanto, com a população heterogênea de folículo, as condições físicas e os meios utilizados na MIV, não é possível reproduzir as condições fisiológicas oferecidas durante a maturação in vivo. Isso é observado pela menor taxa de produção de embriões de ovócitos maturados in vitro em relação aos maturados in vivo (Rizos et al., 2001; Rizos et al., 2002; Watson, 2007).

Durante a maturação ocorrem modificações e reorganização de organelas, além do avanço da meiose para o estágio de metáfase II, sendo que esses eventos podem ser influenciados pelo sistema e pelas condições de cultivo dos CCOs (Warzych et al., 2007). As condições de cultivo comumente utilizadas para a maturação in vitro envolvem o uso de soro fetal bovino (SFB) e alta tensão de oxigênio. Entretanto, está bem estabelecido que o SFB possui compostos indefinidos e quando aliado a altas tensões de $\mathrm{O}_{2}$ durante o cultivo embrionário, pode diminuir a resistência à criopreservação, além de alterar a abundância relativa de transcritos (Rizos et al., 2002).

A origem do ovócito, mais especificamente, o ambiente em que o crescimento e a maturação ocorrem (Lonergan et al., 1994; Austin et al., 1999) tem sido apontada como o fator mais importante para determinar a competência do ovócito, que se manifesta por sua capacidade de suportar o desenvolvimento embrionário e uma gestação saudável. Um reflexo dessas diferenças é a taxa de blastocisto de ovócitos maturados in vitro que raramente ultrapassa os 40 a 50\% enquanto a taxa de ovócitos maturados in vivo pode chegar a 70\% (Van De Leemput et al., 1999). Não somente o desenvolvimento, mas 
também, a qualidade dos embriões é descrita como inferior, a partir de ovócitos maturados in vitro (Lonergan et al., 2008). Essas diferenças são também confirmadas por estudos de caracterização do perfil molecular que mostram variações na expressão gênica em diversas vias entre ovócitos maturados in vivo e in vitro em bovinos (Katz-Jaffe et al., 2009; Mamo et al., 2011), humanos (Jones et al., 2008), e macacos (Lee et al., 2008).

Em humanos tem sido relatado que a produção de blastocistos a partir de ovócitos maturados in vivo e vitrificados alcança taxas de 30\% (Mamo et al., 2011; Chang et al., 2013). Esses mesmos autores descreveram que para cada nascimento em humanos são necessários 17 ovócitos vitrificados. Enquanto que em bovinos, considerando a eficiência atual da vitrificação de ovócitos maturados in vitro (Zhou et al., 2010), além do sistema de PIVE, seriam necessários, aproximadamente, 100 ovócitos vitrificados, para cada nascimento, números que refletem um sistema extremamente ineficiente. Uma das diferenças entre os ovócitos dessas duas espécies é que em humanos apenas ovócitos maturados in vivo são utilizados para a criopreservação, o que sugere que o tipo de maturação/qualidade do ovócito pode ser um dos fatores responsáveis pelo melhor resultado obtido nessa espécie. Portanto, o uso de ovócitos maturados in vivo é uma alternativa que deveria ser testada em ovócitos bovinos, sendo para isso fundamental que se estabeleça nessa espécie um sistema que permita aspirar os folículos ovarianos um pouco antes da ovulação.

Outra opção para fornecer condições in vivo, para ovócitos imaturos depois da criopreservação, seria colocar os ovócitos aspirados, após a vitrificação e aquecimento, de volta no o trato reprodutivo feminino, pela transferência intrafolicular de ovócitos imaturos (TIFOI), proposto pela primeira vez para (Fleming A.D., 1985). Esta técnica consiste na injeção de ovócitos imaturos em folículos pré-ovulatórios, os ovócitos assim podem ser maturados, fecundados, e cultivados no trato reprodutivo da fêmea até à fase de blastocisto, quando os embriões em D7 são recuperados por lavagem uterina. Hinrichs \& DiGiorgio foram os primeiros a executar a injeção de ovócitos com um cateter usando a perfuração da parede do folículo (Hinrichs et al., 1991). Apesar de ser uma técnica desenvolvida no século passado, apenas recentemente, o primeiro blastocisto, prenhez e nascidos vivos saudáveis foram relatados em bovinos, após a injeção de ovócitos maturados in vitro no folículo pré-ovulatório de uma receptora sincronizada (Kassens et al., 2015). Até o momento, não há relato de blastocisto bovino recuperados por lavado uterino no D7, após injeção intrafolicular, tampouco oriundos de transferência de ovócitos imaturos (TIFOI) ou vitrificados. 


\subsubsection{Antioxidantes}

Durante a criopreservação, ovócitos estão susceptíveis a danos osmóticos, tóxicos e físicos. A peroxidação lipídica, um tipo de dano tóxico, é caracterizada por uma cascata de eventos que leva a deterioração oxidativa de lipídeos poli-insaturados, presentes na membrana celular e ao acúmulo de produtos citotóxicos, resultando em alterações de membranas celulares (Hershko, 1989).

Fisiologicamente células de eucariontes lançam mão de moléculas antioxidantes, enzimáticas ou não para combater a formação de espécies reativas de oxigênio (EROs). Antioxidantes enzimáticos tais como superóxido dismutase (SOD), catalases (CAT) e a glutationa peroxidase (GPX) evitam o acúmulo de ânions radical superóxido e de peróxido de hidrogênio.

A proteção não enzimática é feita por pequenas moléculas, dentre as quais se destacam as vitaminas E ( $\alpha$-tocoferol) e C (ácido L-ascórbico) e a própria glutationa (GSH) (Rover et al., 2001). Os antioxidantes podem também ser classificados em hidrofílicos ou hidrofóbicos, de acordo com a sua solubilidade na água. De uma maneira geral, os antioxidantes solúveis em água reagem com oxidantes no citoplasma, enquanto antioxidantes solúveis em lipídeos atuam protegendo as membranas da peroxidação lipídica (Sies, 1999).

Alguns antioxidantes já foram adicionados aos meios de cultivo e/ou de criopreservação de ovócitos e embriões, no intuito de diminuir a produção de radicais livres. Entre os compostos utilizados podemos citar o $\alpha$-tocoferol, ou vitamina E. Este composto é uma substância lipossolúvel, conhecida como inibidora da peroxidação lipídica predominante na membrana plasmática, quantidades significativas desta vitamina estão presentes no ovário e no fluido folicular (Breininger et al., 2005).

Além da vitamina E, seu análogo sintético, o trolox (Feugang et al., 2004) outros antioxidantes como a catalase (Michael et al., 2007; Paudel et al., 2010), e o $\beta$ mercaptoetanol ( $\beta \mathrm{ME}$ ) (Hosseini et al., 2009) já foram adicionados aos meios de cultivo para diminuir os radicais livres e aumentar a resistência de tecidos e células à criopreservação.

Entre os compostos mais utilizados o $\beta \mathrm{ME}$, um tiol de baixo peso molecular, têm sido frequentemente empregado por aumentar a capacidade antioxidante 
dos embriões, através da redução dos níveis intracelulares de EROs. Após a criopreservação, com a utilização do $\beta \mathrm{ME}$ os embriões se mostraram menos susceptíveis aos efeitos deletérios dos EROs (Lane et al., 2002; Martinez et al., 2002).

Outro potente agente oxidante é o Resveratrol (R; 3,4 ', 5triidroxiestilbeno), uma molécula polifenólica natural, encontrada em várias plantas e alimentos (Baur et al., 2006). Vários estudos têm sido realizados para identificar as funções biológicas e atividades do resveratrol para a reprodução de mamíferos (Kwak et al., 2012; Huang et al., 2013). A suplementação dos meios de MIV com resveratrol melhorou os resultados de fecundação, além da capacidade de desenvolvimento embrionário em bovinos (Sugiyama et al., 2015) e suínos (Itami et al., 2015), mais provavelmente por causa da "up regulation" na biossíntese mitocondrial. Também, provocou o aumento os níveis de GSH em ovócitos suínos (Kwak et al., 2012) e bovinos (Wang et al., 2014), concomitantemente com a diminuição de ROS, sem comprometer o desenvolvimento embrionário (Salzano et al., 2014). Além disso em suínos, quando os meios de vitrificação foram suplementados com resveratrol, os níveis apoptóticos diminuíram (Giaretta et al., 2013).

Embora alguns compostos tenham proporcionado certo grau de sucesso na diminuição da produção e acúmulo de radicais livres, ainda são necessárias pesquisas para identificar e quantificar as concentrações de antioxidantes, além das associações que podem ser utilizadas em meios de cultivo e de criopreservação, para que melhores resultados sejam obtidos.

\subsubsection{Delipidação e alterações da membrana plasmática}

$\mathrm{Na}$ tentativa de diminuir os ácidos graxos algumas metodologias como a redução mecânica (Ogawa et al., 2010) e química dos lipídeos (Men et al., 2006) já foram utilizadas em ovócitos de mamíferos.

A técnica de delipidação mecânica foi empregada para ovócitos suínos, espécie que notadamente apresenta uma maior quantidade de lipídeos (Mcevoy et al., 2000). Para a remoção mecânica, os ovócitos são centrifugados fazendo com que as gotículas de lipídeos se polarizem em uma extremidade do citoplasma (Otoi et al., 1997). Através da centrifugação, também é possível a completa remoção das gotículas do citoplasma para o espaço perivitelíneo (Hara et al., 2005). Após a polarização ou extrusão 
das gotículas do citoplasma, é possível remove-las com o auxílio do micro manipulador. Já a delipidação química pode ser feito pela exposição das células à substâncias delipidantes.

Atualmente o uso de compostos químicos com o etosulfato de fenazina (PES), Forskolin (7 $\beta$-acetoxy-8,13-expoxy-1 $\alpha, 6,9 \alpha$-trihydroxy-Labd-14-en-11-one, $\mathrm{C}_{22} \mathrm{H}_{34} \mathrm{O}_{7}$ ) e L-Carnitina (L-3-Hidróxi- 4- trimetilamonio- butanoato) têm sido descritos como agentes que afetam o metabolismo dos lipídeos e que podem ser utilizados para a delipidação química.

O PES é um composto que oxida NADPH em $\mathrm{NADP}^{+}$, desta forma, esta coenzima fica indisponível para a síntese de vários ácidos graxos (Barcelo-Fimbres et al., 2007). Já foi demonstrado que a adição desta molécula, em diferentes fases do cultivo embrionários, antes da vitrificação foi capaz de diminuir as concentrações de lipídeos e a apoptose celular, além de aumentar a taxas de reexpansão da blastocele, após o aquecimentode blastocistos bovinos (Sudano et al., 2011).

O forskolin aumenta os níveis de adenosina monofostada (AMPc), através da ativação da via da adenil ciclase. Este aumento de AMPc mantém fosforilada a proteína quinase A (PKA) e os resíduos de serina, com destaque para o hormônio sensível a lipase (HSL). Por sua vez, o HSL no citoplasma entra em contato com as gotas lipídicas e inicia a lipólise dos triglicerídeos (Lafontan et al., 1993).

Outra substância capaz de reduzir a quantidade de lipídeos é a L-Carnitina, a qual desempenha um papel importante no metabolismo dos triglicerídeos, armazenados no ovócito na forma de gotas lipídicas. A L-carnitina é um agente transportador de TG do citoplasma para as mitocôndrias. Nas mitocôndrias, através da $\beta$-oxidação os TG são metabolizados resultando na adenosina trifosfato (ATP), essencial para a síntese de proteínas, maturação nuclear e citoplasmática (Vanella et al., 2000; Yazaki et al., 2013). Além do metabolismo de ácidos graxos serem mais eficiente na produção de ATP do que vias que utilizam a glicose, ovócitos e embriões nos primeiros estágios do desenvolvimento têm pouca capacidade de usar a via glicolítica (Saito et al., 1994; Dunning et al., 2012).

Recentemente foi demonstrado que o acréscimo de $0,6 \mathrm{mg} / \mathrm{ml} \mathrm{de} \mathrm{L-}$ carnitina ao meio de maturação de ovócitos suínos e bovinos foi capaz de diminuir o acúmulo de TG e alterar a distribuição das gotas lipídicas (Somfai et al., 2011; Chankitisakul et al., 2013). No mesmo trabalho, Chankitisakul et al. (2013) observaram menores taxas de ovócitos degenerados e maiores taxas de clivagem em D2 e blastocisto 
em D7, a partir de ovócitos bovino MII vitrificados, após 24 horas de MIV, na presença de L-carnitina.

Além da diminuição de lipídeos citoplasmáticos, a alteração dos lipídeos de membrana também pode ser uma alternativa para aumentar a fluidez das mesmas, facilitando a entrada e saída de crioprotetores, diminuindo a sensibilidade à criopreservação (Arav et al., 2000). A metil $\beta$ ciclodextrina (M $\beta C D$ ), molécula que tem a capacidade de carrear o colesterol através das membranas já foi utilizada para melhorar a resposta à criopreservação em espermatozoides (Purdy et al., 2004) e ovócitos (Horvath et al., 2006). 


\section{REFERÊNCIAS BIBLIOGRÁFICAS}

ANCHAMPARUTHY VM ;DHALI A ;LOTT WM ;PEARSON RE ;GWAZDAUSKAS FC. Vitrification of bovine oocytes: implications of follicular size and sire on the rates of embryonic development. Journal of assisted reproduction and genetics, v. 26,p. 613619, 2009.

ARAV A ;PEARL M ;ZERON Y. Does membrane lipid profile explain chilling sensitivity and membrane lipid phase transition of spermatozoa and oocytes? Cryo letters, v. 21,p. 179-186, 2000.

ARAV A ;ZERON Y ;LESLIE SB ;BEHBOOdI E ;ANDERSON GB ;CROWE JH. Phase transition temperature and chilling sensitivity of bovine oocytes. Cryobiology, v. 33,p. 589-599, 1996.

ASGARI V ;HOSSEINI SM ;OSTADHOSSEINI S ;HAJIAN M ;NASR-ESFAHANI MH. Time dependent effect of post warming interval on microtubule organization, meiotic status, and parthenogenetic activation of vitrified in vitro matured sheep oocytes.

Theriogenology, v. 75,p. 904-910, 2011.

Austin EJ ;MIHM M ;RYAN MP ;WILLIAMS DH ;ROCHE JF. Effect of duration of dominance of the ovulatory follicle on onset of estrus and fertility in heifers. Journal of animal science, v. 77,p. 2219-2226, 1999.

BARCELO-FIMBRES M ;SEIDEL GE, JR. Effects of either glucose or fructose and metabolic regulators on bovine embryo development and lipid accumulation in vitro. Molecular reproduction and development, v. 74,p. 1406-1418, 2007.

BAUR JA ;SINCLAIR DA. Therapeutic potential of resveratrol: the in vivo evidence. Nature reviews. Drug discovery, v. 5,p. 493-506, 2006.

BILODEAU-GoesEELS S. Cows are not mice: the role of cyclic AMP, phosphodiesterases, and adenosine monophosphate-activated protein kinase in the maintenance of meiotic arrest in bovine oocytes. Molecular reproduction and development, v. 78,p. 734-743, 2011.

BOISO I ;MARTI M ;SANTALO J ;PONSA M ;BARRI PN ;VEIGA A. A confocal microscopy analysis of the spindle and chromosome configurations of human oocytes cryopreserved 
at the germinal vesicle and metaphase II stage. Human reproduction, v. 17,p. 18851891, 2002.

BOLDT J. Current results with slow freezing and vitrification of the human oocyte. Reproductive biomedicine online, v. 23,p. 314-322, 2011.

BREININGER E ;BEORLEGUI NB ;O'FLAHERTY CM ;BECONI MT. Alpha-tocopherol improves biochemical and dynamic parameters in cryopreserved boar semen. Theriogenology, v. 63,p. 2126-2135, 2005.

CHA KY ; CHIAN RC. Maturation in vitro of immature human oocytes for clinical use. Human reproduction update, v. 4,p. 103-120, 1998.

Chamayou S ;Bonaventura G ;Alecci C ;Tibullo D ;Di Raimondo F ;GUGLIELMINO A ;BARCELLONA ML. Consequences of metaphase II oocyte cryopreservation on mRNA content. Cryobiology, v. 62,p. 130-134, 2011.

Chang CC ;Elliott TA ;Wright G ;Shapiro DB ;Toledo AA ;NAGy ZP. Prospective controlled study to evaluate laboratory and clinical outcomes of oocyte vitrification obtained in in vitro fertilization patients aged 30 to 39 years. Fertility and sterility, v. 99,p. 1891-1897, 2013.

Chankitisakul V ;SOMFAi T ;INABA Y ;TeChaKUMPhU M ;NAGAi T. Supplementation of maturation medium with L-carnitine improves cryo-tolerance of bovine in vitro matured oocytes. Theriogenology, v. 79,p. 590-598, 2013.

CHOHAN KR ; HUNTER AG. Meiotic competence of bovine fetal oocytes following in vitro maturation. Animal reproduction science, v. 76,p. 43-51, 2003.

COBO A ;MESEguer M ;REMOHI J ;PELliCER A. Use of cryo-banked oocytes in an ovum donation programme: a prospective, randomized, controlled, clinical trial. Human reproduction, v. 25,p. 2239-2246, 2010.

DALVIT G ;Llanes SP ;DESCALZO A ;InSANi M ;BECONI M ;CETICA P. Effect of alphatocopherol and ascorbic acid on bovine oocyte in vitro maturation. Reproduction in domestic animals = Zuchthygiene, v. 40,p. 93-97, 2005.

DINNYES A ;DAI Y ; JIANG S ; YANG X. High developmental rates of vitrified bovine oocytes following parthenogenetic activation, in vitro fertilization, and somatic cell nuclear transfer. Biology of reproduction, v. 63,p. 513-518, 2000.

DUNNING KR ;ROBKER RL. Promoting lipid utilization with 1-carnitine to improve oocyte quality. Animal reproduction science, v. 134,p. 69-75, 2012.

FARIN CE ;RODRIGUEZ KF ;ALEXANDER JE ;HOCKNEY JE ;HERRICK JR ;KENNEDYSTOSKOPF S. The role of transcription in EGF- and FSH-mediated oocyte maturation in vitro. Animal reproduction science, v. 98,p. 97-112, 2007.

FERREIRA CR ;SARAIVA SA ;CATHARINO RR ;GARCIA JS ;GOZZO FC ;SANVIDO GB ;SANTOS LF ;LO TURCO EG ;PONTES JH ;BASSO AC ;BERTOLLA RP ;SARTORI R 
;GUARDIEIRO MM ;PERECIN F ;MEIRELLES FV ;SANGALLI JR ;EBERLIN MN. Single embryo and oocyte lipid fingerprinting by mass spectrometry. Journal of lipid research, v. 51,p. 1218-1227, 2010.

FEUGANG JM ;DE RoOVER R ;MOENS A ;LEONARD S ;DESSY F ;DONNAY I. Addition of beta-mercaptoethanol or Trolox at the morula/blastocyst stage improves the quality of bovine blastocysts and prevents induction of apoptosis and degeneration by prooxidant agents. Theriogenology, v. 61,p. 71-90, 2004.

FLEMING A.D. SR, KUEHL T.J. Maturation of baboon or cow oocytes transplanted into a surrogate. Theriogenology, v. 23,p. 192, 1985.

Garcia-Velasco JA ;DOMingo J ;COBO A ;MARTINEZ M ;CARMONA L ;PEllicer A. Five years' experience using oocyte vitrification to preserve fertility for medical and nonmedical indications. Fertility and sterility, v. 99,p. 1994-1999, 2013.

GIARETTA E ;EstradA E ;BUCCI D ;SPINACI M ;RODRIGUEZ-GIL JE ;YESTE M. Combining reduced glutathione and ascorbic acid has supplementary beneficial effects on boar sperm cryotolerance. Theriogenology, v. 83,p. 399-407, 2015.

GIARETTA E ;SPINACI M ;BUCCI D ;TAMANINI C ;GALEATI G. Effects of resveratrol on vitrified porcine oocytes. Oxidative medicine and cellular longevity, v. 2013,p. 920257, 2013.

GUALTIERI R ;MOLLO V ;BARBATO V ;FIORENTINO I ;IACCARINO M ;TALEVI R. Ultrastructure and intracellular calcium response during activation in vitrified and slowfrozen human oocytes. Human reproduction, v. 26,p. 2452-2460, 2011.

HARA K ;ABE Y ;KUMADA N ;AONO N ;KOBAYASHI J ;MATSUMOTO H ;SASADA H ;SATO E. Extrusion and removal of lipid from the cytoplasm of porcine oocytes at the germinal vesicle stage: centrifugation under hypertonic conditions influences vitrification.

Cryobiology, v. 50,p. 216-222, 2005.

HERSHKO C. Mechanism of iron toxicity and its possible role in red cell membrane damage. Seminars in hematology, v. 26,p. 277-285, 1989.

HINRICHS K ;DIGIORGIO LM. Embryonic development after intra-follicular transfer of horse oocytes. Journal of reproduction and fertility. Supplement, v. 44,p. 369-374, 1991.

HOCHI S ;ITO K ;HIRABAYASHI M ;UEDA M ;KIMURA K ;HANADA A. Effect of nuclear stages during IVM on the survival of vitrified-warmed bovine oocytes.

Theriogenology, v. 49,p. 787-796, 1998.

HORVATH G ;SEIDEL GE, JR. Vitrification of bovine oocytes after treatment with cholesterol-loaded methyl-beta-cyclodextrin. Theriogenology, v. 66,p. 1026-1033, 2006.

HOSSEINI SM ;FOROUZANFAR M ;HAJIAN M ;ASGARI V ;ABEDI P ;HOSSEINI L ;OSTADHOSSEINI $\mathrm{S}$;MOULAVI F ; SAFAHANI LANGRROODI M ;SADEGHI H ;BAHRAMIAN H 
;EGHBALSAIED S ;NASR-ESFAHANI MH. Antioxidant supplementation of culture medium during embryo development and/or after vitrification-warming; which is the most important? Journal of assisted reproduction and genetics, v. 26,p. 355-364, 2009.

HUANG W ;LI G ; QIU J ;GonZalez P ; Challa P. Protective effects of resveratrol in experimental retinal detachment. PloS one, v. 8,p. e75735, 2013.

HUMBLOT P ;HOLM P ;LONERGAN P ;WRENZYCKI C ;LEQUARRE AS ;JOLY CG ;HERRMANN D ;LOPES A ;RIZOS D ;NIEMANN H ;CALLESEN H. Effect of stage of follicular growth during superovulation on developmental competence of bovine oocytes. Theriogenology, v. 63,p. 1149-1166, 2005.

Hyttel P ;VAJTA G ;CALlesen H. Vitrification of bovine oocytes with the open pulled straw method: ultrastructural consequences. Molecular reproduction and development, v. 56,p. 80-88, 2000.

ITAMI N ; SHIRASUNA K ;KUWAYAMA T ;IWATA H. Resveratrol improves the quality of pig oocytes derived from early antral follicles through sirtuin 1 activation.

Theriogenology, v. 83,p. 1360-1367, 2015.

JONES GM ;CRAM DS ;SONG B ;MAGLI MC ;GIANAROLI L ;LACHAM-KAPLAN O ;FINDLAY JK ;JENKIN G ; TROUNSON AO. Gene expression profiling of human oocytes following in vivo or in vitro maturation. Human reproduction, v. 23,p. 1138-1144, 2008.

KASSENS A ;HELd E ;SALILEW-WONDIM D ;SIEME H ;WRENZYCKI C ;TESFAYE D ;SCHELLANDER K ;HOELKER M. Intrafollicular Oocyte Transfer (IFOT) of AbattoirDerived and In Vitro-Matured Oocytes Results in Viable Blastocysts and Birth of Healthy Calves. Biology of reproduction, v. 92,p. 150, 2015.

KATZ-JAFFE MG ;MCCALLIE BR ;PREIS KA ;FILIPOVITS J ;GARDNER DK. Transcriptome analysis of in vivo and in vitro matured bovine MII oocytes. Theriogenology, v. 71,p. 939-946, 2009.

KIM DH ;PARK HS ;KIM SW ;HWANG IS ;YANG BC ;IM GS ;CHUNG HJ ;SEONG HW ;MOON SJ ;YANG BS. Vitrification of immature bovine oocytes by the microdrop method. The Journal of reproduction and development, v. 53,p. 843-851, 2007.

KuWAyAma M ;VAJTA G ;IEDA S ;KATO O. Comparison of open and closed methods for vitrification of human embryos and the elimination of potential contamination.

Reproductive biomedicine online, v. 11,p. 608-614, 2005a.

KUWAYAMA M ; VAJTA G ; KATO O ;LEIBO SP. Highly efficient vitrification method for cryopreservation of human oocytes. Reproductive biomedicine online, v. 11,p. 300$308,2005 b$.

KWAK SS ;CHEONG SA ;JEON Y ;LEE E ;CHOI KC ;JEUNG EB ;HYUn SH. The effects of resveratrol on porcine oocyte in vitro maturation and subsequent embryonic development after parthenogenetic activation and in vitro fertilization. Theriogenology, v. 78,p. 86-101, 2012. 
LAFONTAN M ;BERLAN M. Fat cell adrenergic receptors and the control of white and brown fat cell function. Journal of lipid research, v. 34,p. 1057-1091, 1993.

LANE M ;MAYBACH JM ;GARDNER DK. Addition of ascorbate during cryopreservation stimulates subsequent embryo development. Human reproduction, v. 17,p. 2686-2693, 2002.

LEE YS ;LATHAM KE;VANDEVOORT CA. Effects of in vitro maturation on gene expression in rhesus monkey oocytes. Physiological genomics, v. 35,p. 145-158, 2008.

LEIBO SP. Cryopreservation of oocytes and embryos: optimization by theoretical versus empirical analysis. Theriogenology, v. 69,p. 37-47, 2008.

LONERGAN P ;FAIR T. In vitro-produced bovine embryos: dealing with the warts. Theriogenology, v. 69,p. 17-22, 2008.

LONERGAN P ;MONAGHAN P ;RIZOS D ;BOLAND MP ;GORDON I. Effect of follicle size on bovine oocyte quality and developmental competence following maturation, fertilization, and culture in vitro. Molecular reproduction and development, v. 37,p. 48-53, 1994.

LUCIANO AM ;CHIGIONI S ;LODDE V ;FRANCIOSI F ;LUVONI GC ;MODINA SC. Effect of different cryopreservation protocols on cytoskeleton and gap junction mediated communication integrity in feline germinal vesicle stage oocytes. Cryobiology, v. 59,p. 90-95, 2009.

LUNA HS ;FERRARI I ;RUMPF R. Influence of stage of maturation of bovine oocytes at time of vitrification on the incidence of diploid metaphase II at completion of maturation. Animal reproduction science, v. 68,p. 23-28, 2001.

MAMO S ;CARTER F ;LONERGAN P ;LEAL CL ;Al NAIB A ;MCGETTIGAN P ;MEHTA JP ;EVANS AC ;FAIR T. Sequential analysis of global gene expression profiles in immature and in vitro matured bovine oocytes: potential molecular markers of oocyte maturation. BMC genomics, v. 12,p. 151, 2011.

Martinez AG ;Brogliatti GM ;Valcarcel A ;De Las H. Pregnancy rates after transfer of frozen bovine embryos: a field trial. Theriogenology, v. 58,p. 963-972, 2002.

McEVoY TG ;COUll GD ;BROADBENT PJ ;HutChInsON JS ;SPEAKE BK. Fatty acid composition of lipids in immature cattle, pig and sheep oocytes with intact zona pellucida. Journal of reproduction and fertility, v. 118,p. 163-170, 2000.

MEN H ;AGCA Y ;CRITSER ES ;CRITSER JK. Beneficial effects of serum supplementation during in vitro production of porcine embryos on their ability to survive cryopreservation by open pulled straw vitrification. Theriogenology, v. 64,p. 13401349, 2005. 
MEN H ;AGCA Y ;RILEY LK ;CRITSER JK. Improved survival of vitrified porcine embryos after partial delipation through chemically stimulated lipolysis and inhibition of apoptosis. Theriogenology, v. 66,p. 2008-2016, 2006.

Michael A ;AleXopoulos C ;PONTIKI E ;HAdJIPAVlou-Litina D ;SARATSis P ;Boscos C. Effect of antioxidant supplementation on semen quality and reactive oxygen species of frozen-thawed canine spermatozoa. Theriogenology, v. 68,p. 204-212, 2007.

MOAWAD AR ;TAN SL ; XU B ;CHEN HY ;TAKETO T. L-carnitine supplementation during vitrification of mouse oocytes at the germinal vesicle stage improves preimplantation development following maturation and fertilization in vitro. Biology of reproduction, v. 88,p. 104, 2013.

MORATO R ;IZQUIERDO D ;ALBARRACIN JL ;ANGUITA B ;PALOMO MJ ;JIMENEZMACEDO AR ;PARAMIO MT ;MOGAS T. Effects of pre-treating in vitro-matured bovine oocytes with the cytoskeleton stabilizing agent taxol prior to vitrification. Molecular reproduction and development, v. 75,p. 191-201, 2008a.

MORATO R ;IZQUIERDO D ;PARAMIO MT ;MOGAS T. Cryotops versus open-pulled straws (OPS) as carriers for the cryopreservation of bovine oocytes: effects on spindle and chromosome configuration and embryo development. Cryobiology, v. 57,p. 137-141, 2008 b.

MORATO R ;IZQUIERDO D ;PARAMIO MT ;MOGAS T. Embryo development and structural analysis of in vitro matured bovine oocytes vitrified in flexipet denuding pipettes.

Theriogenology, v. 70,p. 1536-1543, 2008c.

MoRATO R ; MOGAS T ; MADDOX-HyTtEL P. Ultrastructure of bovine oocytes exposed to Taxol prior to OPS vitrification. Molecular reproduction and development, v. 75,p. 1318-1326, 2008d.

OGAWA B ;UENO S ;NAKAYAMA N ;MATSUNARI H ;NAKANO K ;FUJIWARA T ;IKEZAWA $\mathrm{Y}$;NAGASHIMA H. Developmental ability of porcine in vitro matured oocytes at the meiosis II stage after vitrification. The Journal of reproduction and development, $v$. 56,p. 356-361, 2010.

OTOI T ;YAMAMOTO K ; KOYAMA N ;TACHIKAWA S ;MURAKAMI M ;KIKKAWA Y ;SUZUKI T. Cryopreservation of mature bovine oocytes following centrifugation treatment. Cryobiology, v. 34,p. 36-41, 1997.

PARMEGIANI L ;COGNIGNI GE ;BERNARDI S ;CUOMO S ;CIAMPAGLIA W ;INFANTE FE ;TABARElli De FATIS C ;ARNONE A ;MACCARINI AM ;FILICORI M. Efficiency of aseptic open vitrification and hermetical cryostorage of human oocytes. Reproductive

biomedicine online, v. 23,p. 505-512, 2011.

PAUdel KP ;KUMAR S ;MEUR SK ;KUMARESAN A. Ascorbic acid, catalase and chlorpromazine reduce cryopreservation-induced damages to crossbred bull spermatozoa. Reproduction in domestic animals = Zuchthygiene, v. 45,p. 256-262, 2010 . 
PURDY PH ;GRAHAM JK. Effect of cholesterol-loaded cyclodextrin on the cryosurvival of bull sperm. Cryobiology, v. 48,p. 36-45, 2004.

RACEDO SE ;WRENZYCKI C ;HERRMANN D ;SALAMONE D ;NIEMANN H. Effects of follicle size and stages of maturation on mRNA expression in bovine in vitro matured oocytes. Molecular reproduction and development, v. 75,p. 17-25, 2008.

RALL WF ;FAHY GM. Ice-free cryopreservation of mouse embryos at -196 degrees C by vitrification. Nature, v. 313,p. 573-575, 1985.

RIENZI L ;ROMANO S ;ALBRICCI L ;MAGGIULLI R ;CAPALBO A ;BARONI E ;COLAMARIA S ;SAPIENZA F ;UBALDI F. Embryo development of fresh 'versus' vitrified metaphase II oocytes after ICSI: a prospective randomized sibling-oocyte study. Human reproduction, v. 25,p. 66-73, 2010.

RIZOS D ;WARD F ;BOLAND MP ;LONERGAN P. Effect of culture system on the yield and quality of bovine blastocysts as assessed by survival after vitrification. Theriogenology, v. 56,p. 1-16, 2001.

RIZOS D ; WARD F ;DUfFY P ;BOLAND MP ;LONERGAN P. Consequences of bovine oocyte maturation, fertilization or early embryo development in vitro versus in vivo: implications for blastocyst yield and blastocyst quality. Molecular reproduction and development, v. 61,p. 234-248, 2002.

ROVER L, JR. ;KUBOTA LT ;HOEHR NF. Development of an amperometric biosensor based on glutathione peroxidase immobilized in a carbodiimide matrix for the analysis of reduced glutathione from serum. Clinica chimica acta; international journal of clinical chemistry, v. 308,p. 55-67, 2001.

SAITO T ;HIROI M ;KATO T. Development of glucose utilization studied in single oocytes and preimplantation embryos from mice. Biology of reproduction, v. 50,p. 266-270, 1994.

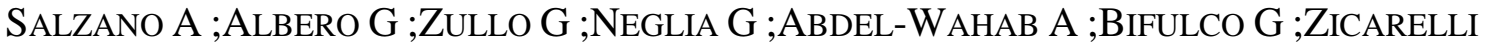
$\mathrm{L}$; GASPARRINI B. Effect of resveratrol supplementation during culture on the quality and cryotolerance of bovine in vitro produced embryos. Animal reproduction science, v. 151,p. 91-96, 2014.

SARAGUSTY J ;ARAV A. Current progress in oocyte and embryo cryopreservation by slow freezing and vitrification. Reproduction, v. 141,p. 1-19, 2011.

SARAGUSTY J ;GACITUA H ;ROZENBOIM I ;ARAV A. Do physical forces contribute to cryodamage? Biotechnology and bioengineering, v. 104,p. 719-728, 2009.

SHIRAZI A ;TAHERI F ;NAZARI H ;NORBAKHSH-NIA M ;AHMADI E ;HEIDARI B. Developmental competence of ovine oocyte following vitrification: effect of oocyte developmental stage, cumulus cells, cytoskeleton stabiliser, FBS concentration, and equilibration time. Zygote, p. 1-9, 2012. 
SIES H. Glutathione and its role in cellular functions. Free radical biology \& medicine, v. 27,p. 916-921, 1999.

SiQueIRA FILHO E ;CAIXETA ES ;PRIBENSZKY C ;MOLNAR M ;HORVATH A ;HARNOS A ;FRANCO MM ;RUMPF R. Vitrification of bovine blastocysts pretreated with sublethal hydrostatic pressure stress: evaluation of post-thaw in vitro development and gene expression. Reproduction, fertility, and development, v. 23,p. 585-590, 2011.

SIRARD MA ;RICHARD F ;BLONDIN P ; ROBERT C. Contribution of the oocyte to embryo quality. Theriogenology, v. 65,p. 126-136, 2006.

SOlE M ;SANTAlO J ;BOAdA M ;Clua E ;ROdRigueZ I ;MARTINEZ F ;COROleU B ;BARRI PN ;VEIGA A. How does vitrification affect oocyte viability in oocyte donation cycles? A prospective study to compare outcomes achieved with fresh versus vitrified sibling oocytes. Human reproduction, v. 28,p. 2087-2092, 2013.

SOMFAI T ;KANEDA M ;AKAGI S ;WATANABE $S$;HARAGUCHI $S$;MizUtANi E ;DANGNGUYEN TQ ; GESHI M ;KIKUCHI K ;NAGAI T. Enhancement of lipid metabolism with Lcarnitine during in vitro maturation improves nuclear maturation and cleavage ability of follicular porcine oocytes. Reproduction, fertility, and development, v. 23,p. 912920, 2011.

SPRICIGO JF ;MORAIS K ;FERREIRA AR ;MACHADO GM ;GOMES AC ;RUMPF R ;FRANCO $\mathrm{MM}$;DODE MA. Vitrification of bovine oocytes at different meiotic stages using the Cryotop method: assessment of morphological, molecular and functional patterns. Cryobiology, v. 69,p. 256-265, 2014.

SPRICIGO JF ;MORAIS KS ;YANG BS ;DODE MA. Effect of the exposure to methyl-betacyclodextrin prior to chilling or vitrification on the viability of bovine immature oocytes. Cryobiology, v. 65,p. 319-325, 2012.

SRIPUNYA N ;SOMFAI T ;INABA Y ;NAGAI T ;IMAI K ;PARNPAI R. A comparison of cryotop and solid surface vitrification methods for the cryopreservation of in vitro matured bovine oocytes. The Journal of reproduction and development, v. 56,p. 176$181,2010$.

SudANO MJ ;PASChOAL DM ;RASCAdo TdA S ;MAgAlHaEs LC ;CROCOMO LF ;DE LIMA-NETO JF ;LANDIM-ALVARENGA FDA C. Lipid content and apoptosis of in vitroproduced bovine embryos as determinants of susceptibility to vitrification. Theriogenology, v. 75,p. 1211-1220, 2011.

SUdANO MJ ;SANTOS VG ;TATA A ;FERREIRA CR ;PASCHOAL DM ;MACHADO R ;BURATINI J ;EBERLIN MN ;LANDIM-ALVARENGA FD. Phosphatidylcholine and sphingomyelin profiles vary in Bos taurus indicus and Bos taurus taurus in vitro- and in vivo-produced blastocysts. Biology of reproduction, v. 87,p. 130, 2012.

SUGIYAMA M ;KAWAHARA-MIKI R ;KAWANA H ;SHIRASUNA K ;KUWAYAMA T ;IWATA $H$. Resveratrol-induced mitochondrial synthesis and autophagy in oocytes derived from early antral follicles of aged cows. The Journal of reproduction and development, $v$. 61,p. 251-259, 2015. 
THARASANIT T ; COLENBRANDER B ;STOUT TA. Effect of maturation stage at cryopreservation on post-thaw cytoskeleton quality and fertilizability of equine oocytes. Molecular reproduction and development, v. 73,p. 627-637, 2006 a.

THARASANIT T ;COLLEONI S ;LAZZARI G ;COLENBRANDER B ;GALli C ;STOUT TA. Effect of cumulus morphology and maturation stage on the cryopreservability of equine oocytes. Reproduction, v. 132,p. 759-769, 2006b.

TriPATHI A ;KUMAR KV ; CHAUbE SK. Meiotic cell cycle arrest in mammalian oocytes. Journal of cellular physiology, v. 223,p. 592-600, 2010.

VAJTA G ;Holm P ;KuWAYAma M ;BOOTH PJ ;JACOBSEN H ;GREVE T ;CALleSEN H. Open Pulled Straw (OPS) vitrification: a new way to reduce cryoinjuries of bovine ova and embryos. Molecular reproduction and development, v. 51,p. 53-58, 1998.

VAJTA G ;KuWAyama M. Improving cryopreservation systems. Theriogenology, v. 65,p. 236-244, 2006.

VAn De Leemput EE ;Vos PL ;Zeinstra EC ;Bevers MM ;VAn Der Weidden GC ;DIELEMAN SJ. Improved in vitro embryo development using in vivo matured oocytes from heifers superovulated with a controlled preovulatory LH surge. Theriogenology, v. 52,p. 335-349, 1999.

VAN DEN HURK R ;ZHAO J. Formation of mammalian oocytes and their growth, differentiation and maturation within ovarian follicles. Theriogenology, v. 63,p. 17171751, 2005.

VANELla A ;RUSSO A ;ACQUAVIVA R ;CAMPISI A ;Di GIACOMO C ;SORRENTI V ;BARCELLONA ML. L -propionyl-carnitine as superoxide scavenger, antioxidant, and DNA cleavage protector. Cell biology and toxicology, v. 16,p. 99-104, 2000.

VIEIRA AD ;MEZZALIRA A ;BARBIERI DP ;LEHMKUHL RC ;RUBIN MI ;VAJTA G. Calves born after open pulled straw vitrification of immature bovine oocytes. Cryobiology, v. 45,p. 91-94, 2002.

WANG F ;TIAN X ;ZHANG L ;HE C ;JI P ;LI Y ;TAN D ;LIU G. Beneficial effect of resveratrol on bovine oocyte maturation and subsequent embryonic development after in vitro fertilization. Fertility and sterility, v. 101,p. 577-586, 2014.

WARZYCH E ; WRENZYCKI C ;PEIPPO J ;LECHNIAK D. Maturation medium supplements affect transcript level of apoptosis and cell survival related genes in bovine blastocysts produced in vitro. Molecular reproduction and development, v. 74,p. 280-289, 2007.

WATSON AJ. Oocyte cytoplasmic maturation: a key mediator of oocyte and embryo developmental competence. Journal of animal science, v. 85,p. E1-3, 2007.

YAZAKI T ;HIRADATE Y ;HOSHINO Y ;TANEMURA K ;SATO E. L-carnitine improves hydrogen peroxide-induced impairment of nuclear maturation in porcine oocytes. Animal science journal = Nihon chikusan Gakkaiho, v. 84,p. 395-402, 2013. 
ZHOU XL ;AL NAIB A ;SUN DW ;LONERGAN P. Bovine oocyte vitrification using the Cryotop method: effect of cumulus cells and vitrification protocol on survival and subsequent development. Cryobiology, v. 61,p. 66-72, 2010. 


\section{CAPITULO 2}

\section{EFEITO DA EXPOSIÇÃO À BETA- METIL-CICLODEXTRINA ANTES DO RESFRIAMENTO OU VITRIFICAÇÃO NA VIABILIDADE DE OVÓCITOS BOVINOS IMATUROS}

José Felipe W. Sprícigo ${ }^{1}$, Karollyne S. Morais ${ }^{2}$, Yang S. Bosuk ${ }^{3}$, Margot A. N. Dode ${ }^{2}$.

${ }^{1}$ Programa de Pós-Graduação em Ciências Animais, Faculdade de Agronomia e Medicina Veterinária, Universidade de Brasília, UnB, Brasília, DF, Brasil;

${ }^{2}$. Embrapa Recursos Genéticos e Biotecnologia, Laboratório de Reprodução Animal, Brasília, DF, Brazil.

${ }^{3}$ Instituto Nacional de Ciências Animais, RDA, República da Coréia 


\section{RESUMO}

O presente estudo teve como objetivo avaliar o efeito da Beta-Metil ciclodextrina $(\beta \mathrm{MCD})$, um carreador de colesterol, para alterar a membrana plasmática de ovócitos imaturos e aumentar a tolerância a criopreservação. $O$ primeiro e segundo experimentos foram realizados para investigar se $\beta M C D$ poderia melhorar a maturação nuclear e citoplasmática de ovócitos após a exposição ao estresse pelo frio, durante 10 ou 30 minutos. Nenhuma diferença $(\mathrm{P}>0,05)$ foi observada na taxa de metáfase II (MII) de ovócitos expostos a $\beta \mathrm{MCD}$ e ao frio. Porém, estes ovócitos apresentaram taxas de maturação mais baixas do que os ovócitos dos grupos controles. No segundo experimento, uma menor porcentagem de ovócito apresentou cromatina degenerada $(\mathrm{P}<0,05)$ após a exposição à 2 $\mathrm{mg} / \mathrm{mL}$ de $\beta \mathrm{MCD}$, comparado com o grupo exposto à $0 \mathrm{mg} / \mathrm{mL}$. Entretanto, o tratamento não afetou $(\mathrm{P}<0,05)$, a maturação citoplasmática. Os grupos expostos ao estresse pelo frio demonstraram uma menor $(\mathrm{P}<0,05)$ capacidade de desenvolvimento embrionário, comparados aos grupos controle. No terceiro experimento ovócitos imaturos foram expostos à $\beta \mathrm{MCD}$ e, em seguida, vitrificados (cryotop). Após o aquecimento foi observado que a capacidade de atingir MII e o índice de degeneração da cromatina foram alterados $(\mathrm{P}<0,05)$ pelo $\beta \mathrm{MCD}$. A taxa de blastocistos no $\mathrm{D} 7$ foi maior $(\mathrm{P}<0,05)$ no grupo exposto à $2 \mathrm{mg} / \mathrm{mL}$ de $\beta \mathrm{MCD}$, entretanto essa diferença não se repetiu no D8 $(\mathrm{P}>0,05)$. A degeneração da cromatina foi maior nos grupos vitrificados. Conclui-se que a não melhorou a maturação nuclear, reduzindo a degeneração dos ovócitos após o estresse pelo frio ou pela vitrificação; no entanto, mais estudos são necessários para esclarecer a utilidade do $\beta \mathrm{MCD}$ na criopreservação de ovócitos bovinos imaturos.

Palavras chaves: Imaturo, bovino, ovócito, vitrificação, cryotop, beta-metil -ciclodextrina. 


\section{ABSTRACT}

The present study aimed to evaluate the effect of methyl- $\beta$-cyclodextrin $(\mathrm{M} \beta \mathrm{CD})$ as a cholesterol loader to change oocyte plasma membrane and increase its tolerance toward cryopreservation. The first and second experiments were conducted to investigate if $\mathrm{M} \beta \mathrm{CD}$ could improve nuclear and cytoplasmic maturation after oocyte exposure to cold stress for 10 or $30 \mathrm{~min}$, respectively. No differences $(\mathrm{P}>0.05)$ in either experiment in the metaphase II (MII) rate of oocytes exposed to $\mathrm{M} \beta \mathrm{CD}$ and cold stress; but these oocytes presented lower maturation rates than control groups. In the second experiment, a lower percentage of oocytes showed degenerated chromatin $(\mathrm{P}<0.05)$ after exposure to $2 \mathrm{mg} / \mathrm{mL}$ of $\mathrm{M} \beta \mathrm{CD}$ compared to the group exposed to $0 \mathrm{mg} / \mathrm{mL}$. However, no differences among treatments were observed in cytoplasmic maturation. Groups exposed to cold stress demonstrated a lower $(\mathrm{P}<0.05)$ capacity for embryonic development compared to the control groups. In the third experiment, immature oocytes were exposed to $\mathrm{M} \beta \mathrm{CD}$ and then, vitrified (cryotop). After warming, we observed that the ability to reach MII and chromatin degeneration were altered $(\mathrm{P}<0.05)$ by $\mathrm{M} \beta C D$. The blastocysts rate $(\mathrm{P}<0.05)$ on $\mathrm{D} 7$ was higher in the $2 \mathrm{mg} / \mathrm{mL} \mathrm{M} \beta \mathrm{CD}$ group, but an identical finding was not observed on D8 (P > 0.05). Chromatin degeneration was higher in the vitrification groups. We conclude that M $\beta C D$ improved nuclear maturation by reducing oocyte degeneration after cold stress or vitrification; however, more studies are required to clarify the usefulness of $\mathrm{M} \beta \mathrm{CD}$ use in oocyte cryopreservation.

Key words: Immature, bovine, oocyte, vitrification, cryotop, methyl-beta-cyclodextrin. 


\section{INTRODUÇÃO}

A capacidade de preservar o gameta feminino é um procedimento importante para as técnicas de reprodução assistida (ARTs), uma vez que aumenta a disponibilidade de ovócitos para utilização em tais técnicas. A criopreservação do ovócito permite não só a conservação dos recursos genéticos de animais domésticos e selvagens, mas também a preservação de gametas de mulheres com perda prematura da função ovariana. No entanto, devido ao seu grande tamanho e alta sensibilidade ao frio, a criopreservação de ovócitos ainda é insuficiente na maioria dos mamíferos.

Inicialmente, a metodologia usada para a criopreservação de ovócitos de mamíferos era a congelação lenta, que inclui baixa taxa de resfriamento e baixas concentrações de crioprotetores. Entretanto a vitrificação, que utiliza altas taxa de resfriamento e elevada concentração de agentes crioprotetores para prevenir a formação de cristais de gelo, vem substituindo a congelação lenta. Este método tem sido utilizado em várias espécies de animais domésticos, como em ovinos (Ebrahimi, Valojerdi, EftekhariYazdi, Baharvand, et al., 2010), equinos (Tharasanit et al., 2006), felinos (Luciano et al., 2009) e bovinos (Morato et al., 2008b). No entanto, no geral o sucesso da criopreservação de ovócitos avaliado pelo desenvolvimento até o estágio de blastocisto, ainda é baixo.

Várias tentativas têm sido feitas para melhorar a eficiência da vitrificação de ovócitos. Considerando esses aspectos, diferentes métodos têm sido propostos para aumentar a taxa de resfriamento e reduzir o volume da solução de vitrificação. O método de volume mínimo (DMS) foi desenvolvido por Arav et al. (1993), e, posteriormente muitos dispositivos foram desenvolvidos tais como o Open Pulled Straw (OPS) (Vajta et al., 1998), cryoloop (Lane et al., 1999), hemi-straw (Vanderzwalmen et al., 2003) e cryotop (Kuwayama et al., 2005). Entre esses métodos, o cryotop utiliza um volume muito reduzido de solução de vitrificação, e é considerado o mais prático e eficiente para criopreservação de ovócitos 
bovinos. Mesmo com todas as vantagens que o cryotop apresenta em relação aos outros métodos, os resultados obtidos com a vitrificação de ovócitos bovinos ainda continuam insatisfatórios (Diez et al., 2005; Morato et al., 2008b; a; Zhou et al., 2010).

O dano celular que ocorre durante a criopreservação é causado por vários fatores, tais como estresse osmótico, toxicidade dos crioprotetores, formação de cristais de gelo com consequente danos às organelas celulares (Saragusty et al., 2009). Injúrias pelo resfriamento induzem a desestabilização de membranas celulares durante a fase de transição entre o estado fluído e o estado de gel, sendo um dos principais obstáculos para o sucesso da criopreservação de ovócitos (Quinn et al., 1966; Arav et al., 1996).

Danos irreversíveis para a integridade da membrana causada pelo frio durante essa fase de transição estão diretamente relacionados à quantidade de lipídios presentes na membrana (Arav et al., 1996). O colesterol é um importante componente lipídico estrutural da membrana e regula a sua função. Portanto, a proporção de colesterol: fosfolípideo é um fator determinante para a fluidez da membrana plasmática e para a sua estabilidade durante a criopreservação (Horvath et al., 2006). Membranas com elevadas concentrações de colesterol são mais fluídicas à temperaturas baixas e, por conseguinte mais resistente a danos durante o resfriamento (Zeron et al., 2001; Zeron et al., 2002). Para aumentar a fluidez e a permeabilidade da membrana em temperaturas baixas, o colesterol pode ser adicionado à membrana plasmática, proporcionando assim um método alternativo para aumentar a tolerância do ovócito a criopreservação.

As ciclodextrinas podem atuar como moléculas carreadoras para que o colesterol seja incorporado à membrana plasmática (Purdy et al., 2004; Horvath et al., 2006; Amorim et al., 2009). As ciclodextrinas são oligossacarídeos cíclicos solúveis em água constituídos por unidades de glicose (AD-glucopiranósido) unidos por ligações tipo $\alpha-1,4$, que contêm um centro hidrofóbico capaz de integrar lipídios.

Devido à sua estrutura, as ciclodextrina livres podem seletivamente retirar o colesterol de membranas intactas ou isoladas de várias células, incluindo os espermatozoides e ovócitos (Nagao et al., 2010). Enquanto que as ciclodextrinas pré-carregado com colesterol podem depositá-lo na membrana plasmática. Portanto, podem ser usadas antes da criopreservação na tentativa de alterar a composição da membrana e minimizar os danos causados pela criopreservação.

A $\beta$-metil-ciclodextrina ( $\beta$ MCD) é um membro da família da ciclodextrina, porém mais potente no que diz respeito à sua afinidade para a ligação ao colesterol. Além disso, já foi demonstrado que o colesterol melhorou a viabilidade espermática após a 
criopreservação em bovinos (Purdy et al., 2004; Ebrahimi, Valojerdi, Eftekhari-Yazdi, Baharvand, et al., 2010) e equinos (Moore et al., 2005; Nagao et al., 2010). Em estudo com bovinos, foi demostrado que o colesterol transportado por ciclodextrina entrou nas células do cumulus, e melhorou a sobrevivência dos ovócitos maturados após vitrificação (Horvath et al., 2006). Entretanto, não existem mais estudos que investigaram essa abordagem simples para reduzir a sensibilidade do ovócito ao frio.

No presente estudo a $\mathrm{M} \beta \mathrm{CD}$ foi utilizada na tentativa de que a mesmo retirasse o colesterol de soro fetal bovino (SFB) e o depositasse na membrana plasmática do ovócito imaturo. Portanto, o objetivo deste estudo foi investigar o efeito da exposição a M $\beta C D$ nas taxas de maturação in vitro e capacidade de desenvolvimento embrionário, de ovócitos bovinos imaturos, submetidos ao estresse pelo frio ou vitrificação. 


\section{MATERIAL E MÉTODOS}

Os experimentos foram realizados nos laboratórios de reprodução animal (LRA) da Embrapa Recursos Genéticos e Biotecnologia, Brasília-DF e no Campo Experimental Sucupira (CES), Riacho Fundo I-DF.

Todos os reagentes utilizados nos experimentos foram adquiridos da Sigma Aldrich (St. Louis, MO, EUA). As hastes para o cryotop foram adquiridos junto à Ingámed (Maringá, PR, Brasil).

\subsection{Obtenção dos Ovócitos e preparação da solução de MßCD}

Os ovários de fêmeas mestiças (Bos indicus x Bos taurus) foram coletados imediatamente após o abate e transportadas para o laboratório em solução salina $(\mathrm{NaCl}$ a 0,9\%) suplementado com penicilina G (100 UI / $\mathrm{ml})$ e sulfato de estreptomicina (100 g/ ml) a $35^{\circ} \mathrm{C}$. Complexos cumulus ovócitos (CCOs) foram aspirados de folículos de 3 a $8 \mathrm{~mm}$ de diâmetro, com uma seringa $10 \mathrm{ml}$ e agulha 40 X 12 (18 G), o liquido folicular era depositado em tubos de $15 \mathrm{ml}$ (TPP ${ }^{\circledR}$, Trasadingen, Suíça), após dez minutos de repouso o pellet era retirado e transferido para uma placa de petri de $100 \mathrm{~mm}\left(\mathrm{TPP}^{\circledR}\right)$ contendo PBS $\left(\right.$ Nutricell $^{\circledR}$, Campinas - SP, Brasil) suplementado com 10\% de Soro Fetal Bovino (Gibco BRL, Burlington, ON, Canada) e antibióticos (penicilina e estreptomicina). Somente CCOs com citoplasma homogêneo e com pelo menos três camadas de células de cumulus foram usados nos experimentos. A $\beta$ MCD foi preparada em tubo de vidro em solução de estoque (SS). Uma grama de $\beta \mathrm{MCD}$ foi dissolvida em $2 \mathrm{~mL}$ de metanol e armazenado (Horvath et al., 2006). Para carregar o colesterol proveniente do FCS, a SS foi diluída a diferentes concentrações (1, 2 ou $3 \mathrm{mg}$ ) de M $\beta C D$ em $1 \mathrm{~mL}$ de HEPES-tamponada com TCM-199 (Gibco BRL, 
Burlington, ON, Canada) suplementado com FCS a 20\%. A solução foi incubada durante a noite a $38,5 \mathrm{C}$.

\subsection{Vitrificação e aquecimento}

Para a vitrificação foram utilizadas as soluções e o protocolo de acordo com a metodologia do cryotop desenvolvido por Kuwayama et al.(2005), porém as hastes e o equipamento utilizado, foram adquiridos da Ingá-med ${ }^{\circledR}$ (Maringá-PR, Brasil). A solução de manutenção (SM), composta de TCM-199 Hank’s (Gibco BRL, Burlington, ON, Canada) suplementada com $20 \%$ de SFB foi usada para manutenção dos ovócitos durante a vitrificação e desvitrificação. Todas as manipulações foram realizadas sobre placa aquecedora na temperatura de $39^{\circ} \mathrm{C}$, em sala aquecida $\left(25-27^{\circ} \mathrm{C}\right)$. Todos os meios utilizados estavam aquecidos a temperatura ambiente, com exceção da solução de desvitrificação 1 (DV1) aquecida a $37^{\circ} \mathrm{C}$.

Para vitrificação os CCOs em grupos de 3 a 5 foram submetidos a 3 banhos sequenciais na solução de equilíbrio (SV1), constituída de SM acrescido de 7,5\% etileno glicol e 7,5\% de DMSO, permanecendo em cada gota (banho) por 3 minutos. O tempo total de exposição à SV1 ficou entre 9 e 15 minutos. Após o equilíbrio os ovócitos eram transferidos para a solução de vitrificação (SV2), composta por SM suplementado com 15\% etileno glicol, $15 \%$ DMSO e 0,5 M de sacarose, nesta solução os ovócitos passaram por 4 banhos sequenciais, totalizando 45 - 60 segundos.

Os ovócitos foram então colocados nas hastes de vitrificação com auxílio de micro pipeta de vidro com diâmetro aproximado de $150 \mu \mathrm{m}$, Imediatamente após a deposição dos ovócitos nas hastes, o excesso de solução era retirado deixando somente uma fina camada (aproximadamente $0,1 \mu \mathrm{L}$ ) sobre os ovócitos. Posteriormente a haste era submergida verticalmente no nitrogênio líquido $\left(\mathrm{N}_{2} \mathrm{~L}\right)$.

Para o aquecimento, a haste era retirada do $\mathrm{N}_{2} \mathrm{~L}$ com o auxílio de uma pinça e a extremidade contendo os CCOs era imersa na solução de auqcimento 1 (DV1), composta por SM mais $1 \mathrm{M}$ de sacarose. Os CCOs permaneciam na DV1 por 1 minuto, e posteriormente eram transferidos para uma solução menos concentrada (DV 2) composta por SM acrescido de 0,5 M de sacarose, durante 3 minutos. Finalmente os CCOs eram submetidos a duas lavagens em gotas de SM, permanecendo 5 minutos em cada gota. 


\subsection{Maturação in vitro}

Após o aquecimento, os CCOs foram lavados e transferidos (grupos de 25-30) para uma gota de $200 \mu 1$ de meio de maturação sob óleo mineral e incubados durante 24 horas à $39^{\circ} \mathrm{C}$, em $5 \%$ de $\mathrm{CO}_{2}$ em ar. O meio de maturação foi o TCM-199 suplementado com $10 \%$ FCS (v/v), $10 \mathrm{mg} / \mathrm{ml}$ de FSH e antibióticos (100 IU / $\mathrm{mL}$ de penicilina e $50 \mathrm{mg} / \mathrm{mL}$ de estreptomicina

\subsection{Avaliação da maturação nuclear}

Para a avaliação da maturação nuclear, CCOs de todos os tratamentos ao término das 24 horas de maturação foram expostos a $0,3 \%$ de hialuronidase durante 5 minutos. Em seguida as células do cumulus foram removidas por sucessivas pipetagens. Os ovócitos desnudos foram fixados em uma solução (3:1) de álcool etílico e ácido acético, onde permaneceram por um mínimo de 48 horas. No dia da avaliação os ovócitos foram colocados sobre lâmina e cobertos com lamínula, corados com corante lacmóide em solução de ácido acético glacial a $45 \%$.

A avaliação morfológica dos ovócitos corados foi realizada em microscópio de contraste de fase (Nikon Eclipse E200, 1,000X). Os ovócitos foram classificados em: (a) maturados, aqueles que apresentam o estágio de metáfase II com cromossomos alinhados na placa metafásica, (b) imaturos, aqueles que não atingiram o estágio de MII, (c) anormais, aqueles com aberrações cromossômicas tais como ploidia, fusos multidirecionais, disco metafásico anormal ou dispersão cromossômica e (d) degenerados, aqueles que apresentavam cromatina não identificável (Figura 2.1).

\subsection{Seleção Espermática e Fecundação In Vitro}

Após a maturação, CCOs (grupos de 25-30) foram transferidos para uma gota de $200 \mu \mathrm{l}$ de meio de fecundação. Para a fecundação, foi utilizado sêmen congelado de um touro Nelore previamente testado, em laboratório. Espermatozoides móveis foram obtidos pelo método de Percoll (Machado et al., 2009) e foram adicionados às gotas contendo CCOs a 
uma concentração final de $1 \times 10^{6}$ espermatozoides $/ \mathrm{mL}$. O meio de fecundação foi o TALP suplementado com penicilamina $(2 \mathrm{mM})$, hipotaurina $(1 \mathrm{mM})$, epinefrina $(250 \mathrm{mM})$ e heparina $(10 \mathrm{mg} / \mathrm{mL})$. Os espermatozoides e ovócitos foram co-incubadas durante $18 \mathrm{~h}$ à 39 ${ }^{\circ} \mathrm{C}$ com $5 \%$ de $\mathrm{CO}_{2}$ em ar, e o dia da inseminação in vitro foi considerado como o dia 0. Dezoito horas após a inseminação (pi), zigotos foram lavados, transferidos para gotas de 200 $\mu 1$ gotas de fluido sintético do oviduto suplementado com aminoácidos, citrato e inositol [SOFaaci; (Holm et al., 1999)], e 5\% SFB. Foram então incubados à $39^{\circ} \mathrm{C}$ com $5 \%$ de $\mathrm{CO}_{2}$ em ar e avaliados no dia 2 (pi) para a clivagem e nos dias 6,7 e 8 (pi) para as taxas de blastocisto.

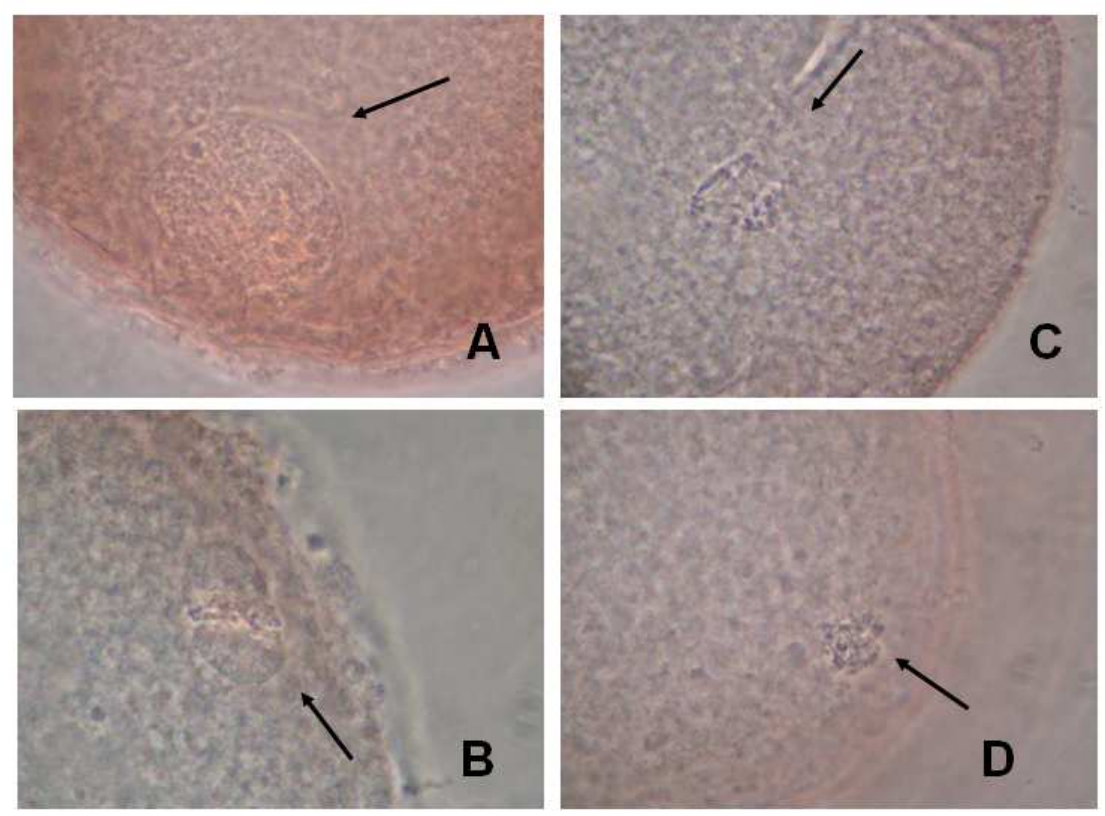

Figura 2.1. Ovócito em VG (A); Ovócito MII (B); Ovócitos com cromatina anormal (C); Ovócitos com cromatina degenerada (D). As setas indicam a cromatina em cada imagem.

\subsection{Avaliação das Taxas de Fecundação}

Para a avaliação das taxas de fecundação $18 \mathrm{~h}$ após i início da FIV, os prováveis zigotos foram fixados em solução (3:1) de álcool etílico e ácido acético, por pelo menos 48 horas.

No dia da avaliação os ovócitos foram colocados sobre lâmina, cobertos com lamínula e corados com lacmóide (solução de $1 \%$ em ácido acético glacial a 45\%). A análise foi realizada em microscopia de contraste de fase (Nikon Eclipse E200, 1.000X). 
As estruturam foram classificadas nas seguintes categorias: a) não fecundados, ovócitos que apresentavam somente a presença da cromatina feminina; b) fecundados aqueles que apresentavam espermatozoide com cabeça integra ou descondensada, pró-núcleos feminino e masculino, polispermia ou clivagem e, c) degenerados, aqueles com cromatina não identificável.

\subsection{Delineamento experimental}

4.7.1. Efeito de diferentes concentrações $\beta M C D$ sobre a maturação in vitro $e$ desenvolvimento de ovócitos de bovinos submetidos ao estresse pelo frio durante 10 minutos.

Neste experimento, um total de 1452 CCOs foram distribuídos em seis tratamentos, como segue: Controle: Os CCOs não tratados; $0 \beta \mathrm{MCD}$ : CCOs foram incubadas durante $1 \mathrm{~h}$ sem $\beta \mathrm{MCD}$ e expostas à $4{ }^{\circ} \mathrm{C}$ durante $10 \mathrm{~min} ; 1 \beta \mathrm{MCD}$ : CCOs foram incubadas durante $1 \mathrm{~h}$ na presença de $1 \mathrm{mg} / \mathrm{mL}$ de $\beta \mathrm{MCD}$ e expostas a $4{ }^{\circ} \mathrm{C}$ durante $10 \mathrm{~min} ; 2 \beta \mathrm{MCD}$ : CCOs foram incubadas durante 1 hora na presença de $2 \mathrm{mg} / \mathrm{mL}$ de $\beta \mathrm{MCD}$ e expostas à $4{ }^{\circ} \mathrm{C}$ durante $10 \mathrm{~min}$; (T5) 3 BMCD: CCOs foram incubadas durante 1 hora na presença de $3 \mathrm{mg} /$ $\mathrm{mL}$ de $\beta \mathrm{MCD}$ e expostas a $4^{\circ} \mathrm{C}$ durante $10 \mathrm{~min}$; controle bancada: CCOs permaneceram à temperatura ambiente durante o mesmo tempo que os grupos tratados. Ao final, ovócitos de todos os tratamentos foram transferidos para meio de maturação.

Após a maturação, os ovócitos foram fixados para avaliação da maturação nuclear ou fecundados e cultivados in vitro até à fase de blastocisto. Para todos os tratamentos embriões foram avaliados em D2, D6, D7 e D8 (pi) para determinar as taxas de clivagem e de blastocistos.

4.7.2. Efeito de BMCD sobre a resposta de ovócitos bovinos imaturos à exposição ao frio por períodos mais longos de tempo

No experimento 1 foi observado que não haviam diferenças entre os grupos tratados com as várias concentrações de $\beta \mathrm{MCD}$. Assim, foi decidido expor os ovócitos a 2 $\mathrm{mg} / \mathrm{mL}$ de $\beta$ MCD. Um total de 966 CCOs foram distribuídos em três tratamentos: Controle: após a seleção, CCOs foram imediatamente lavadas; 0 BMCD: CCOs foram incubadas 
durante $1 \mathrm{~h}$ sem $\beta \mathrm{MCD}$ e expostas a $4{ }^{\circ} \mathrm{C}$ durante $30 \mathrm{~min} ; 2 \beta \mathrm{MCD}$ : CCOs foram incubadas durante 1 hora na presença de $2 \mathrm{mg} / \mathrm{mL}$ de $\beta M C D$ e expostas a $4{ }^{\circ} \mathrm{C}$ durante $30 \mathrm{~min}$. Após todos os tratamentos, os ovócitos foram transferidos para meio de maturação.

Após a maturação, os ovócitos foram fixados para avaliação da maturação nuclear ou fecundados e cultivados in vitro até à fase de blastocisto. Para todos os tratamentos, os embriões foram avaliados no D2, D6, D7 e D8 (pi) para determinar as taxas de clivagem e de blastocistos.

4.7.3. Capacidade de fecundação e de desenvolvimento embrionário de ovócitos bovinos imaturos expostos ao $\beta M C D$ antes da vitrificação e desvitrificação.

Para avaliar o efeito da exposição $\beta \mathrm{MCD}$ antes da vitrificação em ovócitos de bovinos, CCOs foram distribuídos em quatro tratamentos: grupo de controle: após a seleção, CCOs foram imediatamente lavadas; vitrificados expostos a $\beta \mathrm{MCD}$ : CCOs foram incubadas durante 1 hora na presença de $2 \mathrm{mg} / \mathrm{mL}$ de $\beta \mathrm{MCD}$, vitrificados e aquecidos; vitrificados não expostos à $\beta \mathrm{MCD}$ : CCOs foram incubadas durante $1 \mathrm{~h}$ sem $\beta \mathrm{MCD}$, vitrificados e aquecidos; controle bancada: CCOs permaneceram à temperatura ambiente durante o período de incubação dos grupos 1 e 2 . Após, todos os tratamentos, os ovócitos foram transferidos para meio de maturação. Após a maturação, os ovócitos foram fixados para avaliação da maturação nuclear ou fecundados e cultivados in vitro até a fase de blastocisto.

Para todos os tratamentos, os embriões foram avaliados no D2, D6, D7 e D8 (pi) para determinar as taxas de clivagem e de blastocistos. Para avaliar fertilização, um grupo de ovócitos foi removido do meio de cultivo em 18 h (pi), fixados, corados e examinadas em microscopia de contraste de fase (Figura 2.2).

\subsection{Análise Estatística}

Para análise dos dados de taxa de maturação, fecundação e desenvolvimento embrionário foi utilizado o teste do Qui-quadrado $(\mathrm{P}>0,05)$. 

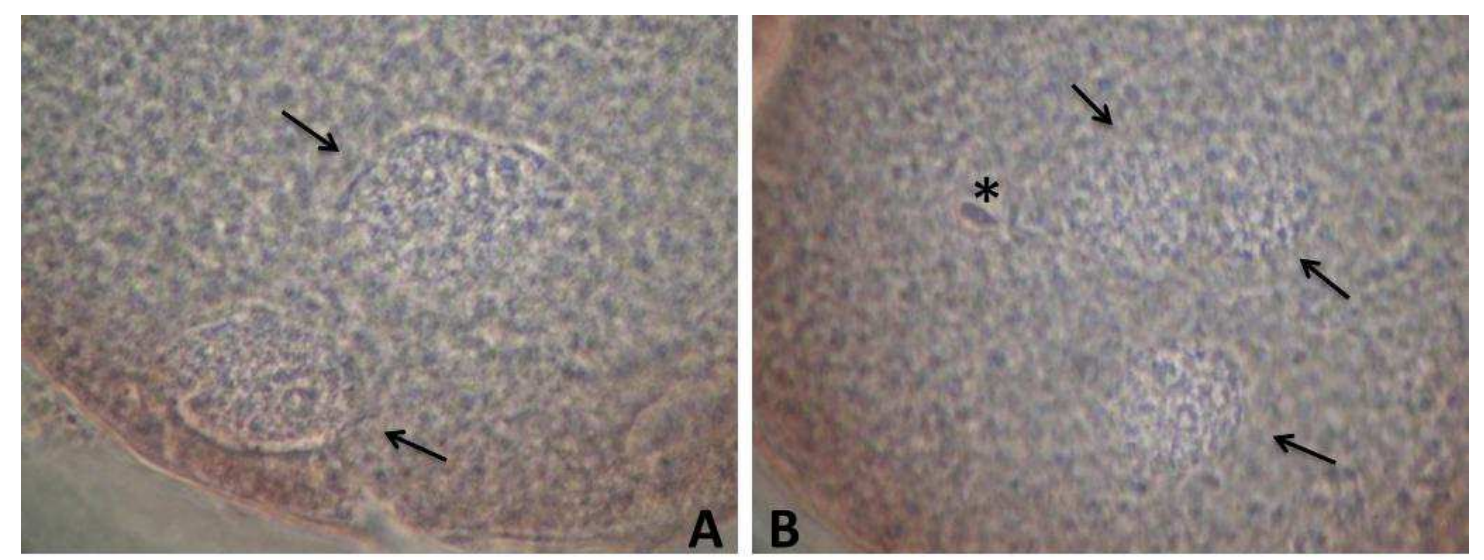

Figura 2.2. Ovócitos fecundados: fecundação normal, presença de dois pró-núcleos (A); fecundação polispérmica, presença de três pró-núcleos e de uma cabeça de espermatozoide solta (B). Setas e asterisco indicam os pró-núcleos e a cabeça do espermatozoide, respectivamente. 


\section{RESULTADOS E DISCUSSÃO}

\subsection{Resultados}

5.1.1 Experimento 1 - Efeito de diferentes concentrações $\beta M C D$ sobre a maturação in vitro e desenvolvimento de ovócitos de bovinos submetidos ao estresse pelo frio durante 10 minutos.

de acordo com a Tabela 2.1, as taxas de maturação nuclear de ovócitos bovinos imaturos expostos a diferentes concentrações de $\beta M C D$ e submetidos ao estresse pelo frio, durante 10 minutos. Um percentual menor $(\mathrm{P}<0,05)$ de ovócitos expostos ao frio atingiu MII após 24 h de maturação, comparada ao grupo controle e controle de bancada. Os ovócitos que permaneceram na bancada, enquanto os outros grupos foram submetidos ao frio mostraram uma taxa de maturação nuclear semelhante $(\mathrm{P}>0,05)$ a do grupo controle. Porém, com porcentagem mais elevada de cromatina anormal $(\mathrm{P}<0,05)$. Embora o estresse ao frio tenha aumentado a porcentagem de ovócitos com cromatina degenerada, a exposição a $\beta \mathrm{MCD}$ protegeu os ovócitos da degeneração ( $\mathrm{P}>0,05)$ (Tabela 2.1).

O desenvolvimento embrionário, em $\mathrm{D} 7$ e $\mathrm{D} 8$, não foi diferente $(\mathrm{P}>0,05)$ entre os ovócitos do grupo controle e controle de bancada (Tabela 2.2). Ambos percentuais foram maiores $(\mathrm{P}<0,05)$ do que os observados para os grupos expostos ao frio e às diferentes concentrações de M $\beta C D$. 
Tabela 2.1. Efeito da exposição à beta-metil-ciclodextrina $(\beta \mathrm{MCD})$, na maturação nuclear de ovócitos bovinos imaturos expostos ao estresse pelo frio (EF) por 10 minutos a $4^{\circ} \mathrm{C}$, antes da maturação in vitro.

\begin{tabular}{lccccc}
\hline \multirow{2}{*}{ Tratamento } & $\mathrm{N}^{\circ}$ & \multicolumn{4}{c}{ Estágio meiótico } \\
\cline { 3 - 6 } & ovócitos & Imaturos & Metáfase II & Anormal & Degenerados \\
& & $(\%)$ & $(\%)$ & $(\%)$ & $(\%)$ \\
\hline Controle & 102 & $12(11,7 \%)^{\mathrm{b}}$ & $78(76,4 \%)^{\mathrm{a}}$ & $5(4,9 \%)^{\mathrm{a}}$ & $7(6,8 \%)^{\mathrm{a}}$ \\
$0 \mathrm{mg} / \mathrm{ml} \mathrm{M} \beta \mathrm{CD}+\mathrm{EF}$ & 114 & $2(1,7 \%)^{\mathrm{a}}$ & $33(28,9 \%)^{\mathrm{b}}$ & $18(15,7 \%)^{\mathrm{b}, \mathrm{c}}$ & $61(53,5 \%)^{\mathrm{c}}$ \\
$1 \mathrm{mg} / \mathrm{ml} \mathrm{M} \beta \mathrm{CD}+\mathrm{EF}$ & 98 & $7(7,1 \%)^{\mathrm{a}, \mathrm{b}}$ & $35(35,7 \%)^{\mathrm{b}}$ & $23(23,4 \%)^{\mathrm{b}, \mathrm{c}, \mathrm{d}}$ & $33(33,6 \%)^{\mathrm{b}}$ \\
$2 \mathrm{mg} / \mathrm{ml} \mathrm{M} \beta \mathrm{CD}+\mathrm{EF}$ & 97 & $5(5,1 \%)^{\mathrm{a}}$ & $37(38,1 \%)^{\mathrm{b}}$ & $25(25,7 \%)^{\mathrm{c}, \mathrm{d}}$ & $30(30,9 \%)^{\mathrm{b}}$ \\
$3 \mathrm{mg} / \mathrm{ml} \mathrm{M} \beta \mathrm{CD}+\mathrm{EF}$ & 92 & $6(6,5 \%)^{\mathrm{a}, \mathrm{b}}$ & $27(29,3 \%)^{\mathrm{b}}$ & $25(27,1 \%)^{\mathrm{d}}$ & $34(36,9 \%)^{\mathrm{b}}$ \\
Controle Bancada & 91 & $7(7,6 \%)^{\mathrm{b}}$ & $58(63,7 \%)^{\mathrm{a}}$ & $13(14,2 \%)^{\mathrm{b}}$ & $13(14,2 \%)^{\mathrm{a}}$ \\
\hline
\end{tabular}

${ }^{a, b, c}$ Valores com letras diferentes nas mesmas colunas indicam resultados diferentes $(\mathrm{P}<0,05)$.

Tabela 2.2. Taxas de clivagem e de desenvolvimento de blastocistos a partir de ovócitos imaturos expostos à diferentes concentrações de beta-metil-ciclodextrina ( $\beta M C D)$ e submetidos ao estresse pelo frio (EF) por 10 minutos a $4^{\circ} \mathrm{C}$, antes da maturação in vitro.

\begin{tabular}{lcccc}
\hline Tratamentos & $\begin{array}{c}\mathrm{N}^{\circ} \\
\text { Ovócitos }\end{array}$ & $\begin{array}{c}\text { Clivagem D2 } \\
\text { N }(\% \pm D . P .)\end{array}$ & $\begin{array}{c}\text { Blastocisto D7 } \\
\text { N }(\% \pm D . P .)\end{array}$ & $\begin{array}{c}\text { Blastocisto D8 } \\
\text { N }(\% \pm D . P .)\end{array}$ \\
\hline Controle & 181 & $142(78,4)^{\mathrm{a}}$ & $63(34,8)^{\mathrm{a}}$ & $70(38,7)^{\mathrm{a}}$ \\
$0 \mathrm{mg} \mathrm{M} \beta C D+\mathrm{EF}$ & 113 & $61(53,9)^{\mathrm{b}}$ & $15(13,3)^{\mathrm{b}}$ & $16(14,2)^{\mathrm{b}}$ \\
$1 \mathrm{mg} \mathrm{M} \beta \mathrm{CD}+\mathrm{EF}$ & 133 & $67(50,4)^{\mathrm{b}}$ & $12(9,0)^{\mathrm{b}}$ & $13(9,8)^{\mathrm{b}, \mathrm{c}}$ \\
$2 \mathrm{mg} \mathrm{M} \beta \mathrm{CD}+\mathrm{EF}$ & 116 & $62(53,4)^{\mathrm{b}}$ & $14(12,1)^{\mathrm{b}}$ & $14(12,1)^{\mathrm{b}, \mathrm{c}}$ \\
$3 \mathrm{mg} \mathrm{M} \beta \mathrm{CD}+\mathrm{EF}$ & 135 & $65(48,1)^{\mathrm{b}}$ & $13(9,6)^{\mathrm{b}}$ & $16(11,9)^{\mathrm{b}, \mathrm{c}}$ \\
Controle Bancada & 126 & $92(73,0)^{\mathrm{a}}$ & $44(34,9)^{\mathrm{a}}$ & $46(36,5)^{\mathrm{a}}$ \\
\hline
\end{tabular}

a, b, c Valores com letras diferentes nas mesmas colunas indicam resultados diferentes $(\mathrm{P}<0,05)$.

5.1.2 Experimento 2 - Efeito de $\beta M C D$ sobre a resposta de ovócitos bovinos imaturos à exposição ao frio por períodos mais longos de tempo.

Para avaliar o efeito protetor da $\beta \mathrm{MCD}$, o tempo da exposição ao frio foi aumentado de 10 para $30 \mathrm{~min}$, após o tratamento com $2 \mathrm{mg} / \mathrm{mL}$ de $\beta$ MCD. Os dados de maturação nuclear e desenvolvimento embrionário são apresentados nas Tabelas 2.3 e 2.4, respectivamente. Não houve diferença $(\mathrm{P}>0,05)$ nas porcentagens de ovócitos imaturos observados entre os grupos. No entanto, uma maior $(\mathrm{P}<0,05)$ porcentagem de ovócitos 
atingiram a MII no grupo controle em relação aos grupos tratados. A exposição de ovócitos à $\beta M C D$ diminuiu a porcentagem de ovócitos que degeneraram devido ao estresse pelo frio. Independentemente disso, os ovócitos expostos à $\mathrm{M} \beta \mathrm{CD}$ e submetidas ao estresse pelo frio durante 30 minutos apresentaram menores $(\mathrm{P}<0,05)$ taxas de clivagem e de blastocistos, comparadas às observadas no grupo controle.

Tabela 2.3. Efeito da beta- metil- ciclodextrina ( $\beta M C D)$ na maturação nuclear de ovócitos bovinos imaturos, expostos ao estresse pelo frio (EF) por 30 minutos a $4^{\circ} \mathrm{C}$, antes da maturação in vitro.

\begin{tabular}{lccccc}
\hline \multirow{2}{*}{ Tratamentos } & $\mathrm{N}^{\circ}$ & \multicolumn{4}{c}{ Estágio da meiose } \\
\cline { 3 - 6 } & ovócitos & Imaturos & Metáfase II & Anormal & Degenerados \\
& & $\mathrm{N}(\%)$ & $\mathrm{N}(\%)$ & $\mathrm{N}(\%)$ & $\mathrm{N}(\%)$ \\
\hline Controle & 108 & $18(16,6 \%)^{\mathrm{a}}$ & $79(73,1 \%)^{\mathrm{a}}$ & $3(2,7 \%)^{\mathrm{a}}$ & $8(7,4 \%)^{\mathrm{a}}$ \\
$0 \mathrm{mg} / \mathrm{ml} \mathrm{M} \beta \mathrm{CD}+\mathrm{EF}$ & 101 & $10(9,9 \%)^{\mathrm{a}}$ & $30(29,7 \%)^{\mathrm{b}}$ & $15(14,8 \%)^{\mathrm{b}}$ & $46(45,5 \%)^{\mathrm{c}}$ \\
$2 \mathrm{mg} / \mathrm{ml} \mathrm{M} \beta \mathrm{CD}+\mathrm{EF}$ & 103 & $14(13,5 \%)^{\mathrm{a}}$ & $40(38,8 \%)^{\mathrm{b}}$ & $21(20,3 \%)^{\mathrm{b}}$ & $28(27,1 \%)^{\mathrm{b}}$ \\
\hline \multicolumn{2}{c}{$\mathrm{a}, \mathrm{b}, \mathrm{c}$ Valores com letras diferentes nas mesmas colunas indicam resultados diferentes $(\mathrm{P}<0,05)}$,
\end{tabular}

Tabela 2.4. Taxas de clivagem e de desenvolvimento de blastocistos de ovócitos imaturos expostos à diferentes concentrações de beta- metil- beta-ciclodextrina ( $\beta M C D)$ e submetidos ao estresse pelo frio (EF) por 30 minutos à $4^{\circ} \mathrm{C}$, antes da maturação in vitro.

\begin{tabular}{lcccc}
\hline Tratamentos & $\mathrm{N}^{\circ}$ & $\mathrm{N}^{\circ}$ clivados & $\mathrm{N}^{\circ}$ Blastocisto & $\mathrm{N}^{\circ}$ Blastocisto \\
& Ovócitos & D2 $(\% \pm$ D.P. $)$ & D7 $(\% \pm D . P)$. & D8 (\% \pm D.P. $)$ \\
\hline Controle & 226 & $190(84,1)^{\mathrm{a}}$ & $84(37,2)^{\mathrm{a}}$ & $97(42,9)^{\mathrm{a}}$ \\
$0 \mathrm{mg} / \mathrm{ml} \mathrm{M} \beta \mathrm{CD}+\mathrm{EF}$ & 205 & $71(34,6)^{\mathrm{b}}$ & $13(6,3)^{\mathrm{b}}$ & $16(7,8)^{\mathrm{b}}$ \\
$2 \mathrm{mg} / \mathrm{ml} \mathrm{M} \beta \mathrm{CD}+\mathrm{EF}$ & 223 & $74(33,2)^{\mathrm{b}}$ & $20(9,0)^{\mathrm{b}}$ & $20(8,9)^{\mathrm{b}}$ \\
\hline
\end{tabular}

$\overline{a, b, c}$ Valores com letras diferentes nas mesmas colunas indicam resultados diferentes $(\mathrm{P}<0,05)$.

5.1.3. Experimento-3 Capacidade de fecundação e de desenvolvimento embrionário de ovócitos bovinos imaturos expostos ao $\beta M C D$ antes da vitrificação e aquecimento.

Ovócitos vitrificados, após a exposição a 2 mg de $\beta \mathrm{MCD}$ apresentaram percentuais mais elevados $(\mathrm{P}<0,05)$ de ovócitos $\mathrm{MII}$ e taxas de degeneração inferiores ( $\mathrm{P}$ $<0,05$ ) aos ovócitos não expostos (Tabela 2.5). O processo de vitrificação também foi prejudicial para a fecundação e para o desenvolvimento in vitro (Tabelas 2.6 e 2.7). Independentemente da concentração $\beta \mathrm{MCD}$, ovócitos vitrificados apresentaram menor (P $<0,05)$ taxa de clivagem e de blastocistos que os controles. Embora, no D8 a taxa de 
blastocisto foi similar para ambos os grupos vitrificados um aumento $(\mathrm{P}<0,05)$ nas taxas de blastocistos em D7 foi observado para ovócitos vitrificados que foram expostos à $\beta \mathrm{MCD}$, antes da vitrificação (Tabela 2.6). Quando a fecundação foi avaliada, observou-se que o grupo vitrificado não exposto ao $\beta \mathrm{MCD}$ mostrou a maior porcentagem $(\mathrm{P}<0,05)$ de ovócitos não fecundados às $18 \mathrm{~h}$ pi. Ambos os grupos vitrificados apresentaram menores taxas de fecundação $(\mathrm{P}<0,05)$ e maiores porcentagens de ovócitos degenerados e com cromatina anormais, comparados aos ovócitos do grupo de controle (Tabela 2.7). Em relação ao controle, observou-se que o grupo que permaneceu na bancada apresentou menores taxas de fecundação $(\mathrm{P}<0,05)$ e porcentagens mais elevadas $(\mathrm{P}<0,05)$ de ovócitos degenerados (Tabela 2.7).

Tabela 2.5. Efeito da $\mathrm{M} \beta \mathrm{CD}$ na maturação nuclear de ovócitos bovinos imaturos expostos a de beta- metil- ciclodextrina ( $\beta M C D)$ e vitrificados (Vit).

\begin{tabular}{lccccc}
\hline \multirow{2}{*}{ Tratamentos } & $\mathrm{N}^{\circ}$ & \multicolumn{4}{c}{ Estágio da meiose } \\
\cline { 3 - 6 } & Ovócitos & Imaturos & Metáfase II & Anormal & Degenerado \\
& & $\mathrm{N}(\%)$ & $\mathrm{N}(\%)$ & $\mathrm{N}(\%)$ & $\mathrm{N}(\%)$ \\
\hline Controle & 92 & $2(2,17 \%)^{\mathrm{a}}$ & $72(78,2 \%)^{\mathrm{a}}$ & $10(10,8 \%)^{\mathrm{a}}$ & $8(8,6 \%)^{\mathrm{a}}$ \\
$0 \mathrm{mg} / \mathrm{ml} \mathrm{M} \beta \mathrm{CD}+\mathrm{Vit}$ & 78 & $4(5,12 \%)^{\mathrm{a}, \mathrm{b}}$ & $23(29,4 \%)^{\mathrm{c}}$ & $13(16,6 \%)^{\mathrm{a}}$ & $38(48,7 \%)^{\mathrm{c}}$ \\
$2 \mathrm{mg} / \mathrm{ml}$ of M $\mathrm{MCD}+\mathrm{Vit}$ & 74 & $2(2,70 \%)^{\mathrm{a}, \mathrm{b}}$ & $34(45,9 \%)^{\mathrm{b}}$ & $14(18,9 \%)^{\mathrm{a}}$ & $24(32,4 \%)^{\mathrm{b}}$ \\
Controle Bancada & 87 & $8(9,19 \%)^{\mathrm{b}}$ & $57(65,5 \%)^{\mathrm{a}}$ & $10(11,4 \%)^{\mathrm{a}}$ & $12(13,7 \%)^{\mathrm{a}}$ \\
\hline
\end{tabular}

${ }^{\mathrm{a}, \mathrm{b}}$ Valores com letras diferentes nas mesmas colunas indicam resultados diferentes $(\mathrm{P}<0,05)$.

Tabela 2.6. Taxas de clivagem e de desenvolvimento embrionário a partir de ovócitos bovinos imaturos expostos a de beta- metil- ciclodextrina ( $\beta M C D)$ e vitrificados (Vit) antes da maturação in vitro.

\begin{tabular}{lcccc}
\hline Tratamentos & $\mathrm{N}^{\circ}$ & Clivagem D2 & Blastocistos D7 & Blastocistos D8 \\
& Ovócitos & N $(\% \pm$ D.P. $)$ & N $(\% \pm$ D.P. $)$ & N $(\% \pm$ D.P. $)$ \\
\hline Controle & 181 & $147(81,2)^{\mathrm{a}}$ & $63(34,8)^{\mathrm{a}}$ & $68(37,5)^{\mathrm{a}}$ \\
$0 \mathrm{mg} / \mathrm{ml} \mathrm{M} \beta \mathrm{CD}+\mathrm{Vit}$ & 121 & $27(22,3)^{\mathrm{b}}$ & $1\left(0,8^{\mathrm{c}}\right.$ & $3(2,4)^{\mathrm{b}}$ \\
$2 \mathrm{mg} / \mathrm{ml} \mathrm{M} \beta \mathrm{CD}+\mathrm{Vit}$ & 131 & $32\left(24,4^{\mathrm{b}}\right.$ & $7(5,3)^{\mathrm{b}}$ & $7(5,3)^{\mathrm{b}}$ \\
Controle Bancada & 183 & $137(74,8)^{\mathrm{a}}$ & $52(28,4)^{\mathrm{a}}$ & $59(32,2)^{\mathrm{a}}$
\end{tabular}

a, b, c Valores com letras diferentes nas mesmas colunas indicam resultados diferentes $(\mathrm{P}<0,05)$. 
Tabela 2.7. Taxas de fecundação de ovócitos bovinos imaturos expostos à beta- metilciclodextrina ( $\beta \mathrm{MCD})$ e vitrificados (Vit), antes da maturação in vitro.

\begin{tabular}{lccccc}
\hline Tratamentos & $\mathrm{N}^{\circ}$ & Não fecundados & Fecundados & Degenerados & Anormal \\
& Zigotos & $\mathrm{N}(\%)$ & $\mathrm{N}(\%)$ & $\mathrm{N}(\%)$ & $\mathrm{N}(\%)$ \\
\hline Controle & 91 & $14(15,3 \%)^{\mathrm{b}}$ & $70(76,9 \%)^{\mathrm{a}}$ & $3(3,2 \%)^{\mathrm{a}}$ & $4(4,3 \%)^{\mathrm{a}}$ \\
$0 \mathrm{mg} / \mathrm{ml} \mathrm{M} \beta \mathrm{CD}+\mathrm{Vit}$ & 88 & $7(7,9 \%)^{\mathrm{b}}$ & $19(21,5 \%)^{\mathrm{c}}$ & $45(51,13 \%)^{\mathrm{c}}$ & $17(19,3 \%)^{\mathrm{b}}$ \\
$2 \mathrm{mg} / \mathrm{ml} \mathrm{M} \beta \mathrm{CD}+\mathrm{Vit}$ & 85 & $1(1,1 \%)^{\mathrm{a}}$ & $28(32,9 \%)^{\mathrm{c}}$ & $44(51,76 \%)^{\mathrm{c}}$ & $12(14,1 \%)^{\mathrm{b}}$ \\
Controle Bancada & 95 & $16(16,8 \%)^{\mathrm{b}}$ & $58(61,0 \%)^{\mathrm{b}}$ & $16(16,84 \%)^{\mathrm{b}}$ & $5(5,2 \%)^{\mathrm{a}}$ \\
\hline
\end{tabular}

${ }^{\mathrm{a}, \mathrm{b}} \mathrm{c}$ Valores com letras diferentes nas mesmas colunas indicam resultados diferentes $(\mathrm{P}<0,05)$.

\subsection{Discussão}

O principal fator limitante para a criopreservação de ovócitos é a sua alta sensibilidade a lesões causadas pelo resfriamento. Entre os componentes celulares, a membrana plasmática é geralmente descrita como uma das estruturas mais afetados durante o processo de criopreservação (Arav et al., 1996; Moore et al., 2005). Esta sensibilidade ao frio é determinado pela composição fosfolipídica da membrana principalmente pela proporção colesterol: fosfolípideo (Arav et al., 1996; Zeron et al., 2001; Zeron et al., 2002; Horvath et al., 2006; Seidel, 2006). Quando o colesterol é adicionado à membrana celular, essa torna-se mais fluída (Arav et al., 1996) e, consequentemente, mais resistente, ao frio. De fato, a manipulação do perfil de lipídios da membrana plasmática de espermatozoides (Zeron et al., 2002; Purdy et al., 2004; Amorim et al., 2009) ovócitos (Horvath et al., 2006; Seidel, 2006) pelo aumento da concentração de colesterol resultou na redução dos danos celulares após criopreservação.

No presente estudo, buscou-se adicionar o colesterol à membrana plasmática do ovócito usando a $\beta \mathrm{MCD}$ como veículo. O objetivo era aumentar a proporção colesterol: fosfolipídio para melhorar os resultados da vitrificação de ovócitos bovinos imaturos. Para isso foi utilizada a $\beta \mathrm{MCD}$ como carreador do colesterol. A hipótese levantada foi que a incubação overnight da $\beta \mathrm{MCD}$ em meio enriquecido com o SFB, seria suficiente para que a $\beta M C D$ ficasse carregada de colesterol, removido a partir do SFB. Portanto, após essa incubação, a $\mathrm{M} \beta \mathrm{CD}$ carregada com colesterol foi adicionada no meio contendo os ovócitos imaturos, que posteriormente, foram expostos ao frio e avaliados quanto a viabilidade citoplasmática e nuclear. 
No primeiro experimento, diferentes concentrações foram testadas, para determinar se a $\beta \mathrm{MCD}$ poderia proteger os ovócitos quando expostos à $4^{\circ} \mathrm{C}$ por $10 \mathrm{~min}$. Os resultados mostram que este tempo de exposição foi suficiente para afetar a viabilidade dos ovócitos e causar uma redução na maturação nuclear e citoplasmática, bem como aumentar a porcentagem de ovócitos com cromatina degenerada. Estes resultados foram semelhantes aos observados por Wu et al. (1999), os quais demonstraram que o armazenamento de ovócitos bovinos imaturos à $4{ }^{\circ} \mathrm{C}$, durante 10 minutos reduziu drasticamente as taxas de maturação e clivagem. Esses resultados também mostraram que mesmo com a exposição prévia à $\beta M C D$, não protegeu efetivamente os ovócitos durante a exposição ao frio porum período curto de tempo (10 min)

As diferentes concentrações de M $\beta C D$ não afetaram a porcentagem de ovócitos que atingiram o estágio de MII no final do período de maturação. No entanto, vale ressaltar que os grupos tratados com $\mathrm{M} \beta \mathrm{CD}$ apresentaram uma redução do número de ovócitos com cromatina degenerada. Estes resultados sugerem que a ciclodextrina pode afetar positivamente os ovócitos. A exposição dos ovócitos à $\mathrm{M} \beta \mathrm{CD}$, também não aumentou a taxa de clivagem ou produção de blastocisto, após maturação, fecundação e cultivo in vitro. Para verificar se o tempo de exposição ao frio, utilizado no primeiro experimento foi ou não suficiente para detectar o efeito benéfico da $\mathrm{M} \beta \mathrm{CD}$, um segundo experimento foi realizado. Neste último, o tempo de exposição ao frio foi aumentado de 10 para 30 min. Como não foi detectada diferença entre as várias concentrações de $\mathrm{M} \beta \mathrm{CD}$, uma concentração intermédia de $2 \mathrm{mg} / \mathrm{ml}$ foi selecionada para ser usada nos demais experimentos. O tempo de exposição dos ovócitos ao frio parece não ser a principal causa dos danos observados, uma vez que o aumento no tempo de exposição não alterou a taxa de ovócitos em MII após a MIV. Independentemente da presença de $\mathrm{M} \beta \mathrm{CD}$, a maturação dos ovócitos foi afetada, quando esses foram expostos a temperatura de $4{ }^{\circ} \mathrm{C}$, mesmo por um curto período de tempo. O tratamento com $\mathrm{M} \beta \mathrm{CD}$ não melhorou as taxas de maturação nuclear e citoplasmática.

Finalmente, testou-se o efeito da M $\beta C D$ em ovócitos antes da vitrificação. Os ovócitos incubados com ou sem $\mathrm{M} \beta \mathrm{CD}$ carregado de colesterol foram vitrificados e, posteriormente, maturados, fecundados e cultivados in vitro. Neste experimento, a M $\beta C D$ reduziu a porcentagem de ovócitos degenerados e aumentou a porcentagem de ovócitos em metáfase MII. Este efeito benéfico da $\mathrm{M} \beta \mathrm{CD}$ não foi observado em nossos experimentos anteriores quando os ovócitos foram expostos à $4{ }^{\circ} \mathrm{C}$, durante 10 ou 30 minutos. É possível que o resfriamento muito rápido, tal como ocorre no método cryotop, minimize o tempo de exposição à temperatura crítica de $15^{\circ} \mathrm{C}$ à $-5^{\circ} \mathrm{C}$ (Arav et al., 1996), diminuindo o efeito 
deletério do estresse ao frio. Assim, o efeito benéfico da $\beta \mathrm{MCD}$ de estabilizar membranas, pode ter protegido outras estruturas do ovócito, permitindo que estes atingissem a metáfase II.

Como esperado (Vieira et al., 2002; Zeron et al., 2002; Vanderzwalmen et al., 2003; Moore et al., 2005; Morato et al., 2008b), a vitrificação afetou negativamente a capacidade de desenvolvimento embrionário, e nenhum efeito benéfico do tratamento com $\beta M C D$ foi observado, nas taxas de clivagem e de blastocistos. Embora Horvarth e Seidel (2006) encontraram diferenças na clivagem e no estágio de oito células após a exposição à $\beta M C D$ e vitrificação, essas diferenças desapareceram gradativamente com o avanço do desenvolvimento embrionário (Horvath et al., 2006).

Enquanto no D8, as taxas de blastocisto foram semelhantes entre os ovócitos vitrificados, taxas mais altas de blastocisto em D7 foram observadas no grupo em que os ovócitos foram expostos à $\beta M C D$. Está bem estabelecido que a velocidade de desenvolvimento está relacionada com a qualidade embrionária. Assim, é possível que a qualidade dos embriões do grupo exposto à $\beta \mathrm{MCD}$ seja melhor do que os do grupo controle. Como não houve diferença na taxa de blastocisto em D8, o atraso no desenvolvimento pode indicar uma viabilidade embrionária inferior (Lechniak et al., 2008). Uma forma de confirmar a diferença na qualidade dos embriões seria realizar outras avaliações, tais como contagem do número de células embrionárias (Horvath et al., 2006), coloração diferencial e quantificação da expressão de genes relacionados à qualidade (Anchamparuthy et al., 2009; Ebrahimi, Valojerdi, Eftekhari-Yazdi, Baharvand, et al., 2010; Siqueira Filho et al., 2011).

A $\beta M C D$ melhorou maturação nuclear de ovócitos vitrificados, mas não afetou a taxa de blastocisto. É difícil avaliar o real impacto desses resultados, já que relatos utilizando a $\beta \mathrm{MCD}$ para esse propósito são muito escassos na literatura. No entanto, algumas hipóteses podem ser abordadas para explicar porque um efeito benéfico não foi observado. Uma possibilidade é que no presente estudo foi utilizada uma outra abordagem para o carregar a $\beta \mathrm{MCD}$ com o colesterol. Esta foi feita pela incubação com o SFB, enquanto que outros grupos, utilizaram uma $\beta \mathrm{MCD}$ que já era previamente carregada com o colesterol (Horvath et al., 2006). Provavelmente, a incubação com o SFB não foi eficaz em carregar a $\beta M C D$ com colesterol. Assim, há possibilidade de o colesterol não ter sido incorporado à membrana. A detecção dos locais de incorporação do colesterol na membrana dos ovócitos, através de técnicas de imunohistoquímica, poderia responder a essas perguntas. Uma outra explicação seria que a $\beta \mathrm{MCD}$ diminuiu os danos na membrana plasmática, o que pode ser confirmado pela menor taxa de degeneração, mas não foi capaz de evitar danos a outras estruturas que são mais importantes para a viabilidade dos ovócitos. 
Durante a maturação do ovócito, organelas citoplasmáticas passam por vários processos de remodelação e de redistribuição (Van Den Hurk et al., 2005; Ferreira et al., 2009), sendo que vitrificação pode afetar alguns desses eventos. Entre as organelas, grânulos corticais são seriamente afetadas (Hyttel et al., 2000; Morato et al., 2008b). Normalmente após a MIV os grânulos corticais exibem uma distribuição periférica, enquanto que os ovócitos que foram submetidos à vitrificação exibem uma distribuição agrupada (Spricigo et al., 2014). Esta alteração poderia prejudicar a fecundação e comprometer o desenvolvimento embrionário. Além disso, estudos mostram que a criopreservação de ovócitos de camundongos pode causar endurecimento da zona pelúcida (Larman et al., 2006), o que também pode afetar a fecundação. Portanto, para garantir que as baixas taxas de clivagem não foram devido a dificuldades de penetração pelo espermatozoide, o processo de fecundação foi também avaliado. Os resultados mostraram que o pré-tratamento com $\beta \mathrm{MCD}$ não beneficiou ovócitos vitrificados, comparados com os ovócitos vitrificados sem a exposição prévia à $\beta \mathrm{MCD}$, pois no momento da fecundação a maioria dos ovócitos já estavam degenerados.

Estes resultados sugerem que, além da membrana plasmática outros sítios de igual importância para a viabilidade dos ovócitos podem ser afetados pela vitrificação. A vitrificação pode causar retenção do corpúsculo polar (Luna et al., 2001), aberrações cromossômicas (Ebrahimi, Valojerdi, Eftekhari-Yazdi e Baharvand, 2010), desorganização do fuso meiótico (Luciano et al., 2009; Asgari et al., 2011), alterações mitocondriais e de grânulos corticais (Spricigo et al., 2014), além da alteração da expressão gênica (Chamayou et al., 2011). 


\section{CONCLUSÕES}

Com base nos resultados aqui apresentados pode-se concluir que a $\beta \mathrm{MCD}$, previamente incubada com SFB, melhora a maturação nuclear de ovócitos submetidos à vitrificação e reduz a degeneração. Entretanto, mais estudos são necessários para esclarecer se a $\beta$ MCD é capaz de modificar a membrana plasmática de ovócitos bovinos e, para determinar a melhor dose e tempo de exposição antes da criopreservação. Estas informações são importantes para otimizar o uso da $\beta \mathrm{MCD}$ em associação a outras substâncias ou a outros procedimentos, que possam melhorar a reposta de ovócitos bovinos a vitrificação. 


\section{REFERÊNCIAS BIBLIOGRÁFICAS}

AMORIM EA ;GRAHAM JK ;SPIZZIRI B ;MEYERS M ;TORRES CA. Effect of cholesterol or cholesteryl conjugates on the cryosurvival of bull sperm. Cryobiology, v. 58,p. 210-214, 2009.

ANCHAMPARUTHY VM ;DHALI A ;LOTT WM ;PEARSON RE ;GWAZDAUSKAS FC. Vitrification of bovine oocytes: implications of follicular size and sire on the rates of embryonic development. Journal of assisted reproduction and genetics, v. 26,p. 613-619, 2009.

ARAV A ;RUBINSKY B ;FletCHER G ;SEREN E. Cryogenic protection of oocytes with antifreeze proteins. Molecular reproduction and development, v. 36,p. 488-493, 1993.

ARAV A ;ZERON Y ;LESLIE SB ;BEHBOOdI E ;ANDERSON GB ;CROWE JH. Phase transition temperature and chilling sensitivity of bovine oocytes. Cryobiology, v. 33,p. 589-599, 1996.

ASGARI V ;HOSSEINI SM ;OSTADHOSSEINI S ;HAJIAN M ;NASR-ESFAHANI MH. Time dependent effect of post warming interval on microtubule organization, meiotic status, and parthenogenetic activation of vitrified in vitro matured sheep oocytes. Theriogenology, $\mathrm{v}$. 75,p. 904-910, 2011.

Chamayou S ;Bonaventura G ;Alecci C ;Tibullo D ;Di Raimondo F ;Guglielmino A ;BARCELLONA ML. Consequences of metaphase II oocyte cryopreservation on mRNA content. Cryobiology, v. 62,p. 130-134, 2011.

DiEZ C ;DUQUe P ;GOMEZ E ;HIDALGO CO ;TAMARGO C ;RODRIGUEZ A ;FERNANDEZ L ;DE LA VARGA $\mathrm{S}$;FERNANDEZ A ;FACAL N ;CARBAJO M. Bovine oocyte vitrification before or after meiotic arrest: effects on ultrastructure and developmental ability. Theriogenology, v. 64,p. 317-333, 2005.

EBRAHIMI B ;VALOJERDI MR ;EFTEKHARI-YAZDI P ;BAHARVAND H. In vitro maturation, apoptotic gene expression and incidence of numerical chromosomal abnormalities following cryotop vitrification of sheep cumulus-oocyte complexes. Journal of assisted reproduction and genetics, v. 27,p. 239-246, 2010.

EBRAHIMI B ;VALOJERDI MR ;EFTEKHARI-YAZDI P ;BAHARVAND H ;FARROKHI A. IVM and gene expression of sheep cumulus-oocyte complexes following different methods of vitrification. Reproductive biomedicine online, v. 20,p. 26-34, 2010. 
FERREIRA EM ;VIREQUE AA ;AdONA PR ;MEIRELlES FV ;FERRIANI RA ;NAVARRO PA. Cytoplasmic maturation of bovine oocytes: structural and biochemical modifications and acquisition of developmental competence. Theriogenology, v. 71,p. 836-848, 2009.

Holm P ;BoOTh PJ ;SCHMIDT MH ;GREVE T ;CALLESEN H. High bovine blastocyst development in a static in vitro production system using SOFaa medium supplemented with sodium citrate and myo-inositol with or without serum-proteins. Theriogenology, v. 52,p. 683-700, 1999.

HORVATH G ;SEIDEL GE, JR. Vitrification of bovine oocytes after treatment with cholesterolloaded methyl-beta-cyclodextrin. Theriogenology, v. 66,p. 1026-1033, 2006.

HytTEL P ; VAJTA G ;CALLESEN H. Vitrification of bovine oocytes with the open pulled straw method: ultrastructural consequences. Molecular reproduction and development, v. 56,p. 80-88, 2000.

KUWAYAMA M ;VAJTA G ;KATO O ;LEIBO SP. Highly efficient vitrification method for cryopreservation of human oocytes. Reproductive biomedicine online, v. 11,p. 300-308, 2005.

LANE M ;SCHOOLCRAFT WB ;GARDNER DK. Vitrification of mouse and human blastocysts using a novel cryoloop container-less technique. Fertility and sterility, v. 72,p. 1073-1078, 1999.

LARMAN MG ;SHEEHAN CB ;GARDNER DK. Calcium-free vitrification reduces cryoprotectantinduced zona pellucida hardening and increases fertilization rates in mouse oocytes.

Reproduction, v. 131,p. 53-61, 2006.

LECHNIAK D ;PERS-KAMCZYC E;PAWLAK P. Timing of the first zygotic cleavage as a marker of developmental potential of mammalian embryos. Reproductive biology, v. 8,p. 23-42, 2008.

LUCIANO AM ;CHIGIONI S ;LODDE V ;FRANCIOSI F ;LUVONI GC ;MODINA SC. Effect of different cryopreservation protocols on cytoskeleton and gap junction mediated communication integrity in feline germinal vesicle stage oocytes. Cryobiology, v. 59,p. 9095, 2009.

LUNA HS ;FERRARI I ;RUMPF R. Influence of stage of maturation of bovine oocytes at time of vitrification on the incidence of diploid metaphase II at completion of maturation. Animal reproduction science, v. 68,p. 23-28, 2001.

MACHADO GM ;CARVALHO JO ;FILHO ES ;CAIXETA ES ;FRANCO MM ;RUMPF R ;DODE MA. Effect of Percoll volume, duration and force of centrifugation, on in vitro production and sex ratio of bovine embryos. Theriogenology, v. 71,p. 1289-1297, 2009.

MOORE AI ;SQUIRES EL ;GRAHAM JK. Effect of seminal plasma on the cryopreservation of equine spermatozoa. Theriogenology, v. 63,p. 2372-2381, 2005. 
MORATO R ;IZQUIERDO D ;PARAMIO MT ;MOGAS T. Cryotops versus open-pulled straws (OPS) as carriers for the cryopreservation of bovine oocytes: effects on spindle and chromosome configuration and embryo development. Cryobiology, v. 57,p. 137-141, 2008a.

MORATO R ;IZQUIERDO D ;PARAMIO MT ;MOgAs T. Embryo development and structural analysis of in vitro matured bovine oocytes vitrified in flexipet denuding pipettes.

Theriogenology, v. 70,p. 1536-1543, 2008b.

NAGAO Y ;OHTA Y ; MURAKAMI H ;KATO Y. The effects of methyl-beta-cyclodextrin on in vitro fertilization and the subsequent development of bovine oocytes. Zygote, v. 18,p. 323$330,2010$.

PURDY PH ;GRAHAM JK. Effect of cholesterol-loaded cyclodextrin on the cryosurvival of bull sperm. Cryobiology, v. 48,p. 36-45, 2004.

QUINN PJ ; WhITE IG ; WIRRICK BR. The effect of dilution on the concentration of sodium, potassium, calcium and magnesium in ram and bull spermatozoa. Journal of reproduction and fertility, v. 12,p. 131-138, 1966.

SARAGUSTY J ;GACITUA H ; ROZENBOIM I ;ARAV A. Do physical forces contribute to cryodamage? Biotechnology and bioengineering, v. 104,p. 719-728, 2009.

SEIDEL GE, JR. Modifying oocytes and embryos to improve their cryopreservation. Theriogenology, v. 65,p. 228-235, 2006.

SiqueIRA FILHO E ;CAIXETA ES ;PrIBENSZKY C ;MOLNAR M ;HORVATH A ;HARNOS A ;FRANCO MM ;RUMPF R. Vitrification of bovine blastocysts pretreated with sublethal hydrostatic pressure stress: evaluation of post-thaw in vitro development and gene expression. Reproduction, fertility, and development, v. 23,p. 585-590, 2011.

SPRICIGO JF ;MORAIS K ;FERREIRA AR ;MACHADO GM ;GOMES AC ;RUMPF R ;FRANCO MM ;DODE MA. Vitrification of bovine oocytes at different meiotic stages using the Cryotop method: assessment of morphological, molecular and functional patterns. Cryobiology, v. 69,p. 256-265, 2014.

THARASANIT T ; COLENBRANDER B ;STOUT TA. Effect of maturation stage at cryopreservation on post-thaw cytoskeleton quality and fertilizability of equine oocytes. Molecular reproduction and development, v. 73,p. 627-637, 2006.

Vajta G ; Holm P ;Kuwayama M ;BoOth PJ ;JaCobSen H ;GreVe T ;CALlesen H. Open Pulled Straw (OPS) vitrification: a new way to reduce cryoinjuries of bovine ova and embryos. Molecular reproduction and development, v. 51,p. 53-58, 1998.

VAN Den HuRK R ;ZHAO J. Formation of mammalian oocytes and their growth, differentiation and maturation within ovarian follicles. Theriogenology, v. 63,p. 1717-1751, 2005.

VANDERZWALMEN P ;BerTin G ;DEBAUCHE C ;STANDAERT V ;BOLlen N ;VAN ROOSENDAAL E;VANDERVORST M ;SCHOYSMAN R ;ZECH N. Vitrification of human blastocysts with the Hemi-Straw carrier: application of assisted hatching after thawing. Human reproduction, v. 18,p. 1504-1511, 2003. 
VIEIRA AD ;MEZZALIRA A ;BARBIERI DP ;LEHMKUHL RC ;RUBIN MI ;VAJTA G. Calves born after open pulled straw vitrification of immature bovine oocytes. Cryobiology, v. 45,p. 91-94, 2002 .

WU B ;TONG J ;LEIBO SP. Effects of cooling germinal vesicle-stage bovine oocytes on meiotic spindle formation following in vitro maturation. Molecular reproduction and development, v. 54,p. 388-395, 1999.

ZERON Y ;OCHERETNY A ;KEDAR O ;BOROCHOV A ;SKLAN D ;ARAV A. Seasonal changes in bovine fertility: relation to developmental competence of oocytes, membrane properties and fatty acid composition of follicles. Reproduction, v. 121,p. 447-454, 2001.

ZERON Y ;SKLAN D ;ARAV A. Effect of polyunsaturated fatty acid supplementation on biophysical parameters and chilling sensitivity of ewe oocytes. Molecular reproduction and development, v. 61,p. 271-278, 2002.

ZHOU XL ;AL NAIB A ;SUN DW ;LONERGAN P. Bovine oocyte vitrification using the Cryotop method: effect of cumulus cells and vitrification protocol on survival and subsequent development. Cryobiology, v. 61,p. 66-72, 2010. 


\section{CAPITULO 3}

\section{EFEITO DA SUPLEMENTAÇÃO COM L-CARNITINA E/OU RESVERATROL DURANTE A MATURAÇÃO IN VITRO NA VITRIFICAÇÃO DE OVÓCITOS BOVINOS}

José Felipe W. Sprícigo ${ }^{1,2}$, Roser Morato $^{2}$, Núria Arcarons ${ }^{1}$, Margot A. N. Dode ${ }^{3}$, Teresa A. Mogas 2.

${ }^{1} 1$ Programa de Pós-Graduação em Ciências Animais, Faculdade de Agronomia e Medicina Veterinária, Universidade de Brasília, UnB, Brasília, DF, Brasil.

${ }^{2}$ Departamento de Medicina e Cirurgia Animal, Universidade Autònoma de Barcelona, UAB, Cerdanyola del Vallès, Espanha.

${ }^{3}$ Embrapa Recursos Genéticos e Biotecnologia, Laboratório de Reprodução Animal, Brasília, DF, Brasil. 


\section{RESUMO}

O objetivo deste estudo foi determinar os efeitos da suplementação do meio de maturação com L-carnitina, um facilitador do metabolismo lipídico e antioxidante, e/ou com Resveratrol, um antioxidante natural, na criotolerância de ovócitos bovinos. Para investigar o efeito dessas substancias a configuração do fusos meióticos, a fragmentação de DNA, a atividade da caspase e o perfil de genes relacionados ao metabolismo de lipídeos e estresse oxidativo foram avaliados, após a maturação in vitro (MIV). Além do desenvolvimento embrionário, após a fecundação in vitro. Ovócitos maturados na ausência (Cont) ou na presença de L-carnitina (LC) e/ou o resveratrol (R) foram submetidos a fecundação e cultivo in vitro após a vitrificação/aquecimento pelo método do Cryotop. Ovócitos não vitrificados de todos os tratamentos apresentaram taxas semelhantes $(\mathrm{P}>0,05)$ de configuração normal de cromossomos, bem como os ovócitos vitrificados após a maturação com LC ou LC + R. Não foram observadas diferenças significativas $(\mathrm{P}>0,05)$ em termos de fragmentação do DNAavaliada pelo TUNEL, quando ovócitos vitrificados foram comparados com os seus homólogos frescos. Porcentagens mais elevadas $(\mathrm{P}<0,05)$ de apoptose precoce, medida pela marcação da caspase ativa, foram detectados no grupo de controle vitrificados, enquanto que não houveram diferenças significativas em comparação com os seus homólogos frescos. Quanto aos níveis de expressão de mRNA, os genes ACACA, PLIN2, SLC2A1, GXP1, HSPA1A e SOD1 foram analisadas por RT-qPCR. A vitrificação alterou significativamente $(\mathrm{P}<0,05)$ na expressão ACAGA, SLC2A1, GPX1 e SOD1, mas não foram encontradas diferenças significativas na $(\mathrm{P}>0,05)$ expressão de PLIN2 e HSP1A. Ovócitos vitrificados mostraram uma taxa de clivagem e blastocisto menor do que os grupos não vitrificados $(\mathrm{P}<0,05)$. Independentemente do tratamento e não houve nenhum efeito significativo de qualquer um dos suplementos durante a maturação foi detectado nos ovócitos frescos ou vitrificados. No entanto, a capacidade de eclosão dos blastocistos no dia 8, foi significativamente maior $(\mathrm{P}<0,05)$ para os ovócitos vitrificados, depois da MIV na presença de 
LC ou LC + R. Em conclusão, L-carnitina resulta em melhorar criotolerância e desenvolvimento de embriões in vitro.

Palavras chaves: antioxidante, lipolítico, apoptose, ultraestrutura. 


\section{ABSTRACT}

The aim of this study was to determine the effects of adding L-carnitine (an enhancer of lipid metabolism and antioxidant) and/or resveratrol (an antioxidant) during IVM on the cryotolerance and developmental competence of bovine oocytes. We investigated spindle and chromosome configuration, DNA fragmentation, caspase activity and gene profile after IVM and subsequent embryonic development after IVF. Oocytes matured in the absence (control) or presence of L-carnitine and/or resveratrol were subjected to IVF and embryo culture after Cryotop vitrification/warming. Oocytes from all non-vitrified treatments presented similar rates $(\mathrm{P}>0.05)$ of normal spindle and chromosome configuration as well as those oocytes vitrified/warmed after maturation with $\mathrm{LC}$ or $\mathrm{LC}+\mathrm{R}$. No significant differences were observed in terms of DNA fragmentation measured by TUNEL when vitrified oocytes were compared to their fresh counterparts. Significantly, higher rates of early apoptosis, measured as active caspase labeling, were detected in the vitrified control group while no significant differences compared to their fresh counterparts were observed for the rest of the vitrified/warmed treatment groups. When the relative mRNA expression levels for ACACA, PLIN2 e SLC2A1, GXP1, HSPA1A and SOD1 gens were analyzed by RT-qPCR, vitrification and warming procedures significantly altered the expression ACACA, SLC2A1, GPX1 and SOD1 but no significant differences were found in the expression of PLIN2 and HSP1A. Vitrified oocytes showed a lower cleavage and blastocyst rate than the non-vitrified groups, regardless of the treatment and there was no significant effect of any of the maturation supplements neither in fresh nor in vitrified oocytes. However, the hatching ability of embryos at day 8 was significantly higher for those oocytes vitrified/warmed after IVM in presence of LC or LC+R. In conclusion, L-carnitine seemed to improve cryotolerance and embryo development of in vitro matured oocytes.

Key words: antioxidant; lipolytic; apoptosis; Ultrastructure. 


\section{INTRODUÇÃO}

O interesse na criopreservação de ovócitos se deve à sua ampla utilização nas técnicas de reprodução assistida tais como na produção in vitro de embriões, transferência nuclear ou para a formação de bancos de germoplasma. Além disso, o armazenamento do gameta feminino permite que o acasalamento genético seja realizado no momento mais oportuno, facilita o intercâmbio internacional de germoplasma, reduz os custos de manutenção de doadoras e possibilita guardar material genético de animais de produção que sofrem algum tipo de enfermidade ou morte súbita e recursos genéticos de raças ameaçadas (Ledda et al., 2001).

Estes benefícios têm contribuído para os esforços realizado nas últimas décadas para melhorar a eficiência da criopreservação de ovócitos. Até o presente, as taxas de sobrevivência de ovócitos criopreservados de pequenos roedores e de seres humanos são elevadas, o que permite a preservação dos gametas destas espécies (Nagy et al., 2009). No entanto, o uso de vitrificação para conservação de ovócitos bovinos ainda é limitado, uma vez que os ovócitos vitrificados apresentam baixo desenvolvimento embrionário (Hwang et al., 2014). Vários fatores parecem estar associados com este sucesso limitado, incluindo grande volume celular (Spricigo et al., 2014), a baixa razão volume/superfície, alto teor de lipídeos e a composição da membrana plasmática do ovócito (Arav et al., 2002; Spricigo et al., 2015). Dentre esses os altos níveis de lipídeos representam um dos principais obstáculos que limitam criopreservação eficiente (Mcevoy et al., 2000).

Os triglicerídeos são armazenados na forma de gotículas lipídicas, e possuem papel importante no metabolismo de energia durante a maturação do ovócito, fecundação e desenvolvimento embrionário inicial. Porém, são também responsáveis pelo aumento da sensibilidade à criopreservação (Morato et al., 2008). Vários estudos têm relatado que a remoção parcial de gotículas lipídicas do citoplasma por manipulação microcirúrgica, agentes 
químicos como citocalasina $\mathrm{B}$ ou $\mathrm{D}$, e métodos físicos como a centrifugação ou aumento da tolerância à pressão, poderia melhorar a resistência dos ovócitos à criopreservação (revisado por Gajda B. (2009).

A L-carnitina (LC; $\beta$-Hidróxi- $\gamma$-trimetilamónio-butírico), uma pequena molécula solúvel em água, é conhecida por desempenhar um papel essencial no metabolismo da gordura. Estudos anteriores relataram que a LC auxilia na $\beta$-oxidação, através do transporte do ácido graxo para dentro da mitocôndria, para a geração de ATP e, consequentemente, influencia os níveis de ATP nas células (Dunning et al., 2012). Além disso, a L-carnitina tem uma atividade antioxidante, reduzindo os níveis de ROS e protegendo as células de danos no DNA (Moawad et al., 2013) e apoptose (Phongnimitr et al., 2013). Os efeitos benéficos da LCarnitina no desenvolvimento embrionário durante o cultivo de embriões foram também relatados em várias espécies de mamíferos como camundongos (Abdelrazik et al., 2009; Mansour et al., 2009; Moawad et al., 2014), bovinos (Phongnimitr et al., 2013) e suínos (Somfai et al., 2011; Wu et al., 2011). Os níveis de ROS intracelulares foram também reduzidos e houve aumento do GSH (Somfai et al., 2011; Wu et al., 2011; You et al., 2012), e um melhor desenvolvimento in vitro de embriões suínos clonados (Wu et al., 2011) ou embriões partenogenéticos, com poucas células apoptóticas (Somfai et al., 2011; Sutton-Mcdowall et al., 2012). Quando adicionada ao meio de MIV de ovócitos bovinos, foi observado um maior desenvolvimento de blastocistos, 8 dias após a vitrificação e fecundação in vitro (Chankitisakul et al., 2013). No entanto, existem relatos de que a suplementação com L-Carnitina não contribuí para melhorar a criotolerância dos ovócitos, em termos de desenvolvimento de blastocisto (Phongnimitr et al., 2013).

Além da L-Carnitina, o Resveratrol (R; 3,4 ', 5-triidroxiestilbeno), uma molécula polifenólica natural, encontrada em várias plantas e alimentos, tem sido descrito como um poderoso agente antioxidante (Baur et al., 2006). Vários estudos têm sido realizados para identificar as funções biológicas e atividades do Resveratrol na reprodução de mamíferos (Kwak et al., 2012; Huang et al., 2013). Suplementação dos meios de MIV com Resveratrol melhorou os resultados de fecundação, além da capacidade de desenvolvimento embrionário em bovinos (Sugiyama et al., 2015) e suínos (Itami et al., 2015), o que foi devido, provavelmente, ao aumento na biossíntese mitocondrial. A suplementação de Resveratrol durante a maturação aumentou os níveis de GSH em suínos (Kwak et al., 2012) e bovinos (Wang et al., 2014), concomitantemente com a diminuição de ROS, sem comprometer o desenvolvimento embrionário (Salzano et al., 2014). Além disso em suínos, quando os meios 
de vitrificação foram suplementados com Resveratrol, os níveis apoptóticos diminuíram (Giaretta et al., 2013).

Apesar da L-Carnitina ser um agente químico já testado durante a maturação in vitro e resultados mostrarem efeito benéficos em ovócitos depois do congelamento (Chankitisakul et al., 2013), não há na literatura estudos avaliando a suplementação dos meios de MIV com Resveratrol, ou mesmo, testando a associação das duas moléculas, L-carnitina e Resveratrol durante a maturação, em ovócitos bovinos, antes da criopreservação. Sendo assim, este experimento teve o objetivo de avaliar a configuração cromossômica, fragmentação de DNA, atividade das caspases e desenvolvimento embrionário. Além de estudar a expressão genica de vias relacionadas com o metabolismo lipídico (ACACA, PLIN2 e SLC2A1), estresse térmico (HSPA1A) e oxidativo (GXP1 e SOD1). 


\section{MATERIAL E MÉTODOS}

Os experimentos foram realizados nos laboratórios de reprodução animal do Departamento de Medicina e Cirurgia Animal da Universidade Autonoma de Barcelona, Cerdanyola del Vallès, Espanha.

Todos os reagente utilizados nos experimentos foram adquiridos junto a Sigma Aldrich (St. Louis, MO, EUA). Os dispositivos de cryotop foram adquiridos junto à DibimedSuprimentos Bioquímicos (S.L Valencia, Espanha).

\subsection{Obtenção dos ovócitos}

Os métodos utilizados para a maturação in vitro dos ovócitos foram descritos previamente (Rizos et al., 2001). Resumidamente, ovários de novilhas holandesas abatidas (1218 meses de idade) foram transportados de um abatedouro local para o laboratório em PBS à 35-37 ${ }^{\circ} \mathrm{C}$. Os CCOs foram obtidos de folículos de 2-8 $\mathrm{mm}$ e apenas CCOs com mais de três camadas de células do cumulus e citoplasma homogêneo foram selecionados. Após a seleção, grupos de 40-50 CCOs foram transferidos para meio de maturação em $500 \mu \mathrm{L}$, em placas de quatro poços e cultivadas durante 24 horas à $38,5{ }^{\circ} \mathrm{C}, 5 \%$ de $\mathrm{CO}_{2} . \mathrm{O}$ meio de maturação era composto de TCM-199 (Gibco BRL, Burlington, ON, Canada) suplementado com 10\% (v/v) de soro fetal bovino (SFB), fator de crescimento epidermal (EGF) $10 \mathrm{ng} / \mathrm{mL}$ e $50 \mathrm{mg} / \mathrm{mL}$ de gentamicina.

\subsection{Vitrificação e aquecimento}


Para a vitrificação foram utilizadas as soluções e o protocolo de acordo com a metodologia descrita por (Kuwayama et al., 2005). A solução de manutenção (SM), composta de TCM-199 Hank's (Gibco BRL, Burlington, ON, Canada) suplementada com 20\% de SFB foi usada para manutenção dos ovócitos durante a vitrificação e desvitrificação. Todas as manipulações foram realizadas sobre placa aquecedora na temperatura de $39^{\circ} \mathrm{C}$, em sala aquecida $\left(25-27^{\circ} \mathrm{C}\right)$. Todos os meios utilizados estavam aquecidos a temperatura ambiente, com exceção da solução de aquecimento 1 (DV1) aquecida a $37^{\circ} \mathrm{C}$. A vitrificação ocorreu em todas as repetições as 22 horas de maturação.

Para vitrificação os CCOs em grupos de 3 a 5 foram submetidos a 3 banhos sequenciais na solução de equilíbrio (SV1), constituída de SM acrescido de 7,5\% etileno glicol e 7,5\% de DMSO, permanecendo em cada gota (banho) por 3 minutos, o tempo total de exposição à SV1 ficou entre 9 e 15 minutos. Após o equilíbrio os ovócitos eram transferidos para a solução de vitrificação (SV2), composta por SM suplementado com 15\% etileno glicol, 15\% DMSO e 0,5 M de sacarose, nesta solução os ovócitos passaram por 4 banhos sequenciais, totalizando 45 - 60 segundos.

Os ovócitos eram então colocados nas hastes de vitrificação com auxilio de micro pipeta de vidro com diâmetro aproximado de $150 \mu \mathrm{m}$, Imediatamente após a deposição dos ovócitos nas hastes o excesso de solução era retirado deixando somente uma fina camada (aproximadamente $0,1 \mu \mathrm{l}$ ) sobre os ovócitos. Então a haste era submergida verticalmente no nitrogênio líquido.

Para o aquecimento, a haste era retirada do $\mathrm{N}_{2} \mathrm{~L}$ com o auxilio de uma pinça e a extremidade contendo os CCOs era mergulhada na solução de aquecimento 1 (DV1), composta por SM mais $1 \mathrm{M}$ de sacarose. Os CCOs permaneciam na DV1 por 1 minuto, e posteriormente eram transferidos para uma solução menos concentrada (DV 2) composta por SM acrescido de 0,5 M de sacarose, durante 3 minutos. Finalmente os CCOs eram submetidos a duas lavagens em gotas de SM, permanecendo 5 minutos em cada gota. Depois, os CCOs voltavam para os meios em que foram maturados, onde permeneciam por mais 2 horas.

\subsection{Maturação in vitro}

Após o aquecimento, os COCs foram lavados e transferidos (grupos de 25-30) para uma gota de $200 \mu 1$ de meio de maturação sob óleo mineral e incubados durante 22 horas 
à $39^{\circ} \mathrm{C}$, em $5 \%$ de $\mathrm{CO}_{2}$ em ar. O meio de maturação foi o TCM-199 suplementado com $10 \%$ FCS (v/v), $10 \mathrm{mg} / \mathrm{mL}$ de EGF e antibióticos (100 IU / $\mathrm{mL}$ de penicilina e $50 \mathrm{mg} / \mathrm{mL}$ de estreptomicina

\subsection{Fecundação e cultivo in vitro}

Em todos os tratamentos a fecundação in vitro foi realizada após as 24 horas de maturação. Resumidamente, os ovócitos foram lavados duas vezes no meio de fecundação, e transferidos em grupos de 20-25, para placas de quatro poços contendo $250 \mathrm{uL}$ de meio de fecundação por poço. $\mathrm{O}$ meio de fecundação era composto por Tyrode suplementado com 25 $\mathrm{mM}$ de bicarbonato, $22 \mathrm{mM}$ de Na-lactato, $1 \mathrm{mM}$ de Na-piruvato, $6 \mathrm{mg} / \mathrm{mL}$ de BSA-FAF (TALP) e $10 \mathrm{ug} / \mathrm{mL}$ de heparina (Calbiochem, Darmstadt, Alemanha). Foi utilizado semen congelado de um touro da raça Holandesa, de fertilidade previamente comprovada no laboratório (ASEAVA, Llanera, Espanha). Para seleção de espermatozoides móveis, a amostra de semen foi centrifugda em um gradiente descontínuo (Bovipure, Nidacon International, Gotemburgo, Suécia) durante 10 minutos a $100 \mathrm{X} g$, à temperatura ambiente. Após a centrifugação o pelete formado foi coletado e lavado (Boviwash, Nidacon Internacional, Gotemburgo, Suécia) por nova centrifugação a $100 \mathrm{X} g$, durante 5 minutos. Os espermatozóides foram diluídos no meio de fecundação para perfazer uma concentração final de $2 \times 10^{6}$ espermatozóides/mL. Uma alíquota de $250 \mu 1$ desta suspensão foi adicionado a cada poço contendo meio de fecundação, para e obter uma concentração final de 1 x $10^{6}$ espermatozóides/ $\mathrm{mL}$.

As placas foram incubadas à $38,5^{\circ} \mathrm{C}, 5 \%$ de $\mathrm{CO}_{2}$, em ar. Cerca de 18 horas pósinseminação (pi), os prováveis zigotos foram completamente desnudados por suaves pipetagens e transferidos para gotas de $25 \mu \mathrm{L}$ de meio de cultivo (SOF) (Holm et al., 1999) (1 embrião/ $\mu \mathrm{L}$ ), suplementado com 5\% de SFB (v/v) e, coberto por óleo mineral. Os embriões foram incubados à $38,5^{\circ} \mathrm{C}, 5 \% \mathrm{CO}_{2}, 5 \% \mathrm{O}_{2}$ e $90 \% \mathrm{~N}_{2}$. As porcentagens de clivagens foram mensuradas 48 horas (pi) e o número de blastocistos foi determinado nos dias 7 (D7) e 8 (D8). Em D7 e D8 foram observadas as taxas de expansão e eclosão, respectivamente.

\subsection{Avaliação dos cromossomos e fusos meióticos}


De acordo com protocolos descritos por (Boiso et al., 2002; Albarracin et al., 2005), após 24 horas de maturação os ovócitos foram completamente desnudados por pipetagem, em PBS. Ovócitos dos grupos fresco (não vitrificados) e grupos vitrificados foram fixados em solução de $4 \%$ (v/v) de formaldeído, durante 30 min à $38,5^{\circ} \mathrm{C}$, permeabilizadas com Triton X-100 [2,5\% (v/v em PBS)] durante 15 min. Para a imunohistoquímica, os ovócitos fixadas foram incubadas com o anticorpo monoclonal anti- $\alpha$ tubulina (Molecular Probes, Paisley, Reino Unido) (1:250) overnight, seguido pela incubação com o anti-mouse anti-Alexa Fluor 488 (Molecular Probes, Paisley, Reino Unido) (1:5000) durante 1 hora. Entre as incubações, os ovócitos foram lavados três vezes em PBS pré-aquecido durante 5 min. Grupos de cinco ovócitos foram montados em lâminas com poli-L-lisina, munidos de um anel de reforço autoadesivo e, em seguida, coradas com 125 ng/mL DAPI (Vysis Inc., Downers Grove, EUA). A preparação foi selada com esmalte de unhas. Um microscópio de epifluorescência (Axioscop 40FL, Carl Zeiss, Alemanha) foi utilizado para examinar a tubulina (Alexa Fluor) e a cromatina (DAPI). Os critérios utilizados para classificar as distribuições de cromossomos e microtúbulos foram descritas previamente (Albarracin et al., 2005). Os ovócitos foram classificados com base na normalidade morfológica do fuso meiótico e da cromatina. O fuso meiótico foi classificado como normal quando carrega a forma de barril simétrica clássica, com cromossomos alinhadas regularmente em um grupo compacto ao longo do plano equatorial. Em contraste, foram considerados fusos anormais, quando esses apresentam-se desorganizados, aglutinados, dispersos, ou pela presença de elementos do fuso não identificáveis e/ou com a aberração da cromatina (Figura 3.1). 

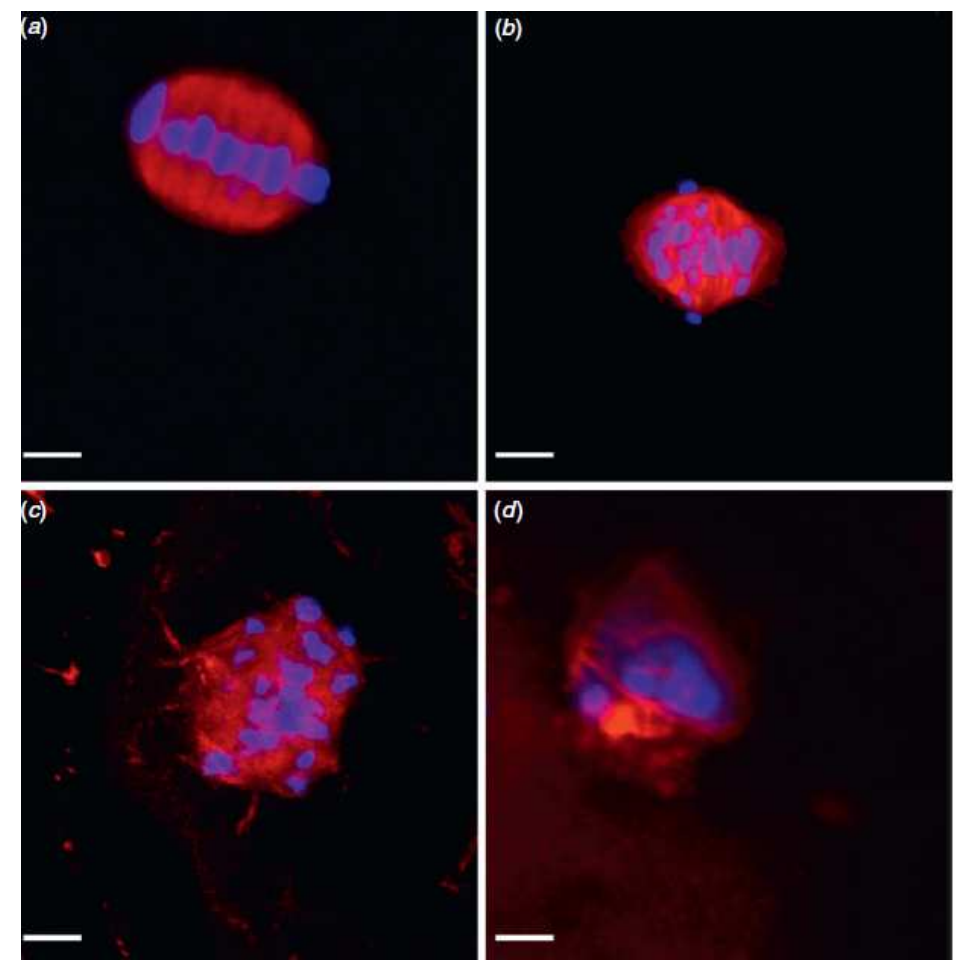

Figura 3.1- Imagem adaptada de Arcarons et al, 2015, exibindo a configurações de microtúbulos e de cromossomos analisados por imunocitoquímica de ovócitos maturados in vitro, frescos ou vitrificados: (A) morfologia dos fusos em MII normal, em forma de barril; (B-D) Ovócitos vitrificados-aquecidos exibindo

estruturas de fuso anormais. (B) Morfologia do fuso anormal mostrando cromossomos, em parte, desorganizados; (C) Microtúbulos e cromossomos desorganizados. Vermelho, indica a tubulina (Alexa Fluor 594); azul, os cromossomos (DAPI).

\subsection{Avaliação da fragmentação de DNA (TUNEL)}

Ovócitos de todos os grupos, frescos e vitrificados foram completamente desnudados das células do cumulus, por pipetagem suave em PBS e a fragmentação do DNA foi avaliada pelo TUNEL, conforme metodologia descrita previamente (Morato et al., 2010). Os ovócitos foram fixadas em 4\% (v/v) de paraformaldeído em PBS, durante 1 hora, à $37^{\circ} \mathrm{C}$. Após a fixação, os ovócitos foram lavados três vezes em PBS, contendo polivinilpirrolidona (0,3\% PVP em PBS; PBS-PVP) e permeabilizadas em 0,5\% de Triton X-100, durante 2 minutos. Os ovócitos foram depois lavados três vezes em PBS-PVP e incubadas no Kit do TUNEL (In-situ celular Death Detection System; Roche Diagnostic, Indianapolis, IN, EUA) à $37{ }^{\circ} \mathrm{C}$, durante 1 hora, em câmara escura. Amostras do controle positivo e negativo foram incluídos em cada ensaio. Os ovócitos expostos a DNAse I durante 15 min à temperatura ambiente [50 RQ1 RNase-free Dnase $(50 \mathrm{U} / \mathrm{mL}$ ] serviram como controles positivos e ovócitos não expostos à enzima TdT serviram como controles negativos. Os ovócitos foram lavados em PBS -PVP e finalmente montadas em lâminas tratadas com poli-lisina e cobertas com uma gota 
de $3 \mu \mathrm{l}$ de Vectashield, contendo $125 \mathrm{ng} / \mathrm{mL}$ de DAPI, para corar todos os núcleos celulares. Em seguida, cobertos com uma lamínula, e para vedação foi usado esmalte de unhas. A avaliação de fluorescência foi realizada num microscópio de epifluorescência (Axioscop 40FL, Carl Zeiss, Alemanha)e, classificados com DNA integro (TUNEL (-); marcados em azul) ou fragmentados (TUNEL $(+)$; marcados em verde).

\subsection{Avaliação da atividade das Caspases}

Para detectar a atividade das Caspases nos ovócitos analisados, foi utilizado o corante FLICA Apoptosis Kit (FAM FLICA Poly Caspase Assay Kit, Immunochemistry Technologies, Bloomington, MN, EUA), de acordo com instruções do fabricante e publicações recentes (Wasielak et al., 2007). Os ovócitos de todos os grupos foram completamente desnudados ao final da maturação por pipetagem suave em PBS. Uma amostra de ovócitos serviu como controle positive para atividade das Caspases. Estes foram tratados com $1 \mu \mathrm{M}$ de staurosporina a $38,5^{\circ} \mathrm{C}$ “overnight”, para induzir a ativação das Caspases. Após banhos em PVP-PBS, os ovócitos eram incubados na solução de FLICA por 1 hora à $38,5^{\circ} \mathrm{C}$, em $5 \% \mathrm{CO}_{2}$. Controles negativos, não expostos ao corante foram incluídos em todas as réplicas. Então, todas as amostras eram lavadas em PVP-PBS e logo coradas com uma mistura de $1 \mu \mathrm{g} / \mathrm{mL}$ de Hoechst 33342 e $1,5 \mu \mathrm{g} / \mathrm{mL}$ de Iodeto de Propídeo (IP), em PBS, por 5 minutos à $37^{\circ} \mathrm{C}$, para a confirmação da presença do núcleo e avaliação da morte celular, respectivamente. Imediatamente antes da avaliação, ovócitos foram montados em lâminas e cobertos com lamínulas. A avaliação foi realizada em um microscópio de epifluorescência (Axioscop 40FL, Carl Zeiss, Alemanha). Os ovócitos foram classificados em: viáveis sem atividade de Caspases (FLICA-/PI-), viáveis com atividade de Caspases (FLICA+/PI-) ou mortos (PI+).

\subsection{Análise da expressão gênica}

O RNA foi extraído a partir de "pools" de 20 ovócitos usando Kit de extração direta de mRNA (Dynal Biotech, Life Technologies, EUA), de acordo com instruções do fabricante e algumas modificações. Os ovócitos dos diferentes tratamentos foram desnudados por pipetagem, lavados três vezes em PBS suplementado com PVA à $38,5^{\circ} \mathrm{C}$ e imediatamente congelados em $\mathrm{N}_{2} \mathrm{~L}$ e armazenados à $-80^{\circ} \mathrm{C}$, até a extração do mRNA. 
Para extração de RNA, cada grupo de ovócitos foi lisado, durante 5 min, em 50 $\mu \mathrm{l}$ de tampão de lise e depois hibridizado com $10 \mu \mathrm{L}$ de "beads" durante 5 minutos, com agitação suave. Após hibridação, complexos de RNA poli (A) ligados aos "beads" foram lavadas duas vezes em um tampão "A" e duas vezes em tampão de lavagem (B). Em seguida, foi realizado a transcição reversa, onde as amostras foram suspensas em $16 \mu \mathrm{L}$ de tampão de diluição e aquecidas à $70^{\circ} \mathrm{C}$ durante 5 minutos. Imediatamente após a extração, $4 \mu \mathrm{L}$ de cDNA (Quanta Biosciences; Gaithersburg, MD, EUA) foi adicionado e deu-se início a reação de transcrição reversa usando primers oligo-dT, primers aleatórios, dNTPs (qScript, Quanta BioSciences, EUA). Depois da reação de transcrição reversa, o cDNA $(25 \mu \mathrm{L})$ foi armazenado à $-20^{\circ} \mathrm{C}$, até seu uso.

Quantificação da abundância relativa de transcritos foi realizada usando o QuantStudio $^{\text {TM }} 7$ Flex Real-Time PCR System (Applied Biosystems, EUA) e SYBR® Select Master Mix (Life Technologies, EUA) para a amplificação dos genes acetyl-CoA carboxylase alpha (ACACA), solute carrier family 2 (facilitated glucose transporter), member 1 (SLC2A1), perilipin 2 (PLIN2), heat shock protein family A member 1A (HSPA1A), glutathione peroxidase 1 (GPX1) e superoxide dismutase 1 (SOD1). Em cada amostra, o cDNA foi analisado em triplicata. Os genes constitutivos, gliceraldeido-3-fosfate deidrogenase (GAPDH) e peptidilprolil isomerase A (PPIA) foram usados para normalização da expressão gênica (Tabela 1). O mix de rt-PCR continha $10 \mu \mathrm{L}$ de Fast SYBR Green Master Mix (Applied Biosystems, EUA), 0,5 $\mu \mathrm{L}$ forward e reverse primers (Life Technologies, Madrid, Espanha), especificos para os genes de interesse e $2 \mu \mathrm{L}$ of cDNA amostral. Água deionizada foi adicionada ao final para completar um volume total de $20 \mu \mathrm{L}$. As amostras foram colocadas em placa de 384 poços sendo a pipetagem realizada por robô. O QuantStudio ${ }^{\mathrm{TM}} 7$ Flex Real-Time PCR System (Applied Biosystems, EUA) foi usado para os RT-qPCR. As reações ocorreram à $95^{\circ} \mathrm{C}$ por 30 segundos, seguidas por 40 ciclos e uma curva padrão de dissociação.

A sequência de cada primer, temperatura de anelamento, concentrações dos primers e referência do GenBank de cada gene, são apresentados na Tabela 3.1. As reações foram realizadas em triplicatas para cada gene. As eficiências dos primers variaram entre 90 e $110 \%$. As expressões dos genes alvos foram normalizadas para a expressão da média aritmética do GAPDH e do PPIA, (valores de Cq). A expressão relativa dos genes foi calculada usando a formula de $\Delta \Delta \mathrm{Ct}$ com correção da eficiência (Pfaffl, 2001). 
Tabela 3.1. Informações sobre os primers e condições utilizados para a amplificação dos fragmentos dos genes de interesse, utilizadas para análises em PCR quantitativo.

\begin{tabular}{|c|c|c|c|c|c|}
\hline Gene & Sequência dos Primers & $\begin{array}{c}\text { Fragmento } \\
\text { Amplificado } \\
\text { (pb) }\end{array}$ & $\begin{array}{c}\text { Temperatura } \\
\text { de anelamento } \\
\left({ }^{\circ} \mathrm{C}\right)\end{array}$ & $\begin{array}{c}\text { Número de } \\
\text { acesso ao Gene } \\
\text { Bank }\end{array}$ & $\begin{array}{l}\text { Referência } \\
\text { Literatura }\end{array}$ \\
\hline ACACA & $\begin{array}{l}\text { F:TGCTTCCCATTTGCCATC } \\
\text { R:CTGCCATCCTCACGACCT }\end{array}$ & 188 & 60 & NM_174224 & $\begin{array}{c}\text { (Brisard et al., } \\
\text { 2014) }\end{array}$ \\
\hline GAPDH & $\begin{array}{l}\text { F:GGCGTGAACCACGAGAAGTATAA } \\
\text { R:CCCTCCACGATGCCAAAGT }\end{array}$ & 119 & 60 & NM_001034034.2 & $\begin{array}{l}\text { (Goovaerts et al., } \\
\text { 2011) }\end{array}$ \\
\hline GPX 1 & $\begin{array}{l}\text { F:GGGACTACACCCAGATGAATGA } \\
\text { R:AGCATAAAGTTGGGCTCGAA }\end{array}$ & 172 & 60 & NM_174076.3 & $\begin{array}{l}\text { (Khalil et al., } \\
\text { 2013) }\end{array}$ \\
\hline HSPA1A & $\begin{array}{l}\text { F:CAAGATCACCATCACCAACG } \\
\text { R:AAATCACCTCCTGGCACTTG }\end{array}$ & 219 & 56 & NM_174550.1 & $\begin{array}{c}\text { (Dhali et al., } \\
\text { 2011) }\end{array}$ \\
\hline PLIN2 & $\begin{array}{l}\text { F:AGTGAACTTGCCAGGAAGAATG } \\
\text { R:TTCATCTGTATCATCGTAGCCG }\end{array}$ & 120 & 60 & NM_173980 & $\begin{array}{l}\text { (Sastre et al., } \\
\text { 2014) }\end{array}$ \\
\hline PPIA & $\begin{array}{l}\text { F:GCCATGGAGCGCTTTGG } \\
\text { R:CCACAGTCAGCAATGGTGATCT }\end{array}$ & 65 & 60 & NM_178320.2 & $\begin{array}{l}\text { (Bessa et al., } \\
\text { 2013) }\end{array}$ \\
\hline SLC2A1 & $\begin{array}{l}\text { F:CAGGAGATGAAGGAGGAGAGC } \\
\text { R:CACAAATAGCGACACGACAGT }\end{array}$ & 258 & 60 & NM_174602 & $\begin{array}{l}\text { (Machado et al., } \\
\text { 2013) }\end{array}$ \\
\hline SOD1 & $\begin{array}{l}\text { F:GTGCAAGGCACCATCCACTTCG } \\
\text { R:CACCATCGTGCGGCCAATGATG }\end{array}$ & 309 & 56 & NM_174615 & $\begin{array}{l}\text { (Valckx et al., } \\
\text { 2014) }\end{array}$ \\
\hline
\end{tabular}

Abreviações: F, forward; R, reverse.

\subsection{Delineamento experimental}

O objetivo dos experimentos foi determinar se a adição de $3,72 \mathrm{mM}(0,6 \mathrm{mg} /$ ml) de L-Carnitina e/ou $1 \mu \mathrm{M}(0,23 \mu \mathrm{g} / \mathrm{m})$ de Resveratrol aos meios de MIV convencionais poderia melhorar a sobrevivência do ovócito bovino após a vitrificação e aquecimento. Para todos os experimentos, os ovócitos foram maturados in vitro em quatro diferentes meios: (1) grupo CRT: ovócitos maturados in vitro em meio MIV convencional; (2) grupo LC: ovócitos foram maturados in vitro em meio MIV convencional suplementado com 3,72 $\mathrm{mM}$ de LCarnitina; (3) Grupo R: Os ovócitos maturados em meio MIV convencional suplementadas com $1 \mu \mathrm{M}$ de $\mathrm{R}$ e (4) grupo LC + R: Os oócitos foram maturados in vitro em meios de MIV convencionais suplementado com 3,72 mM de L-Carnitina e $1 \mu \mathrm{M}$ de Resveratrol. Ás 22 horas após o início de MIV, metade dos ovócitos de cada tratamento vitrificados e aquecidos. Em seguida, os ovócitos foram recolocados em seus respectivos meios de MIV retornaram a estufa por um período adicional de 2 horas, para que pudessem se recuperar antes de realizar as 
diferentes avaliações. Posteriormente, amostras de ovócitos de cada grupo foram coletados para avaliação da configuração cromossômica e dos fusos meiótios (Experimento 1: 5 repetições); fragmentação do DNA pelo TUNEL (Experimento 2: 5 repetições); atividade das Caspases (Experimento 3: 4 repetições) e estudos da expressão gênica (Experimento 4: 4 repetições). Para o experimento 5, ovócitos de cada grupo foram fecundados e cultivados in vitro (7 repetições).

\subsection{Análise estatística}

Todas as análises foram realizadas com o software IBM SPSS 19 para Windows (IBM corp.; EUA). ANOVA foi realizada para as análises de configuração de fusos meióticos e cromossomos; taxas de clivagem e desenvolvimento embrionário, as médias foram comparadas por Tukey's $(\mathrm{P}<0,05)$. Todos os dados foram checados para normalidade usando o teste de Levene e Kolmogorov-Smimov. Para a fragmentação de DNA (TUNEL) e atividade das Caspases foi utilizado o teste de Qui-quadrado $(\mathrm{P}<0,05)$. Para a análise da expressão gênica, todos os dados foram transformados para escala logarítmica $\left[x^{\prime}=\log _{10}(x)\right]$. Depois da transformação, os valores assumiram distribuição normal e uma ANOVA foi utilizada, as médias das expressões relativas de cada gene foram compradas por Tukey's $(\mathrm{P}<0,05)$. para apresentação estão os dados sem transformação. Os resultados foram expressos em médias \pm erro padrão (EP). 


\section{RESULTADOS E DISCUSSÃO}

\subsection{Resultados}

5.1.1 Efeito da suplementação com L-Carnitina, Resveratrol ou L-Carnitina + Resveratrol durante a MIV na configuração dos fusos meióticos de ovócitos bovinos maturos, frescos ou vitrificados.

Nesse experimento, foram avaliados os efeitos da suplementação do meio de MIV com L-Carnitina e / ou Resveratrol antes da vitrificação, sobre a configurações de cromossomos e microtúbulos de ovócitos com o corante de Alexa-Fluor 488 e DAPI. De acordo com os resultados apresentados na Tabela 3.2, a porcentagem de ovócitos em MII após MIV foi maior $(\mathrm{P}<0,05)$ em todos os tratamentos não vitrificados. Ovócitos de todos os tratamentos não vitrificados apresentaram taxas semelhantes $(\mathrm{P}>0,05)$ de configuração normal dos fusos e cromossomos. Ovócitos vitrificados, após a maturação com L-Carnitina ou LC + R apresentaram porcentagens semelhantes $(\mathrm{P}>0,05)$ de configuração normal do fuso quando comparados com ovócitos controle frescos. Entretanto, aqueles vitrificados após a suplementação somente com Resveratrol ou sem suplementação, apresentaram porcentagens mais elevadas $(\mathrm{P}<0,05)$ de fusos anormais e cromossomos descondensados, em comparação com ovócitos não vitrificados. 
Tabela 3.2. Efeito da suplementação com L-Carnitina (LC) e/ou Resveratrol (R) durante a maturação in vitro. Numéro total $(\mathrm{N})$, porcentagem \pm desvio padrão $(\% \pm \mathrm{DP})$ de ovócitos com fusos normais, anormais e cromossomos dispersos ou degenerados, de ovócitos frescos ou vitrificados.

\begin{tabular}{|c|c|c|c|c|c|c|}
\hline \multirow{3}{*}{ Grupo } & \multirow{3}{*}{$\begin{array}{c}\text { Ovócitos } \\
\text { Total } \\
\text { N }\end{array}$} & \multirow{3}{*}{$\begin{array}{c}\text { Ovócitos } \\
\text { MII } \\
\text { N (\% } \pm \text { DP) }\end{array}$} & \multicolumn{2}{|c|}{ Fusos* } & \multicolumn{2}{|c|}{ Cromossomos* } \\
\hline & & & Normal & Anormal & Dispersos** & Descondensados** \\
\hline & & & $\mathbf{N}(\% \pm \mathrm{DP})$ & $\mathbf{N}(\% \pm \mathrm{DP})$ & $\mathbf{N}(\% \pm \mathrm{DP})$ & $\mathrm{N}(\% \pm \mathrm{DP})$ \\
\hline CTR & 91 & $72(79,1 \pm 7,8)^{\mathrm{a}}$ & $57(79,2 \pm 5,6)^{\mathrm{abc}}$ & $15(20,8 \pm 5,6)^{\mathrm{abc}}$ & $13(18,1 \pm 4,6)^{\mathrm{ab}}$ & $2(2,8 \pm 2,9)^{\mathrm{a}}$ \\
\hline $\mathrm{LC}$ & 71 & $54(76,1 \pm 6,9)^{\mathrm{a}}$ & $48(88,9 \pm 6,1)^{\mathrm{a}}$ & $6(11,1 \pm 6,1)^{\mathrm{a}}$ & $5(9,3 \pm 4,1)^{\mathrm{a}}$ & $1(1,9 \pm 3,8)^{\mathrm{a}}$ \\
\hline $\mathrm{R}$ & 60 & $45(75,0 \pm 6,9)^{\mathrm{a}}$ & $39(86,7 \pm 11,3)^{\mathrm{ab}}$ & $6(13,3 \pm 11,3)^{\mathrm{ab}}$ & $4(8,9 \pm 5,4)^{\mathrm{ab}}$ & $2(4,4 \pm 5,8)^{\mathrm{ab}}$ \\
\hline $\mathrm{LC}+\mathrm{R}$ & 80 & $64(80,0 \pm 11,0)^{\mathrm{a}}$ & $53(82,8 \pm 7,2)^{\mathrm{ab}}$ & $11(17,2 \pm 7,2)^{\mathrm{ab}}$ & $9(14,1 \pm 3,0)^{\mathrm{ab}}$ & $2(3,1 \pm 8,3)^{\mathrm{ab}}$ \\
\hline CTR VIT & 101 & $57(56,4 \pm 9,7)^{\mathrm{b}}$ & $25(43,9 \pm 6,1)^{\mathrm{d}}$ & $32(56,1 \pm 6,1)^{\mathrm{d}}$ & $18(31,6 \pm 9,5)^{\mathrm{b}}$ & $15(26,3 \pm 6,2)^{\mathrm{c}}$ \\
\hline LC VIT & 80 & $40(50,0 \pm 6,2)^{\mathrm{b}}$ & $22(55,0 \pm 4,8)^{\mathrm{cd}}$ & $18(45,0 \pm 4,8)^{\mathrm{cd}}$ & $9(22,5 \pm 8,9)^{\mathrm{ab}}$ & $9(22,5 \pm 5,8)^{\mathrm{bc}}$ \\
\hline R VIT & 81 & $46(56,7 \pm 10,5)^{\mathrm{b}}$ & $21(45,7 \pm 10,6)^{\mathrm{d}}$ & $25(54,3 \pm 10,6)^{\mathrm{d}}$ & $12(26,1 \pm 6,3)^{\mathrm{ab}}$ & $10(21,7 \pm 7,7)^{\mathrm{c}}$ \\
\hline LC+R VIT & 78 & $44(56,4 \pm 14,5)^{\mathrm{b}}$ & $27(61,4 \pm 12,7)^{\mathrm{bcd}}$ & $17(38,6 \pm 12,7)^{\mathrm{bcd}}$ & $5(11,4 \pm 10,0)^{\mathrm{ab}}$ & $8(18,2 \pm 3,2)^{b}$ \\
\hline
\end{tabular}

${ }^{\text {abcd }}$ Letras diferentes na mesma coluna indicam diferenças $(\mathrm{P}<0,05)$.

*Porcentagens referentes ao número de ovócitos alcançando MII.

CTR: grupo controle; LC: suplementação com 3.72 mM LC; R: suplementação com $1 \mu \mathrm{M}$ R; LC+R: suplementação com 3.72 mM LC e $1 \mu \mathrm{M}$ R. CTR Vit, LC Vit, R Vit, LC+R Vit: Ovócitos vitrificados e aquecidos, maturados nas mesmas condições de seus respectivos controles.

** Porcentagem referente aos fusos anormais.

5.1.2 Efeito da suplementação com L-Carnitina, Resveratrol ou L-Carnitina + Resveratrol durante a MIV na fragmentação de DNA, em ovócitos bovinos maturados, frescos ou vitrificados.

De acordo com a figura 3.2, a fragmentação do DNA foi detectada em todos os grupos de ovócitos frescos, de todos os tratamentos. Ovócitos do grupo $\mathrm{L}+\mathrm{R}$, apresentaram a menor taxa $(\mathrm{P}<0,05)$ de fragmentação do DNA $(1,6 \%)$. Além desta diferença, não foram encontradas diferenças entre todos os outros grupos, frescos ou vitrificados $(\mathrm{P}>0,05)$. 


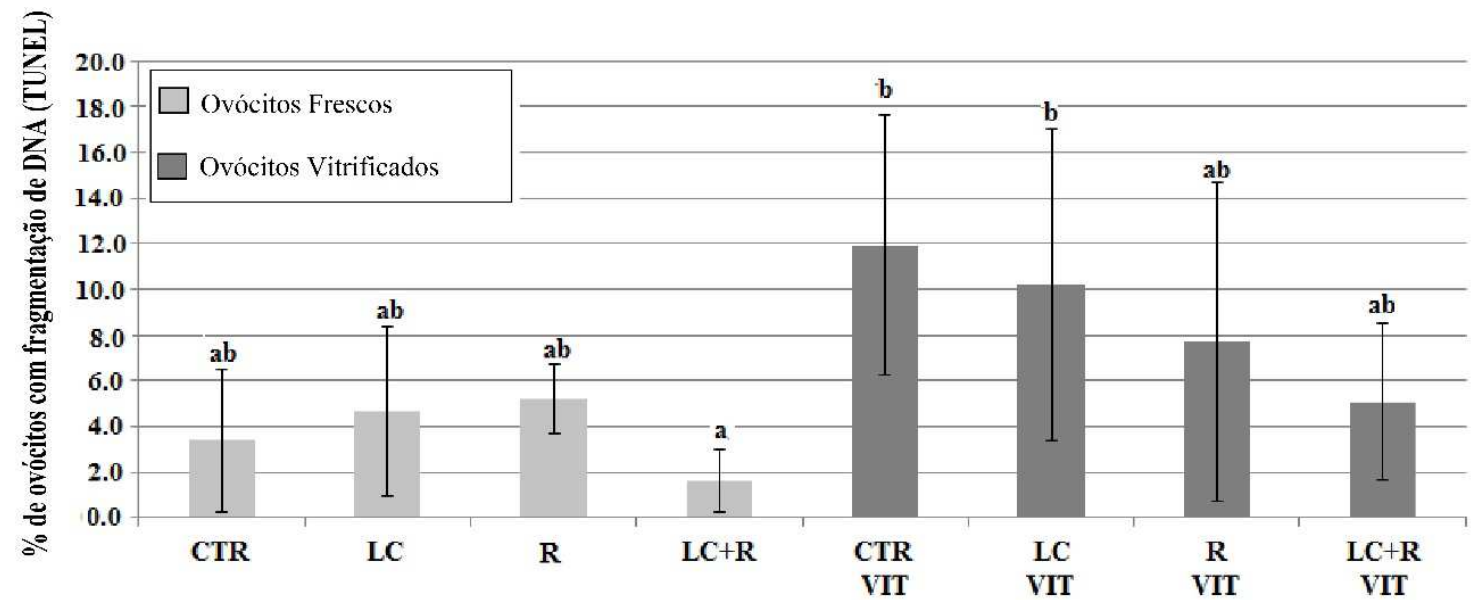

Figura 3.2. Porcentagem de ovócitos com a fragmentação do DNA. Os dados são a porcentagem \pm D.P. ${ }^{a b}$ Letras diferentes indicam diferenças significativas ( $\left.\mathrm{P}<0,05\right)$. CTR: grupo controle $(\mathrm{n}=59)$; LC: MIV suplementação com 3,72 mM de ( $\mathrm{n}=43)$; R: MIV suplementado com $1 \mu \mathrm{M}$ de R ( $=58)$; LC + R: MIV suplementado com 3,72 mM de LC e $1 \mu \mathrm{M}$ de $\mathrm{R}(\mathrm{n}=61)$. CTR Vit $(\mathrm{n}=67)$, LC Vit $(\mathrm{n}=49)$, R Vit $(\mathrm{n}=52)$, LC

$+\mathrm{R}$ Vit $(\mathrm{n}=59)$ : Grupos vitrificados e aquecido, após a maturação in vitro nas mesmas condições de seus respectivos controles.

5.1.3 Efeito da suplementação com L-Carnitina, Resveratrol ou L-Carnitina + Resveratrol durante a MIV na ativação das Caspases, em ovócitos bovinos frescos ou vitrificados.

Como apresentado na Tabela 3.3, a ocorrência da apoptose precoce, medida pela marcação da Caspase ativa, foi detectada entre 1,2-2,6\% nos grupos de ovócitos frescos, sendo semelhante entre os mesmos $(\mathrm{P}>0,05)$. Para ovócitos vitrificados, as taxas mais elevadas $(\mathrm{P}<0,05)$ de apoptose foram detectados no grupo CTR VIT. Enquanto os demais grupos, não apresentaram diferenças entre frescos e vitrificados $(\mathrm{P}>0,05)$. O grupo R-VIT apresentou os menores índices de apoptose $(1,30 \%)$, que não diferem $(\mathrm{P}>0,05)$ do grupo CTR. Quanto à viabilidade dos ovócitos medida pelo Iodeto de Propídeo, foram observadas porcentagens mais elevadas $(\mathrm{P}<0,05)$ de ovócitos mortos para todos os grupos de ovócitos vitrificados quando comparado com os seus homólogos frescos, com taxas que variam de 6,6\% a 9,2\%. 
Tabela 3.3. Efeito da suplementação com L-Carnitina, Resveratrol ou L-Carnitina + Resveratrol durante a MIV. Número total $(\mathrm{N})$, porcentagem \pm desvio padrão $(\% \pm \mathrm{DP})$ de ovócitos normais (FLICA-/PI-), com ativação de Caspases (FLICA+/PI-) ou mortos (PI+), frescos ou vitrificados, após a coloração com FLICCA/Hoechst 33342/PI.

\begin{tabular}{|c|c|c|c|c|}
\hline \multirow{2}{*}{ Grupo } & Total & FLICA-/PI- & FLICA+/PI- & PI+ \\
\hline & $\mathbf{N}$ & $\mathrm{N}(\% \pm \mathrm{DP})$ & $\mathrm{N}(\% \pm \mathrm{DP})$ & $\mathbf{N}(\% \pm \mathrm{DP})$ \\
\hline$\overline{\text { CTR }}$ & 69 & $68(98,6 \pm 2,7)$ & $1(1,4 \pm 2,7)^{\mathrm{a}}$ & $0(0,0 \pm 0,0)^{\mathrm{a}}$ \\
\hline $\mathrm{LC}$ & 79 & $78(98,7 \pm 2,1)$ & $1(1,3 \pm 2,1)^{\mathrm{a}}$ & $0(0,0 \pm 0,0)^{\mathrm{a}}$ \\
\hline $\mathrm{R}$ & 77 & $74(96,1 \pm 2,6)$ & $2(2,6 \pm 3,1)^{\mathrm{ab}}$ & $1(1,3 \pm 2,0)^{\mathrm{ab}}$ \\
\hline $\mathrm{LC}+\mathrm{R}$ & 84 & $82(97,6 \pm 3,9)$ & $1(1,2 \pm 2,0)^{\mathrm{a}}$ & $1(1,2 \pm 2,0)^{\mathrm{ab}}$ \\
\hline CTR VIT & 73 & $61(83,6 \pm 3,8)$ & $6(8,2 \pm 2,5)^{\mathrm{b}}$ & $6(8,2 \pm 2,9)^{\mathrm{c}}$ \\
\hline LC VIT & 74 & $66(89,2 \pm 4,6)$ & $3(4,1 \pm 2,3)^{\mathrm{ab}}$ & $5(6,8 \pm 3,2)^{\mathrm{bc}}$ \\
\hline R VIT & 80 & $73(91,3 \pm 6,3)$ & $1(1,3 \pm 2,5)^{\mathrm{a}}$ & $6(7,5 \pm 4,6)^{\mathrm{c}}$ \\
\hline L+R VIT & 76 & $67(88,2 \pm 6,6)$ & $2(2,6 \pm 3,8)^{\mathrm{ab}}$ & $7(9,2 \pm 7,6)^{\mathrm{c}}$ \\
\hline
\end{tabular}

${ }^{\text {abc }}$ Letras diferentes na mesma coluna indicam diferenças significativas $(\mathrm{P}<0,05)$.

CTR: grupo controle; LC: suplementação com $3.72 \mathrm{mM} \mathrm{LC}$; R: suplementação com $1 \mu \mathrm{M}$ R; LC+R: suplementação com 3.72 mM LC e $1 \mu \mathrm{M}$ R. CTR Vit, LC Vit, R Vit, LC+R Vit: Ovócitos vitrificados e aquecidos, maturados nas mesmas condições de seus respectivos controles.

5.1.4 Efeito da suplementação com L-Carnitina, Resveratrol ou L-Carnitina + Resveratrol durante a MIV na expressão gênica, em ovócitos bovinos frescos ou vitrificados.

Para os ovócitos frescos, nenhuma diferença $(\mathrm{P}>0,05)$ entre os tratamentos foi observada (Figura 3.3) na expressão de todos os genes avaliados (ACACA, SLC2A1, PLIN2, HSP1A, GPX1 e SOD1). Por outro lado, a vitrificação e aquecimento alterou a expressão dos genes ACACA, SLC2A1, GPX1 e SOD1 $(\mathrm{P}<0,05)$. Em contraste, não foram observadas diferenças significativas ( $\mathrm{P}>0,05)$ na expressão de PLIN2 e HSP1A em ovócitos vitrificados, em comparação com os grupos de fresco. A maior expressão de ACACA $(\mathrm{P}<0,05)$ foi observada para os ovócitos maturados com LC + R VIT. A expressão de SOD1 foi superior $(\mathrm{P}<0,05)$ nos grupos CTR VIT e LC + R VIT. Enquanto que não foram observadas diferenças nos níveis de expressão de SOD1 (P>0,05) para os ovócitos dos grupos LC VIT ou R VIT. Em contraste, a expressão do SLC2A1 foi diminuída $(\mathrm{P}<0,05)$ no CTR VIT e LC+R VIT, mas não foram observadas diferenças $(\mathrm{P}<0,05)$ para os tratamentos LC VIT ou R VIR. Com relação ao GPX1, apenas os grupos CTR VIT e R VIT, apresentaram níveis mais baixos $(\mathrm{P}<0,05)$ de expressão. 
5.1.5 Efeito da suplementação com L-Carnitina, Resveratrol ou L-Carnitina + Resveratrol durante a MIV no desenvolvimento embrionário, em ovócitos bovinos frescos ou vitrificados

Independente da suplementação durante a MIV, ovócitos vitrificados apresentaram menores taxas $(\mathrm{P}<0,05)$ de clivagem em $\mathrm{D} 2$ e de desenvolvimento embrionário em D7 e D8 (Tabela 3.4). No entanto, porcentagens de blastocistos eclodidos em D8 foram mais elevadas $(\mathrm{P}<0,05)$ nos grupos LC VIT e LC+R VIT, em comparação aos outros grupos vitrificados. Os grupos de ovócitos frescos, LC e R foram os que entre todos apresentaram as maiores $(\mathrm{P}<0,05)$ taxas de eclosão em D8. 

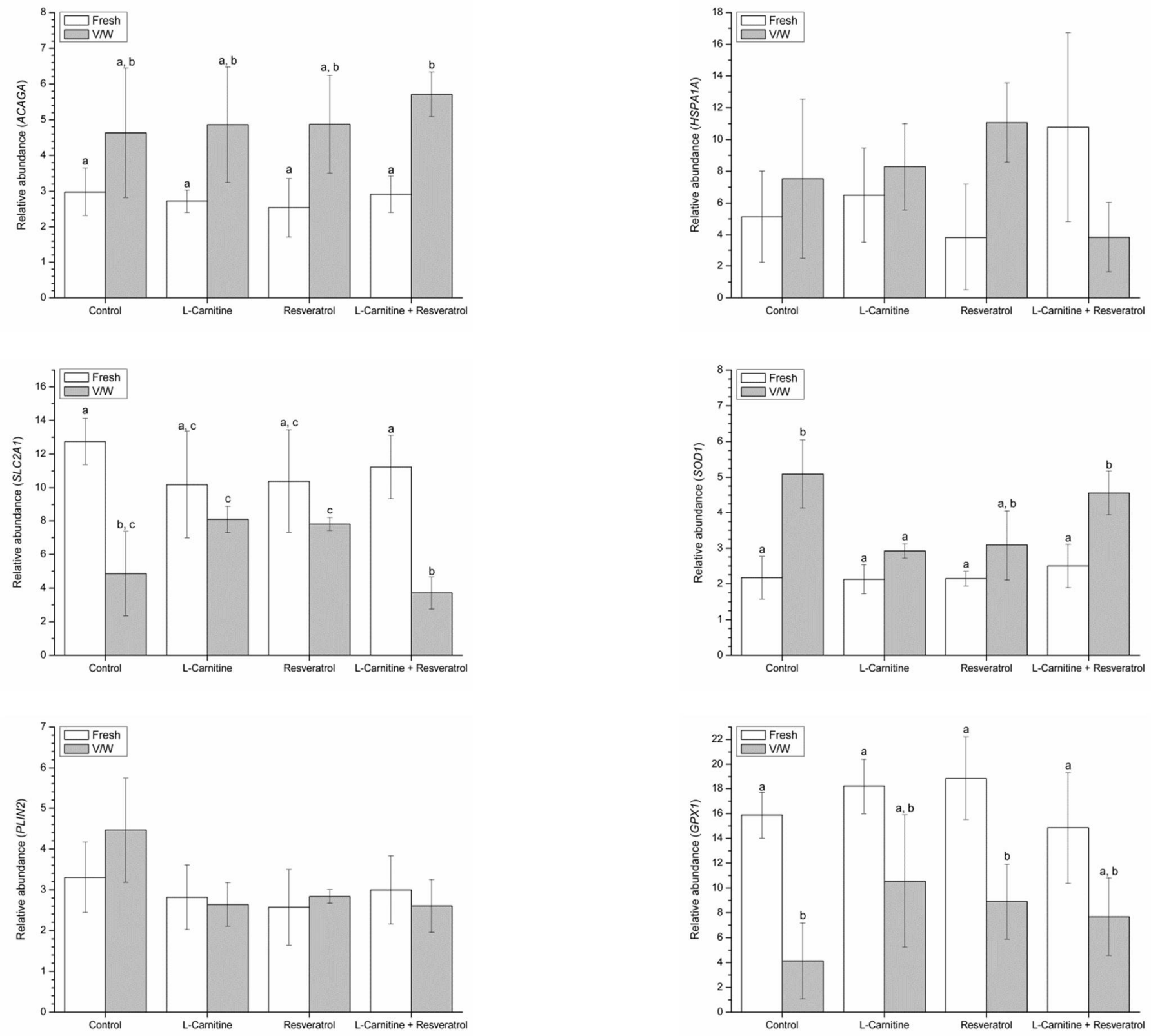

Figura 3.3. A expressão relativa de ACACA, PLIN2, SLC2A, HSPA1A, GXP1 e SOD1, em ovócitos bovinos maturados in vitro na presença de $3,72 \mathrm{mM}$ de $\mathrm{LC}$ e / ou $1 \mu \mathrm{M}$ de R. Em ovócitos frescos ou vitrificados. Os dados são a média relativa \pm E.P. ${ }^{\text {abc }}$ Letras diferentes indicam diferenças significativas $(P<0,05)$ na expressão de um determinado gene. 
Tabela 3.4. Efeito da suplementação com L-Carnitina, Resveratrol ou L-Carnitina + Resveratrol durante a maturação in vitro (MIV). Número total $(\mathrm{N})$, porcentagem \pm desvio padrão (\% $\pm \mathrm{DP})$ de clivagem em D2, no estágio de blastocisto em D7 e D8, para os ovócitos dos grupos frescos ou vitrificados.

\begin{tabular}{|c|c|c|c|c|c|c|}
\hline \multirow{3}{*}{ Grupos } & \multirow{3}{*}{$\begin{array}{c}\text { Ovócitos } \\
\text { N }\end{array}$} & \multirow{3}{*}{$\begin{array}{c}\text { Clivados D2* } \\
\mathbf{N}(\% \pm \mathrm{DP})\end{array}$} & \multicolumn{2}{|c|}{ Blastocistos D7 } & \multicolumn{2}{|c|}{ Blastocistos D8 } \\
\hline & & & Total* & Expandidos ** & Total* & Eclodidos $* * *$ \\
\hline & & & $\mathrm{N}(\% \pm \mathrm{DP})$ & $\mathbf{N}(\% \pm \mathrm{DP})$ & $\mathbf{N}(\% \pm \mathrm{DP})$ & $\mathbf{N}(\% \pm \mathrm{DP})$ \\
\hline CRT & 138 & $110(79,7 \pm 7,1)^{\mathrm{a}}$ & $28(20,3 \pm 2,6)^{\mathrm{a}}$ & $12(42,8 \pm 14,0)^{\mathrm{b}}$ & $28(20,3 \pm 2,6)^{\mathrm{a}}$ & $10(35,7 \pm 14,3)^{\mathrm{b}}$ \\
\hline $\mathrm{LC}$ & 130 & $110(84,6 \pm 4,5)^{\mathrm{a}}$ & $37(28,5 \pm 3,5)^{\mathrm{a}}$ & $22(59,6 \pm 11,8)^{\mathrm{ab}}$ & $37(28,5 \pm 3,5)^{\mathrm{a}}$ & $25(67,6 \pm 7,9)^{\mathrm{a}}$ \\
\hline $\mathrm{R}$ & 149 & $124(83,2 \pm 2,9)^{\mathrm{a}}$ & $36(24,2 \pm 6,4)^{\mathrm{a}}$ & $23(63,81 \pm 13,7)^{\mathrm{a}}$ & $36(24,2 \pm 6,4)^{\mathrm{a}}$ & $19(52,8 \pm 6,0)^{\mathrm{ab}}$ \\
\hline $\mathrm{LC}+\mathrm{R}$ & 128 & $103(80,5 \pm 7,6)^{\mathrm{a}}$ & $31(24,2 \pm 5,5)^{\mathrm{a}}$ & $16(51,6 \pm 13,7)^{\mathrm{ab}}$ & $31(24,2 \pm 5,5)^{\mathrm{a}}$ & $13(41,9 \pm 15,0)^{\mathrm{b}}$ \\
\hline CRT VIT & 123 & $34(27,6 \pm 9,0)^{\mathrm{b}}$ & $3(2,4 \pm 2,6)^{b}$ & 0 & $3(2,4 \pm 2,6)^{b}$ & 0 \\
\hline LC VIT & 112 & $38(33,9 \pm 8,5)^{\mathrm{b}}$ & $5(4,5 \pm 4,0)^{\mathrm{b}}$ & 0 & $5(4,5 \pm 4,0)^{\mathrm{b}}$ & $1(20,0 \pm 24,5)^{\mathrm{c}}$ \\
\hline R VIT & 123 & $45(36,6 \pm 10,9)^{\mathrm{b}}$ & $4(3,3 \pm 2,6)^{b}$ & 0 & $4(3,3 \pm 2,6)^{b}$ & 0 \\
\hline $\mathrm{LC}+\mathrm{R}$ VIT & 115 & $40(34,8 \pm 9,4)^{\mathrm{b}}$ & $3(2,6 \pm 3,5)^{b}$ & 0 & $3(2,6 \pm 3,5)^{b}$ & $1(33,3 \pm 12,2)^{\mathrm{c}}$ \\
\hline
\end{tabular}

${ }^{a b c}$ Letras diferentes na mesma coluna indicam diferenças significativas $(\mathrm{P}<0,05)$.

*Porcentagens de blastocistos em D7 e D8 refere-se ao número total de ovócitos. **Porcentagens de blastocistos expandidos em D7 refere-se ao número total de embriões em D7. *** Porcentagem de blastocistos eclodidos em D8 refere-se ao número total de embriões em D8.

CTR: grupo controle; LC: suplementação com $3.72 \mathrm{mM}$ LC; R: suplementação com $1 \mu \mathrm{M}$ R; LC+R: suplementação com 3.72 mM LC e $1 \mu$ M R. CTR Vit, LC Vit, R Vit, LC+R Vit: Ovócitos vitrificados e aquecidos, maturados nas mesmas condições de seus respectivos controles.

\subsection{Discussão}

Este estudo teve como objetivo avaliar o efeito da adição de L-Carnitina, Resveratrol e a interação dos dois compostos durante a maturação in vitro, visando aumentar a resistência de ovócitos bovinos à criopreservação. Para isto foram avaliadas a estrutura dos fusos meióticos e cromossomos, a apoptose, a expressão gênica e o potencial de desenvolvimento embrionário após os diferentes tratamentos.

Os resultados mostraram que nem a suplementação de L-Carnitina, L-Carnitina +Resveratrol ou Resveratrol foram capazes melhorar a maturação nuclear de ovócitos bovinos. Tampouco tiveram efeito sobre o processo de apoptose. Vários estudos têm relatado efeitos benéficos da suplementação na MIV com L-Carnitina, em suínos (Somfai et al., 2011) e bovinos (Phongnimitr et al., 2013) na taxa de maturação. Em contraste, os nossos resultados são semelhantes aos relatados por outros autores que não observaram melhora na taxa de maturação, após a suplementação da MIV com L-Carnitina (You et al., 2012) ou através da suplementação 
com diversas concentrações de Resveratrol em suínos (Kwak et al., 2012) ou caprinos(Mukherjee et al., 2014).

Diferentes estudos, têm demonstrado que a suplementação do meio de MIV com L-Carnitina ou Resveratrol aumenta o desenvolvimento de blastocistos após a fecundacao in vitro, em bovinos (Phongnimitr et al., 2013; Wang et al., 2014), ou suplementação de LCarnitina em suínos (Wu et al., 2011). Quanto a taxa de clivagem em D2 ou produção embrionária em D7 não foram observadas diferenças entre os grupos. No entanto, no presente estudo foi observado que a capacidade de eclosão dos blastocistos de D8 foi maior para os ovócitos tratados com L-Carnitina. Uma possivel justificativa para a baixa produção embrionária obtida seria que os ovócitos utilizados em nosso estudo foram obtidos de ovários de novilhas. Essa categoria de ovócitos possuem menor capacidade de desenvolvimento embrionário comparado aos de vacas [Revisado por Morato el al. (2010)]. A produção de GSH é um indicador de qualidade pós maturação ovocitária, e tem uma alta correlação com a formação de blastocistos (Abazari-Kia et al., 2014). Esse aumento das taxas de eclosão no grupo de ovócitos frescos e maturados na presença de L-Carnitina, sugerem que a mesma poderia ter auxiliado na melhora do desenvolvimento embrionário talvez pelo aumento de GSH.

Os procedimentos de vitrificação e aquecimento afetaram os ovócitos de todos os tratamentos, diminuindo a porcentagem de ovócitos com morfologia do fuso normal. Esses resultados confirmam o relatado em outros estudos que a vitrificação do ovócito MII afeta o alinhamento dos cromossomos e fusos meióticos (Albarracin et al., 2005; Arcarons et al., 2015). No entanto, a suplementação com L-Carnitina ou ambas as substâncias durante a MIV elevou a proporção de ovócitos com distribuição de microtúbulos e cromossomos normais, à níveis comparáveis aos ovócitos do grupo CTR. É possível que a melhora na morfologia do fuso meiótico e no alinhamento cromossômico causado pela suplementação com L-Carnitina durante a MIV, pode ter contribuído para aumentar a capacidade os embriões de eclodirem em D8. Já que em camundongos (Moawad et al., 2014) a suplementação L-Carnitina durante a MIV, diminui a desorganização dos fusos.

Quando a apoptose foi medida pela fragmentação de DNA, os grupos não diferiram entre si, independente da vitrificação. Porém, quando a atividade da caspase foi avaliada, o tratamento com L-Carnitina e/ou Resveratrol antes da vitrificação não diferiu do controle de ovócitos frescos (CTR), enquanto o controle de ovócitos vitrificados mostraram as maiores porcentagens de ativação caspase. Isto sugere que apesar da técnica de TUNEL ser frequentemente utilizada para embriões (Morato et al., 2010), é menos sensível para detectar apoptose em ovócitos bovinos. O papel da mitocôndria no desencadeamento da apoptose é 
crucial, uma vez que essa organela está envolvida na liberação de fatores pré-apoptóticos dentro do citoplasma, tal como citocromo $\mathrm{C}$, que é diretamente responsável pela ativação da cascata de caspases (Rojewski et al., 2004; Gupta et al., 2015). Embora uma redução significativa da apoptose por meio da via mitocondrial pela suplementação de L-Carnitina na MIV em camundongos (Pillich et al., 2005) e suínos (Wu et al., 2011), nenhum estudo avaliou o efeito da adição de L-Carnitina na apoptose de ovócitos bovinos durante a MIV. Considerando os seus efeitos, era esperado que a L-Carnitina quando associada a suplementação de Resveratrol durante a maturação diminuisse a incidência de apoptose após a vitrificação. Isso porque na literatura o tratamento com resveratrol proporciona diversos benefícios para a saúde. Agindo tanto como agente pró-apoptóticos como anti-apoptóticos (Das, M. et al., 2010; Das, S. K. et al., 2010; Das et al., 2011; Das et al., 2015). Além disso, foi relatado que o resveratrol suplementado aos meios de maturação e de vitrificação na concentração de $2 \mu \mathrm{M}$, foi capaz de diminuir a porcentagem de ovócitos em apotose (Giaretta et al., 2013).

Como descrito recentemente para embriões bovinos (De Oliveira Leme et al., 2015) a criopreservação de ovócitos é capaz de afetar a expressão gênica de diferentes vias com as de estresse oxidativo, apoptóticas e do ciclo celular (Ebrahimi et al., 2010; Dai et al., 2015; Faheem et al., 2015). Estas alterações, aumentando ou diminuindo a expressão, ocorrem possivelmente por duas maneiras, (1) degradação do mRNA presente no momento da vitrificação, ou (2) aumentando ou diminuindo a transcrição gênica em algumas vias (Spricigo et al., 2014). O desenvolvimento do ovócito depende da acumulação de transcritos durante a ovogênese (Barnes et al., 2000). O acúmulo insuficiente ou diminuição do conteúdo de mRNA são considerados os principais responsáveis pelo comprometimento do desenvolvimento embrionário após a FIV (Albuz et al., 2010). Nossa hipótese era que a L-Carnitina pudesse resultar em um aumento de $\beta$ - oxidação e consequentemente de ATP. Além, de atuar na redução do número e tamanho de gotas lipídicas. Da mesma forma, com a suplementação de Resveratrol, esperava-se um aumento de GSH e diminuição de ROS. Em todos os ovócitos dos grupos não vitrificados nenhuma diferença foi observada na expressão dos genes investigados nas vias de: metabolismo de lipídeo (PLIN2, ACACA), metabolismo de glicose (SCL2A1), estresse oxidativo $(G P X-1, S O D-1)$ e estresse térmico (HSP1A1). Entretanto, quando comparados com ovócitos frescos, os ovócitos vitrificados e aquecidos foram afetados negativamente. $\mathrm{O}$ fato é que não foi possível provar os efeitos benéficos dos tratamentos, em preservar os ovócitos dos efeitos sofridos na vitrificação. Além disso, a interação de L-carnitina e Resverartol, durante nossos estudos sempre observamos efeitos antagônicos, sugerindo que quando estas duas moléculas são associadas durante a MIV não há uma proteção contra o EROs 
ou estímulo a oxidação de ácidos graxos de uma maneira eficiente ou de forma apropriada. Apesar uma grande liberação de EROs pode comprometer componentes celulares, uma liberação moderada de EROs pela mitocôndria pode induzir a ativação de vias protetoras de comprometimento celular (Trachootham et al., 2008). Apesar disto, a L-Carnitina de forma isolada modificou a expressão de SODl e GPX1 em ovócitos após a vitrificação, que apresentaram nível de transcritos semelhantes aos de ovócitos frescos, sugerindo uma possível prevenção contra a oxidação. 


\section{CONCLUSÕES}

A vitrificação compromete de forma severa, diversas estruturas de ovócito MII bovino. A suplementação do meio de maturação com L-Carnitina e/ou Resveratrol não foi suficiente para aumentar o desenvolvimento embrionário, a partir de ovócitos vitrificados, após a fecundação e cultivo in vitro. Porém, a L-Carnitina de forma isolada ou em associação com o Resveratrol, foi capaz de modificar a expressão gênica, aumentar a proteção contra a desorganização dos fusos meióticos e aumentar a taxa de eclosão dos blastocistos em D8. 


\section{REFERÊNCIAS BIBLIOGRÁFICAS}

ABAZARI-KIA AH ;MOHAMMADI-SANGCHESHMEH A ;DEHGHANI-MOHAMMADABADI M ;JAMSHIDI-ADEGANI $\mathrm{F}$;VESHKINI A ;ZHANDI M ;CINAR MU ;SALEHI M. Intracellular glutathione content, developmental competence and expression of apoptosis-related genes associated with G6PDH-activity in goat oocyte. Journal of assisted reproduction and genetics, v. 31,p. 313-321, 2014.

ABDELRAZIK H ;SHARMA R ;MAHFOUZ R ;AgARWAL A. L-carnitine decreases DNA damage and improves the in vitro blastocyst development rate in mouse embryos. Fertility and sterility, v. 91,p. 589-596, 2009.

ALBARRACIN JL ;MORATO R ;IZQUIERDO D ;MOGAS T. Vitrification of calf oocytes: effects of maturation stage and prematuration treatment on the nuclear and cytoskeletal components of oocytes and their subsequent development. Molecular reproduction and development, $\mathrm{v}$. 72,p. 239-249, 2005.

AlbuZ FK ;SAsSEVILle M ;LANE M ;ARMSTRONG DT ;THOMPSON JG ;GILCHRIST RB. Simulated physiological oocyte maturation (SPOM): a novel in vitro maturation system that substantially improves embryo yield and pregnancy outcomes. Human reproduction, v. 25,p. 2999-3011, 2010.

AraV A ; YAVIN S ;Zeron Y ;NATAN D ;DeKel I ;GaCitua H. New trends in gamete's cryopreservation. Molecular and cellular endocrinology, v. 187,p. 77-81, 2002.

ARCARONS N ;MORATO R ;SPRICIGO JF ;FERRAZ MA ;MOGAS T. Spindle configuration and developmental competence of in vitro-matured bovine oocytes exposed to $\mathrm{NaCl}$ or sucrose prior to Cryotop vitrification. Reproduction, fertility, and development, 2015.

BARNES FL ;SIRARD MA. Oocyte maturation. Seminars in reproductive medicine, v. 18,p. 123-131, 2000.

BAUR JA ;SINCLAIR DA. Therapeutic potential of resveratrol: the in vivo evidence. Nature reviews. Drug discovery, v. 5,p. 493-506, 2006. 
BESSA IR ;NISHIMURA RC ;FRANCO MM ;DODE MA. Transcription profile of candidate genes for the acquisition of competence during oocyte growth in cattle. Reproduction in domestic animals = Zuchthygiene, v. 48,p. 781-789, 2013.

BOISO I ;MARTÍ M ;SANTALÓ J ;PONSÁ M ;BARRI PN ;VEIGA A. A confocal microscopy analysis of the spindle and chromosome configurations of human oocytes cryopreserved at the germinal vesicle and metaphase II stage. Hum Reprod, v. 17,p. 1885-1891, 2002.

BRISARD D ;CHESNEL F ;ElIS S ;DESMARCHAIS A ;SANCHEZ-LAZO L ;CHASLES M ;MAILlARD $\mathrm{V} ;$ UzBEKOVA $\mathrm{S}$. Tribbles expression in cumulus cells is related to oocyte maturation and fatty acid metabolism. Journal of ovarian research, v. 7,p. 44, 2014.

Chankitisakul V ;SOMfai T ;INABA Y ;TEChaKumPhu M ;NAGAi T. Supplementation of maturation medium with L-carnitine improves cryo-tolerance of bovine in vitro matured oocytes. Theriogenology, v. 79,p. 590-598, 2013.

DAI J ;WU C ;MUNERI CW ;NIU Y ;ZHANG S ;RUI R ;ZHANG D. Changes in mitochondrial function in porcine vitrified MII-stage oocytes and their impacts on apoptosis and developmental ability. Cryobiology, v. 71,p. 291-298, 2015.

DAS DK ;MUKHERJEE S ;RAY D. Erratum to: resveratrol and red wine, healthy heart and longevity. Heart failure reviews, v. 16,p. 425-435, 2011.

DAS M ;DAS DK. Resveratrol and cardiovascular health. Molecular aspects of medicine, $v$. 31,p. 503-512, 2010.

DAS SK ;DESAULNIERS J ;DYCK JR ;KASSIRI Z ;OUDIT GY. Resveratrol mediates therapeutic hepatic effects in acquired and genetic murine models of iron-overload. Liver international : official journal of the International Association for the Study of the Liver, 2015.

DAS SK ;MUKhERJEe S ;GuPTA G ;RAO DN ;VASUdEVAn DM. Protective effect of resveratrol and vitamin $\mathrm{E}$ against ethanol-induced oxidative damage in mice: biochemical and immunological basis. Indian journal of biochemistry \& biophysics, v. 47,p. 32-37, 2010.

De OliveIRA LEME L ;DUfORT I ;SPRICIGO JF ;BRAGA TF ;SirARD MA ;FrANCO MM ;DODE MA. Effect of vitrification using the Cryotop method on the gene expression profile of in vitroproduced bovine embryos. Theriogenology, 2015.

DHALI A ;ANCHAMPARUTHY VM ;BUTLER SP ;MULLARKY IK ;PEARSON RE ;GWAZDAUSKAS FC. Development and quality of bovine embryos produced in vitro using growth factor supplemented serum-free system. Open Journal of Animal Sciences, v. 01,p. 97-105, 2011.

DUNNING KR ;ROBKER RL. Promoting lipid utilization with 1-carnitine to improve oocyte quality. Animal reproduction science, v. 134,p. 69-75, 2012.

EBRAHIMI B ;VALOJERDI MR ;EFTEKHARI-YAZDI P ;BAHARVAND H. In vitro maturation, apoptotic gene expression and incidence of numerical chromosomal abnormalities following cryotop vitrification of sheep cumulus-oocyte complexes. Journal of assisted reproduction and genetics, v. 27,p. 239-246, 2010. 
FAHEEM MS ;BARON E ;CARVALHAIS I ;CHAVEIRO A ;PAVANI K ;DA SiLVA FM. The effect of vitrification of immature bovine oocytes to the subsequent in vitro development and gene expression. Zygote, v. 23,p. 933-942, 2015.

GAJDA B. Factors and methods of pig oocyte and embryo quality improvement and their application in reproductive biotechnology. Reproductive biology, v. 9,p. 97-112, 2009.

GIARETTA E ;SPINACI M ;BUCCI D ;TAMANINI C ;GALEATI G. Effects of resveratrol on vitrified porcine oocytes. Oxidative medicine and cellular longevity, v. 2013,p. 920257, 2013.

GOOVAERTS IG ;LEROY JL ;RIZOS D ;BERMEJO-ALVAREZ P ;GUTIERREZ-ADAN A ;JORSSEN EP ;BOLS PE. Single in vitro bovine embryo production: coculture with autologous cumulus cells, developmental competence, embryo quality and gene expression profiles. Theriogenology, v. 76,p. 1293-1303, 2011.

GUPTA SK ;SAHOO AP ;ROSH N ;GANDHAM RK ;SAXENA L ;SINGH AK ;HARISH DR ;TIWARI AK. Canine parvovirus NS1 induced apoptosis involves mitochondria, accumulation of reactive oxygen species and activation of caspases. Virus research, v. 213,p. 46-61, 2015.

Holm P ;BoOTh PJ ;SCHMIDT MH ;GREVE T ;CALLESEN H. High bovine blastocyst development in a static in vitro production system using SOFaa medium supplemented with sodium citrate and myo-inositol with or without serum-proteins. Theriogenology, v. 52,p. 683-700, 1999.

Huang W ;Li G ; QIU J ;GonZalez P ;Challa P. Protective effects of resveratrol in experimental retinal detachment. PloS one, v. 8,p. e75735, 2013.

HWANG IS ; HOCHI S. Recent progress in cryopreservation of bovine oocytes. BioMed research international, v. 2014,p. 570647, 2014.

ITAMI N ;SHIRASUNA K ;KUWAYAMA T ;IWATA H. Resveratrol improves the quality of pig oocytes derived from early antral follicles through sirtuin 1 activation. Theriogenology, v. 83,p. 1360-1367, 2015.

KHALIL WA ;MAREI WF ; KHALID M. Protective effects of antioxidants on linoleic acid-treated bovine oocytes during maturation and subsequent embryo development. Theriogenology, v. 80,p. 161-168, 2013.

KuWAYAMA M ;VAJTA G ;KATO O ;LEIBO SP. Highly efficient vitrification method for cryopreservation of human oocytes. Reproductive biomedicine online, v. 11,p. 300-308, 2005.

KWAK SS ;CHEONG SA ;JEON Y ;LEE E ;CHOI KC ;JEUNG EB ;HyUn SH. The effects of resveratrol on porcine oocyte in vitro maturation and subsequent embryonic development after parthenogenetic activation and in vitro fertilization. Theriogenology, v. 78,p. 86-101, 2012.

LEDDA $\mathrm{S}$;LEONI G ;BOGLIOLO L ;NAITANA S. Oocyte cryopreservation and ovarian tissue banking. Theriogenology, v. 55,p. 1359-1371, 2001.

MACHADO GM ;FERREIRA AR ;PIVATO I ;FIDELIS A ;SPRICIGO JF ;PAULINI F ;LUCCI CM ;FRANCO MM ;DODE MA. Post-hatching development of in vitro bovine embryos from day 7 
to 14 in vivo versus in vitro. Molecular reproduction and development, v. 80,p. 936-947, 2013.

MANSOUR G ;ABDELRAZIK H ;SHARMA RK ;RADWAN E ;FALCONE T ;AGARWAL A. L-carnitine supplementation reduces oocyte cytoskeleton damage and embryo apoptosis induced by incubation in peritoneal fluid from patients with endometriosis. Fertility and sterility, v. 91,p. 2079-2086, 2009.

MCEVOY TG ;COULl GD ;BROADBENT PJ ;HUTCHINSON JS ;SPEAKE BK. Fatty acid composition of lipids in immature cattle, pig and sheep oocytes with intact zona pellucida. Journal of reproduction and fertility, v. 118,p. 163-170, 2000.

MOAWAD AR ;TAN SL ;XU B ;CHEN HY ;TAKETO T. L-carnitine supplementation during vitrification of mouse oocytes at the germinal vesicle stage improves preimplantation development following maturation and fertilization in vitro. Biology of reproduction, v. 88,p. 104, 2013.

MOAWAD AR ;XU B ;TAN SL ;TAKETO T. 1-carnitine supplementation during vitrification of mouse germinal vesicle stage-oocytes and their subsequent in vitro maturation improves meiotic spindle configuration and mitochondrial distribution in metaphase II oocytes. Human reproduction, v. 29,p. 2256-2268, 2014.

MORATO R ;IZQUIERDO D ;PARAMIO MT ;MOGAS T. Cryotops versus open-pulled straws (OPS) as carriers for the cryopreservation of bovine oocytes: effects on spindle and chromosome configuration and embryo development. Cryobiology, v. 57,p. 137-141, 2008.

Morato R ;IZQuiERdo D ;PARAMIO MT ;Mogas T. Survival and apoptosis rates after vitrification in cryotop devices of in vitro-produced calf and cow blastocysts at different developmental stages. Reproduction, fertility, and development, v. 22,p. 1141-1147, 2010.

MuKHERJEE A ;MALIK H ;SAHA AP ;DUBEY A ;SINGHAL DK ;BOATENG S ;SAUGANDHIKA S ;KUMAR S ;DE S ;GUHA SK ;MALAKAR D. Resveratrol treatment during goat oocytes maturation enhances developmental competence of parthenogenetic and hand-made cloned blastocysts by modulating intracellular glutathione level and embryonic gene expression. Journal of assisted reproduction and genetics, v. 31,p. 229-239, 2014.

NAGY ZP ;CHANG CC ;SHAPIRO DB ;BERnAL DP ;KORT HI ;VAJTA G. The efficacy and safety of human oocyte vitrification. Seminars in reproductive medicine, v. 27,p. 450-455, 2009.

PFAFFL MW. A new mathematical model for relative quantification in real-time RT-PCR. Nucleic acids research, v. 29,p. e45, 2001.

PhONGNIMITR T ;LIANG Y ;SRIRATTANA K ;PANYAWAi K ;SRIPUNYA N ;TREETAMPINICH C ;PARNPAI R. Effect of L-carnitine on maturation, cryo-tolerance and embryo developmental competence of bovine oocytes. Animal science journal = Nihon chikusan Gakkaiho, v. 84,p. 719-725, 2013.

PILLICH RT ;SCARSELla G ;RISULEO G. Reduction of apoptosis through the mitochondrial pathway by the administration of acetyl-L-carnitine to mouse fibroblasts in culture. Experimental cell research, v. 306,p. 1-8, 2005. 
RIZOS D ;WARD F ;BOLAND MP ;LONERGAN P. Effect of culture system on the yield and quality of bovine blastocysts as assessed by survival after vitrification. Theriogenology, v. 56,p. 1-16, 2001.

ROJEWSKI MT ;KORPER S ;THIEL E ;SCHREZENMEIER H. Depolarization of mitochondria and activation of caspases are common features of arsenic(III)-induced apoptosis in myelogenic and lymphatic cell lines. Chemical research in toxicology, v. 17,p. 119-128, 2004.

SAlZANO A ;Albero G ;Zullo G ;NEGlia G ;AbDEl-WAHAB A ;BIFUlCo G ;ZicARElli L ;GASPARRINI B. Effect of resveratrol supplementation during culture on the quality and cryotolerance of bovine in vitro produced embryos. Animal reproduction science, v. 151,p. 91-96, 2014.

SASTRE D ;DA COSTA NN ;DE SA AL ;CONCEICAO SD ;CHIARATTI MR ;AdONA PR ;GUEMRA S ;MEIRELles FV ;SANTOS Sdo S ;SEna L ;OHashi OM ;Dos SANTOS EJ ;MIRANDA Mdos S. Expression of PLIN2 and PLIN3 during oocyte maturation and early embryo development in cattle. Theriogenology, v. 81,p. 326-331, 2014.

SOMFAI T ;KANEDA M ;AKAGI $\mathrm{S}$;WATANABE $\mathrm{S}$;HARAGUCHI $\mathrm{S}$;MIZUTANI E ;DANG-NGUYeN TQ ;GESHI M ;KIKUCHI K ;NAGAI T. Enhancement of lipid metabolism with L-carnitine during in vitro maturation improves nuclear maturation and cleavage ability of follicular porcine oocytes. Reproduction, fertility, and development, v. 23,p. 912-920, 2011.

SPRICIGO JF ;DiOGENES MN ;LEME LO ;GUIMARAES AL ;MUTERLlE CV ;SILVA BD ;SOLAORIOL D ;PIVATO I ;SILVA LP ;DODE MA. Effects of Different Maturation Systems on Bovine Oocyte Quality, Plasma Membrane Phospholipid Composition and Resistance to Vitrification and Warming. PloS one, v. 10,p. e0130164, 2015.

SPRICIGO JF ;MORAIS K ;FERREIRA AR ;MACHADO GM ;GOMES AC ;RUMPF R ;FRANCO MM ;DODE MA. Vitrification of bovine oocytes at different meiotic stages using the Cryotop method: assessment of morphological, molecular and functional patterns. Cryobiology, v. 69,p. 256-265, 2014.

SUGIYAMA M ;KAWAHARA-MiKI R ;KAWANA H ;SHIRASUNA K ;KUWAYAMA T ;IWATA H. Resveratrol-induced mitochondrial synthesis and autophagy in oocytes derived from early antral follicles of aged cows. The Journal of reproduction and development, v. 61,p. 251$259,2015$.

SUTTON-MCDOWALL ML ;FEIL D ;ROBKER RL ;THOMPSON JG ;DUNNING KR. Utilization of endogenous fatty acid stores for energy production in bovine preimplantation embryos. Theriogenology, v. 77,p. 1632-1641, 2012.

TRACHOOTHAM D ;LU W ;OGASAWARA MA ;NILSA RD ;HUANG P. Redox regulation of cell survival. Antioxidants \& redox signaling, v. 10,p. 1343-1374, 2008.

VALCKX SD ;VAN HOECK V ;ARIAS-ALVAREZ M ;MAILlO V ;LOPEZ-CARDONA AP ;GUTIERREZ-ADAN A ;BERTH M ;CORTVRINDT R ;BOLS PE ;LEROY JL. Elevated non-esterified fatty acid concentrations during in vitro murine follicle growth alter follicular physiology and reduce oocyte developmental competence. Fertility and sterility, 2014. 
WANG F ;TIAN X ;ZHANG L ;HE C ;JI P ;LI Y ;TAN D ;LIU G. Beneficial effect of resveratrol on bovine oocyte maturation and subsequent embryonic development after in vitro fertilization. Fertility and sterility, v. 101,p. 577-586, 2014.

WASIELAK M ;BOGACKI M. Apoptosis inhibition by insulin-like growth factor (IGF)-I during in vitro maturation of bovine oocytes. The Journal of reproduction and development, $\mathrm{v}$. 53,p. 419-426, 2007.

WU GQ ;JIA BY ;LI JJ ;FU XW ;ZHOU GB ;HOU YP ;ZHU SE. L-carnitine enhances oocyte maturation and development of parthenogenetic embryos in pigs. Theriogenology, v. 76,p. 785-793, 2011.

YOU $\mathbf{J}$;LEE $\mathbf{J}$;HYUN SH ;LEE E. L-carnitine treatment during oocyte maturation improves in vitro development of cloned pig embryos by influencing intracellular glutathione synthesis and embryonic gene expression. Theriogenology, v. 78,p. 235-243, 2012. 


\section{CAPITULO 4}

\section{EFEITO DOS DIFERENTES SISTEMAS DE MATURAÇÃO OVOCITÁRIA NA QUALIDADE DOS OVÓCITOS BOVINOS, COMPOSIÇÃO DA MEMBRANA PLASMÁTICA E RESISTÊNCIA A VITRIFICAÇÃO E AQUECIMENTO}

José F. W. Sprícigo ${ }^{1}$, Mateus N. Diógenes ${ }^{1}$, Ligiane O. Leme ${ }^{1}$, Ana L. Guimarães ${ }^{1}$, Carolle V. Muterlle $^{1}$, Bianca Damiani Marques Silva ${ }^{2}$, David Solà-Oriol ${ }^{3}$, Ivo Pivato ${ }^{1}$, Luciano P. Silva ${ }^{2}$, Margot A. N. Dode ${ }^{2}$

1 Programa de Pós-Graduação em Ciências Animais, Faculdade de Agronomia e Medicina Veterinária, Universidade de Brasília, UnB, Brasília, DF, Brasil;

2. Embrapa Recursos Genéticos e Biotecnologia, Laboratório de Reprodução Animal, Brasília, DF, Brasil.

3 Serviço de Nutrição e Bem-estar Animal (SNiBA), Departamento de Ciência Animal e Alimentos, Universidade Autônoma de Barcelona, Cerdanyola del Vallès, Espanha. 


\section{RESUMO}

O objetivo deste estudo foi avaliar os efeitos dos diferentes sistemas de maturação na resistência do ovócito após a vitrificação e sobre o perfil fosfolipídico da membrana plasmática (MP) ovocitária. Quatro diferentes sistemas de maturação foram testados: 1) maturação in vitro utilizando ovócitos imaturos aspirados de ovários de abatedouros (CONT; $\mathrm{n}=136) ; 2$ ) maturação in vitro utilizando ovócitos imaturos obtidos por ovum pick-up (OPU) de novilhas não estimuladas (IMA; $\mathrm{n}=433$ ); 3) maturação in vitro utilizando ovócitos imaturos obtidos por OPU de novilhas estimuladas (FSH; $n=444)$; e 4) maturação in vivo utilizando ovócitos obtidos de novilhas estimuladas 24 horas antes da injeção de GnRH (MII; $\mathrm{n}=658$ ). As amostras dos ovócitos maturados de cada grupo fresco foi analisada por ionização dessorção a laser assistido por matrix - tempo de vôo (MALDI-TOF) para determinar a composição da MP. Depois, a metade dos ovócitos maturados de cada grupo foi vitrificada/ aquecida (CONT VIT, IMA VIT, FSH VIT e MII VIT), enquanto a outra metade foi utilizada a fresco como controle. Em seguida, os oito grupos foram submetidos à FIV e CIV, e o desenvolvimento do blastocisto foi avaliado no D2, D7 e D8. Já para comparar o desenvolvimento embrionário entre os grupos foi utilizado o teste do qui-quadrado. A intensidade correspondente de íons fosfolipídios foi expressa em unidades arbitrárias, e na sequência de análise dos componentes principais (CPA) os dados foram distribuídos em gráfico 3D. Os ovócitos obtidos de animais superestimulados mostraram uma taxa de desenvolvimento maior $(\mathrm{P}<0.05)$ para todos os grupos $(\mathrm{CONT}$ VIT $=2.8 \pm 3.5 \%$, IMA VIT $=2.9 \pm 4.0 \%$, FSH VIT $=4.3 \pm 7.2 \%$ e MII VIT $=3.6 \pm 7.2 \%)$. MALDI-TOF revelou que os ovócitos de todos os grupos maturados tiveram o mesmo conteúdo fosfolipídico, exceto para 760.6 ([PC (34:1) + H]+ ), que foi mais altamente expresso em MII comparado ao FSH $(\mathrm{P}<0,05)$. Os resultados sugerem que embora os sistemas de maturação melhorem o desenvolvimento embrionário, eles não mudam a composição da MP nem a resistência dos ovócitos bovinos a vitrificação. 
Palavras chaves: bovino, ovócito, vitrificação, maturação in vivo. 


\section{ABSTRACT}

In the last decade, vitrification methodologies emerged as promising strategies for embryos and oocyte cryopreservation. However, it is not yet an efficient technique for bovine oocytes. The maturation conditions and some of bovine oocyte characteristics such the plasma membrane phospholipid composition could explain the difficulty to cryopreserve this cell type. The objective of this experiment was to evaluate the effect of different maturations system on the membrane phospholipid profile and manly on oocyte resistance after vitrification. Four different maturation systems were tested: 1) immature oocytes aspirated from slaughterhouse ovaries (CONT group); 2) immature oocytes obtained by ovum pick up (OPU) from unstimulated heifers (IMA group); 3) immature oocytes obtained by OPU from stimulated heifers (FSH group) and 4) in vivo matured oocytes obtained from stimulated heifers 24 hours after GnRH (MII group). Immature oocytes were subjected to in vitro maturation for 24 hours. For the membrane phospholipid composition determination, matured oocytes from each group were collected for Matrix Associated Laser Desorption-Ionization - Time of Flight (MALDITOF). At the end of maturation, half of the oocytes in each group were vitrified/warmed (CONT VIT, IMA VIT, FSH VIT and MII VIT). Afterwards, the 8 groups underwent IVF and IVC, and embryo development was assessed at D2, D7 and D8. Embryo development was compared using LSMEANS procedures with a Chi-square test with a 5\% significance level. For MALDITOF, ion intensity was expressed in arbitrary units and was distributed in a 3D PCA. Fresh oocytes showed higher developmental capacity at D2, D7 and D8 compared to all vitrified groups $(\mathrm{P}<0.05)$. Oocytes obtained from superstimulated animals (MII and FSH) had higher developmental rates $(\mathrm{P}<0.05)$ at $\mathrm{D} 7$ and hatching at $\mathrm{D} 8(\mathrm{P}<0.05)$ compared to those obtained from unstimulated animals (CONT and IMA). MALDI-TOF revealed that oocytes from all maturation groups had similar phospholipid content, and the only difference was that the MII group presented a lower intensity $(\mathrm{P}<0.05)$ of 760.6 ions $\left([\mathrm{PC}(34: 1)+\mathrm{H}]^{+}\right)$compared to FSH. 
The results suggest that the low efficiency of bovine oocyte vitrification is not related to maturation system and is probably due to other oocyte characteristics, which may be shared by other species as well.

Key words: Immature, bovine, oocyte, in vivo maturation. 


\section{INTRODUÇÃO}

A capacidade de preservar gametas femininos é uma parte integrante das técnicas de reprodução assistida (TRAs), uma vez que tem um grande impacto nos programas de conservação animal, programas de melhoramento animal, e também na reprodução humana assistida (Kuwayama et al., 2005; Zhou et al., 2010).

Raças e espécies ameaçadas podem ser regeneradas se ambos, espermatozoide e ovócitos, forem recuperados. Além disso, a criopreservação eficaz de ovócitos pode também facilitar as técnicas de reprodução assistida e pode ser utilizada para resgatar gametas quando fêmeas morrem inesperadamente. Para a produção animal, a criopreservação é crucial para superar os problemas de logística associado com o número de ovócitos recuperados, transporte ao laboratório e a disponibilidade de receptoras necessários para transferir os embriões produzidos. Além disso, a criopreservação de ovócitos permite o armazenamento de material genético não fecundado de uma fêmea até que seu potencial possa ser avaliado, permitindo a comercialização posterior, evitando o transporte de animais e os riscos sanitários.

Até hoje, a criopreservação de ovócitos é uma técnica ineficaz para a maioria dos animais domésticos. A capacidade dos ovócitos criopreservados para alcançar o desenvolvimento embrionário posterior é insatisfatória na maioria das espécies de produção. Esta alta sensibilidade para a criopreservação de ovócitos pode ser explicada pelas suas características morfológicas e funcionais únicas, tais como o tamanho celular, o volume de água, que levam a desorganização do citoesqueleto e vacuolização e degeneração do citoplasma (Vieira et al., 2002; Men et al., 2005; Horvath et al., 2006; Morato et al., 2008a; b; Anchamparuthy et al., 2009; Chamayou et al., 2011; Shirazi et al., 2012). Portanto, os ovócitos criopreservados sofrem danos morfológicos e funcionais graves que podem ser exacerbados, especialmente nos animais domésticos, devido ao alto teor de lipídeos no citoplasma, mas também pela composição de fosfolipídeos de membrana (Mcevoy et al., 2000). 
Atualmente a vitrificação é o método mais utilizado para preservar ovócitos. Apesar de já estar bem estabelecida para ovócitos humanos (Chang et al., 2008; Chian et al., 2009), os resultados em bovinos ainda são muito ineficientes (Zhou et al., 2010; Spricigo et al., 2012). Quando se compara ovócitos humanos aos ovócitos bovinos, observa-se que as diferenças mais evidentes entre eles são: o sistema de maturação, que normalmente é in vivo para humanos(Chang et al., 2008) e in vitro para bovinos; a quantidade de lipídios citoplasmáticos (Mcevoy et al., 2000), que é muito maior em bovinos do que em humanos; além das diferenças da composição da membrana plasmática (Ferreira et al., 2010).

Portanto, na tentativa de melhorar os resultados em bovinos essas características deveriam ser levadas em conta.

Na última década, muitos esforços foram feitos para aumentar a eficiência da vitrificação de ovócitos de animais domésticos (Vieira et al., 2002; Kuwayama et al., 2005) incluindo o uso de agentes de estabilização de citoesqueleto (Morato et al., 2008c), antioxidantes (Dalvit et al., 2005), agentes lipolíticos (Men et al., 2006; Moawad et al., 2013) e modificadores de membrana plasmática (MP) (Horvath et al., 2006; Spricigo et al., 2012). Modificar a MP pode afetar a permeabilidade celular e melhorar as trocas de água e crioprotetores (Horvath et al., 2006). Fosfolipídios, particularmente fosfatidilcolina (PC) e esfingomielina (SM), são unidades estruturais da MP funcional, e sua composição determina a maioria das propriedades físico-química da membrana, incluindo a fluidez, permeabilidade e comportamento de fase de transição lipídica (Edidin, 2003). Essa composição também pode variar de acordo com a espécie, raça ou mesmo com as condições de cultivo (Sudano et al., 2012), o que a torna um alvo quando se quer induzir mudanças.

Todas essas alternativas já foram testadas para aumentar a crioresistência de ovócitos bovinos, entretanto o uso de ovócitos maturados in vivo, que supostamente teriam melhor qualidade e responderiam melhor a vitrificação ainda não foi relatado em bovinos. Sudano et al. (2012) mostraram que a origem do embrião, ou seja, ser produzido in vivo ou in vitro, afeta a composição lipídica. Entretanto, não se sabe como a composição fosfolipídica da membrana de ovócitos bovinos é afetada pelo sistema de maturação.

O principal objetivo do experimento foi comparar a resistência à vitrificação de ovócitos bovinos maturados em diferentes sistemas avaliando o desenvolvimento e a qualidade de blastocisto produzidos in vitro. Além do objetivo principal, o experimento também focou no efeito dos diferentes sistemas de maturação sobre a fisiologia do ovário de novilhas Nelore, acompanhando a população folicular, tamanho e vascularização dos folículos antes da OPU, a 
qualidade do ovócito e a composição lipídica na membrana. Utilizou-se o sistema de maturação in vivo como o "sistema ideal", o que resultaria em ovócitos com maior capacidade de desenvolvimento embrionário (Van De Leemput et al., 1999; Dieleman et al., 2002; Tesfaye et al., 2009) e, consequentemente maior resistência à vitrificação. 


\section{MATERIAL E MÉTODOS}

Todos os experimentos foram conduzidos de acordo com as leis brasileiras para a ética animal e pesquisa em saúde, aprovados pelo Comitê de Experimentação e Uso Animal (CEUA), do Instituto de Ciências Biológicas da Universidade de Brasília, sob o protocolo UnBDOC (processo número 132157 / 2012).

Salvo quando especificado, todos os reagentes foram adquiridos junto à SigmaAldrich (St. Louis, MO, EUA). Dispositivos de vitrificação foram adquiridos com a Ingámed (Maringá, PR, Brasil). Os meios para produção de embriões, incluindo maturação, fecundação e cultivo in vitro foram produzidos pela Geneal (Geneal, Genética Animal, Uberaba-MG, Brasil).

\subsection{Delineamento experimental}

Antes de iniciar o experimento, um pré-experimento foi realizado para determinar o melhor intervalo para executar a OPU de ovócitos maturados in vivo. Resumidamente, as novilhas foram sincronizadas, superestimuladas e receberam a administração de GnRH, tal como descrito abaixo, no protocolo de maturação in vivo. Após a administração de GnRH, 20 ( $n=5)$ ou 24 horas $(n=5)$ mais tarde, os animais foram submetidos a OPU, e os CCOs recuperados foram desnudados e avaliadas para a presença do corpúsculo polar. Em seguida, estes foram fixados e corados para determinação da fase meiótica. O grupo que apresentou maior percentual de ovócitos no estágio MII foi escolhido para o experimento.

A Figura 4.1. resume o delineamento experimental. Para avaliar se o sistema de maturação afetou a viabilidade dos ovócitos após vitrificação / aquecimento e composição da membrana fosfolipídica, foram utilizados 1562 ovócitos. Três sistemas de maturação foram 
avaliados: 1) a maturação in vitro de ovócitos obtidos pela OPU de novilhas não estimuladas (IMA); 2) a maturação in vitro de ovócitos obtidos por OPU de novilhas estimuladas, em que a OPU foi realizada 12 horas após a última administração de FSH (FSH); 3) a maturação in vivo em que os ovócitos foram obtidos a partir de novilhas estimuladas, com OPU realizada 24 horas após a administração de um análogo de GnRH (MII). Um quarto grupo foi também utilizado em todas as réplicas como um grupo controle do laboratório (CONT), consistindo da maturação in vitro de ovócitos aspirados de ovários de abatedouro.

O experimento foi conduzido em 9 repetições, com 5 animais em cada um dos três grupos sendo submetido a OPU em cada repetição, de tal maneira que os animais de todos os grupos estavam presentes na repetição. Para os grupos IMA e FSH (ovócitos imaturos), os CCOs foram recuperados, selecionado, transferido para o meio MIV e maturados durante 24 horas. Para o grupo maturado in vivo (MII), as novilhas foram submetidas à OPU 24 horas mais tarde do que para os outros dois grupos.

Pouco antes de cada seção de OPU, ambos os ovários dos animais dos grupos IMA, FSH e MII foram avaliados usando um ultrassom com Color Doppler (30 MyLab Vet Ouro, Esaote, Itália). Os ovários foram digitalizados e os folículos foram contados e classificados de acordo com a intensidade da vascularização sanguínea.

Os ovócitos de todos os tratamentos foram classificados como viáveis ou não viáveis. Para ovócitos dos grupos IMA e FSH, apenas aqueles com mais de três camadas de células cumulus e citoplasma homogêneo foram classificados como viáveis e para o grupo MII, apenas a ovócitos com citoplasma homogêneo, apresentando a primeira extrusão do corpúsculo polar e / ou expansão das células do cumulus.

Após a maturação in vivo ou in vitro, metade dos ovócitos de cada tratamento foram vitrificados (VIT) e imediatamente aquecidos (CONT-VIT, -ima-VIT, -FSH-VIT e MIIVIT). A outra metade foi mantida na bancada durante a vitrificação/aquecimento dos grupos contemporâneos. Para ser consistente durante todo o experimento, apenas CCOs com um corpúsculo polar visível e/ou a expansão das células do cumulus, foram classificados como maturados in vivo e foram usadas no grupo MII. Após o aquecimento, os ovócitos criopreservados e seus controles frescos foram submetidos a fecundação in vitro e cultivo de embriões. A taxa de clivagem foi avaliada 48 horas após a fecundação (D2) e o desenvolvimento embrionário foi avaliado em D7 e D8. No D8, os embriões foram medidos e corados para contar o número total de células. 
Amostras de ovócitos frescos $(n=15 /$ tratamento $)$ de cada grupo foram coletadas para avaliação de fosfolipídeos utilizando os perfis de espectrometria de massa (MALDI / TOF).

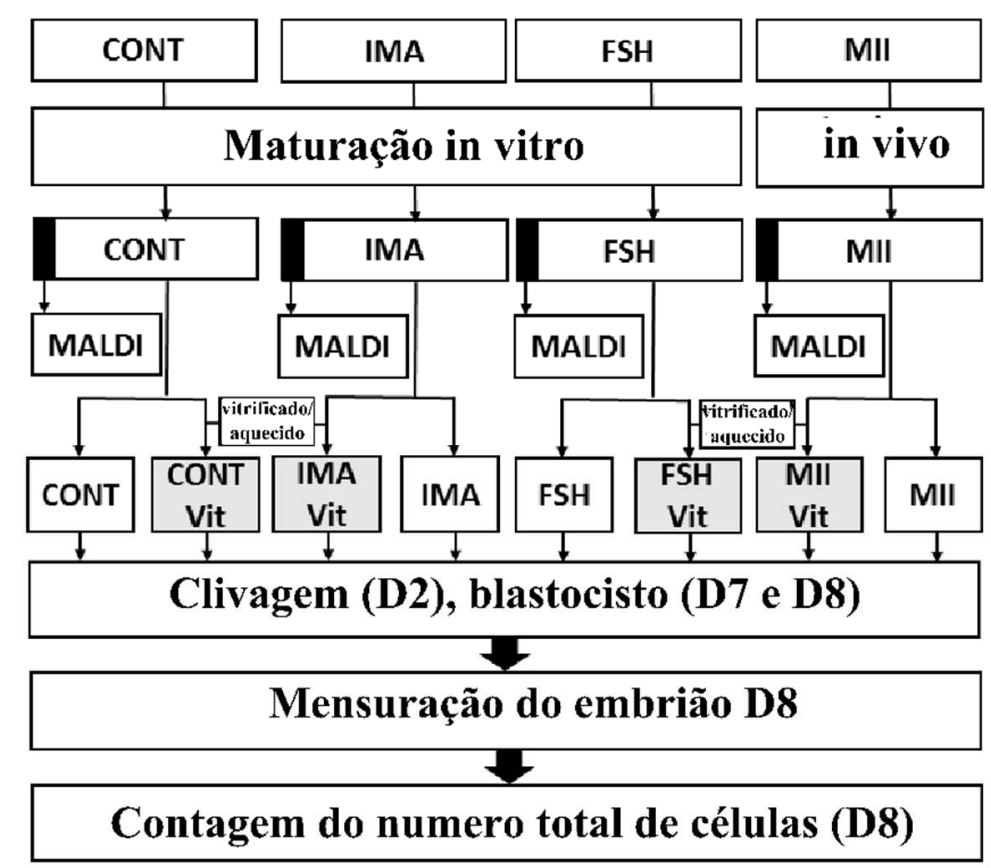

Figura 4.1. Esquema representativo do desenho experimental.

\subsection{Obtenção de ovócitos de abatedouro}

Os ovários (Bos indicus) foram coletados imediatamente após o abate e transportadas para o laboratório em solução salina $(\mathrm{NaCl}$ a $0,9 \%)$ suplementado com penicilina $\mathrm{G}(100 \mathrm{UI} / \mathrm{mL})$ e sulfato de estreptomicina $(100 \mathrm{~g} / \mathrm{mL})$ a $35^{\circ} \mathrm{C}$. Os complexos cumulus ovócitos (CCOs) foram aspirados de folículos de 3 a $8 \mathrm{~mm}$ de diâmetro com uma agulha de calibre $18 \mathrm{G}$ e transferidos para um tubo cônico de $15 \mathrm{~mL}$. Os CCOs foram recuperados e selecionados em meio de manutenção, consistindo de TCM-199 tamponado com HEPES (Gibco BRL, Burlington, ON, Canadá) suplementado com 10\% de soro fetal bovino [SFB (Invitrogen, Carlsbad, CA, EUA)]. Somente CCOs com citoplasma homogêneo e, pelo menos, três camadas de células de cumulus foram usadas para os experimentos. Após seleção, os ovócitos foram submetidos a maturação in vitro. 


\subsection{Recuperação de ovócitos por OPU}

Foram utilizadas 43 novilhas da raça Nelore (Bos taurus indicus), com cerca de 2 anos de idade e com condições corporais semelhantes. As novilhas foram mantidas em pastagem de Brachiaria sp., suplementada com silagem de milho, sal e água ad libitum. As novilhas foram distribuídas aleatoriamente em três grupos experimentais $(n=14 ; n=14$ e $n=$ 15) em um estudo "crossover" com um intervalo mínimo entre repetições de 30 dias.

Para OPU, foi utilizada uma guia de aspiração (WTA, Brasil) acoplada a um transdutor convexo de 7,5 MHz (Aloka, UST 9125, Japão). Os CCOs recuperados foram selecionados sob um microscópio estereoscópico (Zeiss ® - Stemi SV6, Alemanha) e submetidos à MIV e/ ou vitrificação.

\subsection{Maturação in vitro}

CCOs selecionados foram lavados e transferidos em grupos de 25-30 para uma gota de $200 \mathrm{~mL}$ de meio de maturação, sob óleo de silicone e incubadas durante $22 \mathrm{~h}$ a $39{ }^{\circ} \mathrm{C}$ com 5\% de $\mathrm{CO}_{2}$, em ar. O meio de maturação consistiu de TCM -199 (Invitrogen, Carlsbad, CA, EUA) suplementado com 10\% (SFB, $0.01 \mathrm{UI} / \mathrm{mL}$ de FSH, 0,1 mg $/ \mathrm{mL}$ de L-glutamina e antibióticos (amicacina, 0,075 mg/mL).

\subsection{Sincronização de estro, estimulação ovariana e maturação in vivo}

Após estabelecer o momento apropriado para a recuperação de ovócitos maturados in vivo (Van De Leemput et al., 1999; Rizos et al., 2002), todos os animais foram submetidos a protocolos idênticos para a sincronização do estro. Os animais receberam uma injeção de 2 mg de benzoato de estradiol (i.m., BE Ric-; Syntex, Buenos Aires, Argentina) e a inserção de um dispositivo intravaginal de progesterona (Sincrogest; Ourofino, Cravinhos-SP, Brasil), sendo esse momento considerado o D-10 do protocolo. Cinco dias mais tarde (D-5), os animais receberam uma injeção de $0,150 \mathrm{mg}$ de prostaglandina PGF2 (d-cloprostenol, Prolise ${ }^{\circledR}$ ARSA SRL, Argentina). No dia -2, os implantes de progesterona foram removidos, e no dia 1, $1 \mathrm{mg}$ de benzoato de estradiol foi injetado (i.m.). O D0 do protocolo foi considerado o início do tratamento. 
No Dia 8, todos os folículos com um diâmetro maior do que $5 \mathrm{~mm}$, foram puncionados por OPU. Imediatamente após a ablação, os animais receberam um dispositivo intravaginal d de progesterona. Para os animais não estimulados (grupo IMA), 108 horas após a inserção do dispositivo de progesterona, $0,150 \mathrm{mg}$ de PGF2a (i.m) foi administrada. Após 72 h, o dispositivo de progesterona foi removido e a OPU realizada. Todos os folículos presentes nos ovários maiores do que $3 \mathrm{~mm}$, foram aspirados.

Nos outros dois grupos, dois dias após a ablação (D10), os animais foram superstimulados com um total de $80 \mathrm{mg}$ de pFSH (Folitropin-V; Bioniche Animal Health Canada Inc., Belleville, Canadá) em doses decrescentes, recebendo duas aplicações por dia ao longo de quatro dias. A luteólise foi induzida com 0,150 mg de PGF2a (i.m.), administrada junto à quinta aplicação de pFSH. Na última aplicação, o dispositivo de progesterona foi removido e a OPU realizada.

Para a obtenção de ovócitos maturados in vivo (grupo MII), simultaneamente com a última injeção de FSH e a remoção do dispositivo de progesterona, foi administrado 0,025 mg (i.m.) de lecirelina (Gestran ®, Tecnopec, São Paulo, Brasil), um análogo da GnRH. A OPU foi realizada 24 horas depois, e os folículos maiores do que $6 \mathrm{~mm}$ foram aspirados.

\subsection{Avaliação da vascularização folicular com o Color Doppler}

Em todos os tratamentos, os ovários foram avaliados imediatamente antes do procedimento de OPU. Foi utilizado para a avaliação a ultrassonografia com Color Doppler com uma sonda linear de 7,5 MHz. A vascularização foi observada e classificada de acordo com Matsui et al. (2009) do seguinte modo: 3- vascularização ausentes, não foram observadas imagens coloridas em torno do folículo; 2- vascularização intermediária, com imagens coloridas parciais; e 1- vascularização intensa, quando o folículo foi completamente cercado por imagens coloridas (Figura 4.2). 


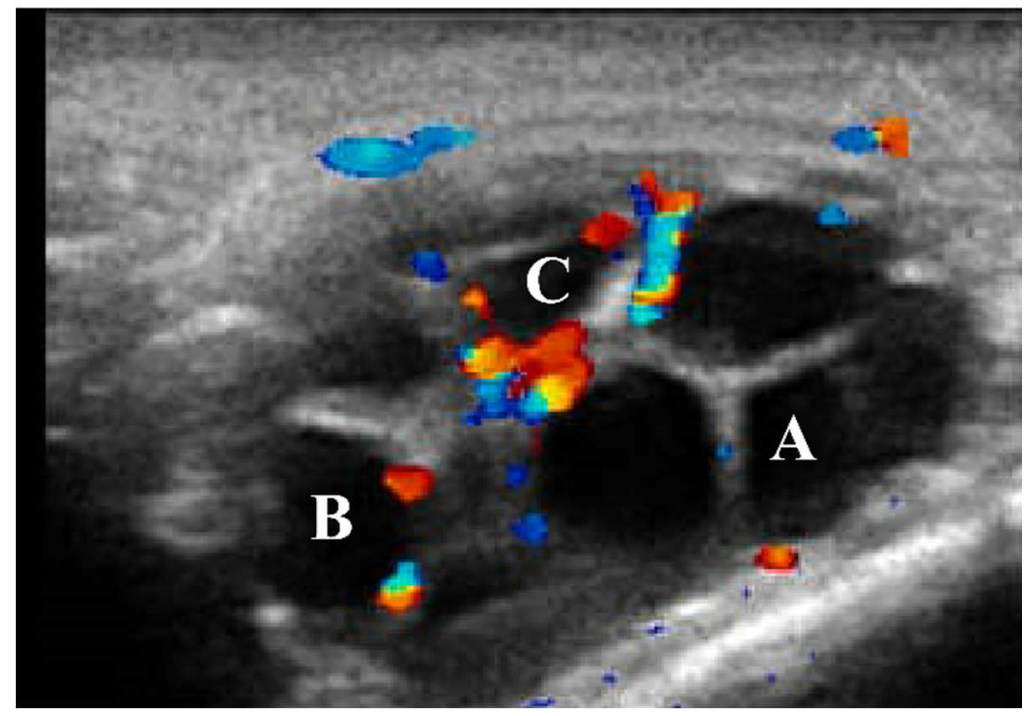

Figura 4.2. Imagem do ultrassom Color Dopller, indicando folículo com irrigação ausente (a), irrigação intermediária (b) e com irrigação intensa (c).

\subsection{Fecundação (FIV) e cultivo in vitro de embriões (CIV)}

Após a maturação, CCOs (grupos de 25 a 30) foram transferidos para uma gota de $200 \mathrm{~mL}$ de meio de fecundação. Foi utilizado para a fecundação sêmen congelado de um touro Nelore, previamente testado em nosso laboratório. Espermatozoides móveis foram obtidos pelo método de Percoll (Machado et al., 2009) e foram adicionados às gotas contendo CCOs a uma concentração final de $1 \times 10^{6}$ espermatozoides $\mathrm{mL}^{-1}$. O meio de fecundação foi TALP (Parrish et al., 1995) suplementado com penicilamina (2 mM), hipotaurina (1 mM), epinefrina $(250 \mathrm{mM})$ e heparina $(10 \mathrm{ug} / \mathrm{mL}-1)$. Os espermatozoides e ovócitos foram coincubadas durante $18 \mathrm{~h}$ a $39{ }^{\circ} \mathrm{C}$ com $5 \%$ de $\mathrm{CO}_{2}$, em ar. O dia da FIV foi considerado dia 0. Depois da co-incubação, os zigotos $(n=25-30)$ foram lavados e transferidos para gotas de 200 uL de SOFaaci (Holm et al., 1999) suplementado com 2,77 mM de mio-inositol e 5\% de SFB e cultivados à $39{ }^{\circ} \mathrm{C}$ e $5 \%$ de $\mathrm{CO}_{2}$, em ar, durante 8 dias. $\mathrm{O}$ desenvolvimento de blastocisto foi avaliado no dia 2 pós-inseminação (pi) para a clivagem e no Dia 7 e Dia 8 pi para a taxa de blastocisto.

\subsection{Vitrificação e aquecimento}

A vitrificação de ovócitos foi realizada como descrito por Kuwayama (2005), com pequenas modificações. A solução de manutenção (SM), que foi utilizado para manipular 
ovócitos durante a vitrificação e aquecimento, foi composta por TCM-199 tamponado com HEPES- (Gibco) suplementado com 20\% de SFB. Para a vitrificação, os grupos de ovócitos (35) foram lavados três vezes em solução de equilíbrio constituído por 7,5\% de etileno glicol e 7,5\% de dimetilsulfóxido (DMSO) dissolvido em SM, por 9 minutos. Os ovócitos foram transferidos para uma solução de vitrificação composta de $15 \%$ de etileno glicol, $15 \%$ de DMSO e 0,5 M de Sacarose em SM, onde foram incubados durante 45-60 segundos. Em seguida, os ovócitos foram colocados na haste de vitrificação em conjuntos de 3-5, sob um estereomicroscópio (Nikon- SMZ 650). Antes de vitrificação, a maior parte da solução, que foi transferida junto aos ovócitos foi removida, e apenas uma fina camada $(<0,1 \mu \mathrm{L})$ permaneceu cobrindo os ovócitos. Subsequentemente, haste foi imediatamente imersa em $\mathrm{N}_{2}$ líquido. $\mathrm{O}$ aquecimento foi realizado imediatamente após vitrificação, mergulhando a extremidade da haste em uma gota de SM suplementado com $1 \mathrm{M}$ de sacarose, pré-aquecida a $37{ }^{\circ} \mathrm{C}$, durante 1 min. Os ovócitos foram então transferidos para uma solução de 0,5 M de Sacarose, em meio SM, durante 3 minutos. Finalmente, os ovócitos foram expostos ao meio manutenção (SM). Em seguida, os ovócitos foram colocados nas placas de cultivo para serem submetidos a fecundação in vitro.

\subsection{Avaliação da maturação}

Para a avaliação da maturação, CCOs aspirados 20 ou 24 horas após a administração de GnRH foram desnudados e fixados por pelo menos 48 h com álcool acético (1: 3). No dia da avaliação, estes ovócitos foram colocadas sobre uma lâmina, coberta com uma lamínula e coradas com $1 \%$ lacmóide em $45 \%$ de ácido acético glacial. O estágio de maturação de cada ovócito foi determinado utilizando microscopia de contraste de fase. Ovócitos foram classificados da seguinte forma: imaturo - não chegaram a metáfase II ou maturados - com a presença de placa metafásica.

\subsection{Mensuração dos embriões e contagem do número de células}

Após a fecundação in vitro, os prováveis zigotos foram cultivados até D8, quando os embriões foram classificados e medidos por uma câmera Imagem Motic (Moticam 
( 2.0, Japão). Os embriões com um diâmetro > $160 \mu \mathrm{m}$ foram utilizadas para avaliar o número total de células. Os embriões foram expostos ao corante Hoechst 33342 (Invitrogen, Carlsbad, CA, EUA) a uma concentração de $1 \mathrm{ug} / \mathrm{mL}$ durante 5 minutos e foram, subsequentemente, transferidos para uma lâmina e cobertos com uma lamínula. As lâminas foram avaliadas utilizando um microscópio de epifluorescência (Zeiss Axiophot ${ }^{\circledR}$, Alemanha, filtro de 24) com um comprimento de onda de 494/518 nm (excitação / emissão), e os núcleos de células foram contadas (Figura 4.3).

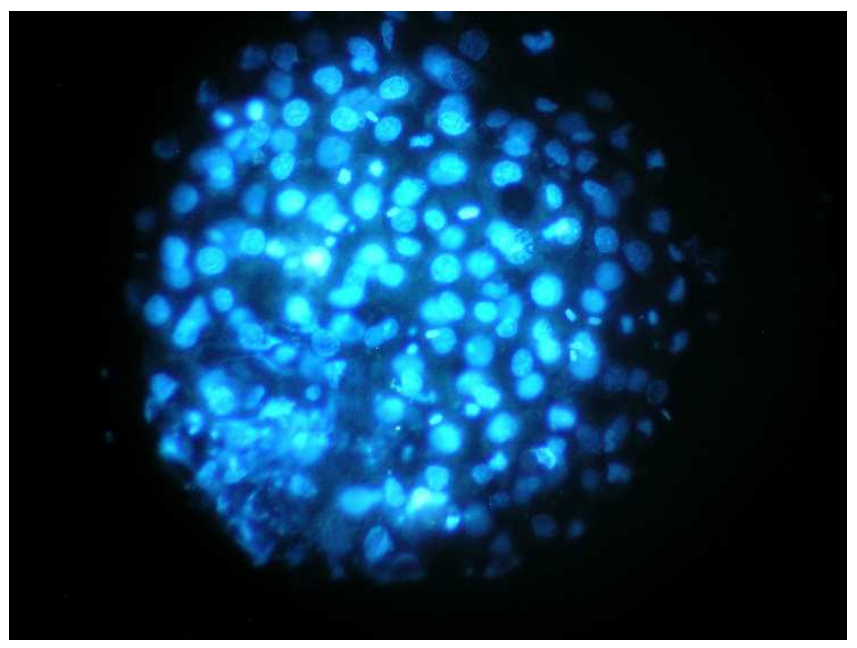

Figura 4.3. Embrião em D8, maior que $160 \mu \mathrm{m}$, corado com Hoechst 3334, para contagem do número total de células, com coloração em azul, indicando o núcleo celular.

\subsection{Espectrometria de massa lipídio MALDI-TOF}

\subsubsection{Preparação de amostra}

Ovócitos maturados a partir dos diferentes tratamentos foram completamente desnudados das células do cumulus, depois de 3 minutos expostos à uma solução de $1 \%$ de hialuronidase. Cada ovócito foi lavado cinco vezes em gotas de metanol/água pura 1:1 (v/v) e armazenados na mesma solução em tubos de micro centrífuga a $-80^{\circ} \mathrm{C}$, até à análise. Após o descongelamento, os ovócitos foram alocados individualmente em um poço MALDI, numa placa de aço de 96 poços. Os ovócitos foram deixados para secar à temperatura ambiente. Antes da análise, $1 \mu \mathrm{l}$ de ácido 2,5-di-hidroxibenzóico (0,125 M, DHB) diluído em metanol puro foi depositado em cada poço, para cobrir os ovócitos e para permitir a cristalização. Os ovócitos foram novamente deixados para secar à temperatura ambiente. 


\subsubsection{MALDI-TOF}

Os espectros obtidos com a espectrometria de massa MALDI-TOF foram adquiridos em modo positivo por espectrômetro de massa refletida Auto Flex velocidade MALDI-TOF / TOF (Bruker Daltonics, Bremen, Alemanha). Os dados foram adquiridos em uma escala entre 600-1200 m/z, com 1500 disparos de laser em diferentes regiões de ovócitos. O laser foi aplicado até o momento em que os sinais tinham desaparecido na região de interesse, devido à dessorção das amostras. A intensidade do laser foi padronizada à 40\%, para a aquisição de espectro em todas as amostras. Os espectros foram centrados e alinhados utilizando o software mMass 5.5.0 (Niedermeyer et al., 2012). Os íons mais intensos após a detecção de picos correspondentes às distribuições isotópicas foram considerados para identificar o ponto de partida equivalente aos íons de lipídeos. Utilizou-se um total de 10-15 ovócitos por grupo.

\subsubsection{Determinação dos fosfolípideo da membrana plasmática}

Para determinação dos fosfolipídios (FL) e identificação das fosfatidilcolina (PC) e esfingomielina (SM), os valores de $\mathrm{m} / \mathrm{z}$ foram obtidos e comparados com os recentemente descrito na literatura (Ferreira et al., 2009; Apparicio et al., 2012; Sudano et al., 2012). Um banco de dados on-line (www.lipidmaps.org) foi também utilizado para ajudar na determinação de lipídeos.

\subsection{Análises estatística}

Todos os dados foram analisados por meio do software Statistical Analysis System (SAS, 1999). Para avaliação do estado de maturação do ovócito no pré-experimento, os dados foram analisados pelo teste do Qui-quadrado, com nível de significância de 5\%. Dados da população, tamanho e vascularização folicular, diâmetro de blastocisto e número total de células não apresentaram uma distribuição normal. Portanto, os tratamentos foram comparados pelo teste de Kruskal-Wallis, com nível de significância de 5\%. Para o desenvolvimento embrionário em D2, D7 e D8 e para as taxas de eclosão no D8, as variáveis foram analisadas utilizando o procedimento GENMOD do pacote estatístico SAS v.9.2. O modelo utilizado incluiu os tratamentos experimentais como o principal efeito. Todas as diferenças emparelhadas 
foram analisadas utilizando LSMEANS com base em uma inferência do Qui-quadrado como um teste de comparação, com o nível de significância de 5\%.

Para analisar os dados MALDI-TOF, uma análise de componentes principais (APC) foi realizada pela primeira vez usando o procedimento PRINCOMP no pacote estatístico SAS. Cargas e escores foram plotadas em gráficos 2D e 3D. Finalmente, as intensidades dos íons mais dispersos e sua média relativa foram comparados com ANOVA e de Tukey para a comparação de médias, a 5\% de significância. 


\section{RESULTADOS E DISCUSSÃO}

\subsection{Resultados}

O principal objetivo deste estudo foi avaliar se ovócitos bovino maturados in vivo, supostamente de melhor qualidade, resistiriam melhor à criopreservação. Portanto, foram comparados ovócitos maturados in vivo e in vitro, obtidos a partir de ovários de animais superestimuladas ou não. Foram usados ovócitos obtidos de ovários de abatedouro como controle experimental.

5.1.1 Pré-experimento: Determinação do momento ideal para a obtenção de ovócitos maturados in vivo.

Após a coloração com lacmoide, uma percentagem mais elevada $(\mathrm{P}<0,05)$ dos ovócitos maturados (MII) foi observado quando os folículos foram aspirados 24 horas (85\%; $\mathrm{n}$ = 31) após a administração de GnRH, em comparação com aqueles aspirados após 20 horas $(31 \% ; \mathrm{n}=34)$.

\subsubsection{Contagem do número total e vascularização folicular no momento da OPU e} recuperação ovocitária para os diferentes tratamentos.

Inicialmente, foram comparadas as quantidades de folículos para ser aspirados nos ovários, no momento da OPU, nos diferentes tratamentos. De acordo com a Tabela 4.1, não foram observadas diferenças na população folicular no momento da OPU $(\mathrm{P}>0,05)$. No entanto, quando o diâmetro folicular foi considerado, o grupo IMA apresentou o maior número de folículos $<6 \mathrm{~mm}(\mathrm{P}<0,05)$. A população de folículos com diâmetro $>6 \mathrm{~mm}$ foi semelhante $(\mathrm{P}>0,05)$ entre FSH e MII e menor no grupo IMA $(\mathrm{P}<0,05)$. 
Tabela 4.1. Número total $(\mathrm{N})$, média do número total e desvio padrão ( \pm D.P.) de folículos por fêmea, média de folículos por diâmetro, em um total de nove repetições, em animais não superstimulados (IMA), superestimuladas (FSH) e de fêmeas superovuladas que receberam um indutor da ovulação (MII).

\begin{tabular}{lcccc}
\hline & \multicolumn{2}{c}{$\begin{array}{c}\text { Número de folículos } \\
\text { puncionados }\end{array}$} & \multicolumn{2}{c}{ Diâmetro Folicular } \\
\cline { 3 - 4 } & Tratamentos & Média $( \pm$ SD) & Média $( \pm$ SD $)$ & Médias $( \pm$ SD $)$ \\
\cline { 2 - 4 } & $\mathrm{N}$ & $20,2( \pm 11,5)^{\mathrm{a}}$ & $19,7( \pm 11,4)^{\mathrm{a}}$ & $0,6( \pm 0,8)^{\mathrm{b}}$ \\
\hline IMA & 852 & $22,8( \pm 11,7)^{\mathrm{a}}$ & $2,1( \pm 3,5)^{\mathrm{b}}$ & $20,7( \pm 12,1)^{\mathrm{a}}$ \\
FSH & 914 & $22,5( \pm 15,0)^{\mathrm{a}}$ & - & $22,5( \pm 15,1)^{\mathrm{a}}$ \\
MII & 1013 & &
\end{tabular}

Também foi avaliado o nível de vascularização do folículo em todos os tratamentos antes da OPU. No grupo de animais que não tinham recebido superestimulação (IMA), a maioria dos folículos mostraram ausência de vascularização $(\mathrm{P}<0,05)$ e o número médio de folículos com o fluxo de sangue intenso foi menor $(\mathrm{P}<0,05)$ do que nos outros grupos. $\mathrm{O}$ grupo em que os animais receberam apenas FSH teve o maior número $(\mathrm{P}<0,05)$ dos folículos com vascularização moderada, enquanto aqueles que receberam FSH e GnRH (MII) teve o maior número $(\mathrm{P}<0,05)$ de folículos com vascularização intensa (Tabela 4.2).

No que diz respeito a viabilidade dos CCOs recuperados (Tabela 4.3), o grupo de FSH $(n=444)$ tinha uma percentagem mais elevada $(\mathrm{P}<0,05)$ de CCOs viáveis $(\mathrm{P}<0,05)$ em comparação com os grupos MII $(n=658)$ e IMA $(n=433)$, que não diferiram entre si (P> $0,05)$. No entanto, quando se avaliam os ovócitos inviáveis, o grupo MII teve o menor $(\mathrm{P}<0,05)$ percentagem de ovócitos degenerados, enquanto que nos outros grupos, a maioria dos ovócitos não viáveis $(\mathrm{P}<0,05)$ tinha degenerado. 
Tabela 4.2. Número total $(\mathrm{N})$, média e desvio padrão ( $\pm \mathrm{DP})$ de folículos por fêmea, após nove repetições. Avaliados e classificados pelo Color Doppler, como tendo, vascularização intensa, moderada ou ausente nos ovários de fêmeas não superestimuladas (IMA), de fêmeas superovuladas (FSH) e de fêmeas superovuladas que receberam um indutor da ovulação (MII).

\begin{tabular}{|c|c|c|c|c|c|}
\hline \multirow{3}{*}{ Grupos } & \multirow{2}{*}{\multicolumn{2}{|c|}{$\begin{array}{l}\text { Numero de folículos } \\
\text { avaliados pelo Dopller }\end{array}$}} & \multicolumn{3}{|c|}{ Vascularização sanguinea folicular } \\
\hline & & & Intenso & Moderado & Ausente \\
\hline & $\begin{array}{c}\text { Total } \\
\mathrm{N}\end{array}$ & Média $( \pm \mathrm{DP})$ & Média $( \pm \mathrm{DP})$ & Média $( \pm D P)$ & Média $( \pm D P)$ \\
\hline IMA & 1016 & $24,1( \pm 10,0)^{\mathrm{a}}$ & $0,3( \pm 0,8)^{\mathrm{c}}$ & $6,7( \pm 3,6)^{\mathrm{c}}$ & $17,1( \pm 7,7)^{\mathrm{a}}$ \\
\hline FSH & 1098 & $27,4( \pm 12,4)^{\mathrm{a}}$ & $4,1( \pm 4,2)^{b}$ & $16,7( \pm 8,5)^{\mathrm{a}}$ & $6,6( \pm 4,8)^{b}$ \\
\hline MII & 1341 & $29,8( \pm 17,0)^{\mathrm{a}}$ & $16,7( \pm 12,2)^{\mathrm{a}}$ & $11,9( \pm 8,7)^{\mathrm{b}}$ & $1,1( \pm 1,8)^{\mathrm{c}}$ \\
\hline
\end{tabular}

${ }_{\text {abc }}$ Valores com letras diferentes nas mesmas colunas indicam resultados diferentes, segundo o teste de KruskalWallis $(\mathrm{P}<0,05)$.

Table 4.3. Número total $(\mathrm{N})$ e porcentagem (\%) de ovócitos viáveis e não viáveis recuperados por OPU, depois de nove repetições, a partir de ovários de fêmeas não superestimuladas (IMA), de fêmeas superestimuladas (FSH) e de fêmeas superestimuladas, que receberam o indutor de ovulação (MII).

\begin{tabular}{lcccc}
\hline & & & \multicolumn{2}{c}{ Ovócitos não viáveis } \\
\cline { 3 - 5 } Grupos & Total & Viáveis & Total* & Degenerados/ \\
& $\mathrm{N}$ & $\mathrm{N}(\%)$ & $\mathrm{N}(\%)$ & Inviáveis**N $(\%)$ \\
\hline IMA & 433 & $235(54,3)^{\mathrm{b}}$ & $198(45,7)^{\mathrm{a}}$ & $155(78,3)^{\mathrm{b}}$ \\
FSH & 444 & $337(75,9)^{\mathrm{a}}$ & $107(24,1)^{\mathrm{c}}$ & $99(92,5)^{\mathrm{a}}$ \\
MII & 658 & $438(66,6)^{\mathrm{b}}$ & $220(33,4)^{\mathrm{b}}$ & $63(28,6)^{\mathrm{c}}$ \\
\hline Valores com letras diferentes nas mesmas colunas indicam resultados diferentes, segundo o teste de Qui- \\
quadrado (P < 0,05). \\
* Porcentagem calculada sobre o total de ovócitos recuperados;
\end{tabular}

5.1.3 Desenvolvimento embrionário e qualidade dos blastocistos, depois da vitrificação e aquecimento dos ovócitos

A resistência dos ovócitos de diferentes sistemas de maturação para vitrificação /aquecimento foi avaliada pelo desenvolvimento embrionário (Tabela 4.4). Embora a taxa de clivagem tenha sido maior no grupo CONT-VIT (P <0,05), o desenvolvimento em D7 e D8 foi semelhante $(\mathrm{P}>0,05)$ entre todos os grupos vitrificados, inferiores $(\mathrm{P}<0,05)$ a todos os grupos frescos. Em contrapartida, a taxa de eclosão no D8 para os grupos de FSH-Vit e MII-Vit foi semelhante $(\mathrm{P}>0,05)$ ao grupo CONT Fresco. As taxas de clivagem foram semelhantes em 
todos os grupos frescos $(\mathrm{P}>0,05)$ e maior do que todos os grupos vitrificados $(\mathrm{P}<0,05)$. No entanto, o sistema de maturação afetou a produção de blastocistos no D7 e D8, com uma maior taxa de blastocistos $(\mathrm{P}<0,05)$ nos grupos FSH e MII $(\mathrm{P}>0,05)$, do que para CONT e IMA. Uma análise posterior revelou que entre os ovócitos frescos, o grupo CONT teve a menor $(\mathrm{P}<0,05)$ taxa de eclosão no D8 e o grupo MII e FSH as maiores taxas $(\mathrm{P}<0,05)$.

No D8, todos os embriões foram medidos, e aqueles com um diâmetro superior a $160 \mu \mathrm{m}$ tiveram o seu número total de células contadas. Devido às baixas taxas de desenvolvimento embrionário em todos os grupos vitrificados, não havia número suficiente de embriões para realizar uma análise estatística. A qualidade embrionária entre os ovócitos frescos, avaliada pelo tamanho do embrião e número total de células, foi semelhante para todos os tratamentos. A única diferença observada foi que os embriões do grupo MII apresentaram um número de células maior $(\mathrm{P}<0,05)$ do que embriões do grupo CONT (Tabela 4.5. 
Tabela 4.4. Desenvolvimento de blastocistos a partir de ovócitos MII, após a vitrificação e aquecimento. Os ovócitos foram obtidos a partir de ovários de abatedouro (CONT) ou pela OPU, pela punção de ovários de fêmeas não superestimuladas (IMA), fêmeas superestimuladas (FSH) e fêmeas superestimuladas que receberam um indutor da ovulação (MII).

\begin{tabular}{|c|c|c|c|c|c|}
\hline Groupos & $\begin{array}{l}\text { Total } \\
\mathrm{N}\end{array}$ & $\begin{array}{l}\text { Clivados D2 } \\
\mathrm{N}(\% \pm \mathrm{DP})\end{array}$ & $\begin{array}{c}\text { Blastocistos D7 } \\
\mathrm{N}(\% \pm \mathrm{DP})\end{array}$ & $\begin{array}{c}\text { Blstocistos D8 } \\
\mathrm{N}(\% \pm \mathrm{DP})\end{array}$ & $\begin{array}{c}\text { Blastocistos } \\
\text { Eclodidos em D8* } \\
\mathrm{N}(\% \pm \mathrm{DP})\end{array}$ \\
\hline CONT & 136 & $110(79,4 \pm 10,7)^{\mathrm{a}}$ & $52(37,9 \pm 8,5)^{\mathrm{b}}$ & $52(37,9 \pm 8,5)^{\mathrm{b}}$ & $13(9,0 \pm 6,1)^{\mathrm{c}}$ \\
\hline IMA & 97 & $78(82,2 \pm 12,0)^{\mathrm{a}}$ & $48(50,6 \pm 14,4)^{\mathrm{b}}$ & $49(51,4 \pm 13,9)^{\mathrm{b}}$ & $19(19,6 \pm 13,8)^{b}$ \\
\hline FSH & 128 & $111(86,3 \pm 10,3)^{\mathrm{a}}$ & $73(58,8 \pm 16,1)^{\mathrm{a}}$ & $75(60 \pm 15,5)^{\mathrm{a}}$ & $24(20,7 \pm 14,9)^{a b}$ \\
\hline MII & 212 & $176(83,6 \pm 14,8)^{\mathrm{a}}$ & $132(62,4 \pm 17,5)^{\mathrm{a}}$ & $133(62,7 \pm 17,2)^{\mathrm{a}}$ & $77(38,9 \pm 23,2)^{\mathrm{a}}$ \\
\hline CONT VIT & 101 & $25(25,7 \pm 5,6)^{\mathrm{b}}$ & $3(2,8 \pm 3,53)^{\mathrm{c}}$ & $4(3,6 \pm 4,8)^{\mathrm{c}}$ & $2(1,8 \pm 3,2)^{\mathrm{d}}$ \\
\hline IMA VIT & 92 & $15(16,4 \pm 7,2)^{\mathrm{c}}$ & $3(2,9 \pm 4,0)^{\mathrm{c}}$ & $3(2,9 \pm 4,0)^{\mathrm{c}}$ & $3(2,8 \pm 8,1)^{\mathrm{d}}$ \\
\hline FSH VIT & 111 & $18(14,5 \pm 8,92)^{\mathfrak{c}}$ & $4(4,3 \pm 7,2)^{\mathrm{c}}$ & $4(4,3 \pm 7,2)^{\mathrm{c}}$ & $1(3,6)^{\mathrm{cd}}$ \\
\hline MII VIT & 139 & $19(14,3 \pm 8,9)^{\mathrm{c}}$ & $5(3,6 \pm 7,2)^{\mathrm{c}}$ & $6(4,5 \pm 7,2)^{\mathrm{c}}$ & $5(3,5 \pm 2,1)^{\mathrm{cd}}$ \\
\hline
\end{tabular}


Tabela 4.5. Média e desvio padrão (DP) do tamanho $(\mu \mathrm{m})$ dos embriões em D8 e número total de células dos blastocistos > que $160 \mu \mathrm{m}$, derivados de ovócitos de diferentes condições de maturação: ovócitos obtidos por punção de ovários de abatedouro (CONT) ou por OPU, a partir de ovários de não fêmeas superestimuladas (IMA), fêmeas superestimuladas (FSH) e fêmeas superestimuladas que tinham recebido um indutor de ovulação (MII).

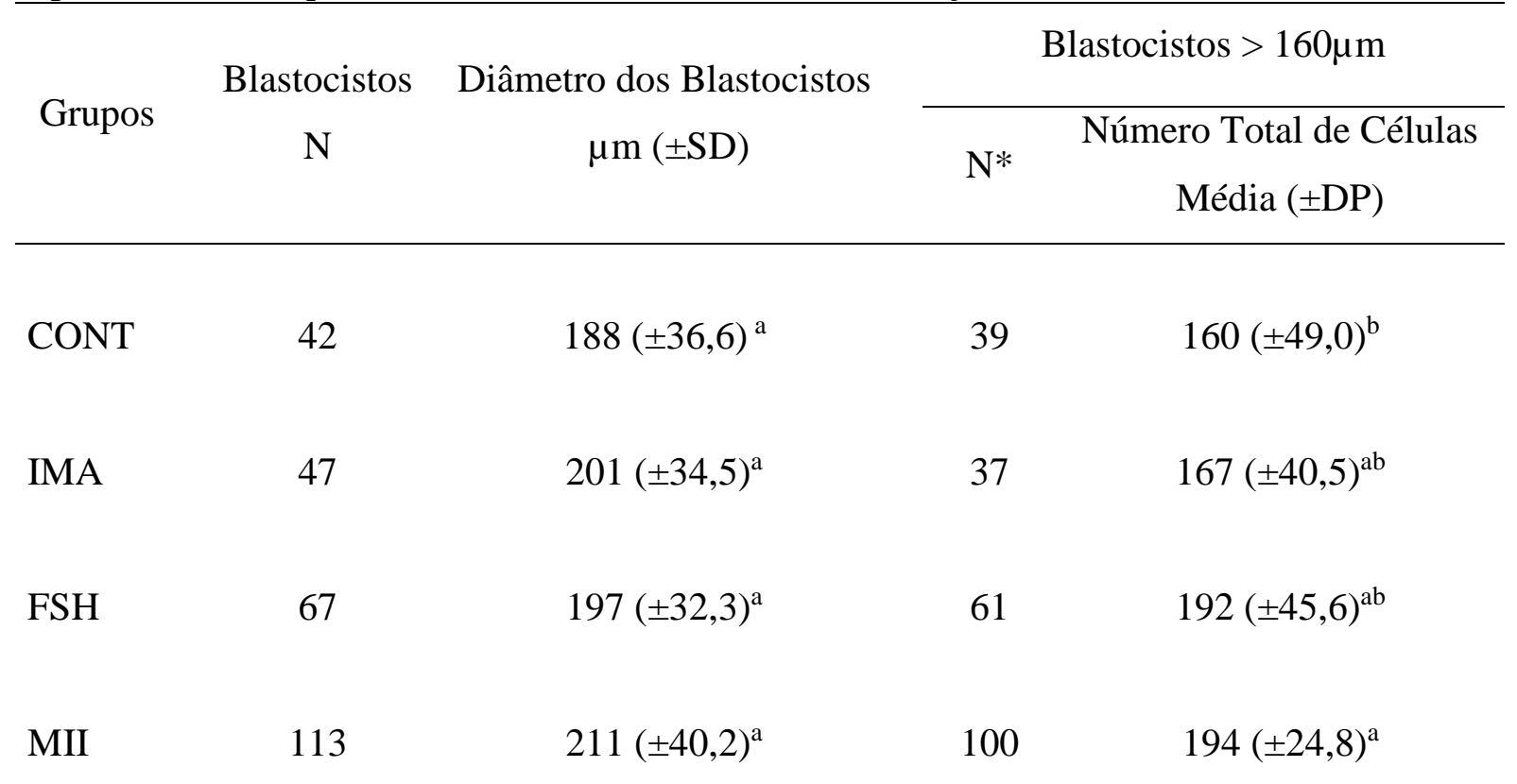

$\overline{\text { abcd }}$ Valores com letras diferentes nas mesmas colunas indicam resultados diferentes, segundo o teste de KruskalWallis $(\mathrm{P}<0,05)$,

CONT = ovócitos de ovários de abatedouro e maturados in vitro; IMA= ovócitos obtidos por OPU fêmeas não superestimuladas e maturados in vitro; $\mathrm{FSH}=$ ovócitos obtidos por OPU fêmeas superestimuladas e maturados in vitro; MII= ovócitos obtidos por OPU de fêmeas superestimuladas que receberam um indutor de ovulação e maturados in vivo.

*Representa os embriões os quais foram possíveis fazer a contagem do número total células, porque alguns embriões foram perdidos durante a coloração.

\subsubsection{Determinação do perfil de fosfolipídeos de membrana plasmáticas, em ovócitos} oriundos dos diferentes sistemas de maturação.

Os dados do perfil de fosfolipídio de cada ovócito após a análise de componentes principais (ACP) foram representadas num gráfico 2D (Figura 4.4). Esta análise foi capaz de explicar 65\% da variação dos dados, mas não foi capaz de descrever as diferenças entre os tratamentos. Para melhorar as análises, os dados foram representados numa ACP 3D, que foi capaz de explicar 73\% da variação (Figura 4.5). A análise de ACP, identificou aglomerados de alguns íons de 640,6, 760,6 e 782,6 m/z como sendo os mais dispersos ( $\mathrm{P}<0,05)$. A análise de variância, indicou que apenas o conjunto de íons de intensidade de $760,6 \mathrm{~m} / \mathrm{z}$, foi mais abundante $(\mathrm{P}<0,05)$ em ovócitos do grupo FSH, em comparação com ovócitos do grupo MII. De acordo com os dados publicados anteriormente (Ferreira et al., 2010), o cluster intensidade $760,6 \mathrm{~m} / \mathrm{z}$ corresponde a uma fosfatidilcolina [PC (34: 1) + H] + (Figura 4.6). 
a)

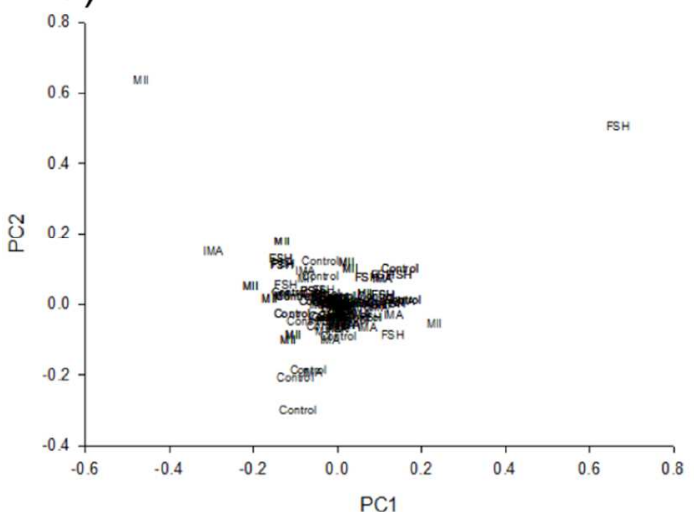

b)

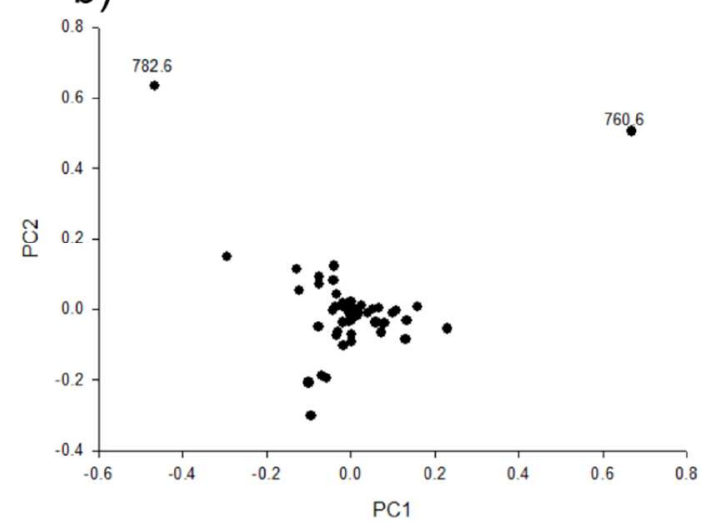

Figura 4.4- APC 2D para os dados de MALDI-TOF de único ovócito: a) CONT indica o perfil lipídico de ovócitos maturados in vitro, depois da punção de ovários de abatedouro $(\mathrm{n}=12)$; IMA- ovócitos obtidos por OPU de fêmeas não superestimuladas $(\mathrm{n}=13)$ e FSH, puncionados de fêmeas superestimuladas $(\mathrm{n}=13)$.

Também o perfil de ovócitos maturados in vivo, obtidos por OPU de fêmeas superestimuladas e que receberam um indutor da ovulação (MII, $\mathrm{n}=10$ ). b) indica os íons responsáveis pela diferença encontrada: 782,6; 760,4. Os componentes principais 2D foram capazes de explicar $>65 \%$ da variabilidade dos dados. 

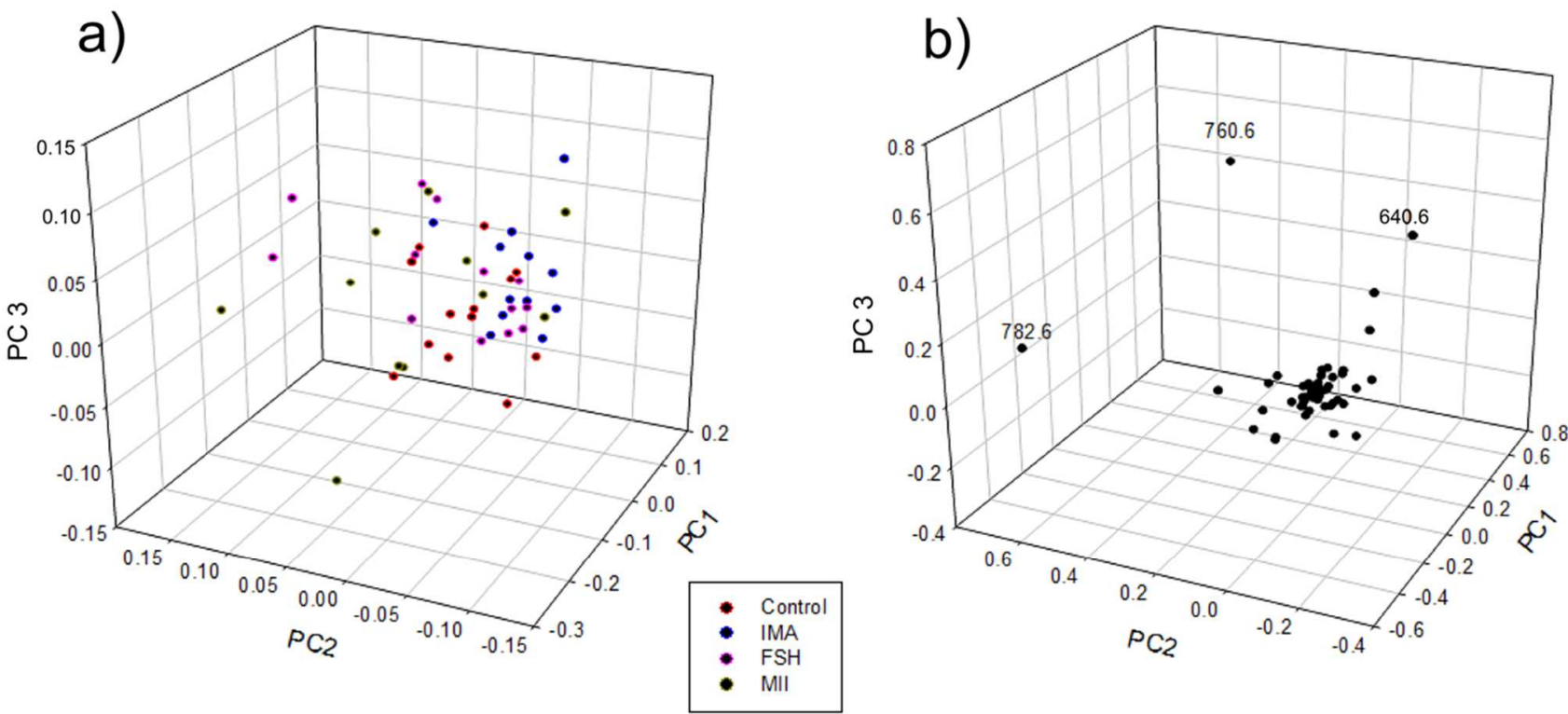

Figura 4.5- APC 3D para os dados de MALDI-TOF de único ovócito. a) vermelho $(\mathrm{n}=12)$, azul $(\mathrm{n}=13)$, rosa $(n=13)$ e amarelo escuro $(n=10)$ indica o resultados do APC 3D do perfil lipídico para ovócitos maturados in vitro imaturos e em recuperados de ovários de abatedouro (CONT), obtido por OPU de fêmeas não superestimuladas (IMA) e a partir de fêmeas superestimuladas (FSH) e de ovócitos maturados in vivo após OPU de fêmeas superovuladas que receberam um indutor da ovulação (MII), respectivamente; b) indica os principais íons apontados pelo APC: 782,6, 760,4 e 640,6 e que foram responsáveis pela maior variabilidade entre os tratamentos. O APC 3D foi capaz de explicar > 73\% da variabilidade entre os dados. 

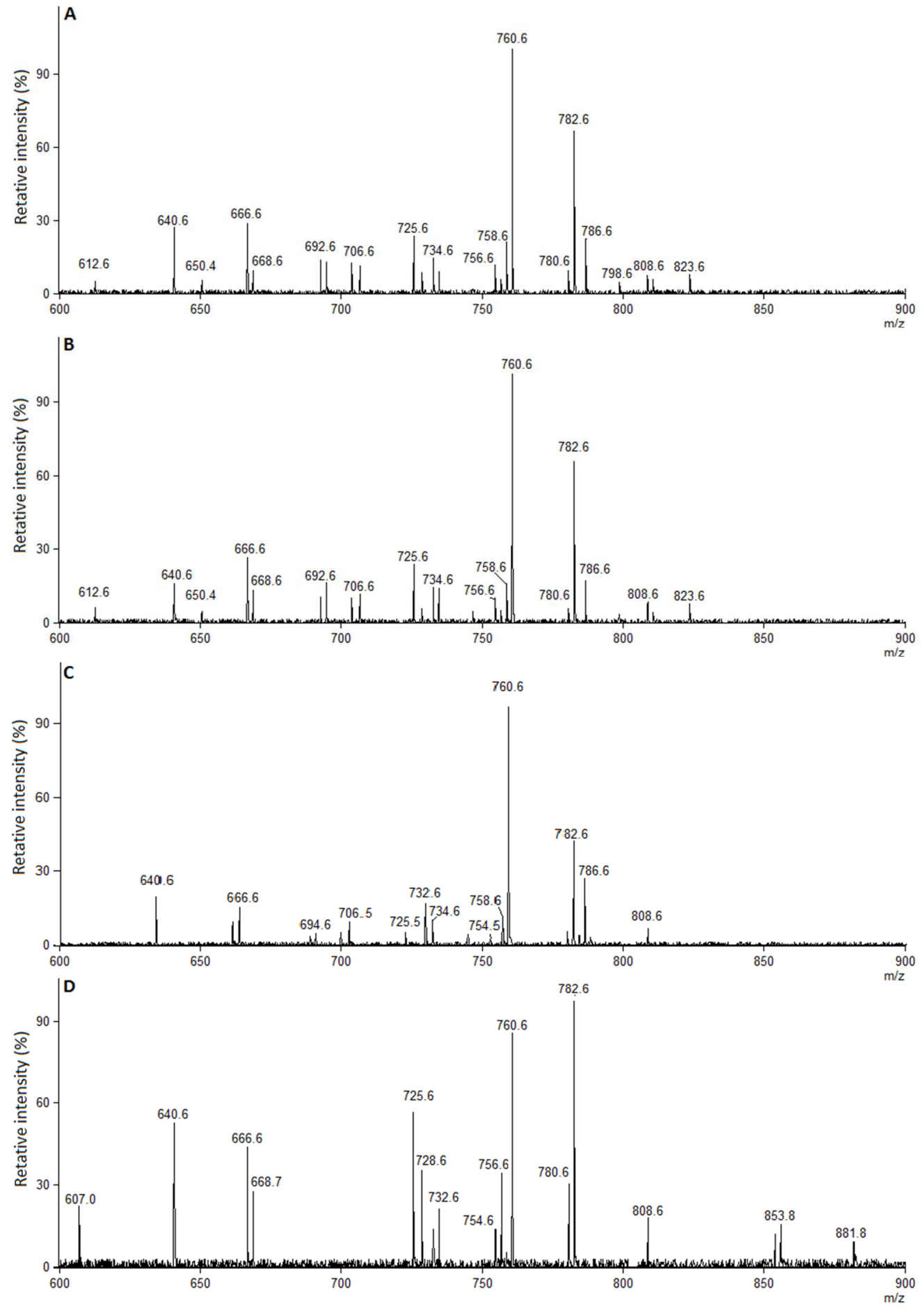

Figura 4.6- Espectros ilustrativos, adquiridos de um único ovócito maturado em diferentes sistemas, após MALDI-TOF, no modo de íons positivo. A intensidade apresentada é relativa a máxima obtida: (A) ovócitos de ovários de abatedouro maturados in vitro $(\mathrm{CONT} ; \mathrm{n}=12)$; (B) ovócitos recuperados por OPU de fêmeas não superestimuladas e maturados in vitro (IMA; $\mathrm{n}=13$ ); (C) ovócitos recuperados por OPU de fêmeas superestimuladas e maturados in vitro (FSH; $\mathrm{n}=13)$ e (D) ovócitos maturados in vivo (MII; $\mathrm{n}=10$ ). 


\subsection{Discussão}

Quando os resultados obtidos a partir da vitrificação de ovócitos humanos e bovinos são comparados (Kuwayama et al., 2005), uma enorme discrepância nas taxas de sobrevivência e na viabilidade entre estas duas espécies são observadas (Zhou et al., 2010; Chang et al., 2013). Um dos fatores que pode conferir maior crioresistência ao ovócito de humano é o sistema no qual este é maturado. Em humanos, os ovários são superstimulados, e os ovócitos maturados in vivo são recuperados por OPU (Chang et al., 2008; Chang et al., 2013). Em contrapartida a maturação de ovócitos bovinos, ocorre in vitro, as fêmeas não são submetidas a um tratamento hormonal (Guerreiro et al., 2014).

Baseado nestas observações, a nossa hipótese foi que ovócitos maturados in vivo, que teoricamente são de melhor qualidade do que ovócitos maturados in vitro, seriam mais resistentes a criopreservação e este sistema poderia resultar num aumento do desenvolvimento embrionário após o aquecimento e fecundação e cultivo in vitro.

Visto que a maioria dos sistemas de maturação in vivo para ovócitos bovinos relatados foram desenvolvidos para Bos taurus (Rizos et al., 2002; Mamo et al., 2011; CoyralCastel et al., 2012), foi necessário confirmar se esses protocolos também seriam capazes de produzir um ovócito em metáfase II (MII) em animais Bos indicus. Um experimento prévio foi conduzido para determinar qual seria o melhor momento para realizar a OPU, se as 20 ou 24 horas após o GnRH. Com base nos resultados desse pré-experimento, definimos que o momento ideal para se recuperar ovócitos maturados in vivo, seria as 24 horas após a administração de GnRH.

Independentemente do tratamento utilizado, o número de folículos presentes nos ovários, no momento da OPU foi de aproximadamente 20, o que está de acordo com observações publicadas em raças Bos indicus (Silva-Santos et al., 2014). A diferença entre os animais que foram ou não foram superestimuladas com FSH foi evidente, quando se considera o tamanho dos folículos visíveis. Animais superstimulados apresentaram maior percentagem de folículos maiores do que $6 \mathrm{~mm}$ de diâmetro, em comparação com animais não superestimuladas. No entanto, o número de folículos foi similar entre os dois grupos. Este resultado está em desacordo com os dados reportados por Blondin et al. (2002), onde as fêmeas da raça Holandesa apresentaram aumento do diâmetro e número folicular após a estimulação com FSH. Essas diferenças na população folicular são possivelmente devido a particularidades de cada subespécie, como o nosso estudo foi realizado utilizando animais da raça Nelore (Bos 
taurus indicus) que têm uma população folicular maior em comparação com raças Bos Taurus (Batista et al., 2014).

A hipótese de que a maior vascularização de sangue no folículo indica proximidade da ovulação (Matsui et al., 2009), foi testado quando fizemos o ultrassom dos ovários momentos antes à OPU utilizando o Color Doppler. A maioria dos folículos presentes em animais que receberam GnRH (grupo MII) mostraram vascularização intensa de sangue, enquanto que no grupo apenas superovulados (FSH), a maioria dos folículos apresentaram vascularização moderada. Nos animais não estimuladas (grupo IMA), a vascularização de sangue no folículo estava ausente. Esta informação pode ser utilizada como uma ferramenta para indicar os folículos que estão mais próximos da ovulação e dessa forma assegurar que os ovócitos maturados in vivo podem ser recuperados quando os folículos maiores, com vascularização intensa de sangue são aspirados.

Inesperadamente, a percentagem de ovócitos viáveis no grupo MII foi semelhante ao que foi observado para o grupo IMA. No entanto, deve notar-se que no grupo MII, apenas os ovócitos que foram consideradas como maturados in vivo foram classificados como viáveis. O método mais preciso para classificar se um ovócito está maturo é pela visualização da extrusão do primeiro corpo polar. No entanto, em ovócitos bovinos, isso exigiria a remoção completa das células cumulus (Mamo et al., 2011), o que requer mais tempo de manipulação e este procedimento poderia afetar a viabilidade destes ovócitos (Taylor et al., 2008). Portanto, para evitar qualquer dano, optamos por não remover as células do cumulus, e para garantir que nós só utilizaríamos ovócitos viáveis e maturados, só consideramos os CCOs com células cumulus expandidas /ou a presença do corpúsculo polar visível. Assim, alguns ovócitos viáveis podem ter sido excluídos.

Em seguida, avaliamos o desenvolvimento embrionário de ovócitos maturados nos diferentes sistemas, vitrificados ou não. Como controle para nosso sistema de produção de embriões, outro grupo foi incluído, este constituído de ovócitos obtidos a partir de ovários de abatedouro e maturados in vitro. Corroborando com resultados descritos na literatura, observouse que as taxas de blastocistos foram maiores para ovócitos obtidos de fêmeas superestimuladas (Blondin et al., 2002; Rizos et al., 2002), em comparação com aqueles puncionados das fêmeas não estimuladas ou a partir de ovários de abatedouro. Os embriões do grupo CONT tinham números de células mais baixos comparado aos embriões do grupo MII. Estas observações podem estar relacionadas com a maior heterogeneidade de animais abatidos, onde a alimentação e a idade não puderam ser controladas. Também, a taxa de eclosão em D8, um parâmetro de 
qualidade, foi menor em blastocistos produzidos a partir de ovários de abatedouro do que os obtidos a partir de OPU, refletindo o efeito do ovócito na qualidade final dos embriões.

O desenvolvimento ao estágio de blastocisto e eclosão foram maiores em ovócitos que haviam sido expostos ao FSH (FSH e MII) em relação aqueles que não foram expostos (CONT e IMA). De acordo com Rizos et al. (2002), Dieleman et al. (2002) e van de Leemput et al. (1999), a maturação in vivo é o "gold standard" para a maturação de ovócitos, sendo o sistema ideal para a produção de ovócitos de qualidade superior, em comparação com sistemas de maturação in vitro. Apesar desses estudos, não encontramos diferenças no desenvolvimento de embriões, porcentagem de eclosão ou número total de células, em blastocistos D8, em ovócitos maturados in vivo (grupo MII) comparados a ovócitos maturados in vitro, provenientes de novilhas superestimuladas (grupo FSH). Em relação aos ovócitos imaturos que devem ser maturados in vitro, Blondin et al. (2002) demonstraram que a superestimulação com FSH pode aumentar a qualidade dos ovócitos, resultando em melhor desenvolvimento do embrião. Tem sido proposto que, durante a fase de dominância folicular em um ovário não estimuladado com hormônios, o folículo dominante vai suprimir a aquisição da capacidade de desenvolvimento dos CCO inclusos nos folículos subordinados (Hagemann, 1999). A perda da dominância quando se lança mão da supertimulação pode aumentar a competência de desenvolvimento dos CCOs de todos os folículos antrais. Nosso trabalho é o primeiro estudo a usar animais Bos indicus para comparar no mesmo experimento diferentes sistemas de maturação. Os nossos resultados sugerem que a administração de GnRH induz um aumento repentino de $\mathrm{LH}$, e este ambiente folicular é necessário para desencadear a retomada da meiose pelos CCOs, levando a completa maturação citoplasmática e nuclear, resultando em ovócitos competentes e capazes de suportar a fecundação e desenvolvimento embrionário após a FIV (Blondin et al., 2002; Humblot et al., 2005).

Embora esperava-se que ovócitos maturados in vivo mostrariam desenvolvimento embrionário superior ao daqueles maturados in vitro, os resultados não mostraram exatamente o esperado. Isso porque a diferença na qualidade do ovócito foi muito clara entre os grupos que foram expostos (FSH e MII) e não expostos (IMA e CONT) ao FSH, e essas duas populações foram essenciais para testar a nossa hipótese principal que ovócitos de melhor qualidade seriam mais resistente a vitrificação/aquecimento. Nossos resultados mostraram que a melhoria da qualidade do ovócito não resultou no aumento da resistência à criopreservação. O desenvolvimento embrionário de ovócitos bovinos vitrificados não foi superior a 5\%, mesmo para aqueles derivados de condições in vivo. No entanto, estes resultados estão de acordo com outros relatos (Vieira et al., 2002; Zhou et al., 2010; Spricigo et al., 2012). 
Os melhores resultados foram publicados por Zhou et al. (2010), com 10\% de desenvolvimento de blastocisto após a vitrificação de ovócitos bovinos. Nosso grupo já havia descrito taxas de desenvolvimento semelhantes às observadas no presente estudo (Spricigo et al., 2012). Apesar de ambos os estudos terem sido realizados utilizando a metodologia Cryotop, esta discrepância pode ser devido à diferentes subespécies de animais utilizadas.

O ovócito é uma célula com peculiaridades em áreas como armazenamento de triglicerídeos e composição fosfolipídica que podem desempenhar papéis importantes em sua resistência a vitrificação / aquecimento (Men et al., 2006; Sudano et al., 2011; Chankitisakul et al., 2013). Devido à importância da fluidez da membrana plasmática para a resistência à criopreservação, Zeron et al. (2002), Horvath et al.(2006) e nosso grupo (Spricigo et al., 2012) investigaram metodologias para alterar a composição da membrana plasmática. Sudano et al. (2012) demonstraram que a composição de fosfolipídeos de membrana pode ser modificado, dependendo da composição dos meios de cultura ou se o embrião é produzido in vivo ou in vitro. Devido a estes achados, o presente estudo também teve como objetivo determinar se o sistema de maturação afeta a composição fosfolipídica da membrana de ovócitos bovinos pela análise de MALDI-TOF. Apesar da diferença observada ocasionalmente na fosfatidilcolina [PC $(34: 1)+\mathrm{H}]^{+}$entre ovócitos dos grupos MII e FSH, o sistema de maturação não alterou o perfil de fosfolipídeos de ovócitos de fêmeas Nelore. Para este íon já foram relatadas diferenças de expressão dependendo da subespécie e/ou origem, quando embriões foram analisados (Sudano et al., 2012). Este é menos abundante em Nelore do que em Simental e menos abundante em embriões produzidos vivo comparados aos in vitro. Este FL tem uma grande cadeia de carbono e apenas uma instauração, estas duas características conferem maior rigidez a MP, consequentemente menor permeabilidade celular durante o processo de criopreservação (Ferreira et al., 2010). No entanto, não foi possível correlacionar as alterações detectadas em ovócitos com a sua origem, nem com a sua capacidade de desenvolvimento embrionário após criopreservação. Portanto, é possível que o sistema não foi capaz alterar a fluidez da membrana de forma eficiente ou talvez a mudança na MP não seja a principal responsável pelos danos causados aos ovócitos durante a vitrificação e aquecimento. 


\section{CONCLUSÕES}

Os resultados mostraram que, apesar do sistema de maturação in vivo produzir ovócito altamente competentese alterar a composição lipídica da membrana plasmática quando comparado a ovócitos maturados in vitro de animais superestimulados, esse sistema não aumentou o desenvolvimento embrionário, após a vitrificação de ovócitos bovinos. 


\section{REFERÊNCIAS BIBLIOGRÁFICAS}

ANCHAMPARUTHY VM ;DHALI A ;LOTT WM ;PEARSON RE ;GWAZDAUSKAS FC. Vitrification of bovine oocytes: implications of follicular size and sire on the rates of embryonic development. Journal of assisted reproduction and genetics, v. 26,p. 613-619, 2009.

APPARICIO M ;FERREIRA CR ;TATA A ;SANTOS VG ;Alves AE ;MOSTACHIO GQ ;PIRESBUTLER EA ;MOTHEO TF ;PADILHA LC ;PILAU EJ ;GOZZO FC ;EBERLIN MN ;LO TURCO EG ;LUVONI GC ;VICENTE WR. Chemical composition of lipids present in cat and dog oocyte by matrix-assisted desorption ionization mass spectrometry (MALDI- MS). Reproduction in domestic animals = Zuchthygiene, v. 47 Suppl 6,p. 113-117, 2012.

BATISTA EO ;MACEDO GG ;SALA RV ;ORTOLAN MD ;SA FilHo MF ;DEL VALLE TA ;Jesus EF ;LOPES RN ;RENNO FP ;BARUSELLI PS. Plasma antimullerian hormone as a predictor of ovarian antral follicular population in Bos indicus (Nelore) and Bos taurus (Holstein) heifers. Reproduction in domestic animals = Zuchthygiene, v. 49,p. 448-452, 2014.

BLONDIN P ;BOUSQUET D ;TwAGIRAMUNGU H ;BARNES F ;SIRARD MA. Manipulation of follicular development to produce developmentally competent bovine oocytes. Biology of reproduction, v. 66,p. 38-43, 2002.

Chamayou S ;Bonaventura G ;Alecci C ;Tibullo D ;Di Raimondo F ; Guglielmino A ;BARCELLONA ML. Consequences of metaphase II oocyte cryopreservation on mRNA content. Cryobiology, v. 62,p. 130-134, 2011.

Chang CC ;Elliott TA ;Wright G ;Shapiro DB ;Toledo AA ;NAGy ZP. Prospective controlled study to evaluate laboratory and clinical outcomes of oocyte vitrification obtained in in vitro fertilization patients aged 30 to 39 years. Fertility and sterility, v. 99,p. 18911897, 2013.

CHANG CC ;SHAPIRO DB ;BERNAL DP ;WRIGHT G ;KORT HI ;NAGY ZP. Human oocyte vitrification: in-vivo and in-vitro maturation outcomes. Reproductive biomedicine online, $v$. 17,p. 684-688, 2008.

ChankitisaKul V ;SOMFAi T ;InABa Y ;TECHAKUMPhU M ;NAGAi T. Supplementation of maturation medium with L-carnitine improves cryo-tolerance of bovine in vitro matured oocytes. Theriogenology, v. 79,p. 590-598, 2013. 
CHIAN RC ;HUANG JY ;GILBERT L ;SON WY ;HOLZER H ;CUI SJ ;BUCKETT WM ;TULANDi T ;TAN SL. Obstetric outcomes following vitrification of in vitro and in vivo matured oocytes. Fertility and sterility, v. 91,p. 2391-2398, 2009.

COYRAL-CASTEL S ;BRISARD D ;TOUZE JL ;DUPONT M ;RAME C ;UZBEKOVA S ;DUPONT J. Analysis of in vivo oocyte maturation, in vitro embryo development and gene expression in cumulus cells of dairy cows and heifers selected for one fertility quantitative trait loci (QTL) located on BTA3. Theriogenology, v. 77,p. 1822-1833 e1821, 2012.

DALVIT G ;Llanes SP ;DESCALZO A ;InSANi M ;BECONI M ;CETICA P. Effect of alphatocopherol and ascorbic acid on bovine oocyte in vitro maturation. Reproduction in domestic animals = Zuchthygiene, v. 40,p. 93-97, 2005.

DIELEMAN SJ ;HENDRIKSEN PJ ; VIUFF D ;THOMSEN PD ; HYTTEL P ;KNIJN HM ;WRENZYCKI C ;KRUIP TA ;NIEMANN H ;GADELLA BM ;BEVERS MM ;VOS PL. Effects of in vivo prematuration and in vivo final maturation on developmental capacity and quality of preimplantation embryos. Theriogenology, v. 57,p. 5-20, 2002.

EDIDIN M. Lipids on the frontier: a century of cell-membrane bilayers. Nature reviews. Molecular cell biology, v. 4,p. 414-418, 2003.

FERREIRA CR ;SARAIVA SA ;CATHARINO RR ;GARCIA JS ;GOZZO FC ;SANVIDO GB ;SANTOS LF ;LO TURCO EG ;PONTES JH ;BASSO AC ;BERTOLLA RP ;SARTORI R ;GUARDIEIRO MM ;PERECIN F ;MEIRELLES FV ;SANGALLI JR ;EBERLIN MN. Single embryo and oocyte lipid fingerprinting by mass spectrometry. Journal of lipid research, v. 51,p. 1218-1227, 2010.

FERREIRA CR ;SOUZA GH ;RICCIO MF ;CATHARINO RR ;PONTES JH ;BASSO AC ; JUNIOR JC ;PERECIN F ;EBERLIN MN. Mass spectrometry fingerprinting of media used for in vitro production of bovine embryos. Rapid communications in mass spectrometry : RCM, v. 23,p. 1313-1320, 2009.

GUERREIRO BM ;BATISTA EO ;VIEIRA LM ;SA FILHO MF ;RODRIGUES CA ;CASTRO NeTTO A ;SILVEIRA CR ;BAYEUX BM ;DIAS EA ;MONTEIRO FM ;ACCORSI M ;LOPES RN ;BARUSELLI PS. Plasma anti-mullerian hormone: an endocrine marker for in vitro embryo production from Bos taurus and Bos indicus donors. Domestic animal endocrinology, v. 49,p. 96-104, 2014.

HAGEMANN LJ. Influence of the dominant follicle on oocytes from subordinate follicles. Theriogenology, v. 51,p. 449-459, 1999.

Holm P ;Booth PJ ;SCHMIDT MH ;GREVE T ;CALLESEN H. High bovine blastocyst development in a static in vitro production system using SOFaa medium supplemented with sodium citrate and myo-inositol with or without serum-proteins. Theriogenology, v. 52,p. 683-700, 1999.

HoRVATH G ;SEIDEL GE, JR. Vitrification of bovine oocytes after treatment with cholesterolloaded methyl-beta-cyclodextrin. Theriogenology, v. 66,p. 1026-1033, 2006.

HUMBLOT P ;HOLM P ;LONERGAN P ;WRENZYCKI C ;LEQUARRE AS ;JOLY CG ;HERRMANN D ;LOPES A ;RIZOS D ;NIEMANN H ;CALLESEN H. Effect of stage of follicular growth during 
superovulation on developmental competence of bovine oocytes. Theriogenology, v. 63,p. 1149-1166, 2005.

KUWAYAMA M ;VAJTA G ;KATO O ;LEIBO SP. Highly efficient vitrification method for cryopreservation of human oocytes. Reproductive biomedicine online, v. 11,p. 300-308, 2005.

MACHADO GM ;CARVALHO JO ;FILHO ES ;CAIXETA ES ;FRANCO MM ;RUMPF R ;DODE MA. Effect of Percoll volume, duration and force of centrifugation, on in vitro production and sex ratio of bovine embryos. Theriogenology, v. 71,p. 1289-1297, 2009.

MAMO S ;CARTER F ;LONERGAN P ;LEAL CL ;Al NAIB A ;MCGETTIGAN P ;MEHTA JP ;Evans AC ;FAIR T. Sequential analysis of global gene expression profiles in immature and in vitro matured bovine oocytes: potential molecular markers of oocyte maturation. BMC genomics, v. 12,p. 151, 2011.

MAtsui M ; MiYAmoto A. Evaluation of ovarian blood flow by colour Doppler ultrasound: practical use for reproductive management in the cow. Veterinary journal, v. 181,p. 232240, 2009.

MceVoy TG ;COUll GD ;BROAdBEnT PJ ;Hutchinson JS ;SPeAKE BK. Fatty acid composition of lipids in immature cattle, pig and sheep oocytes with intact zona pellucida. Journal of reproduction and fertility, v. 118,p. 163-170, 2000.

MEN H ;AGCA Y ;CRITSER ES ;CRITSER JK. Beneficial effects of serum supplementation during in vitro production of porcine embryos on their ability to survive cryopreservation by open pulled straw vitrification. Theriogenology, v. 64,p. 1340-1349, 2005.

MEN H ;AGCA Y ;RILEY LK ;CRITSER JK. Improved survival of vitrified porcine embryos after partial delipation through chemically stimulated lipolysis and inhibition of apoptosis.

Theriogenology, v. 66,p. 2008-2016, 2006.

MOAWAD AR ;TAN SL ;XU B ;CHEN HY ;TAKETO T. L-carnitine supplementation during vitrification of mouse oocytes at the germinal vesicle stage improves preimplantation development following maturation and fertilization in vitro. Biology of reproduction, $v$. 88,p. 104, 2013.

MORATO R ;IZQUIERDO D ;PARAMIO MT ;MOGAS T. Cryotops versus open-pulled straws (OPS) as carriers for the cryopreservation of bovine oocytes: effects on spindle and chromosome configuration and embryo development. Cryobiology, v. 57,p. 137-141, 2008a.

MORATO R ;IZQUIERDO D ;PARAMIO MT ;MOgAS T. Embryo development and structural analysis of in vitro matured bovine oocytes vitrified in flexipet denuding pipettes.

Theriogenology, v. 70,p. 1536-1543, 2008b.

MORATO R ;MOGAS T ; MADDOX-HYTTEL P. Ultrastructure of bovine oocytes exposed to Taxol prior to OPS vitrification. Molecular reproduction and development, v. 75,p. 13181326, 2008c. 
NIEDERMEYER TH ;STROHALM M. mMass as a software tool for the annotation of cyclic peptide tandem mass spectra. PloS one, v. 7,p. e44913, 2012.

PARRISH JJ ;KROGENAES A ;SUSKO-PARRISH JL. Effect of bovine sperm separation by either swim-up or Percoll method on success of in vitro fertilization and early embryonic development. Theriogenology, v. 44,p. 859-869, 1995.

RIZOS D ; WARD F ;DUFFY P ;BOLAND MP ;LONERGAN P. Consequences of bovine oocyte maturation, fertilization or early embryo development in vitro versus in vivo: implications for blastocyst yield and blastocyst quality. Molecular reproduction and development, v. 61,p. 234-248, 2002.

SHIRAZI A ;TAHERI F ;NAZARI H ;NORBAKHSH-NIA M ;AHMADI E ;HEIDARI B. Developmental competence of ovine oocyte following vitrification: effect of oocyte developmental stage, cumulus cells, cytoskeleton stabiliser, FBS concentration, and equilibration time. Zygote, p. $1-9,2012$.

Silva-Santos K ;FERreira C ;SANTOS G ;Eberlin M ;Siloto L ;Rosa C ;MARCANTONio T ;SENEDA M. MALDI-MS Lipid Profiles of Oocytes Recovered by Ovum Pickup from Bos indicus and 1/2 indicus $x$ taurus with High vs Low Oocyte Yields. Reproduction in domestic animals = Zuchthygiene, v. 49,p. 711-718, 2014.

SPRICIGO JF ;MORAIS KS ;YANG BS ;DODE MA. Effect of the exposure to methyl-betacyclodextrin prior to chilling or vitrification on the viability of bovine immature oocytes. Cryobiology, v. 65,p. 319-325, 2012.

SUdANO MJ ;PASCHOAL DM ;RASCAdO TdA S ;MAGALHAES LC ;CROCOMO LF ;DE LIMANETO JF ;LANDIM-ALVARENGA FDA C. Lipid content and apoptosis of in vitro-produced bovine embryos as determinants of susceptibility to vitrification. Theriogenology, v. 75,p. 1211-1220, 2011.

SUdANO MJ ;SANTOS VG ;TATA A ;FERREIRA CR ;PASCHOAL DM ;MACHAdO R ;BURATINI J ;EBERLIN MN ;LANDIM-ALVARENGA FD. Phosphatidylcholine and sphingomyelin profiles vary in Bos taurus indicus and Bos taurus taurus in vitro- and in vivo-produced blastocysts. Biology of reproduction, v. 87,p. 130, 2012.

TAYlOR TH ;ChANG CC ;ElliotT T ;COLTURATO LF ;KORT HI ;NAGY ZP. Effect of denuding on polar body position in in-vitro matured oocytes. Reproductive biomedicine online, $\mathrm{v}$. 17,p. 515-519, 2008.

TESFAYE D ;GHANEM N ;CARTER F ;FAIR T ;SIRARD MA ;HOELKER M ;SCHELlANDER K ;LONERGAN P. Gene expression profile of cumulus cells derived from cumulus-oocyte complexes matured either in vivo or in vitro. Reproduction, fertility, and development, $v$. 21,p. 451-461, 2009.

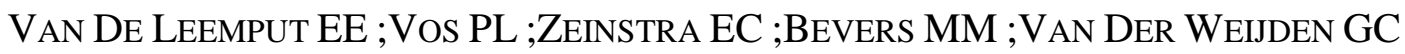
;DIELEMAN SJ. Improved in vitro embryo development using in vivo matured oocytes from heifers superovulated with a controlled preovulatory LH surge. Theriogenology, v. 52,p. 335349, 1999. 
VIEIRA AD ;MEZZALIRA A ;BARBIERI DP ;LEHMKUHL RC ;RUBIN MI ;VAJTA G. Calves born after open pulled straw vitrification of immature bovine oocytes. Cryobiology, v. 45,p. 91-94, 2002.

ZERON Y ;SKLAN D ;ARAV A. Effect of polyunsaturated fatty acid supplementation on biophysical parameters and chilling sensitivity of ewe oocytes. Molecular reproduction and development, v. 61,p. 271-278, 2002.

ZHOU XL ;AL NAIB A ;SUN DW ;LONERGAN P. Bovine oocyte vitrification using the Cryotop method: effect of cumulus cells and vitrification protocol on survival and subsequent development. Cryobiology, v. 61,p. 66-72, 2010. 


\section{CAPÍtUlO 5}

\section{TRANSFERÊNCIA INTRAFOLICULAR DE OVÓCITOS FRESCOS OU VITRIFICADOS: UMA OPÇÃO PARA A PRODUÇÃO DE EMBRIÕES IN VIVO}

José Felipe W. Sprícigo ${ }^{1}$; Severino B. Sena Netto ${ }^{1}$; Carolle V. Muterlle ${ }^{1}$; Sara A. D. Rodrigues $^{1}$; Ligiane O. Leme ${ }^{1}$; Ana Luiza Guimarães ${ }^{1}$; Maurício M. Franco ${ }^{2}$; Ivo Pivato. ${ }^{1}$; Margot Alves Nunes Dode ${ }^{2}$.

${ }^{1}$ Programa de Pós-Graduação em Ciências Animais, Faculdade de Agronomia e Medicina Veterinária, Universidade de Brasília, UnB, Brasília, DF, Brasil;

${ }^{2}$ Embrapa Recursos Genéticos e Biotecnologia, Laboratório de Reprodução Animal, Brasília, DF, Brasil. 


\section{RESUMO}

Embora a transferência intrafolicular de ovócitos (TIFOI) ter sido relatada para ovócitos maturados in vitro, a produção de um grande número de embriões sem a necessidade de hormônios ou qualquer instalação de laboratório, só pode ser obtida se forem utilizados ovócitos imaturos. Tivemos como objetivo (i) avaliar a viabilidade da TIFOI utilizando ovócitos imaturos (IFIOT) e (ii) comparar o desenvolvimento embrionário de ovócitos imaturos frescos e vitrificados. Primeiro, 6 injeções foram realizadas utilizando ovócitos imaturos obtidos pela ovum pick up (OPU) de animais da raça Gir. A taxa de recuperação total foi de $26 \%, 39 \%$ dos quais eram embriões viáveis. Após a transferência do embrião $(\mathrm{n}=11)$, foram obtidas 4 prenhes. No segundo experimento, metade dos COCs de ovários de abatedouro foram vitrificados por cryotop. Distribuídos em quatro grupos: 1) COCs imaturos frescos (VitroCont); 2) vitrificados COCs imaturos (Vitro-VIT), com ambos os grupos 1 e 2 sendo maturados, fecundados e cultivados in vitro; 3) COCs imaturos frescos submetidos a TIFOI (Vivo-Cont); e 4) vitrificados COCs imaturos submetidos a TIFOI (Vivo-Vit). Os COCs $(n=25)$ nos grupos Vit-Vivo Cont-Vivo ou foram injetados em folículos dominantes (>10 mm) de novilhas sincronizadas, que foram submetidas à inseminação artificial e lavagem uterina, 7 dias depois. As taxas de recuperação foram maiores ( $\mathrm{P}<0,05)$ para Cont $(52,1 \%)$ do que para Vit $(18,0 \%)$. O desenvolvimento embrionário também foi maior para Vitro (42\%) e Vivo (32\%) do que para os grupos vitrificados (Vitro $=6 \%$; Vivo $=13 \%)$. Este é o primeiro relato que embriões viáveis e prenhezes foram produzidos após TIFOI. Embora nenhuma melhora no desenvolvimento embrionário foi obtida utilizando ovócitos vitrificados, a técnica de TIFOI pode ser uma opção para a produção de embriões de bovino.

Palavras chaves: bovino, ovócito, vitrificação, maturação in vivo. 


\section{ABSTRACT}

Although intra-follicular oocyte transfer (IFOT) has been reported using in vitro matured oocytes, production of large numbers of embryos without requiring any hormones or any lab facility can are only possible if immature oocytes are used. We aimed to (i) evaluate the viability of IFOT using immature oocytes (IFIOT) and (ii) compare the embryo development of fresh and vitrified immature oocytes using IFIOT. First, 6 IFIOTs were performed using immature oocytes obtained by ovum pick up (OPU). The total recovery rate was $26 \%, 39 \%$ of which were viable embryos. After embryo transfer $(n=11), 4$ pregnancies were obtained. Second, COCs from slaughterhouse ovaries were vitrified by cryotop. Four groups were used: 1) fresh immature COCs (Vitro-Cont); 2) vitrified immature COCs (VitroVit), with both groups 1 and 2 being matured, fertilized and cultured in vitro; 3) fresh immature COCs submitted to IFIOT (Vivo-Cont); and 4) vitrified immature COCs submitted to IFIOT (Vivo-Vit). COCs ( $\mathrm{n}=25)$ from the Cont-Vivo or Vit-Vivo groups were injected into dominant follicles (>10 mm) of synchronized heifers, which were submitted to artificial insemination and uterine flushing 7 days later. The recovery rates were higher $(\mathrm{P}<0.05)$ for Cont $(52.1 \%)$ than for Vit (18.0\%). Blastocyst yield was also higher for Vitro (42\%) and Vivo (32\%) controls than for the vitrified groups (Vitro $=6 \%$; Vivo $=13 \%$ ). This is the first report that viable embryos and pregnancies were produced after IFIOT. Although no improvement in embryo development has been obtained using vitrified oocytes, the IFIOT technique may be an option for bovine embryo production.

Key words: follicular injection; in vivo; in vitro; blastocyst. 


\section{INTRODUÇÃO}

A capacidade de preservar gametas femininos é um procedimento essencial para as técnicas de reprodução assistida (TRAs), já que possibilita disponibilizar os gametas para serem utilizados no momento e condição mais oportunos. Além disso, essa técnica tem um grande impacto na formação de bancos de germoplasma tanto de animais de produção como de conservação e na preservação da fertilidade humana (Kuwayama et al., 2005; Zhou et al., 2010).

Até o momento, a capacidade de ovócitos criopreservados de serem fecundados e de apresentarem desenvolvimento embrionário é insatisfatória na maioria dos animais domésticos. Esta alta sensibilidade dos ovócitos para a criopreservação pode ser explicada pelas suas características morfológicas e funcionais únicas, tais como o tamanho da célula, o volume de água, a organização do citoplasma e do citoesqueleto (Vieira et al., 2002; Men et al., 2005; Horvath et al., 2006; Morato et al., 2008a; b; Anchamparuthy et al., 2009; Chamayou et al., 2011; Shirazi et al., 2012). Portanto, os ovócitos criopreservados sofrem graves danos morfológicos e funcionais, especialmente nos animais domésticos, devido ao alto teor de lípidos no citoplasma e a composição de fosfolípidos de membrana (Mcevoy et al., 2000).

Na última década, muitos esforços têm sido feitos no sentido de aumentar a eficiência de vitrificação de ovócitos de animais domésticos (Vieira et al., 2002; Kuwayama et al., 2005). Já foram testadoso uso de agentes estabilizadores para o citoesqueleto (Morato et al., 2008c), de antioxidantes (Dalvit et al., 2005), de agentes lipolíticos (Men et al., 2006; Moawad et al., 2013) e de modificadores da membrana de plasmática (PM) (Horvath et al., 2006; Spricigo et al., 2012), entretanto nenhuma melhora significativa tem sido obtida.

O ovócito é a maior célula em mamíferos e, portanto é muito afetado pela criopreservação, pois durante esse processo as moléculas de água organizam-se e formam cristais de gelo, ocasionando muitas lesões para a célula (Leibo, 2008). Mesmo durante a vitrificação, em que não ocorre a formação de cristais de gelo, as trocas de fluídos entre os 
meio intra e extracelulares induzem a instabilidade da membrana plasmática (Horvath et al., 2006).

Apesar de não haver diferença no diâmetro dos ovócitos de bovinos e humanos (Van Den Hurk et al., 2005) a produção de embriões a partir de ovócitos vitrificados é significativamente diferente entre essas duas especies. Enquanto em humanos as taxas de embriões são semelhante as obtidas a partir de ovócitos frescos, e estão em média de 50\% (Chang et al., 2008), em bovinos essas nao ultrapassam 10\% (Zhou et al., 2010; Spricigo et al., 2014; Arcarons et al., 2015; Spricigo et al., 2015). Estas observações indicam que o tamanho celular pode não ser o problema mais crítico na vitrificação de ovócitos. Estudos em nosso laboratório testaram a hipótese de que o ambiente onde a maturacao ocorre é um importante fator para a qualidade do ovócito e, consequentemente estaria envolvido na alta sensibilidade dos ovócitos de bovino a vitrificação. No entanto, quando ovócitos maturados in vivo foram vitrificados, nenhuma melhora na produção de blastocistos foi observada (Spricigo et al., 2015).

É sabido que o sistema in vitro induz várias alterações morfológicas e bioquímicas, tais como o acumulo de lípidos (Sudano et al., 2011), mudanças no consumo de $\mathrm{O}_{2}$ (Gaspar et al., 2015) e alterações na expressão gênica (Machado et al., 2013). Além da propria condição ambiental que já é totalmente artificial, várias moléculas específicas que são produzidas no trato reprodutivo da vaca e que são essenciais para o embrião, também estão ausentes no sistema de produção in vitro. Portanto, se um sistema inteiramente in vivo, que é a condição ideal, fosse utilizado para a produção de embriões a partir de ovócitos vitrificados talvez, taxas mais elevadas pudessem ser obtidas.

Uma opção para fornecer condições in vivo para os ovócitos vitrificados seria recolocar-los no trato reprodutivo feminino logo após o aquecimento, de forma que todas as demais etapas ocorressem no organismo materno. Isso pode ser realizado pela transferência intrafolicular de ovócitos imaturos (TIFOI), proposto pela primeira vez por (Fleming A.D., 1985). Esta técnica consiste na injeção de ovócitos imaturos em folículos pré-ovulatórios, desta forma os ovócitos eriam maturados, fecundados após a inseminação artificial, e cultivados no trato reprodutivo da fêmea até à fase de blastocisto, quando esses seriam recuperados no D7 por lavagem uterina.

Hinrichs \& DiGiorgio e foram os primeiros a realizar a injecção em equinos de ovócitos, após perfurar a parede do folículo com um cateter (Hinrichs et al., 1991). Depois disso, a técnica foi aperfeiçoada e uma guia de ultrassom transvaginal foi utilizada para realizar a injecção em equinos (Goudet et al., 1997), bovinos (Bergfelt et al., 1998) e até mesmo em seres humanos (Werner-Von Der Burg et al., 1993). Apesar de ser uma técnica desenvolvida 
no século passado, apenas recentemente, o primeiro blastocisto, prenhez e nascimento de produto vivo e e saudável foram relatados, após a injeção de ovócitos maturados in vitro no folículo pré-ovulatório de uma receptora sincronizada (Kassens et al., 2015). Entretanto, até o momento, não há relato de blastocisto bovino recuperados por lavado uterino no D7, após injeção intrafolicular de ovócitos imaturos (TIFOI) ou vitrificados.

Nesse estudo é testada a hipótese de que o sistema in vivo utilizando a TIFOI afetaria positivamente o ovócito, mesmo depois da vitrificação e aquecimento. Para tal, comparou-se a quantidade e qualidade de embriões produzidos a partir de ovócitos imaturos vitrificados ou não, no sistema in vitro e no sistema in vivo utilizando a TIFOI 


\section{MATERIAL E MÉTODOS}

Salvo quando especificado, todos os reagentes foram adquiridos junto à SigmaAldrich (St. Louis, MO, EUA). Os dispositivos de Cryotop foram adquiridos junto à DibimedSuprimentos Bioquímicos (S.L Valencia, Espanha).

\subsection{Delineamento experimental}

Em primeiro lugar, um pré-experimento foi realizado para verificar a viabilidade da utilização de ovócitos imaturos para a transferência intrafolicular. Foi realizada OPU uma vez por semana, durante três semanas, em 5 vacas da raça Gir (Bos taurus indicus). Os COCs recuperados com citoplasma intactos e pelo menos 3 camadas de células de cumulus, foram então usados para TIFOI ( $\mathrm{n}=10-22)$, em que novilhas Nelore (Bos taurus indicus) foram as receptoras, para injeção dos ovócitos. Sêmen do mesmo touro Gir foi utilizado para inseminação artificial após TIFOI. A recuperação dos blastocistos por lavagem uterina no dia 7, após a TIFOI. Os embriões viáveis recuperados foram imediatamente transferidos para novilhas Nelore sincronizadas (D7 do ciclo), e as prenhezes foram avaliadas por ultrassonografia, 60 dias após a transferência.

Para a avaliação da técnica de TIFOI para ovócitos vitrificados, um total de 40 novilhas da raça Nelore (Bos taurus indicus) de aproximadamente 2 anos de idade, com escore corporal semelhante foram utilizadas para o experimento. As novilhas foram mantidas em pastagem de Brachiaria sp, e suplementadas com silagem de milho e água ad libitum. Para cada réplica, 5 novilhas foram previamente sincronizadas. No dia da TIFOI as receptoras foram examinadas e apenas aquelas que apresentam um folículo pré ovulatório com um diâmetro $\geq$ $10 \mathrm{~mm}$ e vascularização intermediária, foram usadas. CCOs recuperados de ovários de abatedouro foram selecionados e distribuídos em 4 grupos: 1) ovócitos imaturos frescos (Cont- 
vitro); 2) ovócitos imaturos vitrificados / aquecido (Vit-Vitro), ambos (1 e 2) foram maturados, fecundados e cultivados in vitro; 3) ovócitos imaturos frescos submetidos a TIFOI (Cont-Vivo), e 4) ovócitos imaturos vitrificados / aquecido submetidos a TIFOI (Vit-Vivo). No D7 após a AI, os embriões produzidos in vivo pela TIFOI foram recuperados por lavagem uterina e foram avaliados e comparados quanto à morfologia com seus homólogos produzidos in vitro. Blastocistos expandidos de todos os grupos foram, então, corados para avaliação do número total de células, número de celular apoptóticas e razão entre estes dois parâmetros (Figura 5.1). Para avaliar se a injeção folicular afetaria o CL formado após a ovulação, momentos antes da coleta, o CL foi examinado com a ajuda de um ultrassom Color Doppler.

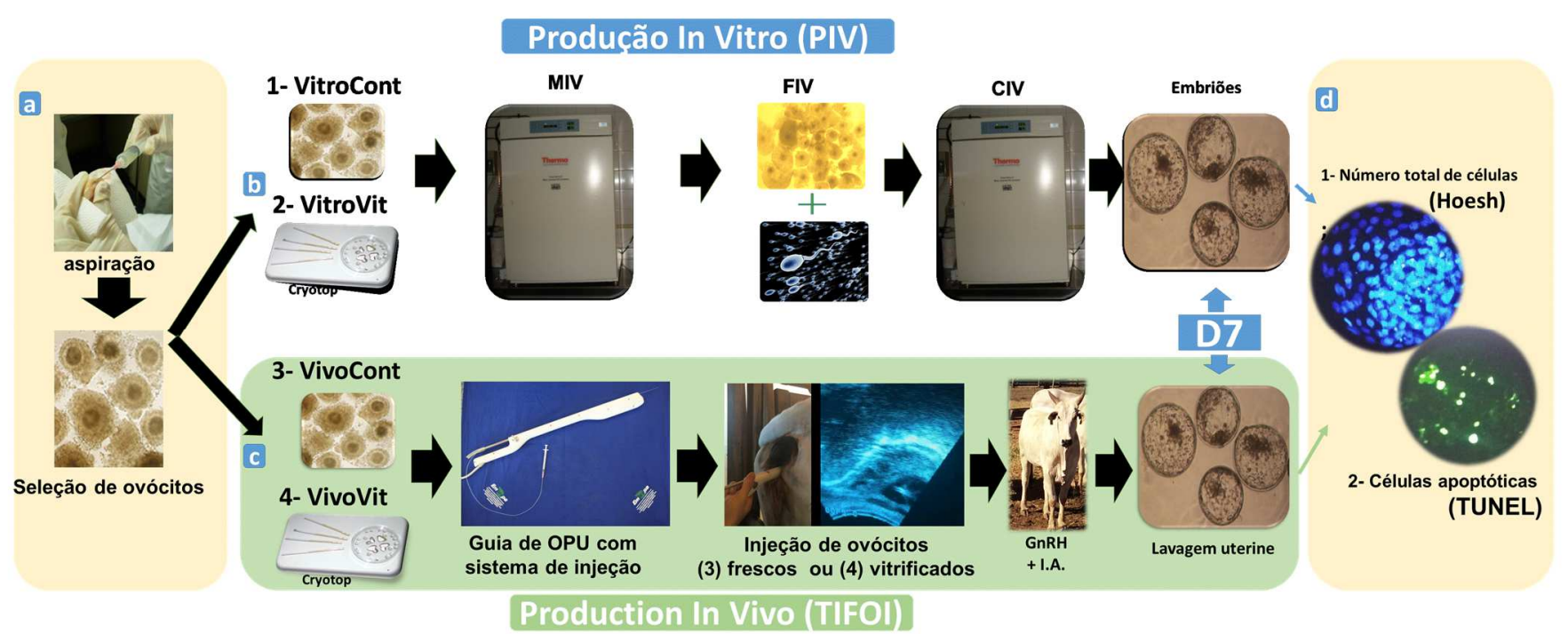

Figura 5.1. Representação da sequência do experimento: a) aquisição de oócitos e seleção; b) ovócitos frescos ou vitrificados seguindo na produção in vitro, resultando em blastocistos no D7; c) ovócitos frescos ou vitrificados seguindo para a produção in vivo (TIFOI), resultando em blastocistos em D7 e d) microscopia fluorescente para avaliação dos blastocistos expandidos, quanto ao número total de células (Hoechst) e número de céluals em apoptose (TUNEL), para os quatro grupos (VitroCont, VitroVit, VivoCont e VivoVit).

\subsection{Obtenção de ovócitos de abatedouro}

Os ovários (Bos indicus) foram coletados imediatamente após o abate e transportadas para o laboratório em solução salina $(\mathrm{NaCl}$ a $0,9 \%)$ suplementado com penicilina G (100 UI/mL) e sulfato de estreptomicina $(100 \mathrm{~g} / \mathrm{mL})$ a $35^{\circ}$ C. Os complexos cumulus ovócitos (CCOs) foram aspirados de folículos de 3 a $8 \mathrm{~mm}$ de diâmetro com uma agulha de calibre $18 \mathrm{G}$ e transferidos para um tubo cônico de $15 \mathrm{~mL}$. Os CCOs foram recuperados e selecionados em meio de manutenção, consistindo TCM-199 tamponado com HEPES (Gibco 
BRL, Burlington, ON, Canadá) suplementado com 10\% de soro fetal bovino [SFB (Invitrogen, Carlsbad, CA, EUA)]. Somente CCOs com citoplasma homogêneo e, pelo menos, três camadas de células de cumulus foram usadas para os experimentos. Após seleção, os ovócitos foram submetidos a maturação in vitro.

\subsection{Maturação in vitro}

Os CCOs selecionados foram lavados e transferidos em grupos de 25-30 para uma gota de $200 \mathrm{~mL}$ de meio de maturação, sob óleo de silicone e incubadas durante $22 \mathrm{~h}$ a 39 ${ }^{\circ} \mathrm{C}$ em atmosfera de $5 \%$ de $\mathrm{CO}_{2}$, em ar. O meio de maturação consistiu de TCM -199 (Invitrogen, Carlsbad, CA, EUA) suplementado com 10\% de SFB), $0.01 \mathrm{UI} / \mathrm{mL}$ de FSH, 0,1 $\mathrm{mg} / \mathrm{mL}$ de L-glutamina e antibióticos (amicacina, 0,075 mg/mL).

\subsection{Fecundação e cultivo in vitro}

Após a maturação, os CCOs (grupos de 25 a 30) foram transferidos para uma gota de $200 \mathrm{~mL}$ de meio de fecundação. Foi utilizado para a fecundação sêmen congelado de um touro Nelore, previamente testado em nosso laboratório. Espermatozoides móveis foram obtidos pelo método de Percoll (Machado et al., 2009) e foram adicionados às gotas contendo CCOs a uma concentração final de $1 \times 10^{6}$ espermatozoides $\mathrm{mL}^{-1}$. O meio de fecundação utilizado foi TALP (Parrish et al., 1995) suplementado com penicilamina (2 mM), hipotaurina (1 $\mathrm{mM})$, epinefrina $(250 \mathrm{mM})$ e heparina $(10 \mathrm{ug} / \mathrm{mL}-1)$. Os espermatozoides e ovócitos foram co-incubadas durante $18 \mathrm{~h}$ a $39{ }^{\circ} \mathrm{C}$ com $5 \%$ de $\mathrm{CO}_{2}$, em ar. O dia da FIV foi considerado dia 0. Depois da co-incubação, os zigotos $(n=25-30)$ foram lavados e transferidos para gotas de 200 uL de SOFaaci (Holm et al., 1999) suplementado com 2,77 mM de mio-inositol e 5\% de SFB e cultivados à $39{ }^{\circ} \mathrm{C}$ e $5 \%$ de $\mathrm{CO}_{2}$, em ar, durante 8 dias. $\mathrm{O}$ desenvolvimento embrionário foi avaliado no dia 2 pós-inseminação (pi) para a clivagem e no Dia 7 (pi) para a taxa de blastocisto.

\subsection{Sincronização do ciclo estral e transferência intrafolicular de ovócitos imaturos (TIFOI)}


Com a intenção de ter um folículo pré-ovulatório no dia da TIFOI, as novilhas foram submetidas a um protocolo de sincronização de estro. O protocolo teve início com a inserção de um implante intravaginal de progesterona (Primer® Tecnopec, São Paulo, Brasil) associada à aplicação de $2 \mathrm{mg}$ de benzoato de estradiol [im (RIC-BE ®, Brasil) ]. Após 8 dias, os animais receberam uma injeção de $2 \mathrm{~mL}$ (im) de prostaglandina F2 $\alpha[0,150 \mathrm{mg}$ de dcloprostenol (ARSA Prolise ${ }^{\circledR}$ SRL, Argentina], juntamente com a remoção do implante de progesterona, e no dia seguinte $1 \mathrm{mg}$ de benzoato de estradiol (im). A injeção dos ovócitos no folículo pré-ovulatório foi realizada 52-58 horas após a remoção da progesterona e cerca de 4 6 horas após o início do estro. A TIFOI foi realizada somente em novilhas em que um folículo pré-ovulatório superior a $10 \mathrm{~mm}$ foi detectado.

Para a injeção intrafolicular foi usada uma guia transvaginal (WTA, Brasil), que contém uma probe convexa de ultrassom de 7,5 MHz (Aloka, Japão). A guia transvaginal continha um mandril montado em um sistema fechado, tendo em uma extremidade uma seringa de insulina e uma agulha ( $\mathrm{G}$ 27) na outra extremidade. Todos os 25 CCOs foram alocados dentro da agulha, juntamente com um volume de $60 \mathrm{uL}$ de fluido folicular. Em seguida, todo o sistema foi preenchido com PBS e a guia foi posicionada no fundo de saco vaginal, no mesmo lado do ovário contendo o folículo dominante. A agulha foi então "empurrada" através do fundo de saco vaginal, perfurando também a parede do folículo. Uma vez possível a visualização da agulha no antro folicular, os $60 \mu \mathrm{L}$ de fluido folicular contendo CCOs foi injetado no folículo. Logo após a TIFOI, $1 \mathrm{~mL}$ de um análogo da GnRH (Gestran®, Tecnopec, São Paulo, Brasil) foi administrada, para auxiliar na indução da ovulação.

A inseminação artificial foi realizada na sequência, utilizando uma única dose de sêmen descongelado, de um touro Nelore previamente provada, sendo o mesmo sêmen utilizado para os ovócitos submetidos à fecundação in vitro.

\subsection{Avaliação do diâmetro e vascularização folicular com o Color Doppler}

Em todos os tratamentos, os ovários foram avaliados imediatamente antes do procedimento de TIFOI. Foi utilizado para a avaliação a ultrassonografia com Collour Doppler com uma sonda linear de 7,5 MHz. A vascularização foi classificada de acordo com Matsui et al. (2009) em: 1- vascularização ausente, quando não foram observadas imagens coloridas em torno do folículo; 2- vascularização inicial, quando 20 a $40 \%$ do folículo estava colorido; 3 vascularização intermédia, quando 41 a $60 \%$ do folículo estava colorido; 4- vascularização 
intensa, quando 61 a $80 \%$ do folículo a estrutura estava colorida e 5- vascularização completa, quando 81 a $100 \%$ do folículo estava colorido .

\subsection{Lavagem uterina e recuperação embrionária}

Sete dias após a TIFOI de ovócitos fresco ou vitrificados, as novilhas foram submetidas a lavagem uterina usando uma sonda de Foley (No. 18, Rusch, EUA) fixada no corpo uterino. Os embriões foram recuperados pela lavagem do útero utilizando $1000 \mathrm{~mL}$ de PBS. O liquido contendo os embriões foi filtrado em uma malha de $80 \mu \mathrm{m}$. Os embriões foram avaliados em estereomicroscópio e classificadas de acordo com o estágio de desenvolvimento. O número total de estruturas recuperadas foi registrado e classificadas em: (1) não-fecundados: ovócitos não clivados ou (2) fecundados: estruturas que chegaram ao estágio de mórula ou blastocisto e aqueles que apresentavam clivagens inicias.

\subsection{Vitrificação e aquecimento}

A vitrificação de ovócitos foi realizada como descrito anteriormente (Kuwayama et al., 2005) com pequenas modificações. A solução de manutenção (SM), que foi utilizado para manipular ovócitos e durante a vitrificação e aquecimento, foi composta por - TCM-199 tamponado com HEPES (Gibco) suplementado com 20\% de SFB. Para a vitrificação, os grupos de ovócitos (3-5) foram primeiro lavados três vezes numa solução de equilíbrio constituído por 7,5\% de etileno glicol e 7,5\% de dimetilsulfóxido (DMSO) dissolvido em SM, por 9 minutos. Os ovócitos foram transferidos para uma solução de vitrificação composta de $15 \%$ de etileno glicol, $15 \%$ de DMSO e 0,5 M de Sacarose em SM. Onde foram incubados durante 45-60 segundos. Em seguida, os ovócitos foram colocados na haste de vitrificação em conjuntos de 3-5, sob um estereomicroscópio (Nikon- SMZ 650). Antes de vitrificação, a maior parte da solução, que foi transferida junto aos ovócitos foi removida, e apenas uma fina camada $(<0,1$ $\mu$ l) permaneceu cobrindo os ovócitos. Subsequentemente, a haste foi imediatamente imersa em $\mathrm{N}_{2}$ líquido. $\mathrm{O}$ aquecimento foi realizado imediatamente após vitrificação, mergulhando a extremidade da haste em uma gota de SM suplementado com 1 M de sacarose, pré-aquecida a $37{ }^{\circ} \mathrm{C}$, durante $1 \mathrm{~min}$. Os ovócitos foram então transferidos para uma solução de $0,5 \mathrm{M}$ de Sacarose, em meio SM, durante 3 minutos. Finalmente, os ovócitos foram expostos ao meio 
manutenção (SM). Em seguida, metade dos ovócitos prosseguiu para maturação in vitro e a outra metade seguiu para TIFOI.

\subsection{Contagem do número total de células (Hoechst 33342), número total e razão de células apoptóticas (Terminal deoxinucleotidil transferase dUTP nick end labeling [TUNEL])}

Para determinar o número total de células e número e proporção de células apoptóticas, embriões expandidos em D7 foram corados com Hoechst 33342 e TUNEL respectivamente. De forma resumida, os blastocistos foram lavados em PBS suplementado com $1 \mathrm{mg} / \mathrm{mL}$ polivinilpirrolidona (PBS- PVP antes da fixação em paraformaldeído a 4\%, durante 1 hora. Todos os passos de incubação ocorreram à temperatura ambiente, em câmara escura, salvo quando especificado. Os blastocistos foram então incubados em 0,5\% de Triton-X, durante 60 minutos. Subsequentemente, controles positivos (desnaturação de DNA artificial, TUNEL e coloração Hoechst 33342) e controlos negativos (desnaturação de DNA artificial, coloração Hoechst) foram incubadas com $50 \mathrm{U} / \mathrm{mL}$ de Dnase I (Roche, Vilvoorde, Bélgica) durante 1 hora. Blastocistos (exceto os controlos negativos) foram então corados com uma mistura de TUNEL-marcação com enzima, durante 60 minutos à $37{ }^{\circ} \mathrm{C}$, logo após com coloração Hoechst 33342, durante 10 minutos. Finalmente, os blastocistos foram lavados em PBS-PVP, montadas em lâminas de vidro e observados sob um microscópio de epifluorescência. Para cada blastocisto, foram determinados o número total de células (núcleos azuis, Hoechst 33342) e o número total de células apoptóticas (núcleos verdes, TUNEL). A proporção de células apoptóticas foi definida como a percentagem de células apoptóticas sobre número total de células (Figura 5.2).

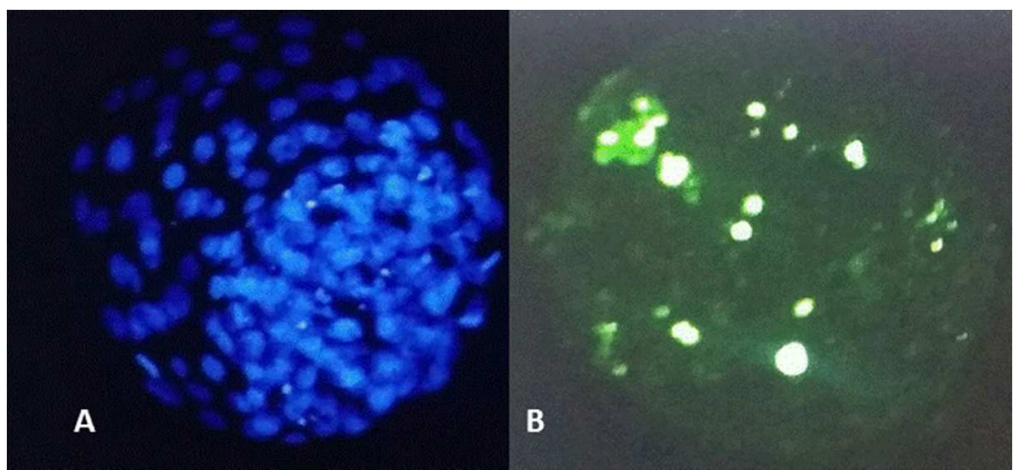

Figura 5.2. Imagens ilustrativa da contagem do número total de células, avaliado pela coloração com Hoechst (A) e contagem de células apoptóticas, após coloração pelo Tunel (B). 


\subsection{Análise estatística}

Todos os dados foram analisados por meio do software Statistical Analysis System (SAS, 1999). As porcentagens de clivagem, fertilização e desenvolvimento embrionário foram comparadas pelo teste de Kruskall-Wallis ( $\mathrm{P}<0.05)$. Os parâmetros foliculares, número total de células, total de células apoptóticas e razão entre os dois, foram calculados por ANOVA, e o teste Tukey's foi usado para comparação das médias $(\mathrm{P}<0.05)$. 


\section{RESULTADOS E DISCUSSÃO}

\subsection{Resultados}

\subsubsection{Viabilidade da TIFOI}

Sete dias após TIFOI, 26\% de estruturas foram recuperadas, e 39\% destas eram embriões viáveis. Considerando que em cada lavagem uterina, uma estrutura era derivada do folículo da receptora, a taxa de recuperação excluindo esta estrutura (sempre a mais desenvolvida) foi de $21 \%$, e $26 \%$ destas estruturas eram embriões viáveis (Tabela 5.1). Após a transferência dos 11 embriões, 4 (36\%) prenhezes foram obtidas (Tabela 5.2). Após a lavagem uterina de uma única receptoras, 5 embriões foram recuperados (Tabela 5.1); após a transferência destes embriões para 5 receptoras em D7, 3 prenhezes foram obtidas (Tabela 5.2).

5.1.2 Taxas de recuperação de estruturas após a TIFOI de ovócitos imaturos frescos ou vitrificados

Como apresentado na Tabela 5.3, o tamanho e a vascularização dos folículos que receberam os ovócitos foram semelhantes $(\mathrm{P}>0,05)$ para ambos os grupos. Por conseguinte, o CL formado após a ovulação foi também semelhante $(\mathrm{P}>0,05)$ entre eles.

No entanto, a taxa de recuperação do grupo vitrificado foi inferior $(\mathrm{P}<0,05)$ à taxa observada para o grupo fresco. 
Tabela 5.1. Número $(\mathrm{N})$ ode ovócitos injetados (D0), número e porcentagem de estruturas recuperadas (D7), estágio de desenvolvimento dos embriões recuperados, recuperação total e porcentagem de recuperação depois da exclusão do ovócito incluso no folículo da receptora, em cada injeção.

\begin{tabular}{|c|c|c|c|c|c|c|c|c|c|c|c|c|c|c|c|}
\hline \multirow{3}{*}{$\begin{array}{l}\text { Referência } \\
\text { da injeção }\end{array}$} & \multirow{3}{*}{$\begin{array}{c}\text { Número } \\
\text { de } \\
\text { ovócitos } \\
\text { (D0) }\end{array}$} & \multicolumn{6}{|c|}{ Recuperação (D7) } & \multicolumn{4}{|c|}{ Recuperação total (D7) } & \multicolumn{4}{|c|}{ Extra (D7) } \\
\hline & & \multirow{2}{*}{ NF } & \multirow{2}{*}{ Dg } & \multirow{2}{*}{ Mc } & \multirow{2}{*}{$\mathbf{B i}$} & \multirow{2}{*}{$\mathbf{B l}$} & \multirow{2}{*}{$\mathbf{B x}$} & \multicolumn{2}{|c|}{ Estruturas } & \multicolumn{2}{|c|}{ Embriões* } & \multicolumn{2}{|c|}{ Estruturas } & \multicolumn{2}{|c|}{ Embriões** } \\
\hline & & & & & & & & $\mathbf{N}$ & $(\%)$ & $\mathbf{n}$ & $(\%)$ & $\mathbf{n}$ & $(\%)$ & $\mathbf{n}$ & $(\%)$ \\
\hline 1 & 22 & 2 & & & & & 1 & 3 & $(13.6)$ & 1 & $(33.3)$ & 2 & $(9.1)$ & 0 & $(0.0)$ \\
\hline 2 & 22 & 1 & 5 & & 1 & & & 7 & $(31.8)$ & 1 & $(14.3)$ & 6 & $(27.3)$ & 0 & $(0.0)$ \\
\hline 3 & 10 & & & 1 & & & 2 & 3 & $(30.0)$ & 3 & $(100.0)$ & 2 & $(20.0)$ & 2 & $(66.7)$ \\
\hline 4 & 10 & & & & & & & 0 & $(0.0)$ & 0 & $(0.0)$ & 0 & $(0.0)$ & 0 & $(0.0)$ \\
\hline 5 & 22 & & 6 & & 1 & & & 7 & $(31.8)$ & 1 & $(14.3)$ & 6 & $(27.3)$ & 0 & $(0.0)$ \\
\hline 6 & 22 & & 3 & & & & 5 & 8 & $(36.4)$ & 5 & $(62.5)$ & 7 & $(31.8)$ & 4 & $(50.0)$ \\
\hline Total & 108 & 3 & 14 & 1 & 2 & $\mathbf{0}$ & 8 & 28 & (25.9) & 11 & (39.3) & 23 & $(21.3)$ & 6 & $(26.1)$ \\
\hline
\end{tabular}

\footnotetext{
* A taxa total recuperado embrionária foi calculada como a proporção de embriões totais sobre o total de estruturas recuperadas.

** A taxa de recuperação de embriões foi registada como a proporção do total de embriões (extras) sobre o total das estruturas (extras) recuperadas. Para a apresentação dos dados, uma estrutura / embrião foi excluído após cada lavagem uterina.
} 
Tabela 5.2. Estágio de desenvolvimento e classificação embrionária. Diagnóstico de gestação com 60 dias após a transferência dos embriões produzidos.

\begin{tabular}{cccc}
\hline Transferência & $\begin{array}{c}\text { Referência } \\
\text { da injeção }\end{array}$ & $\begin{array}{c}\text { Embrião } \\
\text { (qualidade) }\end{array}$ & $\begin{array}{c}\text { Prenhes } \\
\text { 60 dias }\end{array}$ \\
\hline 1 & 1 & $\mathrm{Bi}(2)$ & - \\
2 & 2 & $\mathrm{Bx}(1)$ & - \\
3 & 3 & $\mathrm{Bx}(1)$ & - \\
4 & 3 & $\mathrm{Bx}(1)$ & - \\
5 & 3 & $\mathrm{Mc}(1)$ & + \\
6 & 6 & $\mathrm{Bx}(1)$ & - \\
7 & 6 & $\mathrm{Bx}(1)$ & + \\
8 & 6 & $\mathrm{Bx}(1)$ & + \\
9 & 6 & $\mathrm{Bx}(1)$ & + \\
10 & 6 & $\mathrm{Bx}(1)$ & - \\
11 & 5 & $\mathrm{Bi}(2)$ & - \\
\hline
\end{tabular}

Tabela 5.3. Média \pm desvio padrão do diâmetro e da irrigação folicular no dia da transferência folicular de ovócitos imaturos (TIFOI) em D0 e do corpo lúteo em D7 e, recuperação total de estruturas e de embriões em D7, após a TIFOI com ovócitos frescos ou vitrificados.

\begin{tabular}{|c|c|c|c|c|c|c|c|c|}
\hline Grupos & $\begin{array}{c}\text { Repetições } \\
\text { N }\end{array}$ & $\begin{array}{c}\text { Ovócitos } \\
\text { injetados } \\
\mathbf{N}\end{array}$ & \multicolumn{2}{|c|}{ Folículo no D0 } & \multicolumn{2}{|c|}{ Corpo Lúteo em D7 } & \multicolumn{2}{|c|}{ Recuperação em D7 } \\
\hline Frescos & 11 & 240 & $12,6 \pm 0,9$ & $1,6 \pm 0,6$ & $19,0 \pm 1,9$ & $4,8 \pm 0,4$ & $125(52,1 \pm 23,9)^{\mathrm{a}}$ & $39(31,2 \pm 18,7)^{\mathrm{a}}$ \\
\hline Vitrificados & 9 & 200 & $13,1 \pm 0,6$ & $1,6 \pm 0,5$ & $19,5 \pm 2,2$ & $4,8 \pm 0,3$ & $36(18,0 \pm 16,0)^{\mathrm{b}}$ & $6(13,9 \pm 43,7)^{\mathrm{b}}$ \\
\hline
\end{tabular}

${ }^{\mathrm{a}, \mathrm{b}}$ Letras diferentes indicam diferenças na mesma coluna depois do teste de ANOVA e teste Tukey $(P<0.05)$.

*Taxa de recuperação de blastocistos calculada com base nas estruturas recuperadas em D7.

5.1.3 Desenvolvimento embrionário a partir de ovócitos bovinos frescos ou vitrificados, produzidos in vitro ou in vivo pela TIFOI

A produção de embriões para os grupos que foram submetidos à TIFOI foi calculada considerando o total de estruturas recuperadas, após a lavagem uterina. A clivagem foi maior no grupo Vivo-Cont $(\mathrm{P}<0,05)$, independentemente do sistema de produção de embriões (Tabela 5.4). Embora uma taxa de clivagem mais elevada foi observada no sistema in vitro em comparação com in vivo para ovócitos frescos, quando os ovócitos vitrificados foram 
avaliados as taxas de clivagem não diferiram $(\mathrm{P}>0,05)$ entre os sistemas in vitro e TIFOI (Tabela 5.4). O desenvolvimento de blastocisto em D7 foi mais elevado nos grupos frescos (Vivo Cont e Vitro Cont) em relação a todos os grupos vitrificados $(\mathrm{P}<0,05)$ A velocidade de desenvolvimento dos embriões dos grupos Vivo-Cont e Vitro-Cont foi semelhante ( $\mathrm{P}>0,05)$, já que a percentagem de embriões em estágio de blastocisto expandido no D7 não diferiu entre eles. Quando os grupos vitrificados foram comparados, Vivo Vit apresentou uma maior taxa de blastocisto expandido $(\mathrm{P}<0,05)$.

Tabela 5.4. Avaliação do desenvolvimento embrionário, a partir de ovócitos frescos ou vitrificados e submetidos ao sistema in vivo ou in vitro, expressos em número $(\mathrm{N})$, porcentagem \pm desvio padrão (\% \pm DP), da clivagem em D2, blastocistos total e blastocistos expandidos (D7).

\begin{tabular}{lcccc} 
Grupos & N & $\begin{array}{c}\text { Clivados } \\
(\mathbf{D 2} \text { ou D7) }\end{array}$ & Blastocistos D7 & $\begin{array}{c}\text { Blastocistos } \\
\text { expandidos em D7 }\end{array}$ \\
& & $\mathbf{N}(\% \pm \mathbf{D P})$ & $\mathbf{N}(\% \pm \mathbf{D P})$ & $\mathbf{N}(\boldsymbol{\%} \pm \mathbf{D P})$ \\
\hline Vitro-Cont & 190 & $154(81,0 \pm 6,8)^{\mathrm{a}}$ & $80(42,1 \pm 14,5)^{\mathrm{a}}$ & $57(71,2 \pm 16,0)^{\mathrm{a}}$ \\
Vitro-Vit & 173 & $30(17,3 \pm 6,2)^{\mathrm{d}}$ & $11(6,3 \pm 4,4)^{\mathrm{b}}$ & $4(36,3 \pm 45,1)^{\mathrm{c}}$ \\
Vivo-Cont & 125 & $82(65,6 \pm 26,6)^{\mathrm{bc}}$ & $39(31,2 \pm 18,7)^{\mathrm{a}}$ & $31(79,4 \pm 25,9)^{\mathrm{a}}$ \\
Vivo-Vit & 36 & $14(38,9 \pm 38,9)^{\mathrm{cd}}$ & $5(13,9 \pm 43,7)^{\mathrm{b}}$ & $3(60,0 \pm 48,9)^{\mathrm{b}}$ \\
\hline
\end{tabular}

$\overline{\mathrm{abc}}$ Letras diferentes indicam diferenças na mesma coluna depois do teste de Kruskall-Wallis $(P<0.05)$.

5.1.4 Contagem do número total de células, número de células apoptóticas e a razão total/apoptóticas.

Como demonstrado na Tabela 5.5, apesar da menor taxa de desenvolvimento observada para os grupos vitrificados, nenhuma diferença $(\mathrm{P}>0,05)$ foi encontrada entre todos os grupos, quanto ao número total de células, número de células apoptóticas e razão (total/apoptóticas). 
Tabela 5.5. Avaliação da qualidade dos blastocistos expandidos (D7), produzidos a partir de ovócitos frescos ou vitrificados e submetidos ao sistema in vivo ou in vitro. Expressa quanto ao número \pm desvio padrão $(\mathrm{N} \pm \mathrm{DP})$ de células totais e apoptóticas. Além, da porcentagem de células apoptóticas (\%).

\begin{tabular}{|c|c|c|c|c|}
\hline \multirow{3}{*}{ Grupos } & \multirow{3}{*}{$\begin{array}{c}\text { Blastocistos } \\
\text { Expandidos (Bx) } \\
\mathbf{N}\end{array}$} & \multicolumn{2}{|c|}{ Número de Células } & \multirow{3}{*}{$\begin{array}{c}\text { Células } \\
\text { apoptóticas } \\
(\%)\end{array}$} \\
\hline & & Total & Apoptóticas & \\
\hline & & $\mathrm{N} \pm \mathrm{DP}$ & $\mathbf{N} \pm \mathbf{D P}$ & \\
\hline Vitro-Cont & 47 & $135,0 \pm 17,2$ & $4,9 \pm 2,9$ & $3,60 \%$ \\
\hline Vitro-Vit & 4 & $135,3 \pm 6,8$ & $3,8 \pm 2,6$ & $2,80 \%$ \\
\hline Vivo-Cont & 23 & $135,1 \pm 11,1$ & $4,9 \pm 2,4$ & $3,60 \%$ \\
\hline Vivo-Vit & 2 & $126,5 \pm 9,5$ & $6,5 \pm 0,5$ & $5,10 \%$ \\
\hline
\end{tabular}

\subsection{Discussão}

Apesar da sua importância, a criopreservação de ovócitos ainda é ineficiente na maioria das espécies de animais domésticos, tais como suínos (Somfai et al., 2014; Dai et al., 2015), ovinos (Ebrahimi et al., 2012; Ariu et al., 2014), e bovinos (Zhou et al., 2013; Spricigo et al., 2014; Arcarons et al., 2015). Porém, nas últimas décadas tem se buscado várias alternativas para compensar os danos causados pela vitrificação e melhorar os resultados obtidos com essa técnica. Na tentativa de propiciar um ambiente fisiologicamente "ideal" para os ovócitos submetidos a vitrificação, neste experimento foi estabelecido um sistema de produção in vivo de embriões, após a injeção de ovócitos imaturos, em um folículo préovulatório. Este modelo de produção in vivo, foi descrito por Kassens et al. (2015), e baseia-se na injeção de ovócitos maturados em folículos pré-ovulatórios de receptoras sincronizadas, que posteriormente são submetidas à AI e a lavagem uterina 7 dias após. Estes autores foram os primeiros a relatar a produção de blastocistos, gestação e nascimento de bezerros saudáveis, após a transferência intrafolicular de ovócitos maturados.

Diferente de Kassens et al. (2015), o nosso objetivo foi realizar a injeção de ovócitos imaturos. Apesar desse procedimento já ter sido realizado em bovinos (Bergfelt et al., 1998), ainda não há relatos de produção de blastocistos em D7, usando fêmeas Bos indicus ou Bos taurus. Já que no estudo de Bergfelt (1998) os embriões foram coletados, após o abate das fêmeas em D3. Assim, no pré-experimento utilizando COCs obtidos por OPU. Os resultados 
revelaram que, embora a recuperação de estruturas em D7 foi baixa, em 5 de 6 novilhas mais do que uma estrutura foi recuperada. Se consideramos que uma dessas estruturas era oriunda da receptora, pelo menos, 2 estruturas adicionais foram recuperadas. Este fato sugere que estas estruturas eram resultantes dos COCs injetados. Também, é importante destacar que, para 5 das 6 novilhas, pelo menos, um embrião grau I foi recuperado. Resumindo, 11 embriões de grau I e II foram transferidos para receptoras, e 60 dias depois, 4 gestações foram detectadas. Como apresentado na tabela 5.2, três prenhezes foram produzidas após a transferência de embriões, obtidas a partir de uma única novilha. Sabemos que as análises genotípicas devem ser realizadas para garantir que as gestações resultaram de embriões derivados da TIFOI. No entanto, é muito incomum para uma fêmea bovina ovular três folículos. Assim, os resultados sugerem que o sistema funciona para ovócitos imaturos e, portanto, poderia ser usado para ovócitos vitrificados. Considerando uma ovulação simples, o presente estudo representa o primeiro relato de prenhez usando ovócitos imaturos para TIFOI.

Seguindo o experimento, quando comparadas a TIFOI com ovócitos frescos ou vitrificados, para o grupo fresco, o total de estruturas recuperadas após a lavagem foi de 52,1\%. Apesar de não ter sido realizada a subtração do ovócito incluso no folículo no momento da injeção, a taxa de recuperação foi maior do que os 35\% observados por Kassens et al. (2015). Uma possível explicação seria que diferente dos 60 ovócitos (Kassens et al., 2015), neste estudo foram injetados apenas 25 ovócitos em cada folículo pré-ovulatório, facilitando a captura dos CCOs pelas fimbrias do oviduto no momento da ovulação. Entretanto, a recuperação de ovócitos imaturos após vitrificação (18\%) foi menor do que de a observada para ovócitos frescos. É possível que a vitrificação no estágio de VG tenha afetado as células do cumulus, de tal forma que a expansão foi comprometida. Como a expansão das CC facilita a captação do ovócito pelo epitélio ciliar das células do infundíbulo (Russell et al., 2006) se esse processo estiver afetado pode afetar a captação e com isso diminuir a taxa de recuperação.

Não só a quantidade de estruturas recuperadas após a TIFOI foi maior para ovócitos frescos em comparação aos vitrificados, mas também, a porcentagem de embriões viáveis. Estes resultados podem ser explicados, pelo fato de que os danos causados durante a vitrificação e aquecimento, são tão severos que não podem ser minimizados mesmo quando os ovócitos são maturados dentro do folículo.

A clivagem e o desenvolvimento embrionário para ovócitos frescos (81\% e 42\%) e vitrificados (17\% e 6\%) nos grupos in vitro, estão de acordo com a literatura (Spricigo et al., 2012; Spricigo et al., 2014; Spricigo et al., 2015). Para os grupos maturados in vivo Vivo-Cont ou Vivo-Vit, a clivagem em D2 não pode ser mensurada, uma vez em que as estruturas foram 
recuperadas em D7, depois da IA. Desta forma, foram considerados clivados os zigotos que nos grupos in vivo apresentassem clivagens inicias (2 ou mais células) ou estágios tardios e que pararam o seu desenvolvimento e aqueles em estágio de blastocistos no momento da coleta, em D7. A clivagem e desenvolvimento embrionário para Vivo-Cont (65 e 31\%) foi maior do que para Vivo-Vit (38 e 14\%). Os dados mostram que o sistema proposto não aumentou o desenvolvimento embrionário a partir de ovócitos frescos ou vitrificados, quando comparado com os grupos produzidos in vitro.

Não só o desenvolvimento do blastocisto foi comparado, mas também a qualidade dos blastocistos em D7. A qualidade do embrião in vivo é influenciada pelo estado uterino (Roberts et al., 2015). Em D7 o útero tem de estar sobre a influência da progesterona, produzida por um corpo lúteo saudável. Assim, momentos antes da coleta por lavagem uterina, escaneados os ovários com o Color Doppler, mas não foram observadas diferenças, quanto ao diâmetro ou vascularização do CL, parâmetros os quais condiziam com padrões fisiológicos.

A técnica mais eficiente para avaliar s a qualidade embrionária seria a transferência para receptora, para a aviação de gestão e nascimento de um produto. Porém, devido as dificuldades e altos custos de manutenção de receptoras, não foi possível realizar esse tipo de análise. Como parâmetro de avaliação da qualidade, foi utilizado o número total de células (Hoechst) e o total de células apoptóticas (TUNEL), além da razão entre estes dois indicativos. Entretanto, não foi detectada diferença nesses parâmetros quando blastocistos expandidos de D7 dos diferentes tratamentos foram analisados. Desde que Zhao et al. (2011), demonstraram que o sistema in vitro aumenta a produção de EROs e que a vitrificação induz a apoptose (Rocha-Frigoni et al., 2014), esperávamos que a qualidade do embrião produzido in vivo pela TIFOI seria melhor do que embriões produzidos in vitro, mesmo depois de vitrificados, porém foram de qualidade semelhantes. 


\section{CONCLUSÕES}

Esta é a primeira vez que a técnica de injecção de oócitos imaturos de bovinos resultou em blastocistos viáveis em D7 e em prenhez aos 60 dias. Embora, ovócitos vitrificados, não resultaram em melhores resultados de desenvolvimento embrionário, os resultados demonstram que é possível utilizar a técnica, para a produção de embriões. Esta técnica abre uma ampla gama de possibilidades para programas de melhoramento. Além, de ser um sistema interessante para a pesquisa, pois permite a produção de um elevado número de embriões num sistema totalmente in vivo, sem quaisquer estimulação hotmonal ou a necessidades de instalações laboratoriais. Juntos, estes dados sugerem que este procedimento "simples e barato" deve representar a nova geração da multiplicação de embriões bovinos. 


\section{REFERÊNCIAS BIBLIOGRÁFICAS}

ANCHAMPARUTHY VM ;DHALI A ;LOTT WM ;PEARSON RE ;GWAZDAUSKAS FC. Vitrification of bovine oocytes: implications of follicular size and sire on the rates of embryonic development. Journal of assisted reproduction and genetics, v. 26,p. 613-619, 2009.

ARCARONS N ;MORATO R ;SPRICIGO JF ;FERRAZ MA ;MOGAS T. Spindle configuration and developmental competence of in vitro-matured bovine oocytes exposed to $\mathrm{NaCl}$ or sucrose prior to Cryotop vitrification. Reproduction, fertility, and development, 2015.

ARIU F ;BOGLIOLO L ;LEONI G ;FALCHI L ;BEBBERE D ;NIEDDU SM ;ZEDDA MT ;PAU S ;LEDDA S. Effect of caffeine treatment before vitrification on MPF and MAPK activity and spontaneous parthenogenetic activation of in vitro matured ovine oocytes. Cryo letters, v. 35,p. 530-536, 2014.

BERGFELT DR ;BROGLIATTI GM ;ADAMS GP. Gamete recovery and follicular transfer (graft) using transvaginal ultrasonography in cattle. Theriogenology, v. 50,p. 15-25, 1998.

Chamayou S ;Bonaventura G ;Alecci C ;Tibullo D ;Di Raimondo F ;Guglielmino A ;BARCELLONA ML. Consequences of metaphase II oocyte cryopreservation on mRNA content. Cryobiology, v. 62,p. 130-134, 2011.

ChANG CC ;SHAPIRO DB ;BERNAL DP ;WRIGHT G ;KORT HI ;NAGY ZP. Human oocyte vitrification: in-vivo and in-vitro maturation outcomes. Reproductive biomedicine online, $v$. 17,p. 684-688, 2008.

DAI J ;WU C ;MUNERI CW ;NIU Y ;ZHANG S ;RUI R ;ZHANG D. Changes in mitochondrial function in porcine vitrified MII-stage oocytes and their impacts on apoptosis and developmental ability. Cryobiology, v. 71,p. 291-298, 2015.

DALVIT G ;Llanes SP ;DESCALZO A ;INSANI M ;BECONI M ;CETICA P. Effect of alphatocopherol and ascorbic acid on bovine oocyte in vitro maturation. Reproduction in domestic animals = Zuchthygiene, v. 40,p. 93-97, 2005.

EBRAHIMI B ;VALOJERDI MR ;EFTEKHARI-YAZDI P ;BAHARVAND H. Ultrastructural changes of sheep cumulus-oocyte complexes following different methods of vitrification. Zygote, v. 20,p. 103-115, 2012. 
FLEMING A.D. SR, KUEHL T.J. Maturation of baboon or cow oocytes transplanted into a surrogate. Theriogenology, v. 23,p. 192, 1985.

GASPAR RC ;ARNOLD DR ;CORREA CA ;DA ROCHA CV, JR. ;PENTEAdO JC ;DEL COLLADO M ;VANTINI R ;GARCIA JM ;LOPES FL. Oxygen tension affects histone remodeling of in vitroproduced embryos in a bovine model. Theriogenology, v. 83,p. 1408-1415, 2015.

GOUDET G ;BEZARD J ;DUCHAMP G ;PALMER E. Transfer of immature oocytes to a preovulatory follicle: an alternative to in vitro maturation in the mare? Equine veterinary journal. Supplement, p. 54-59, 1997.

HiNRICHS K ;DIGIORGIO LM. Embryonic development after intra-follicular transfer of horse oocytes. Journal of reproduction and fertility. Supplement, v. 44,p. 369-374, 1991.

Holm P ;BoOTh PJ ;SCHMIDT MH ;GREVE T ;CALLESEN H. High bovine blastocyst development in a static in vitro production system using SOFaa medium supplemented with sodium citrate and myo-inositol with or without serum-proteins. Theriogenology, v. 52,p. 683-700, 1999.

HORVATH G ;SEIDEL GE, JR. Vitrification of bovine oocytes after treatment with cholesterolloaded methyl-beta-cyclodextrin. Theriogenology, v. 66,p. 1026-1033, 2006.

KASSENS A ;HELD E ;SALILEW-WONDIM D ;SIEME H ;WRENZYCKI C ;TESFAYE D ;SCHELLANDER K ;HOELKER M. Intrafollicular Oocyte Transfer (IFOT) of Abattoir-Derived and In Vitro-Matured Oocytes Results in Viable Blastocysts and Birth of Healthy Calves. Biology of reproduction, v. 92,p. 150, 2015.

KUWAYAMA M ;VAJTA G ;KATO O ;LEIBO SP. Highly efficient vitrification method for cryopreservation of human oocytes. Reproductive biomedicine online, v. 11,p. 300-308, 2005.

LEIBO SP. Cryopreservation of oocytes and embryos: optimization by theoretical versus empirical analysis. Theriogenology, v. 69,p. 37-47, 2008.

MACHADO GM ;CARVALHO JO ;FILHO ES ;CAIXETA ES ;FRANCO MM ;RUMPF R ;DODE MA. Effect of Percoll volume, duration and force of centrifugation, on in vitro production and sex ratio of bovine embryos. Theriogenology, v. 71,p. 1289-1297, 2009.

MACHADO GM ;FERREIRA AR ;GUARDIEIRO MM ;BASTOS MR ;CARVALHO JO ;LUCCI CM ;DIESEL TO ;SARTORI R ;RUMPF R ;FRANCO MM ;DODE MA. Morphology, sex ratio and gene expression of day 14 in vivo and in vitro bovine embryos. Reproduction, fertility, and development, v. 25,p. 600-608, 2013.

MATSUI M ;MiYAmoto A. Evaluation of ovarian blood flow by colour Doppler ultrasound: practical use for reproductive management in the cow. Veterinary journal, v. 181,p. 232$240,2009$.

MCEVoY TG ;COUll GD ;BROAdBENT PJ ;HutChInSON JS ;SPEAKE BK. Fatty acid composition of lipids in immature cattle, pig and sheep oocytes with intact zona pellucida. Journal of reproduction and fertility, v. 118,p. 163-170, 2000. 
MEN H ;AGCA Y ;CRITSER ES ;CRITSER JK. Beneficial effects of serum supplementation during in vitro production of porcine embryos on their ability to survive cryopreservation by open pulled straw vitrification. Theriogenology, v. 64,p. 1340-1349, 2005.

MEN H ;AGCA Y ; RILEY LK ;CRITSER JK. Improved survival of vitrified porcine embryos after partial delipation through chemically stimulated lipolysis and inhibition of apoptosis. Theriogenology, v. 66,p. 2008-2016, 2006.

MOAWAD AR ;TAN SL ;XU B ;CHEN HY ;TAKETO T. L-carnitine supplementation during vitrification of mouse oocytes at the germinal vesicle stage improves preimplantation development following maturation and fertilization in vitro. Biology of reproduction, $v$. 88,p. 104, 2013.

MORATO R ;IZQUIERDO D ;PARAMIO MT ;MOGAS T. Cryotops versus open-pulled straws (OPS) as carriers for the cryopreservation of bovine oocytes: effects on spindle and chromosome configuration and embryo development. Cryobiology, v. 57,p. 137-141, 2008a.

MORATO R ;IZQUIERDO D ;PARAMIO MT ;MOgAS T. Embryo development and structural analysis of in vitro matured bovine oocytes vitrified in flexipet denuding pipettes.

Theriogenology, v. 70,p. 1536-1543, 2008b.

MORATO R ;MOGAS T ;MADDOX-HYTTEL P. Ultrastructure of bovine oocytes exposed to Taxol prior to OPS vitrification. Molecular reproduction and development, v. 75,p. 13181326, 2008c.

PARRISH JJ ;KROGENAES A ;SUSKO-PARRISH JL. Effect of bovine sperm separation by either swim-up or Percoll method on success of in vitro fertilization and early embryonic development. Theriogenology, v. 44,p. 859-869, 1995.

ROBERTS SA ;HANN M ;BRISON DR. Factors affecting embryo viability and uterine receptivity: insights from an analysis of the UK registry data. Reproductive biomedicine online, 2015.

ROCHA-FrigONI NA ;LEAO BC ;NOGUEIRA E ;ACCORSI MF ;MINGOTI GZ. Reduced levels of intracellular reactive oxygen species and apoptotic status are not correlated with increases in cryotolerance of bovine embryos produced in vitro in the presence of antioxidants.

Reproduction, fertility, and development, v. 26,p. 797-805, 2014.

RUSSELL DL ; SALUSTRI A. Extracellular matrix of the cumulus-oocyte complex. Seminars in reproductive medicine, v. 24,p. 217-227, 2006.

SHIRAZI A ;TAHERI F ;NAZARI H ;NORBAKHSH-NIA M ;AHMADI E ;HEIDARI B. Developmental competence of ovine oocyte following vitrification: effect of oocyte developmental stage, cumulus cells, cytoskeleton stabiliser, FBS concentration, and equilibration time. Zygote, p. $1-9,2012$.

SOMFAI T ; YOSHIOKA K ;TANIHARA F ;KANEKO H ;NOGUCHI J ;KASHIWAZAKI N ;NAGAI T ;KIKUCHI K. Generation of live piglets from cryopreserved oocytes for the first time using a defined system for in vitro embryo production. PloS one, v. 9,p. e97731, 2014. 
SPRICIGO JF ;DIOGENES MN ;LEME LO ;GUIMARAES AL ;MUTERLLE CV ;SILVA BD ;SOLAORIOL D ;PIVATO I ;SILVA LP ;DODE MA. Effects of Different Maturation Systems on Bovine Oocyte Quality, Plasma Membrane Phospholipid Composition and Resistance to Vitrification and Warming. PloS one, v. 10,p. e0130164, 2015.

SPRICIGO JF ;MORAIS K ;FERREIRA AR ;MACHADO GM ;GOMES AC ;RUMPF R ;FRANCO MM ;DODE MA. Vitrification of bovine oocytes at different meiotic stages using the Cryotop method: assessment of morphological, molecular and functional patterns. Cryobiology, v. 69,p. 256-265, 2014.

SPRICIGO JF ;MORAIS KS ;YANG BS ;DODE MA. Effect of the exposure to methyl-betacyclodextrin prior to chilling or vitrification on the viability of bovine immature oocytes. Cryobiology, v. 65,p. 319-325, 2012.

SUdANO MJ ;PASCHOAL DM ;RASCAdO TdA S ;MAGALHAES LC ;CROCOMO LF ;DE LiMANETO JF ;LANDIM-ALVARENGA FDA C. Lipid content and apoptosis of in vitro-produced bovine embryos as determinants of susceptibility to vitrification. Theriogenology, v. 75,p. 1211-1220, 2011.

VAN DEN HURK R ;ZHAO J. Formation of mammalian oocytes and their growth, differentiation and maturation within ovarian follicles. Theriogenology, v. 63,p. 1717-1751, 2005.

VIEIRA AD ;MEZZALIRA A ;BARBIERI DP ;LEHMKUHL RC ;RUBIN MI ;VAJTA G. Calves born after open pulled straw vitrification of immature bovine oocytes. Cryobiology, v. 45,p. 91-94, 2002.

Werner-Von Der Burg W ;COORDES I ;HATZMANN W. Pregnancy following intrafollicular gamete transfer. Human reproduction, v. 8,p. 771-774, 1993.

ZHAO XM ;DU WH ;WANG D ;HAO HS ;LIU Y ;QIN T ;ZHU HB. Recovery of mitochondrial function and endogenous antioxidant systems in vitrified bovine oocytes during extended in vitro culture. Molecular reproduction and development, v. 78,p. 942-950, 2011.

ZHOU GB ;ZENG Y ;MENG QG ;LIU Y ;DAI YP ;ZHU SE ;BUNCH TD ;HOU YP. Decreased expression of CD9 in bovine oocytes after cryopreservation and the relationship to fertilization capacity. Molecular reproduction and development, v. 80,p. 451-459, 2013.

ZhOU XL ;Al NAIB A ;SUN DW ;LONERGAN P. Bovine oocyte vitrification using the Cryotop method: effect of cumulus cells and vitrification protocol on survival and subsequent development. Cryobiology, v. 61,p. 66-72, 2010. 


\section{CONSIDERAÇÕES FINAIS}

A necessidade de aumentar a produtividade dos rebanhos e de conservar a variabilidade e a diversidade genética animal, resultou em um esforço internacional pelo desenvolvimento de biotecnologias capazes de acelerar a multiplicação e possibilitar o armazenamento de gametas e embriões. Neste contexto, a criopreservação de sêmen, embriões e ovócitos tornaram-se alvos de pesquisas, em diversas universidades e centros de pesquisa ao redor do mundo.

Considerando o avanço já obtido na eficiência da criopreservação para sêmen e embriões, o objetivo do nosso trabalho foi aumentar a eficiência da criopreservação de ovócitos em bovinos que ainda permanece com resultados insatisfatórios. A preservação do gameta feminino é importante não só em programas de conservação, mas também em programas de melhoramento animal. Além, de ser importante ferramenta terapêutica, pois, possibilita a manutenção da fertilidade da fêmea, mesmo após apresentar problemas de infertilidade adquirida.

Baseados em estudos prévios, identificamos que entre os pontos críticos da criopreservação do ovócito bovino estão: o alto teor lipídico, a composição de membrana plasmática, o volume celular, a fonte do ovócito e o próprio sistema in vitro de produção de embriões. Tomando por base estas características, propusemos: (1) alterar a membrana plasmática do ovócito imaturo, para assim diminuir os danos osmóticos causados durante a criopreservação; (2) utilizar substâncias delipidantes e antioxidantes durante a MIV, para diminuir o teor de ácidos graxos e aumentar a proteção contra a peroxidação, para a conservação de ovócitos maturados; (3) adaptar um sistema de maturação in vivo, para avaliar se a fonte de ovócitos, maturados in vivo ou in vitro, influenciaria na sua crioresistência e (4) usar um sistema de maturação, fecundação e cultivo in vivo, para ovócitos imaturos, após a vitrificação. 
Quando utilizamos a beta-metil-ciclodextrina para tentar carrear colesterol para a membrana celular, e deixa-la mais fluída, observamos um aumento do número de ovócitos imaturos vitrificados que chegaram à metáfase II, após a MIV, reduzindo a taxa de degeneração. Apesar da taxa de blastocisto em D7 ter sido superior para o grupo de ovócitos expostos a betametil- ciclodextrina antes da vitrificação, essa taxa ainda permaneceu muito baixa.

Para o propósito seguinte, a suplementação do meio de maturação com LCarnitina de forma isolada ou em associação ao Resveratrol foi capaz de modificar a expressão gênica, aumentar a proteção à desorganização dos fusos meióticos causada pela vitrificação e, aumentar a taxa de eclosão dos embriões em D8, após a vitrificação de ovócitos maturados.

Observamos também que o sistema de maturação in vivo é capaz de produzir ovócitos altamente competentes e também, alterar a composição lipídica da membrana plasmática, mas não melhora a produção de embriões após a vitrificação dos ovócitos.

Por fim, quando avaliamos o sistema no qual o embrião foi produzido, in vivo ou in vitro, notamos que o sistema in vivo proposto, pode se tornar mais uma opção para a produção de embriões e, que estes têm qualidade comparáveis aos produzidos pelo sistema in vitro. Contudo, o desenvolvimento embrionário a partir de ovócitos imaturos vitrificados, e que foram maturados, fecundados e cultivados in vivo, foi semelhante ao sistema in vitro. Esse achado foi importante, pois percebemos que o ovócito bovino é severamente acometido pela vitrificação, independentemente de sua qualidade e ou do sistema ao qual é submetido.

Portanto, apesar dos nossos esforços e das diferentes abordagens para preparar ovócito para a criopreservação, não obtivemos êxito em melhorar o desenvolvimento embrionário a partir de ovócitos vitrificados. Independente da alternativa utilizada, essas não foram suficientes para compensar o severo comprometimento causado aos ovócitos durante a vitrificação.

Contudo, baseado nos estudos de coloração nuclear por lacmóide ou identificação dos fusos e cromossomos por imunohistoquímica, observamos que a cromatina apesar de ser afetada, continua estável morfologicamente, em aproximadamente $50 \%$ dos ovócitos, após vitrificação. Somando estes achados as observações feitas durante o mestrado, que mostram a intensa vacuolização citoplasmática, e desorganização de organelas, independentemente do estágio em que o ovócito é submetido a vitrificação. Acreditamos que o citoplasma é mais afetado do que o núcleo celular. 
Sendo assim, concluímos que a conservação do gameta feminino continua sendo um desafio. São necessárias mais pesquisas básicas para se conhecer melhor a estrutura bioquímica e física do ovócito bovino, para que metodologias de criopreservação possam ser desenvolvidas, especificamente para esta célula, respeitando as peculiaridades da espécie. Outra opção, seria lançar mão de técnicas em que somente o núcleo do ovócito criopreservado fosse utilizado, como na transferência nuclear, para um citoplasma fresco. Provavelmente, estas são as alternativas restantes, para se buscar melhores resultados com a criopreservação de ovócitos, em bovinos. 